$$
\text { UNIVERSIDADE DE SÃO PAULO }
$$

FACULDADE DE ECONOMIA, ADMINISTRAÇÃO E CONTABILIDADE DEPARTAMENTO DE ADMINISTRAÇÃO PROGRAMA DE PÓS-GRADUAÇÃO EM ADMINISTRAÇÃo

FATORES DETERMINANTES DO DESEMPENHO DE PEQUENAS E MÉDIAS EMPRESAS DA REGIÃO CENTRO-SUL DO ESTADO DO PARANÁ

Léo Raifur

Orientador: Prof. Dr. Almir Ferreira de Sousa 
Prof. Dr. João Grandino Rodas Reitor da Universidade de São Paulo

Prof. Dr. Reinaldo Guerreiro

Diretor da Faculdade de Economia, Administração e Contabilidade

Prof. Dr. Roberto Sbragia

Chefe do Departamento de Administração

Prof. Dr. Lindolfo Galvão de Albuquerque Coordenador do Programa de Pós-Graduação em Administração 


\section{LÉO RAIFUR}

\section{FATORES DETERMINANTES DO DESEMPENHO DE PEQUENAS E MÉDIAS EMPRESAS DA REGIÃO CENTRO-SUL DO ESTADO DO PARANÁ}

Tese de Doutorado apresentada ao Departamento de Administração da Faculdade de Economia, Administração e Contabilidade da Universidade de São Paulo como requisito para a obtenção do título de Doutor em Ciências.

Orientador: Prof. Dr. Almir Ferreira de Sousa

\section{Versão Corrigida}

(versão original disponível na Faculdade de Economia, Administração e Contabilidade)

\section{SÃO PAULO}


FICHA CATALOGRÁFICA

Elaborada pela Seção de Processamento Técnico do SBD/FEA/USP

Raifur, Léo

Fatores determinantes do desempenho de pequenas e médias empresas da região centro-sul do estado do Paraná / Léo Raifur. - São Paulo, 2013.

$193 \mathrm{p}$

Tese (Doutorado) - Universidade de São Paulo, 2013.

Orientador: Almir Ferreira de Sousa.

1. Pequenas e médias empresas 2. Empreendedorismo 3. Finanças 4. Medidas de desempenho I. Universidade de São Paulo. Faculdade de Economia, Administração e Contabilidade. II. Título.

CDD -658.022 
À Deus e à Família, sempre presentes. 



\section{AGRADECIMENTOS}

Agradeço ao Prof. Dr. Almir Ferreira de Sousa, orientador desta Tese, pela grande motivação e direção dada, desde a escolha do tema até a conclusão do trabalho. A escolha das disciplinas do programa, a participação em eventos, reuniões e debates certamente enriqueceram a forma de ver a academia e sociedade que nos cerca. Ao longo de quatro anos tive a oportunidade de conhecer e conviver com sua dedicação diária em prol da compreensão e do desenvolvimento das pequenas e médias empresas. Não poderia esquecer de uma expressão da nossa primeira reunião, no ano de 2010: "sinto que academia está em débito com a sociedade". Acima de tudo, aprendi que a humildade é uma grande virtude e que o melhor de nós é esperado em todas as oportunidades a nós confiadas.

À minha família, pelo apoio e motivação recebidos. Ao meu irmão Luiz, que se envolveu um grave acidente durante essa Tese, e me ensinou que grandes vitórias requerem grandes batalhas. Ao meu filho Léo Matheus por ser paciente com minha ausência, e à Juliane, pelos incentivos diários.

Aos professores Rosana e Wadico, membros da banca de qualificação, e aos Professores Cláudio Rojo, Adelino de Bortoli e José Roberto, membros da banca de defesa, pelas recomendações e refinamentos adicionados a esta Tese

Aos professores Securato, Roy, Zwicker (in memoriam), Cláudio, Alessandra e Cantón, pelas disciplinas cursadas no programa, proporcionando crescimento e aperfeiçoamentos teóricos e didáticos.

Aos professores, funcionários e amigos da FEA, que diariamente contribuem para que a escola tenha o reconhecido destaque nacional e internacional. Às empresas e aos empreendedores que participaram deste trabalho, respondendo ao questionário que constituiu a base de dados.

Aos colegas professores de Departamento de Administração da Unicentro, com quem sempre pude trocar ideias, experiências, e que me apoiaram nestes quatro anos. À Unicentro, por ter me concedido tempo integral para se dedicar ao doutorado. 

"Nunca tenha certeza de nada, porque a sabedoria começa com a dúvida." Sigmund Freud 



\section{RESUMO}

Pequenas e médias empresas (PMEs) cumprem um importante papel no desenvolvimento econômico e social das nações: geram riquezas, empregos e produzem inovação. Empresas como Apple ${ }^{\circledR}$ e Microsoft ${ }^{\circledR}$, maiores do mundo na atualidade, já figuraram na dimensão dessas empresas. Entretanto, compreender a dinâmica desse universo empresarial tem se revelado um desafio para a pesquisa acadêmica. No contexto mundial constata-se que em torno de $25 \%$ das empresas nascentes sobrevivem menos de dois anos e, em torno de $50 \%$, menos de cinco. O objetivo desta Tese consistiu em identificar e testar os fatores que determinam a sobrevivência e o desempenho de PMEs. A amostra foi formada por 410 empresas da região centro-sul do Estado do Paraná, sendo 74 empresas inativas (não sobreviventes) e 336 ativas (sobreviventes). A medida de desempenho resultou de oito indicadores, e foi testada sob três modalidades: a) sobrevivência versus não sobrevivência; b) grupos: não sobreviventes, sobrevivência marginal e alto desempenho, e; c) desempenho como variável contínua. As variáveis independentes foram distribuídas em oito dimensões: capital humano, capital social, características gerenciais, condições do ambiente, características organizacionais, motivação e percepção do risco, demografia pessoal e tamanho que, por sua vez, formaram as oito hipóteses declaradas no estudo. As inferências foram realizadas no contexto de cada uma das dimensões e em relação ao conjunto geral, mediante utilização das estatísticas análise fatorial, regressão linear múltipla e regressão logística. Das oito dimensões, seis (capital humano, capital social, características gerenciais, condições do ambiente, características organizacionais e tamanho) apresentaram pelo menos um indicador influente, e tiveram a hipótese nula rejeitada. A maior densidade nas evidências foi apresentado pelo modelo logístico geral $\left(R^{2}=75 \%\right)$ onde o suporte governamental, experiência ocupacional, capital social, sazonalidade e a qualificação dos empregados foram os indicadores que apresentaram maior poder discriminatório, demonstrando que as chances de sobrevivência de PMEs aumentam com a melhora desses fatores. Pelo modelo multinomial $\left(R^{2}=80 \%\right)$ constatou-se que o planejamento antes da abertura da empresa, a disponibilidade de recursos, o acesso ao crédito e as fontes e os custos de financiamento de curto prazo apresentaram maior capacidade de discriminação, demonstrando que o empobrecimento e a deterioração das características gerenciais e de fatores de capital social diminuem a probabilidade da empresa sobreviver ou de obter elevado desempenho. Na regressão linear $\left(R^{2}=42 \%\right)$ a qualificação dos empregados $(32 \%)$ e o suporte governamental $(22 \%)$ melhor explicaram o desempenho de PMEs. Constatou-se, ainda, que aproximadamente $35 \%$ das variáveis influentes estão associadas com a fase anterior à abertura da empresa, como: planejamento ou plano de negócio, experiências e disponibilidade de capital.

\section{Palavras-Chave:}

Pequenas e Médias Empresas. Medidas de desempenho. Empreendedorismo. Finanças. 



\begin{abstract}
Small and medium enterprises (SMEs) play an important role in economic and social development of nations: they generate wealth, jobs and innovation. Companies like Apple ${ }^{\circledR}$

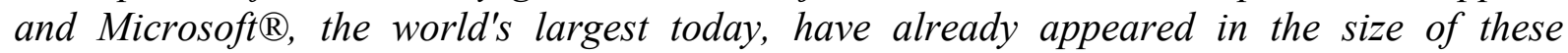
companies. However, understanding the dynamics of these enterprises has proven a challenge for academic research. In the international context it appears that about $25 \%$ of new companies survive less than two years, and about 50\%, less than five. The aim of this study consisted in to identify and test the factors that determine the survival and performance of SMEs. The sample consisted of 410 companies in the central southern State of Paraná, including 74 inactive companies (non-survivors) and 336 active (survivors). The performance measure resulted from eight indicators, and was tested in three ways: a) survival versus nonsurvival b) groups: no survivors, marginal survival and high performance, and; c) performance as a continuous variable. The independent variables were divided into eight dimensions: human capital, social capital, managerial characteristics, environmental conditions, organizational characteristics, motivation and perceived risk, personal demographics and size, that, in turn, formed the eight hypothesis reported in the study. Inferences were made in the context of each of the dimensions and in relation to the general assembly by use of statistical factor analysis, multiple linear regression and logistic regression. Of the eight dimensions, six (human capital, social capital, managerial characteristics, environmental conditions, organizational characteristics and size) had at least one influential indicator, and had rejected the null hypothesis. The highest density was presented by the general logistic model $\left(R^{2}=75 \%\right)$ where government support, occupational experience, capital, seasonality and quality of staff were indicators that showed greater discriminatory power, demonstrating that the chances of survival of SMEs increase with the improvement of these factors. By multinomial model $\left(R^{2}=80 \%\right)$ found that planning before of the opening of the company, the availability of resources, access to credit and the sources and costs of short-term financing had higher capacity discrimination, demonstrating that the impoverishment and deterioration of managerial characteristics and factors of capital decrease the likelihood of the company surviving or get high performance. In OLS regression $\left(R^{2}=42 \%\right)$ the quality of staff $(32 \%)$ and government support $(22 \%)$ best explained the performance of SMEs. It was noted also that about 35\% of influential variables are associated with earlier stage the opening of the company, such as planning or business plan, experience and availability of capital.
\end{abstract}

\title{
Keywords:
}

Small and Medium Enterprises. Performance measures. Entrepreneurship. Finance. 



\section{SUMÁRIO}

LISTA DE ABREVIATURAS E SIGLAS …................................................................ 3

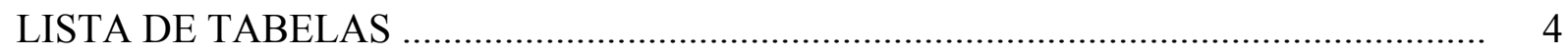

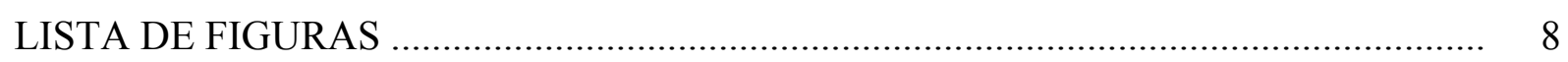

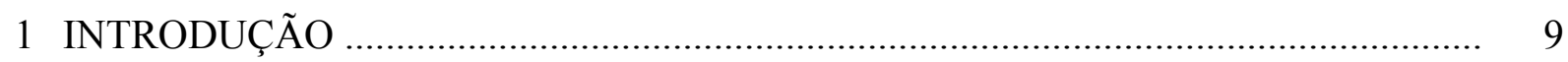

1.1 Identificação e definição da situação problema ..................................................... 12

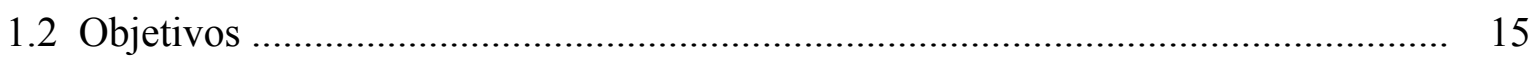

1.2.1 Objetivo Geral ............................................................................... 15

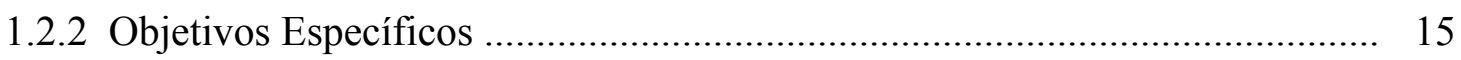

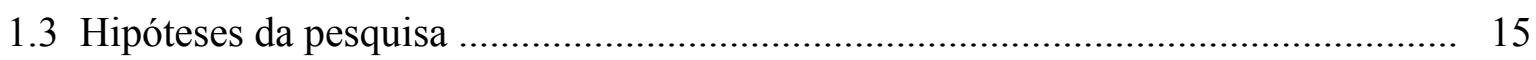

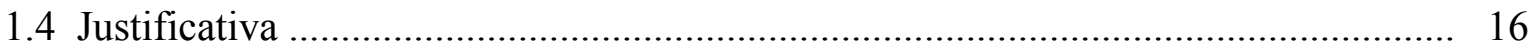

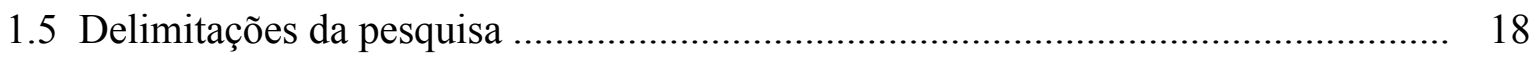

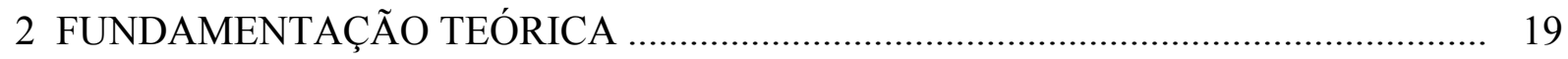

2.1 Empreendedorismo e Empreendedor ............................................................. 19

2.1.1 Empreendedorismo no mundo .......................................................... 23

2.1.2 Empreendedorismo no Brasil ................................................................. 25

2.1.3 Porte das empresas ........................................................................... 27

2.2 Teoria de Finanças ................................................................................... 30

2.2.1 Decisão de investimento em ambiente de incerteza ................................... 31

2.2.2 Teoria dos Custos de Transação e Finanças Comportamentais ..................... 36

2.2.3 Planejamento e Controle Financeiro ........................................................ 38

2.3 Avaliação de Desempenho ......................................................................... 40

2.3.1 Indicadores Financeiros ..................................................................... 42

2.3.2 Indicadores de Desempenho em Pequenas e Médias Empresas .................... 44

2.4 Determinantes de Desempenho nas Pequenas e Médias Empresas ........................ 47

2.4.1 Impacto do Capital Humano ................................................................... 50

2.4.2 Impacto do Capital Social ........................................................................ 54

2.4.3 Impacto das Características Gerenciais ..................................................... 57

2.4.4 Impacto das Características Organizacionais ........................................... 60

2.4.5 Impacto das Condições do Ambiente ........................................................... 62

2.4.6 Impacto da Motivação e Expectativas .......................................................... 63

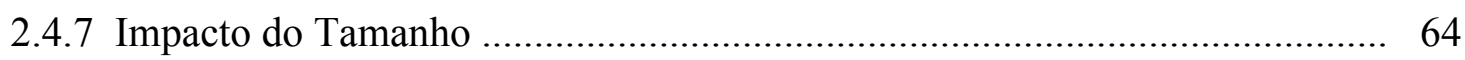

2.4.8 Impacto da Demografia Pessoal ........................................................... 65

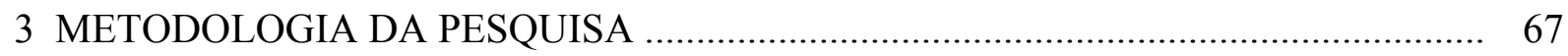

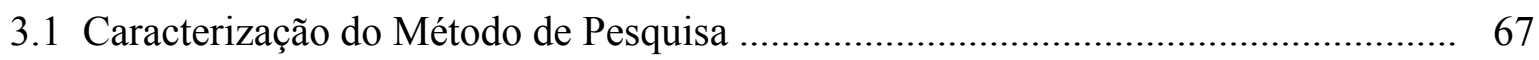

3.2 Caracterização do Universo e Amostra da Pesquisa .............................................. 67

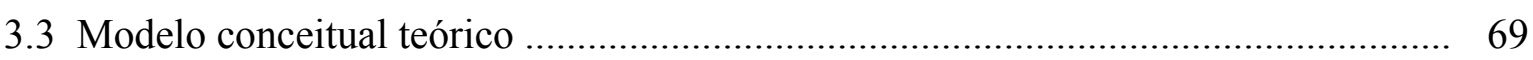


3.3.1 Definição das variáveis explicativas (independentes) .................................. 70

3.3.2 Definição da variável explicada: Desempenho ............................................ 77

3.4 Instrumento de coleta de dados ..................................................................... 79

3.5 Procedimentos estatísticos para teste de hipóteses ............................................... 80

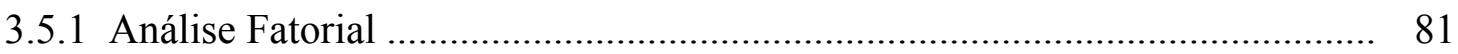

3.5.2 Regressão Linear Múltipla ................................................................ 83

3.5.3 Regressão Logística Binária .................................................................. 85

3.5.4 Regressão Logística Multinomial ................................................................. 89

4. APRESENTAÇÃO E ANÁLISE DE RESULTADOS ................................................. 91

4.1 Descrição da Amostra ......................................................................................... 91

4.1.1 Perfil dos Empreendedores .................................................................... 91



4.1.3 Descrição dos indicadores de Desempenho ................................................ 96

4.1.4 Descrição dos indicadores de Capital Humano .............................................. 99

4.1.5 Descrição dos indicadores de Capital Social ................................................. 102

4.1.6 Descrição dos indicadores de Características de Gestão ................................. 107

4.1.7 Descrição dos indicadores de Condições do Ambiente .................................. 110

4.1.8 Descrição dos indicadores de Motivação e Percepção do Risco ...................... 112

4.1.9 Descrição dos indicadores de Características Organizacionais ..................... 115

4.2 Teste das hipóteses - inferência parcial por dimensão ........................................ 117

4.2.1 Validação do construto de desempenho ...................................................... 117

4.2.2 Teste da Hipótese $\mathrm{H}_{0,1}$ - Capital Humano ...................................................... 119

4.2.3 Teste da Hipótese $\mathrm{H}_{0,2}-$ Capital Social ....................................................... 124

4.2.4 Teste da Hipótese $\mathrm{H}_{0,3}-$ Características Gerenciais .................................... 131

4.2.5 Teste da Hipótese $\mathrm{H}_{0,4}-$ Condições do Ambiente ........................................ 139

4.2.6 Teste da Hipótese $\mathrm{H}_{0,6}$ - Motivação e Percepção do risco .............................. 145

4.2.7 Teste da Hipótese $\mathrm{H}_{0,5}$ - Características Organizacionais ............................. 146

4.2.8 Teste da Hipótese $\mathrm{H}_{0,7}-$ Tamanho .............................................................. 150

4.2.9 Teste da Hipótese $\mathrm{H}_{0,8}$ - Demografia Pessoal ............................................. 152

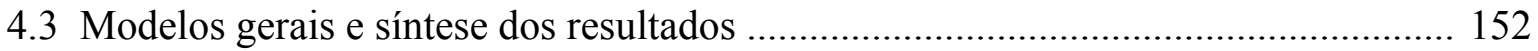

4.3.1 - Desempenho: Regressão Linear Múltipla .............................................. 152

4.3.2 - Sobrevivência versus Não Sobrevivência - Regressão Logística ................. 155

4.3.3 - Grupos de Desempenho - Regressão Logística Multinomial ...................... 160

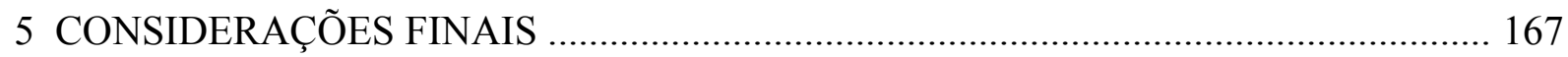



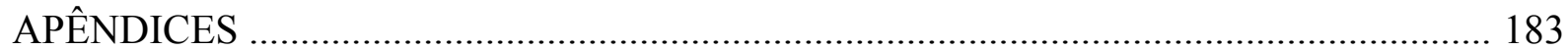




\section{LISTA DE ABREVIATURAS E SIGLAS}

$\begin{array}{ll}\text {-2LL } & \text {-2 log likelihood } \\ \text { AF } & \text { Análise Fatorial } \\ \text { ANOVA } & \text { Analysis of Variance } \\ \text { BNDES } & \text { Banco Nacional de Desenvolvimento Econômico e Social } \\ \text { CAGED } & \text { Cadastro Geral de Empregados e Desempregados } \\ \text { CAPM } & \text { Capital Assets Price Model } \\ \text { CEPAL } & \text { Comissão Econômica para América Latina e Caribe } \\ \text { CPC } & \text { Comitê de Pronunciamentos Contábeis } \\ \text { EU } & \text { European Union } \\ \text { GEM } & \text { Global Entrepreneurship Monitor } \\ \text { gl } & \text { Graus de liberdade } \\ \text { IBGE } & \text { Instituto Brasileiro de Geografia e Estatística } \\ \text { IBPQ } & \text { Instituto Brasileiro de Produtividade e Qualidade } \\ \text { KMO } & \text { Teste Kaiser-Meyer-Olkin } \\ \text { MPME } & \text { Micro, Pequena e Média Empresa } \\ M S A & \text { Measures Sample Adequacy } \\ \text { MTE } & \text { Ministério do Trabalho e Emprego } \\ \text { OCDE } & \text { Organização para Cooperação e Desenvolvimento Econômico } \\ \text { OLS } & \text { Ordinary Least Squares } \\ \text { PIB } & \text { Produto Interno Bruto } \\ \text { PME } & \text { Pequena e Média e Empresa } \\ \text { RMSR } & \text { Root Mean Squared Residuals } \\ \text { ROA } & \text { Return on Assets } \\ \text { ROC } & \text { Receiver Operational Chracterístics (teste de probabilidade prevista) } \\ \text { SBA } & \text { Small Business Administration } \\ \text { SEBRAE } & \text { Serviço Brasileiro de Apoio à Pequena e Média Empresa } \\ \text { Sig. } & \text { Significância estatística } \\ \text { SME } & \text { Small and Medium Enterprises } \\ \text { SQE } & \text { Soma dos Quadrados dos Erros } \\ \text { SQR } & \text { Soma dos Quadrados da Regressão } \\ \text { SQT } & \text { Soma dos Quadrados Totais da regressão } \\ \text { TCT } & \text { Teoria dos Custos de Transação } \\ \text { VTE } & \text { Variância Total Explicada } \\ & \end{array}$




\section{LISTA DE TABELAS}

Tabela 1 Número de empresas, empregos e participação no PIB, na zona do Euro, de

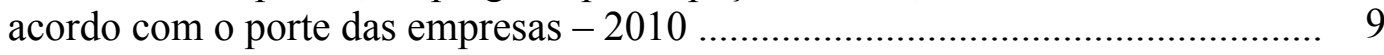

Tabela $\quad 2$ Taxa de sobrevivência de empresas - Europa …............................................... 10

Tabela 3 Entradas e saídas de empresas - Brasil ......................................................... 12

Tabela 4 Publicações internacionais sobre determinantes de desempenho nas PMEs ...... 17

Tabela 5 Sumário das abordagens para descrição do Empreendedorismo ........................ 22

Tabela $6 \mathrm{~N}^{\mathrm{o}}$ de empresas, empregos e participação no PIB na zona do Euro segundo o

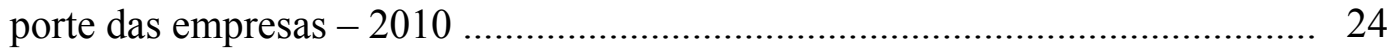

Tabela 7 Participação das Micro e Pequenas Empresas nas economias ........................... 24

Tabela 8 Número de Empresas no Brasil (2000 - 2010; em mil) ................................... 25

Tabela 9 Porte das empresas - Comissão Europeia ...................................................... 27

Tabela 10 Porte das empresas - BNDES ................................................................... 28

Tabela 11 Porte das empresas - Lei Geral da MPE (PLC 11/2011) ................................... 29

Tabela 12 Porte das empresas - OCDE ........................................................................ 29

Tabela 13 Porte das empresas - SEBRAE ............................................................... 29

Tabela 14 Variáveis identificadas como medidas de desempenho nas PMEs .................... 46

Tabela 15 Determinantes do sucesso: clássicos e modernos ........................................... 47

Tabela 16 Variáveis explicativas significantes na determinação da sobrevivência ou desempenho das pequenas e médias empresas .................................................. 48

Tabela 17 Variáveis de Capital Humano determinantes do desempenho das PMEs .......... 49

Tabela 18 Impacto de fatores de capital humano na descontinuidade das empresas ........... 51

Tabela 19 Variáveis de capital social determinantes do desempenho nas PMEs ............... 54

Tabela 20 Características gerenciais determinantes do desempenho das PMEs ................ 57

Tabela 21 Características Organizacionais determinantes do desempenho das PMEs ....... 59

Tabela 22 Características do ambiente determinantes do desempenho das PMEs .............. 62

Tabela 23 Motivação e percepção do risco determinantes do desempenho das PMEs ....... 63

Tabela 24 Variáveis de Tamanho determinantes do desempenho das PMEs ..................... 63

Tabela 25 Variáveis demográficas pessoais determinantes do desempenho das PMEs ...... 64

Tabela 26 Caracterização operacional dos indicadores de Capital Humano ....................... 70

Tabela 27 Caracterização operacional dos indicadores de Capital Social .......................... 71

Tabela 28 Caracterização operacional dos indicadores das Características Gerenciais ...... 72

Tabela 29 Caracterização operacional dos indicadores de Condições do Ambiente ........... 73

Tabela 30 Caracterização operacional dos indicadores - Características Organizacionais . 75

Tabela 31 Caracterização operacional dos indicadores de motivação e percepção risco .... 75

Tabela 32 Caracterização operacional dos indicadores de tamanho e demografia pessoal . 76

Tabela 33 Definição dos indicadores para determinação do Desempenho ......................... 77

Tabela 34 Níveis de alfa de Cronbach $(\alpha)$ para aceitação da confiabilidade ....................... 79

Tabela 35 Testes estatísticos utilizados para analisar sobrevivência e/ou desempenho ...... 81

Tabela 36 Perfil da amostra por status da empresa e gênero ............................................. 91 
Tabela 37 Perfil: estado civil e gênero .......................................................................... 91

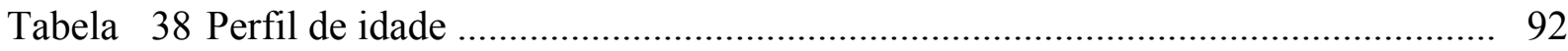

Tabela 39 Escolaridade e status da empresa .............................................................. 92



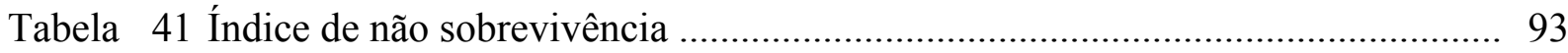

Tabela 42 Taxa de sobrevivência das empresas - Europa e Brasil (amostra) .................... 94

Tabela 43 Empregos gerados na constituição da empresa ................................................ 94

Tabela 44 Quadro de empregados no momento de descontinuidade da empresa .............. 95

Tabela 45 Quadro atual de empregados das empresas sobreviventes ................................ 95

Tabela 46 Valor gasto para constituir a empresa ............................................................ 95

Tabela 47 Faturamento bruto anual das empresas sobreviventes .................................... 96

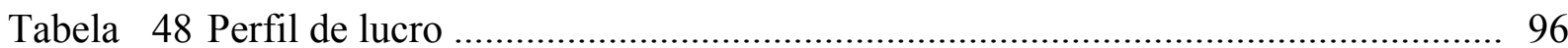

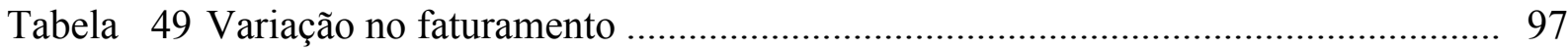

Tabela 50 Variação no quadro de empregados .............................................................. 97

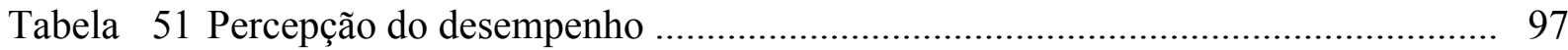

Tabela 52 Satisfação pessoal com o negócio .................................................................. 98

Tabela 53 Impacto na qualidade de vida pessoal e familiar ............................................. 98

Tabela 54 Grau de confirmação da decisão ....................................................................... 98

Tabela 55 Experiência ocupacional antes de empreender ................................................ 99



Tabela 57 Experiência em cargo de liderança ................................................................... 100

Tabela 58 Treinamento (cursos, eventos etc.) - empresas sobreviventes ...........................101

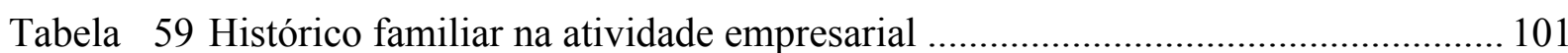

Tabela 60 Experiência em negócio (empresa) anterior .................................................. 102

Tabela 61 Disponibilidade de capital para constituição da empresa .................................. 103

Tabela 62 Utilização de empréstimos na abertura da empresa .......................................... 103

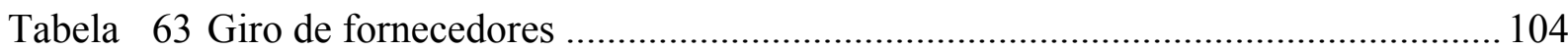

Tabela 64 Reciprocidade bancaria e acesso ao crédito …................................................. 105

Tabela 65 Nível de planejamento antes da abertura do negócio ......................................... 108

Tabela 66 Registros, controles e custos financeiros .......................................................... 109

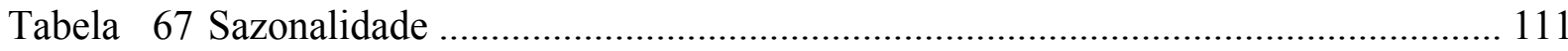



Tabela 69 Suporte Institucional / Governamental ....................................................... 112

Tabela 70 Decisão de empreender: oportunidade versus necessidade .............................. 113

Tabela 71 Motivação para decisão de empreender - sobreviventes .................................... 113

Tabela 72 Motivação para decisão de empreender - não sobreviventes .............................. 114

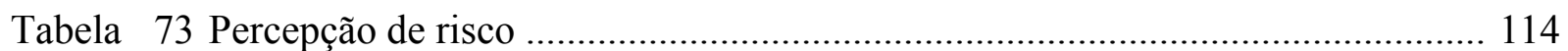

Tabela 74 Expectativa de desempenho: antes versus após a abertura ................................ 115

Tabela 75 Grau de especialidade ou diversidade do negócio ............................................ 116

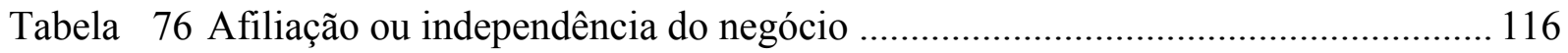

Tabela 77 Matriz de Correlações - Desempenho ............................................................. 117 


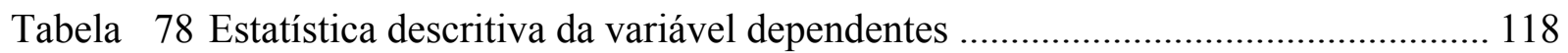

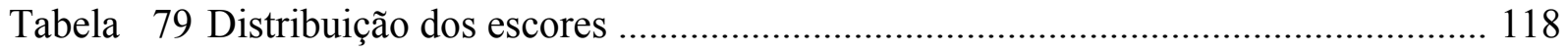

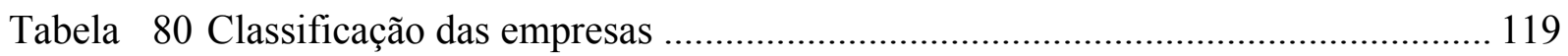

Tabela 81 Ajuste dos indicadores de capital para regressão logística ............................... 120

Tabela 82 Coeficientes do modelo logístico - capital humano .......................................... 120

Tabela 83 Informações de ajuste do modelo multinomial - capital humano ...................... 122

Tabela 84 Teste de razão de verossimilhança ..................................................................... 122

Tabela 85 Coeficientes do modelo logístico multinomial - capital humano ........................ 123

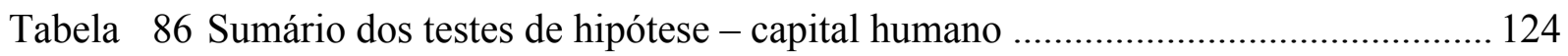

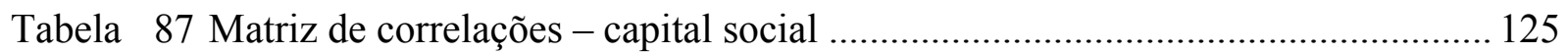

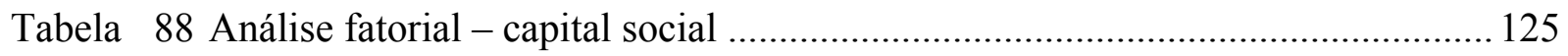



Tabela 90 Regressão múltipla - capital social - valores de entrada .................................. 126

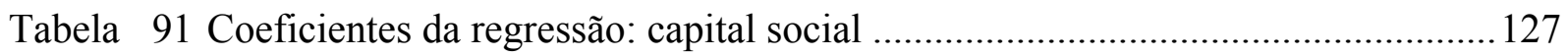

Tabela 92 Coeficientes do modelo logístico: capital social ............................................... 128

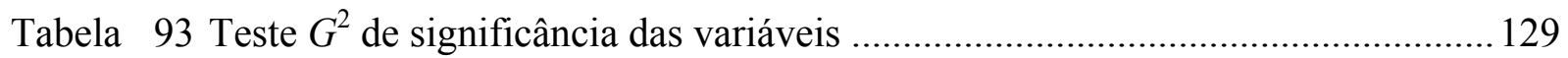

Tabela 94 Coeficientes do modelo multinomial - capital social ........................................ 129

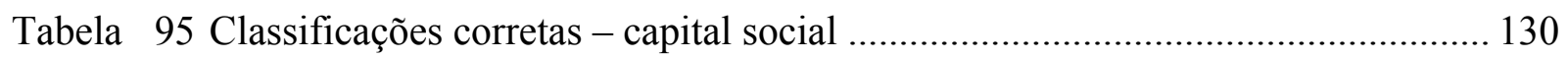

Tabela 96 Sumário dos testes de hipótese - capital social .............................................. 131

Tabela 97 Matriz de correlações dos indicadores de planejamentos antes da abertura ....... 132





Tabela 100 Matriz de correlações: registros, controles e custos financeiros .......................... 133

Tabela 101 Valores de entrada da regressão múltipla - características gerenciais ............... 134

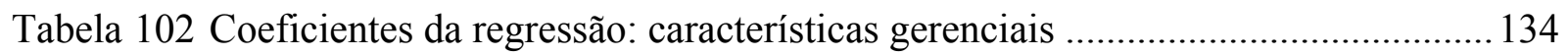

Tabela 103 Ajuste dos indicadores para regressão logística binária .....................................135

Tabela 104 Coefícientes do modelo logístico binário - características gerenciais ................. 136

Tabela 105 Informações de ajuste do modelo multinomial - características gerenciais ........ 137

Tabela 106 Coeficientes do modelo multinomial - características gerenciais ....................... 137

Tabela 107 Classificações corretas - características gerenciais .......................................... 138

Tabela 108 Sumário dos testes de hipóteses - características gerenciais .............................. 138

Tabela 109 Matriz de correlações - condições do ambiente ................................................ 139

Tabela 110 Variáveis de entrada da regressão múltipla - condições do ambiente ................. 140

Tabela 111 Coeficientes da regressão: condições do ambiente ........................................... 140

Tabela 112 Ajuste dos indicadores para regressão logística binária .....................................142

Tabela 113 Coeficientes do modelo logístico binário - condições do ambiente .................... 142

Tabela 114 Informações de ajuste do modelo multinomial - condições do ambiente ........... 143

Tabela 115 Coeficientes do modelo multinomial - condições do ambiente .......................... 143

Tabela 116 Coeficientes do modelo binário: "não sobreviventes" e "alto desempenho" ..... 144

Tabela 117 Classificações corretas - condições do ambiente ............................................... 144

Tabela 118 Sumário dos testes de hipótese - condições do ambiente .................................. 145 
Tabela 119 Decisão de empreender e status da empresa 146

Tabela 120 Matriz de correlações - características organizacionais ................................... 147

Tabela 121 Variáveis de entrada da regressão múltipla - características organizacionais .... 147

Tabela 122 Coeficientes da regressão - características organizacionais ............................... 148

Tabela 123 Coeficientes do modelo logístico - características organizacionais ................... 149

Tabela 124 Classificações corretas - características organizacionais ................................. 149

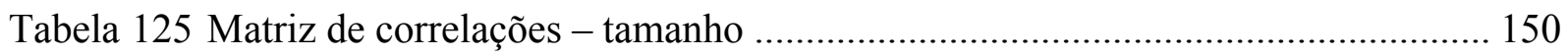

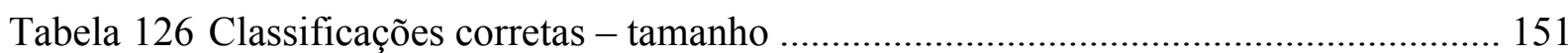

Tabela 127 Resumo do modelo geral - regressão linear múltipla ....................................... 152

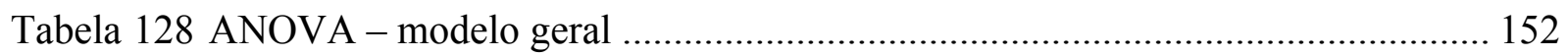

Tabela 129 Coeficientes da regressão - modelo geral ......................................................... 153

Tabela 130 Frequência e codificação das variáveis qualitativas ......................................... 155

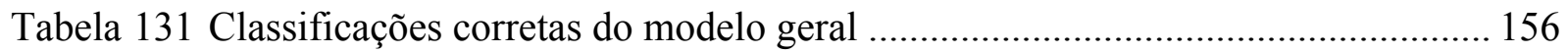

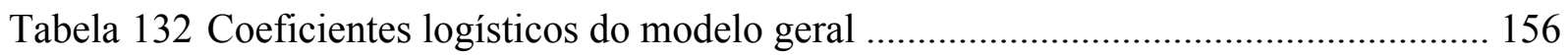

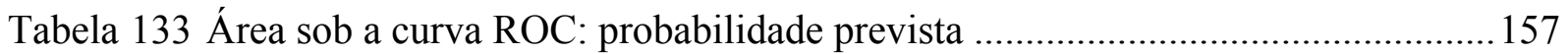

Tabela 134 Informações de ajuste do modelo multinomial ................................................. 159

Tabela 135 Coeficientes do modelo multinomial geral ........................................................ 160

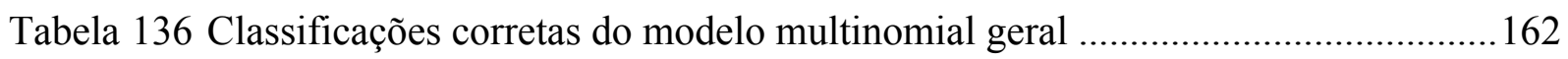








\section{LISTA DE FIGURAS}

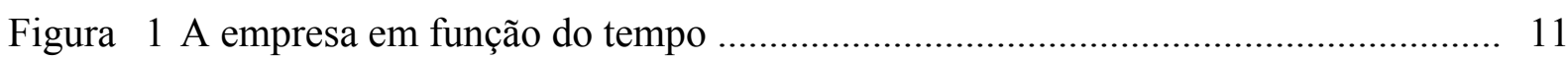

Figura 2 Grade do empreendedorismo .................................................................... 21

Figura 3 Distribuição das empresas por tamanho e região - 2010 ……………………...... 27

Figura 4 Curva da utilidade da riqueza .................................................................... 32

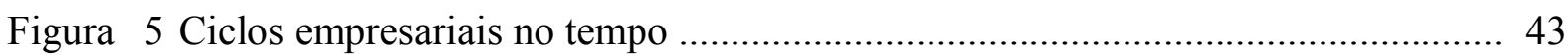

Figura 6 Matriz de medidas de desempenho na indústria do turismo ................................ 45

Figura 7 Taxas de juros de longo prazo entre PMEs e grandes empresas .......................... 59

Figura 8 Delimitação da área da pesquisa ..................................................................... 68

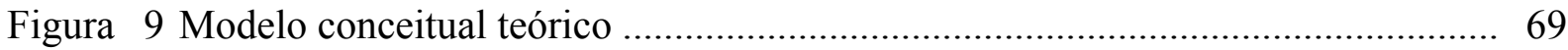

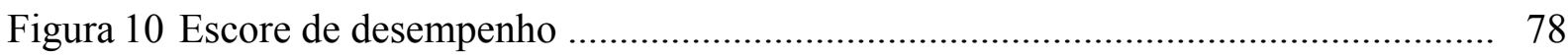

Figura 11 Infográfico - Crédito: reciprocidade, acesso e impactos ...................................... 106

Figura 12 Variáveis influentes e poder explicativo - regressão linear .................................... 154

Figura 13 Variáveis influentes e poder discriminante - modelo logístico geral ................... 159

Figura 14 Variáveis influentes - modelo multinomial ......................................................... 163

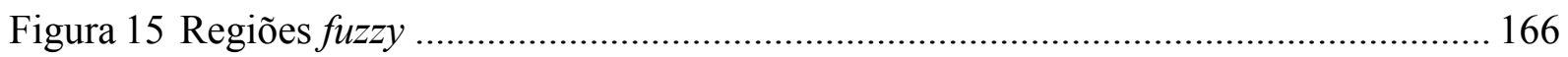

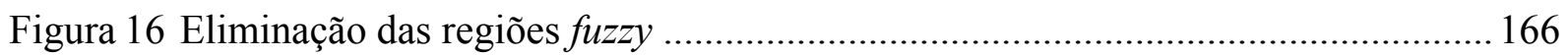

Figura 17 Indicadores influentes: pré e pós constituição do negócio ..................................... 168 


\section{Capítulo 1}

\section{INTRODUÇÃO}

Muitas esperanças e expectativas estão conectadas com o desenvolvimento dos pequenos negócios: sob a visão schumpeteriana (SCHUMPETER, 1911, 1934) novas empresas criam novos empregos, abrem oportunidades de ascensão social, promovem a flexibilidade econômica, estimulam a competição, a eficiência produtiva e a inovação. Entretanto, estas esperanças e expectativas somente serão justificadas se os negócios recém-criados prosperarem.

Em diversas economias as Pequenas e Médias Empresas (PMEs) cumprem um papel de destaque. De acordo com o Relatório Anual das PMEs na União Europeia (2011), na zona do euro (formada por 27 nações) essas empresas representam 99,8\% do total de empresas, respondem por $66,9 \%$ da mão de obra empregada e $58,4 \%$ do PIB (Tabela 1 ).

\begin{tabular}{|c|c|c|c|c|c|c|}
\hline \multirow{2}{*}{ Porte } & \multicolumn{2}{|c|}{ Empresas } & \multicolumn{2}{|c|}{ Empregos } & \multicolumn{2}{|c|}{ Produto Interno Bruto PIB } \\
\hline & $\mathbf{N}^{0}$ Empresas & $\%$ & $\mathbf{N}^{0}$ Empregos & $\%$ & Participação PIB* & $\%$ \\
\hline Micro & 19.198 .539 & 92,1 & 38.905 .519 & 29,8 & 1.293 .391 & 21,6 \\
\hline Pequenas & 1.378 .401 & 6,6 & 26.605 .166 & 20,4 & 1.132 .202 & 18,9 \\
\hline Médias & 219.252 & 1,1 & 21.950 .107 & 16,8 & 1.067 .387 & 17,9 \\
\hline PMEs & 20.796 .192 & 99,8 & 87.460 .792 & 66,9 & 3.492 .979 & 58,4 \\
\hline Grandes & 43.043 & 0,2 & 43.257 .098 & 33,1 & 2.485 .457 & 41,6 \\
\hline TOTAL & 20.839.226 & 100,0 & 130.717 .890 & 100,0 & 5.978 .436 & 100,0 \\
\hline
\end{tabular}

(*) Em milhões de Euros

FONTE: Annual Report on EU SMEs 2010/2011, 2011,p. 8.

Individualmente, em termos de geração de emprego destacam-se as PMEs de Portugal com $75 \%$ da mão de obra empregada, enquanto que em termos de PIB as PMEs da Espanha contribuem com 65\% (ANNUAL REPORT on EU SMEs, 2011).

No Brasil, as pequenas e médias empresas representam 20\% do PIB e são responsáveis por $60 \%$ dos empregos (PORTAL BRASIL, 2012). 
Na América Latina e Caribe, em termos de participação no PIB, países como Argentina 60\%, Colômbia 35\%, Uruguai 30\% e México 23\%, comparadas ao Brasil (20\%), apresentam patamares superiores (SEBRAE, 2010). Ao se compararem os índices da América Latina e Caribe com a União Europeia constata-se que há um grande desafio para região em termos de avanços demandados.

Apesar da importância desse segmento empresarial no Brasil e no mundo, ainda é um desafio para a academia compreender a dinâmica e a ecologia (competição e sobrevivência) desses negócios. Dunne et. al. (1988) realizaram um estudo com as empresas entrantes no setor de manufatura nos EUA, concluindo que, após cinco anos, 61,5\% delas não estavam mais ativas. No período de 10 anos, o índice de sobrevivência é de apenas 20,5\%. Brüderl et. al. (1992) realizaram estudos sobre mortalidade na Alemanha e identificaram um índice de insucesso de $24 \%$ nos primeiros dois anos, e de $37 \%$ no período de cinco anos.

Tabela 2 - Taxa de sobrevivência de empresas - Europa

\begin{tabular}{lccc}
\hline \multirow{2}{*}{ País } & \multicolumn{3}{c}{ Taxa de sobrevivência após (\%) } \\
\cline { 2 - 4 } & 1 ano & 2 anos & 5 anos \\
\hline França & 84 & 62 & 48 \\
Alemanha & 86 & 70 & 63 \\
Irlanda & 91 & 70 & 57 \\
Itália & 87 & 66 & 54 \\
Portugal & 76 & 56 & 47 \\
Reino Unido & 87 & 62 & 47 \\
\hline FONTE: BRIDGE et. al., 2003 , p. 208.
\end{tabular}

Bridge et. al. (2003) apresentam dados (Tabela 2) de sobrevivência de seis países da zona do euro. Das empresas iniciantes, transcorridos dois anos da data de constituição, o índice de sobrevivência foi de $65 \%$. Esse panorama se assemelha com a sobrevivência evidenciada pelos estudos do SEBRAE/SP (2008), que identificou um índice de 68\% das entrantes paulistas após dois anos. Ainda, nas evidências apontadas por Bridge et. al. (id.), o índice médio de sobrevivência dessas empresas, após cinco anos, foi em torno de 50\%.

Dos cenários observados deduz-se que, anualmente, enquanto cinco novas empresas estão sendo criadas, quatro estão sendo encerradas. Schumpeter $(1911,1934)$ preconizou a destruição criativa ao definir o empreendedorismo como a quebra da visão econômica tradicional pautada no equilíbrio da oferta e demanda, pela substituição de empresas obsoletas e ineficientes por alternativas inovadoras. O fenômeno se assemelha à teoria darwinista da 
seleção natural. Nesse sentido, Penrose (1973) igualmente defende a necessidade de adaptação contínua da organização como condição de sobrevivência.

Allen (2012) aponta a existência de diferenças entre empreendimento empresarial e pequena empresa. Um empreendimento empresarial pauta-se pela inovação, criação de valor e crescimento, enquanto um pequeno negócio cumpre um papel de subsistência do proprietário e da família. Nessa linha de entendimento, Cooper et. al. (1994) definiram o primeiro grupo como empresas de "alto crescimento" e o segundo grupo como "sobrevivência marginal", enquanto Sadler-Smith et. al. (2003) classificaram em "alto crescimento" e "baixo crescimento".

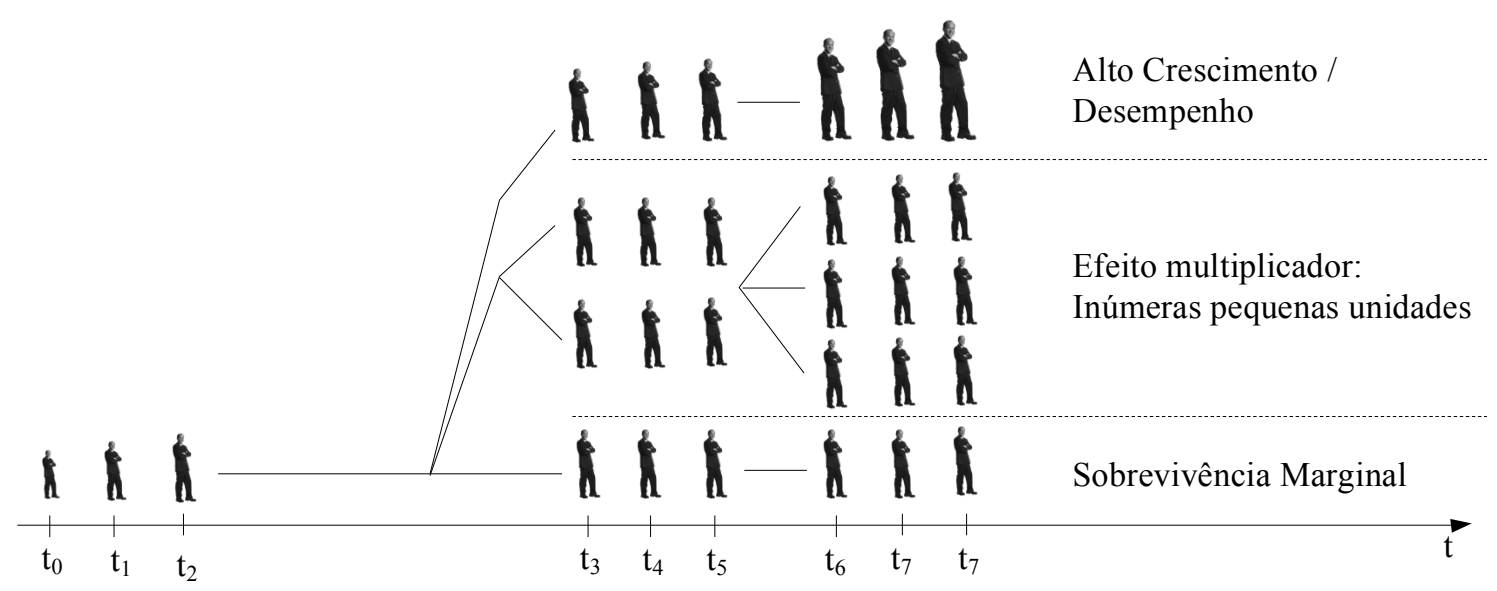

Figura 1 - A empresa no tempo

A Figura 1 procura explicitar a função empreendedora no tempo a partir do entendimento de Allen (2012) e Cooper et. al. (id). Uma empresa caracterizada como sobrevivente marginal é aquela que mantem sua atividade operacional apoiada em elementos mínimos que sustentem sua condição como empresa. Nesse grupo figuram as empresas que rapidamente atingem a maturidade pelas delimitações impostas por seu escopo ou propostas estratégicas, como por exemplo, uma padaria delimita-se pela quantidade de clientes potenciais residentes na região de abrangência do seu negócio. Um segundo grupo de empresas é formado pela replicação de unidades marginalmente sobreviventes. E o terceiro grupo, defendido por Allen (id) e Schumpeter (1911), pauta-se pela inovação, geração de valor e crescimento.

As pesquisas sobre desempenho de PMEs concentraram-se em classificar essas empresas em dois grupos: sobreviventes e não sobreviventes (BRUDERL et. al., 1992; VAN GELDEREN, 
et. al., 2006; VAN PRAAG, 2003; CARTER e VAN HAUKEN, (2006); BATES, (1995); LUSSIER $(1995,1996)$.

Diante das perspectivas e expectativas que nascem com os pequenos empreendimentos e sua ecologia complexa, este estudo dedicou-se à investigação dos determinantes do desempenho de pequenas e médias empresas sob ótica tradicional (sobrevivência versus não sobrevivência), e também incluindo as propostas de Cooper et. al. (1994) e Sadler-Smith et. al. (2003) que, no conjunto, produziram três dimensões para variável dependente.

$\mathrm{Na}$ primeira dimensão foram testados os fatores discriminantes da sobrevivência das empresas, utilizando-se dois grupos ( 0 = não sobrevivente, e; $1=$ sobrevivente). A segunda dimensão incluiu uma adaptação das propostas de Cooper et. al. (id) e Sadler-Smith et. al. (id) onde foi testada a discriminação para três grupos $(0=$ não sobreviventes; 1 = sobrevivência marginal, e; 2 = alto desempenho). Na terceira dimensão a variável dependente foi definida como escala contínua resultante do escore somado dos indicadores de desempenho.

\section{I.1 Identificação e definição da situação problema}

No período de 2007 a 2011 foram criadas, no Brasil, anualmente, em média, 622.455 empresas (Tabela 3), apresentando uma taxa anual de crescimento de 9,2\%.

Tabela 3 - Entradas e saídas de empresas - Brasil

\begin{tabular}{|c|c|c|c|c|c|c|c|c|c|c|}
\hline \multirow{2}{*}{ Situação } & \multicolumn{2}{|l|}{2007} & \multicolumn{2}{|l|}{2008} & \multicolumn{2}{|l|}{2009} & \multicolumn{2}{|l|}{2010} & \multicolumn{2}{|l|}{2011} \\
\hline & Empresas & $\%$ & Empresas & $\%$ & Empresas & $\%$ & Empresas & $\%$ & Empresas & $\%$ \\
\hline Entrac & 59.132 & 22 & 889 & 22 & 946.6 & 22 & 999 & 22 & 871.804 & 19 \\
\hline Nascim & 464.728 & 12 & 558.608 & 14 & 694.461 & 16 & 733.585 & 16 & 660.893 & 15 \\
\hline Reent & 394.404 & 10 & 330.878 & 8 & 252.215 & 6 & 265.538 & 6 & 210.911 & 5 \\
\hline Saídas & 726.363 & 19 & 719.915 & 18 & 755.154 & 18 & 736.428 & 16 & 864.035 & 19 \\
\hline Crescimento & 132.769 & 3 & 169.571 & 4 & 191.522 & 4 & 262.695 & 6 & 7.769 & 0 \\
\hline TOTAL ATIVO & 3.908.091 & - & 4.077.662 & - & 4.268 .930 & - & 4.530 .583 & - & 4.538.347 & - \\
\hline
\end{tabular}

FONTE: IBGE, 2013.

O índice anual de entradas (nascimentos + reentradas) em relação ao total de empresas ativas foi de $22 \%$ no período de 2007 a 2010, caindo para 19\% em 2011. O crescimento médio no

\footnotetext{
${ }^{1}$ De acordo com a metodologia do IBGE, "reentrante" é uma empresa que estava inativa (sem movimentação) no ano anterior, ou até três anos anteriores, e que retomou sua atividade econômica.
} 
número de empresas foi de 3,8\% no período, tendo apresentado o maior crescimento em 2010 (6\%), enquanto em 2011 foi nulo. Nota-se que o crescimento do número de empresas tem sido sustentado pelas reentrantes, as quais vêm diminuindo anualmente de tal forma que, ao se comparar o ano de 2007 com 2011, constata-se uma queda de 50\%. Isso fez com que o crescimento fosse nulo em 2011. A observação a ser destacada é que, não fossem as reentrantes, não haveria crescimento no número de empresas, e sim, decrescimento.

Tomando-se por base que se, a cada 21,4 empresas (média das entradas no período) que entram no mercado, outras 18 saem, então a probabilidade da empresa permanecer no mercado, a cada ano, é de $16 \%$.

De acordo com o SEBRAE-SP (2008), o perfil de sobrevivência das entrantes, após seis anos, é de 36\% (Gráfico 1). Dentre inúmeros motivos para fechamento dos negócios, destacaram-se no estudo: falta de clientes/inadimplência $(23 \%)$, falta de capital $(20 \%)$ e problemas de planejamento/administração (20\%).

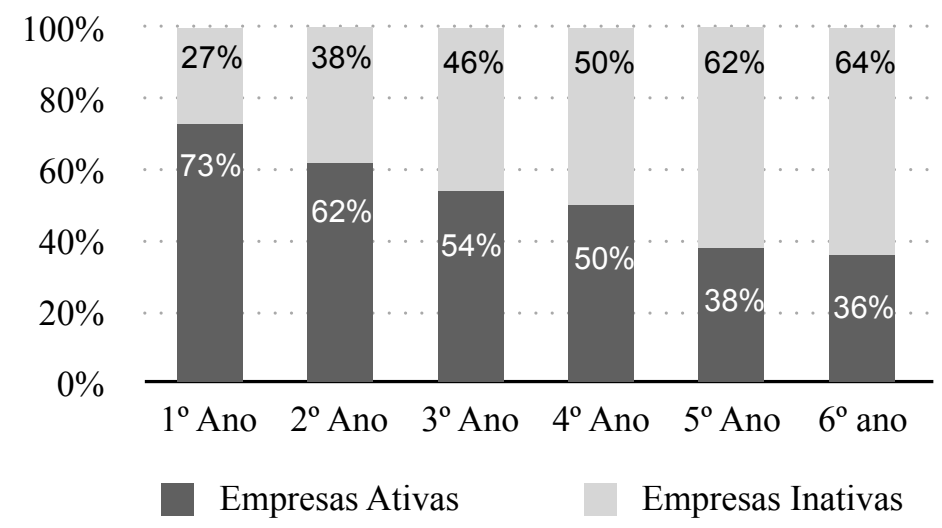

Gráfico 1 - Mortalidade de MPEs no Estado de São Paulo (2000 a 2005) FONTE: SEBRAE-SP, 2008.

Ainda, nesse mesmo estudo, o SEBRAE (id) identifica que dentre inúmeros impactos causados pela mortalidade dessas empresas, destacam-se as perdas de postos de trabalho, em média 3,2 por empresa, e do capital investido, em média 15 mil reais. Em termos totais esse impacto envolve a eliminação de cerca de 2 milhões de postos/ano de trabalho e perdas financeiras de capital investido da ordem de 7,5 bilhões de reais anuais. 
Dentre estudos sobre o desempenho de PMEs no Brasil, Mizumoto et. al. (2010) identificaram a cultura empreendedora, o plano de negócio, o tamanho da empresa e o motivo para empreender como determinantes da falência de pequenas empresas no estado de São Paulo. Nos estudos de Najberg et. al. (2000), o porte e a idade foram os fatores determinantes da sobrevivência das micro e pequenas empresas. Mendes (2006), em um estudo qualitativo multicaso com PMEs da região metropolitana de Curitiba/PR, concluiu que 37,5\% dos empreendedores admitiram terem fracassado em negócios anteriores e que os principais obstáculos enfrentados são a "falta de capital de giro" e a "oscilação da receita".

Apesar de ainda pouco explorado no Brasil, no âmbito internacional a literatura é bastante densa em termos dos esforços para se identificar os motivos que levam à descontinuidade de pequenas e médias empresas (FLAHVIN, 1985; BARSLEY e KLEINER, 1990; BRÜDERL et. al., 1992; GASKILL et. al., 1993; LUSSIER, 1995; LUSSIER e CORMAN, 1996; WATSON et. al. 1998; HEADD, 2003; VAN GELDEREN et. al., 2006; SCHAEFER, 2012; CARTER e VAN AUKEN, 2006; BRUNO et. al., 1987; WOOD, 1989; FOTOPOULOS e LOURI, 2000; BATES, 1995; YUSUF, 1995; VESPER, 1990; COOPER et. al, 1994, HEADD, 2003; VAN PRAAG, 2003).

Entretanto, pouco é encontrado na literatura internacional, e no Brasil, sobre mensuração de desempenho de pequenas e médias empresas.

O primeiro obstáculo para se medir o desempenho dessas empresas é a própria definição do conceito de desempenho. As medidas largamente utilizadas tiveram sua origem na literatura de finanças e, por consequência, delimitaram-se à indicadores financeiros como: retorno sobre o ativo, retorno sobre o patrimônio líquido, margens sobre a receita e liquidez. Nas decisões de investimentos das grandes corporações e de investidores sofisticados, estes indicadores revestem-se de parâmetros úteis e importantes. Entretanto, no contexto de pequenas e médias empresas são inviáveis por dois motivos: a) as informações financeiras não estão disponíveis, e/ou; b) as informações não são confiáveis. Dess e Robinson (1984), ao observarem a ausência ou deficiência dessas informações, testaram a aderência entre medidas objetivas e suas equivalentes subjetivas. Os resultados mostraram que as medidas subjetivas produziram as mesmas conclusões que as objetivas. 
Como forma de contornar o problema "mensuração do desempenho de PMEs", a literatura tem abordado um contexto multicritério, com variáveis de fácil entendimento do empresário, como variação nas vendas, percepção sensitiva do desempenho da sua empresa em relação à concorrência, aumento no número de empregados, satisfação pessoal, efetividade das expectativas, fluxo de caixa etc. (ROBINSON et. al., 1984; GORGIEVSKI et. al., 2011).

Diante do contexto apresentado, o presente estudo foi norteado pelo seguinte problema de pesquisa: Quais são os fatores determinantes do desempenho de pequenas e médias empresas da região centro-sul do Estado do Paraná?

\subsection{Objetivos}

\subsubsection{Objetivo Geral}

O objetivo geral deste trabalho é identificar e testar os fatores determinantes do desempenho de pequenas e médias empresas da região centro-sul do Estado do Paraná.

\subsubsection{Objetivos Específicos}

a) Definir e construir um modelo para mensuração do desempenho de PMEs;

b) Identificar e sistematizar as evidências empíricas disponíveis na literatura como determinantes do desempenho de pequenas e médias empresas;

c) Constituir um conjunto de contribuições voltadas ao planejamento e gestão de pequenas e médias empresas. Oferecer subsídios para o desenvolvimento de políticas públicas e ações institucionais voltadas a este contingente empresarial;

d) Contribuir para o aprofundamento da pesquisa acadêmica na temática envolvendo pequenas e médias empresas.

\subsection{Hipóteses da pesquisa}

Tendo em vista o problema proposto, o estudo partirá das seguintes hipóteses: 
$\mathbf{H}_{0,1}$ : O capital humano não é determinante do desempenho de pequenas e médias empresas.

$\mathbf{H}_{\mathbf{0}, \mathbf{2}}$ : O capital social não é determinante do desempenho de pequenas e médias empresas.

$\mathbf{H}_{\mathbf{0 , 3}}$ : O estilo de gestão não é determinante do desempenho de pequenas e média empresas.

$\mathbf{H}_{\mathbf{0}, \mathbf{4}}$ : As condições do ambiente não são determinantes do desempenho de pequenas e médias empresas.

$\mathbf{H}_{\mathbf{0}, \mathbf{5}}$ : A motivação e a percepção de risco não são determinantes do desempenho de pequenas e médias empresas.

$\mathbf{H}_{0,5}$ : As características organizacionais não são determinantes do desempenho de pequenas e médias empresas.

$\mathbf{H}_{0,7}$ : Os aspectos demográficos pessoais do proprietário não são determinantes do desempenho de pequenas e médias empresas.

$\mathbf{H}_{\mathbf{0 , 8}}$ : O tamanho da empresa não é determinante do desempenho de pequenas e médias empresas.

\subsection{Justificativa}

A primeira justificativa do presente estudo relaciona-se com o retorno social esperado da Universidade. Nesse caso, dada a importância de pequenas e médias empresas no conjunto socioeconômico do Brasil, o número de pesquisas envolvendo este segmento de negócios é muito pequeno: há uma dívida da academia perante a sociedade.

A segunda justificativa relevante deste estudo reside no esforço da busca de um arcabouço conceitual e empírico para se medir o desempenho dessas empresas. O desafio apoia-se fundamentalmente na ausência de informações confiáveis e acuradas, exigindo a utilização de medidas semânticas ou perceptivas.

Subentende-se que à medida que se conhece os fatores determinantes da sobrevivência e do desempenho de PMEs, tem-se um ganho de eficiência na construção de políticas públicas e no desenvolvimento de tecnologias de conhecimento voltadas ao planejamento e gestão de pequenas e médias empresas. Evita-se bater na tecla errada.

Uma terceira justificativa apoia-se no fato de que há poucos estudos acadêmicos envolvendo a sobrevivência e o desempenho de pequenas e médias empresas no Brasil. Mizumoto et. al. 
(2010), utilizando uma amostra de 1.915 observações no Estado de São Paulo, testaram a sobrevivência e não sobrevivência das PMEs, incluindo três conjuntos de indicadores: a) capital humano; b) capital social, e; c) práticas gerenciais. As evidências apontaram as práticas gerenciais como o principal conjunto determinante da sobrevivência das PMEs paulistas. O tamanho, ano de fundação e vendas para o governo foram outras variáveis significativas do modelo.

Filardi (2006), a partir de uma amostra de 100 empresas do Estado de São Paulo, analisou qualitativamente alguns fatores que podem ser determinantes na mortalidade precoce das PMEs, como inovação, planejamento, aspectos legais, relação com clientes, concorrentes e fornecedores, carga tributária e aspectos do ambiente. Najberg et. al. (2000) analisaram, no período de 1995 a 1997, a dinâmica de natalidade e mortalidade das PMEs e o seu impacto sobre o emprego formal.

Tabela 4 - Publicações internacionais sobre determinantes do desempenho de PMEs.

\begin{tabular}{|c|c|}
\hline Variável Dependente & Autor(es) \\
\hline Sobrevivência versus Não Sobrevivência & $\begin{array}{l}\text { Fotopoulos e Louri (2000) } \\
\text { Van Praag }(2003) \\
\text { Bates }(1990,1995) \\
\text { Lussier }(1995) \\
\text { Lussier e Pfeifer (2001) } \\
\text { Watson et al (1998) } \\
\text { Scherr (1989) } \\
\text { Fairlie e Robb (2009) } \\
\text { Carter e Van Auken (2006) }\end{array}$ \\
\hline Sobrevivência e Desempenho & Cooper et al (1994) \\
\hline Desempenho & $\begin{array}{l}\text { Benzing et al (2009) } \\
\text { Haber e Reichel (2005) } \\
\text { West III e Noel (2009) } \\
\text { Wijiwardena e Tibbits (1999) } \\
\text { Sadler-Smith et al (2003) } \\
\text { Wang e Ang (2004) } \\
\text { Kozan et al (2006) } \\
\text { Dess e Robinson (1984) }\end{array}$ \\
\hline
\end{tabular}

No contexto internacional percebem-se avanços mais acelerados, como destacou Kuratko (2009) evidenciando que a comunidade científica já conta com aproximadamente 50 journals destinados às publicações de pesquisas relacionadas às PMEs. Na Tabela 4 estão apresentadas algumas publicações internacionais relacionadas com o escopo de estudo da presente pesquisa. 
O design conceitual proposto para o presente trabalho ainda não foi desenvolvido no Brasil. Em termos de literatura internacional, esta pesquisa assemelha-se aos estudos realizados por Sadler-Smith et. al. (2003), Cooper et. al. (1994) e, Dess e Robinson (1984).

\subsection{Delimitações da Pesquisa}

Este estudo delimita-se nos seguintes pontos e conceitos:

a) Pequenas e Médias Empresas (PMEs) são definidas como o conjunto de empresas que possuem de uma até 249 pessoas ocupadas e assalariadas e tem faturamento bruto inferior à 90 milhões de reais anuais, resultante da combinação das metodologias do BNDES (faturamento) e da União Europeia (número de empregados e faturamento).

b) Uma PME não sobrevivente é aquela que deu baixa formal na junta comercial, ou que não apresentou movimentação por um período de três anos ou mais, de acordo com a metodologia utilizada pelo Instituto Brasileiro de Geografia e Estatística (IBGE). Também foram incluídos nesse grupo os casos em que houve a suspensão do CNPJ junto à Receita Federal, e a empresa já decidiu não retomar a atividade econômica.

c) Sob a dimensão temporal, essa pesquisa caracteriza-se como transversal (cross section), onde cada PME consistiu em uma única observação no tempo, compreendido no espaço de coleta de dados, realizada no período de jul./2013 a set./2013.

d) $\mathrm{O}$ estudo delimita-se geograficamente à região centro-sul do Estado do Paraná, por proporcionar facilidade de acesso por meio de contatos institucionais (SEBRAE, Associações Comerciais) para essa região.

e) Como a amostra incluiu empresas descontinuadas no período de 2003 a 2013, o estudo encontra delimitações decorrentes dos efeitos do tempo entre a descontinuação da empresa e o momento em que o questionário foi respondido. 


\section{CApítulo 2}

\section{FUNDAMENTAÇÃO TEÓRICA}

\subsection{Empreendedorismo e Empreendedor}

O empreendedorismo e seu agente o empreendedor estão inscritos em uma base conceitual complexa e norteada por diferentes correntes de pensamento. Na literatura, a linha mais explorada é o empreendedorismo de negócios, onde o empreendedor é o fundador de um novo negócio ou a pessoa que cria uma atividade econômica que ainda não existia (Gartner, 1985). Entretanto, no que se denomina fase pré-paradigmática, Kuhn $\left(1962^{2}\right)$ pautou o empreendedorismo como uma ação humana que, apoiada em algum tipo de valor, tem uma finalidade. Depreende-se, sob essa ótica, que o empreendedorismo é algo próprio do ser humano.

O termo empreendedorismo tem sua origem no vocábulo francês entrepreneur que, em tradução literal, significa "aquele que está entre" ou "intermediário". Hébert e Link (2006), apoiados na perspectiva histórica, definem três atributos ao termo entrepeneur (empreendedor): aventureiro, projetor e empresário. Não obstante, o pioneiro nos estudos de empreendedorismo de negócios é atribuído a Cantillon $\left(1755^{2}\right)$. Na obra Essai Sur la Nature $d u$ Commerce en General a atividade de empreendedor é discutida em vários capítulos. Numa clara alusão à percepção moderna do empreendedorismo, o autor afirma que o empreendedor é um indivíduo que compra um produto por um preço certo para revendê-lo a um preço incerto. Portanto, que assume riscos. Ao estudar o processo de falência da empresa Mississipi Company, Cantillon (id) foi um dos pioneiros a desenvolver estudos relacionados ao insucesso empresarial.

Cunningham e Lischeron (1991) sintetizaram as correntes sobre o estudo do empreendedorismo em seis escolas de pensamento: a) Escola "great person"; b) Escola das características psicológicas; c) Escola clássica; d) Escola de gestão; e) Escola da liderança, e; f) Escola do intraempreendedorismo. Para os autores, essas escolas podem ser categorizadas

\footnotetext{
${ }^{2}$ As obras com mais de 20 anos foram citadas por representarem os estudos seminais ou correntes teóricas de referência.
} 
em quatro enfoques: a) avaliação das qualidades pessoais; b) exploração de oportunidades; c) ação e gestão, e; d) reavaliação e adaptação.

A escola "great person" tem por pressuposto que o indivíduo possui instintos e habilidades natas, tornando-o diferente do senso comum e o candidatando a um potencial empreendedor de sucesso. Cunningham e Lischeron (id) observam que a biografia frequentemente identifica a habilidade intuitiva que uma "pessoa extraordinária" possui para identificar e tomar decisões apropriadas frente a uma oportunidade. Um empreendedor de sucesso é um indivíduo que revela altos níveis de vigor, persistência e autoconfiança.

A escola baseada nas características psicológicas concentrou seu foco nos fatores de personalidade, defendendo que os indivíduos possuem atitudes e crenças intrínsecas com relação ao trabalho e a vida. O comportamento do indivíduo baseia-se nesses fatores intrínsecos. Os autores ainda ressaltam que a literatura tem dado especial atenção a esses aspectos, destacando: a) valores pessoais como honestidade, respeito, responsabilidade e comportamento ético; b) propensão ao risco, e; c) necessidade de realização.

A escola clássica, que teve Cantillon (1755) e Say (1803) como precursores, apoiou-se fundamentalmente no pressuposto schumpeteriano de que a inovação é a característica distintiva do empreendedor. Cunningham e Lischeron (1991) ressaltam que a base desse pensamento apoiou-se em três palavras chave: a) inovação; b) criatividade, e; c) descobrimento.

As escolas da gestão e da liderança consubstanciam-se no campo da competência gerencial e da capacidade de liderar equipes. Essas escolas ocupam um campo extenso nos estudos organizacionais pelo pressuposto lógico de que o empreendedor desde o início assume as funções de planejar, organizar, comandar e coordenar as ações de seus empreendimentos. Cunningham e Lischeron (1991) salientam que a escola da gestão não compartilha com a ideia de que o empreendedor seja um "indivíduo extraordinário" com habilidades natas, mas que o potencial para o empreendedorismo de sucesso pode ser desenvolvido e treinado em sala de aula.

Na opinião de Dunphy (1996), a natureza do trabalho empreendedor é diferente do trabalho gerencial. Ou autor, incluindo os estudos de Dunphy (1993), Smith e Miner (1983) e Vésper 
(1980) delineou a grade do empreendedorismo (Figura 2). Não necessariamente um indivíduo que possui habilidades para empreender atividades empresariais tem também habilidades para empreender atividades administrativas. Entretanto, para ele, o empreendedorismo real consubstancia-se na presença de ambas.

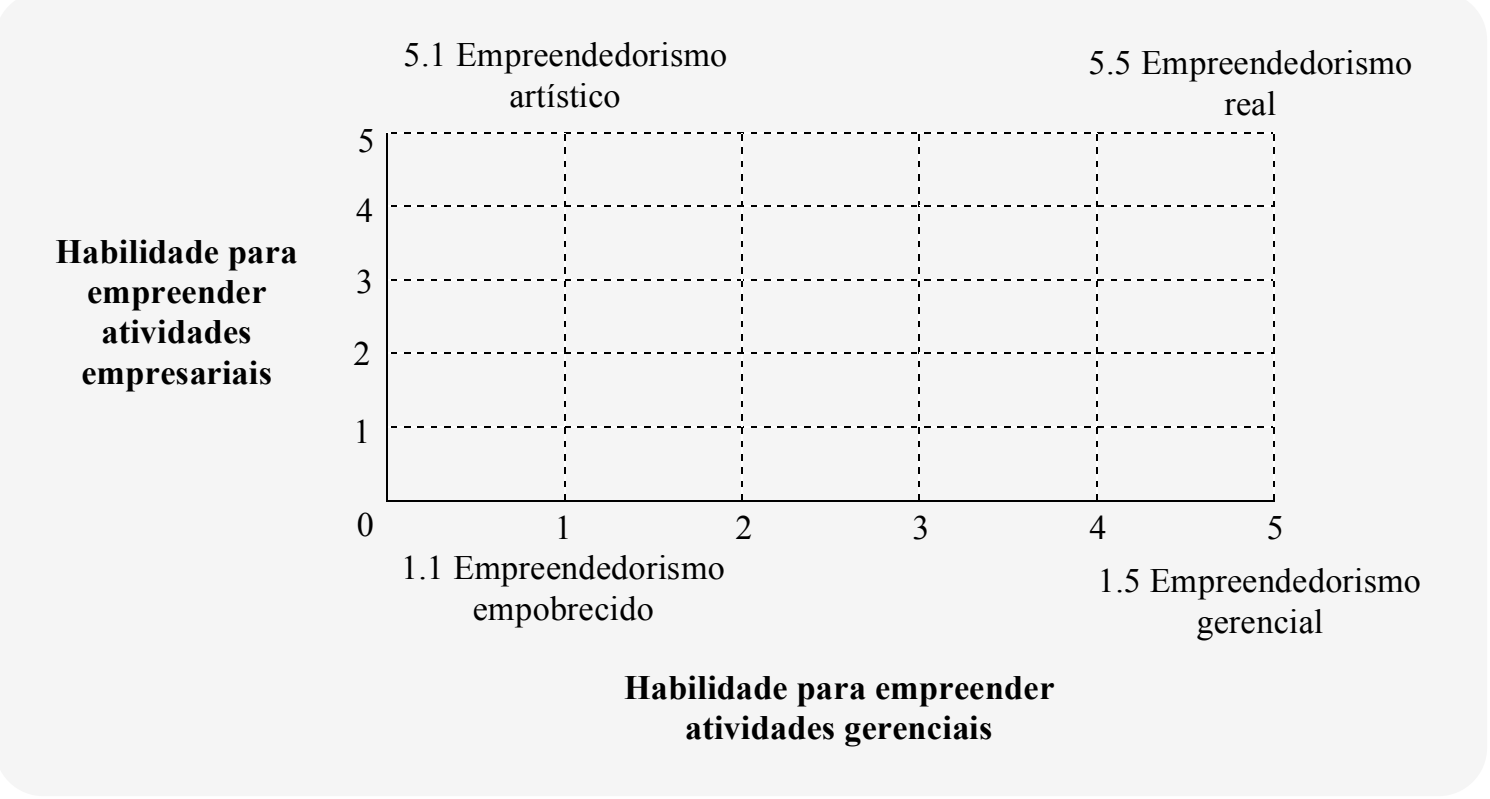

Figura 2 - Grade do Empreendedorismo Fonte: DUNPHY, 1996

Esta associação entre empreender e coordenar ganha contribuições importantes de Coase (1937) quando questionou a razão da existência das firmas. Para ele o papel fundamental das firmas, ao substituírem os mercados na realização das transações, está apoiado na coordenação necessária ao agente.

Ao se retomar os motivos que levam os indivíduos a empreender, fica mais fácil construir relações entre PMEs e a grade do empreendedorismo. Quando a empresa nasce baseada numa necessidade do proprietário, existem grandes possibilidades do negócio pairar no grupo de empresas marginalmente sobreviventes, que guardam semelhanças com o empreendedorismo empobrecido, caracterizado pela presença de baixo grau de criatividade (arte) associado com baixa ou nenhuma capacitação gerencial.

Com relação à escola da liderança, Cunningham e Lischeron (1991) ressaltam que essa escola tem sido debatida na literatura sob duas vertentes: a) a primeira está próxima do que defende a escola do "indivíduo extraordinário" - compartilhando com a ideia de que traços e 
características pessoais são importantes para o sucesso, e; b) a segunda, e mais amplamente explorada, é dada por Hemphill (1959) como a habilidade do líder em conseguir que as tarefas sejam realizadas e ao mesmo tempo atender às necessidades pessoais dos seus liderados.

A Tabela 5 sumariza as escolas do empreendedorismo incluindo suas abordagens e enfoques.

Tabela 5 - Síntese das abordagens para descrição do Empreendedorismo

\begin{tabular}{|c|c|c|c|c|}
\hline $\begin{array}{c}\text { Modelo } \\
\text { Empresarial }\end{array}$ & Foco Central ou Propósito & Pressuposto & $\begin{array}{c}\text { Comportamentos } \\
\text { e Habilidades }\end{array}$ & Situação \\
\hline $\begin{array}{l}\text { Escola } \\
\text { "Great } \\
\text { Person" }\end{array}$ & $\begin{array}{l}\text { O empreendedor tem uma } \\
\text { habilidade intuitiva - um } \\
\text { sexto sentido - e traços e } \\
\text { instintos que nascem com ele. }\end{array}$ & $\begin{array}{l}\text { Sem essa intuição de } \\
\text { "berço", o indivíduo } \\
\text { seria um mortal como } \\
\text { qualquer outro. }\end{array}$ & $\begin{array}{l}\text { Intuição, vigor, } \\
\text { energia, } \\
\text { persistência e } \\
\text { autoestima. }\end{array}$ & $\begin{array}{l}\text { Abertura da } \\
\text { empresa. }\end{array}$ \\
\hline $\begin{array}{l}\text { Escola das } \\
\text { Caracterís- } \\
\text { ticas } \\
\text { Psicológicas }\end{array}$ & $\begin{array}{l}\text { Empreendedores têm valores } \\
\text { únicos, atitudes, e } \\
\text { necessidades que os dirigem. }\end{array}$ & $\begin{array}{l}\text { Pessoas comportam-se } \\
\text { de acordo com os seus } \\
\text { valores; o } \\
\text { comportamento resulta } \\
\text { de atitudes para } \\
\text { satisfazer necessidades. }\end{array}$ & $\begin{array}{l}\text { Valores pessoais, } \\
\text { tomada de riscos, } \\
\text { necessidade de } \\
\text { realização, e } \\
\text { outros. }\end{array}$ & $\begin{array}{l}\text { Abertura da } \\
\text { empresa. }\end{array}$ \\
\hline $\begin{array}{l}\text { Escola } \\
\text { Clássica }\end{array}$ & $\begin{array}{l}\text { A característica central do } \\
\text { empreendedor é a inovação. }\end{array}$ & $\begin{array}{l}\text { O aspecto crítico do } \\
\text { empreendedor está no } \\
\text { processo de fazer ao } \\
\text { invés de possuir. }\end{array}$ & $\begin{array}{l}\text { Inovação, } \\
\text { criatividade e } \\
\text { descobrimento. }\end{array}$ & $\begin{array}{l}\text { Abertura da } \\
\text { empresa e } \\
\text { fase inicial de } \\
\text { crescimento. }\end{array}$ \\
\hline $\begin{array}{l}\text { Escola de } \\
\text { Gestão }\end{array}$ & $\begin{array}{l}\text { Os empreendedores são } \\
\text { organizadores de } \\
\text { empreendimento econômico: } \\
\text { organizam, apropriam, } \\
\text { gerenciam e assumem riscos. }\end{array}$ & $\begin{array}{l}\text { Empreendedores podem } \\
\text { ser desenvolvidos ou } \\
\text { treinados por meio de } \\
\text { funções técnicas de } \\
\text { gestão. }\end{array}$ & $\begin{array}{l}\text { Planejamento da } \\
\text { produção, } \\
\text { organização de } \\
\text { pessoas, } \\
\text { capitalização e } \\
\text { orçamentação. }\end{array}$ & $\begin{array}{l}\text { Fase inicial } \\
\text { de } \\
\text { crescimento e } \\
\text { maturidade. }\end{array}$ \\
\hline $\begin{array}{l}\text { Escola da } \\
\text { Liderança }\end{array}$ & $\begin{array}{l}\text { Empreendedores são líderes } \\
\text { de pessoas; eles têm a } \\
\text { habilidade de adaptar seu } \\
\text { estilo para as necessidades } \\
\text { das pessoas. }\end{array}$ & $\begin{array}{l}\text { Um empreendedor não } \\
\text { pode realizar seus } \\
\text { objetivos por si próprio. } \\
\text { Ele depende de outros. }\end{array}$ & $\begin{array}{l}\text { Motivação, } \\
\text { direção e } \\
\text { liderança. }\end{array}$ & $\begin{array}{l}\text { Fase inicial } \\
\text { de } \\
\text { crescimento e } \\
\text { maturidade. }\end{array}$ \\
\hline $\begin{array}{l}\text { Escola do } \\
\text { Intra- } \\
\text { empreende- } \\
\text { dorismo }\end{array}$ & $\begin{array}{l}\text { Habilidades empreendedoras } \\
\text { podem ser úteis em } \\
\text { organizações complexas; } \\
\text { intraempreendedorismo é o } \\
\text { desenvolvimento de unidades } \\
\text { independentes para criar, } \\
\text { comercializar e expandir } \\
\text { serviços. }\end{array}$ & $\begin{array}{l}\text { Organizações precisam } \\
\text { se adaptar para } \\
\text { sobreviver; a atividade } \\
\text { empreendedora leva à } \\
\text { construção. } \\
\text { organizacional e de } \\
\text { empreendedores antes de } \\
\text { gestores. }\end{array}$ & $\begin{array}{l}\text { Estado de alerta } \\
\text { para } \\
\text { oportunidades, } \\
\text { maximização nas } \\
\text { decisões. }\end{array}$ & $\begin{array}{l}\text { Maturidade e } \\
\text { Mudança }\end{array}$ \\
\hline
\end{tabular}

Fonte: Adaptado de Cunningham e Lischeron, 1991.

A escola do intraempreendedorismo, cujas bases teóricas apoiam-se em Pinchot (1983), consubstancia-se como um complemento à falta de inovação e competitividade dentro das organizações. As características centrais desta escola estão em linha com os pressupostos defendidos por Penrose (1973), de que a sobrevivência das organizações depende substancialmente da sua capacidade de adaptação. Cunningham e Lischeron (id) lembram que 
dentro das organizações os indivíduos, com liberdade de ação, serão mais hábeis para agirem e implementarem suas ideias como empreendedores sem que o sejam.

Uma visão direcional importante na economia foi dada por Schumpeter $(1911,1934)$ ao afirmar que a função empreendedora reside na inovação. As empresas que não inovarem não sobreviverão. A proposta de Schumpeter rompe com a visão clássica do equilíbrio entre oferta e demanda. O empreendedor rompe esse equilíbrio por meio da inovação, substituindo empresas obsoletas e estagnadas, com oferta de produtos e serviços em um arcabouço mais eficiente na relação custo-benefício.

Para Knight (1921, 1971), o sucesso do empreendedor está baseado na capacidade intelectual do indivíduo, além da autoconfiança e disposição para ação. Ele deve ser ao mesmo tempo, ousado e previdente.

Allen (2012) observa que empreendimentos empresariais e pequenos negócios estão relacionados, mas não são iguais em muitos aspectos. Ambos são importantes sob a ótica econômica, mas por sua vez, proporcionam diferentes produtos e resultados. Enquanto o empreendedorismo de empreendimentos empresariais, em essência fundamenta-se na função Schumpeteriana da inovação, o empreendedorismo de pequenas empresas constitui-se de proprietários que operam pequenos negócios cuja finalidade é garantir a subsistência própria e a familiar, como pequenas lojas, restaurantes e serviços profissionais. Allen (id.) ainda destaca que o empreendedorismo empresarial começa pequeno, porém seus objetivos não são pequenos. Em geral, o empreendedorismo pode ser caracterizado por três atributos básicos: a) inovação; b) criação de valor, e; c) orientação para o crescimento.

Em algumas pesquisas percebe-se a utilização dessas duas características distintivas: subsistência e crescimento. Estudos, como de Cooper et. al. (1994), testaram os fatores que distinguiam os negócios puramente voltados à subsistência (que classificaram com "sobrevivência marginal") daqueles caracterizados por alto crescimento.

\subsubsection{Empreendedorismo no mundo}

As empresas de micro, pequeno e médio porte tem sido alvo de políticas públicas e de pesquisas institucionais e acadêmicas. Timmons (1994) descreve que os pequenos negócios 
representarão para o século XXI mais do que a revolução industrial representou para o século XX. Essa revolução carreada pelas PMEs, que até então vinha correndo silenciosamente, ganhou força baseada nas suas contribuições socioeconômicas, despertando atenção das autoridades públicas e do meio acadêmico que, como lembrado por Kuratko (2009), já conta com mais de 50 importantes journals especializados em PMEs.

A importância das pequenas e médias empresas revela-se pela sua contribuição no desenvolvimento socioeconômico das nações. Conforme apresentado na Tabela 6, na Zona do Euro, formada por 27 países, observa-se que as micro, pequenas e médias empresas representaram, em $2010,99,8 \%$ do total das empresas, responderam por $66,9 \%$ dos empregos da região e contribuíram com $58,4 \%$ do $\mathrm{PIB}$.

Tabela 6 - Número de empresas, empregos e participação no PIB na zona do Euro - 2010

\begin{tabular}{|c|c|c|c|c|c|c|}
\hline \multirow{2}{*}{ Porte } & \multicolumn{2}{|c|}{ Empresas } & \multicolumn{2}{|l|}{ Empregos } & \multicolumn{2}{|c|}{ Produto Interno Bruto PIB } \\
\hline & $\mathrm{N}^{\circ}$ Empresas & $\%$ & $\mathrm{~N}^{\circ}$ Empregos & $\%$ & Participação PIB* & $\%$ \\
\hline Micro & 19.198 .539 & 92,1 & 38.905 .519 & 29,8 & 1.293 .391 & 21,6 \\
\hline Pequenas & 1.378 .401 & 6,6 & 26.605 .166 & 20,4 & 1.132 .202 & 18,9 \\
\hline Médias & 219.252 & 1,1 & 21.950 .107 & 16,8 & 1.067 .387 & 17,9 \\
\hline PMEs & 20.796 .192 & 99,8 & 87.460 .792 & 66,9 & 3.492 .979 & 58,4 \\
\hline Grandes & 43.043 & 0,2 & 43.257 .098 & 33,1 & 2.485 .457 & 41,6 \\
\hline TOTAL & 20.839 .226 & 100,0 & 130.717 .890 & 100,0 & 5.978 .436 & 100,0 \\
\hline
\end{tabular}

(*) Em milhões de Euros

FONTE: Annual Report on EU SMEs 2010/2011, 2011, p. 8.

Ao se analisar alguns países em particular (Tabela 7), verifica-se que o emprego gerado pelas PMEs de Portugal e da Alemanha foi de 74,4\% e 65,7\%, respectivamente. Com relação ao PIB, destacam-se as PMEs da Espanha e da Itália, com participação de 64\% e 55,6\%. No Canadá essas empresas respondem por $64 \%$ do emprego e por $54,3 \%$ do PIB (INDUSTRY CANADÁ, 2012). Na Índia, 93\% do emprego é gerado pelas micro, pequenas e médias empresas (DEVELOPMENT COMISSIONER - MSME, 2011).

Tabela 7 - Participação das Micro e Pequenas Empresas nas Economias

\begin{tabular}{lcccc}
\hline \multicolumn{1}{c}{ Participação das MPEs } & Portugal & Itália & Alemanha & Espanha \\
\hline Total das Empresas (\%) & 99,5 & 99,7 & 99,7 & 99,1 \\
PIB (\%) & 32 & 55,6 & 35 & 64 \\
Geração de Emprego (\%) & 74,4 & 49 & 65,7 & 63,7 \\
\hline FONTE: GEM, 2010. & & & &
\end{tabular}


Na América Latina e Caribe, em termos de participação no PIB, na Argentina o índice atinge $60 \%$, Colômbia 35\%, Uruguai 30\% e México 23\%. Com relação à geração de emprego, destacam-se as MPEs do México que absorvem 80\% do emprego, enquanto na Colômbia esse percentual gira em torno de $63 \%$ (SEBRAE, 2010).

\subsubsection{Empreendedorismo no Brasil}

O Brasil vem conquistando espaço no cenário internacional por suas características empreendedoras. De acordo com o Relatório Global de Monitoramento sobre Empreendedorismo (GEM/IBPQ, 2010), do qual participam 59 economias, no ano de 2010 o Brasil obteve a maior Taxa de Empreendedores em Estágio Inicial (TEA $\left.{ }^{3}\right)$ dentre 17 países do G20 que participam do relatório, com um índice de 17,5\%, seguido pela China $(14,4 \%)$ e Argentina (14,2\%). Outro aspecto a ser destacado é inversão do empreendedor por necessidade pelo empreendedor por oportunidade. Em 2002, nesse estudo, os empreendimentos por necessidade representavam cerca de $70 \%$ dos novos negócios, enquanto que o empreendimento por oportunidade representava 30\%. Em 2010, 68\% dos novos negócios foram criados por oportunidade e $32 \%$ por necessidade.

Entretanto, comparativamente ao cenário internacional, o Brasil tem ainda muitas lacunas a preencher. Com relação ao PIB, com uma participação em torno de $20 \%$, o país perde em desempenho para inúmeras outras nações, como Argentina, Colômbia, Uruguai, México, Zona do Euro, Canadá e Índia. Em termos de geração de emprego, com cerca de $60 \%$ da mãode-obra ocupada, percebe-se que há espaço para avanços ao se comparar com a Índia, onde as PMEs respondem por 93\% do emprego, a Zona do Euro com 66,9\%, o México com $80 \%$ e a Colômbia com $63 \%$.

Tabela 8 - Número de Empresas no Brasil (2000 - 2010; em mil)

\begin{tabular}{lrrrrrrrrrrr}
\hline & $\mathbf{2 0 0 0}$ & $\mathbf{2 0 0 1}$ & $\mathbf{2 0 0 2}$ & $\mathbf{2 0 0 3}$ & $\mathbf{2 0 0 4}$ & $\mathbf{2 0 0 5}$ & $\mathbf{2 0 0 6}$ & $\mathbf{2 0 0 7}$ & $\mathbf{2 0 0 8}$ & $\mathbf{2 0 0 9}$ & $\mathbf{2 0 1 0}$ \\
\hline Micro & 1.903 & 1.983 & 2.077 & 2.143 & 2.216 & 2.293 & 2.380 & 2.454 & 2.573 & 2.688 & 2.827 \\
Pequenas & 273 & 287 & 304 & 316 & 336 & 354 & 373 & 395 & 420 & 440 & 473 \\
Médias & 50 & 52 & 54 & 55 & 59 & 61 & 65 & 69 & 74 & 76 & 83 \\
Grandes & 12 & 13 & 13 & 14 & 15 & 15 & 16 & 18 & 18 & 19 & 20 \\
TOTAL & $\mathbf{2 . 2 3 9}$ & $\mathbf{2 . 3 3 5}$ & $\mathbf{2 . 4 4 8}$ & $\mathbf{2 . 5 2 7}$ & $\mathbf{2 . 6 2 6}$ & $\mathbf{2 . 7 2 4}$ & $\mathbf{2 . 8 3 4}$ & $\mathbf{2 . 9 3 5}$ & $\mathbf{3 . 0 8 5}$ & $\mathbf{3 . 2 2 4}$ & $\mathbf{3 . 4 0 3}$ \\
\hline FONTE: MTE/CAGED & 2012 & & & & & & & & &
\end{tabular}

\footnotetext{
${ }^{3}$ Taxa de Empreendedorismo em Estágio Inicial, TEA, é a proporção de pessoas na faixa etária entre 18 e 64 anos envolvidos em negócios nascentes ou novos (menos de 42 meses de existência).
} 
$\mathrm{Na}$ Tabela 8 e no Gráfico 2 pode ser observado, no período de 2000 a 2010, que houve um crescimento relativamente homogêneo em função do porte das empresas. $\mathrm{O}$ crescimento médio anual de micro, pequenas e médias empresas (MPMEs) foi de 4\%, 5,6\% e 5,1\% respectivamente. As empresas foram classificadas em função do número de empregados, conforme a metodologia definida pela OCDE.

Nos 10 anos em análise, as MPMEs representaram, em média, 99,5\% do total das empresas. Este índice coincide com o perfil internacional.

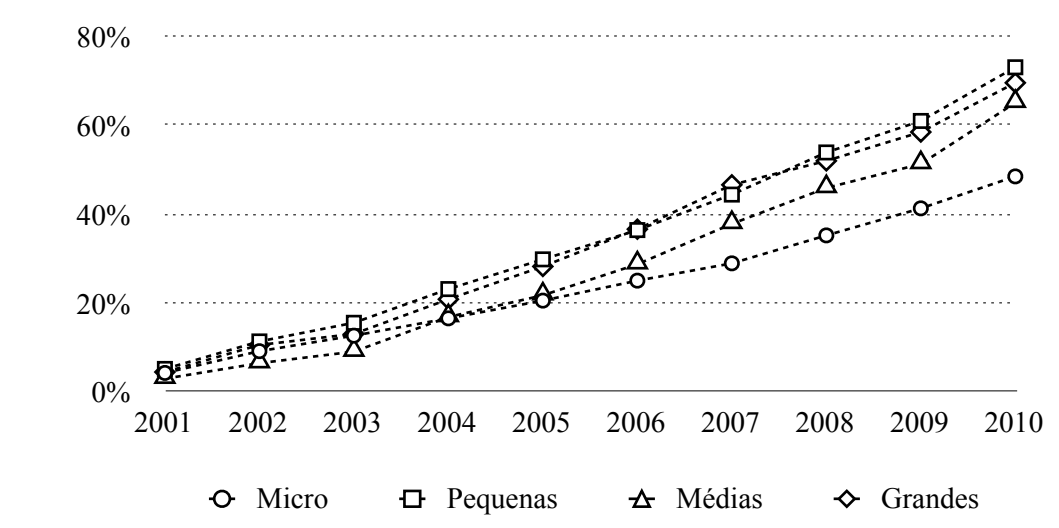

Gráfico 2 - Crescimento acumulado do número de empresas (2000 a 2010) FONTE: MTE/CAGED, 2012

Com relação aos ramos de atividade, observa-se que as PMEs do Brasil estão concentradas no setor de serviços (35\%) e no comércio (40\%).

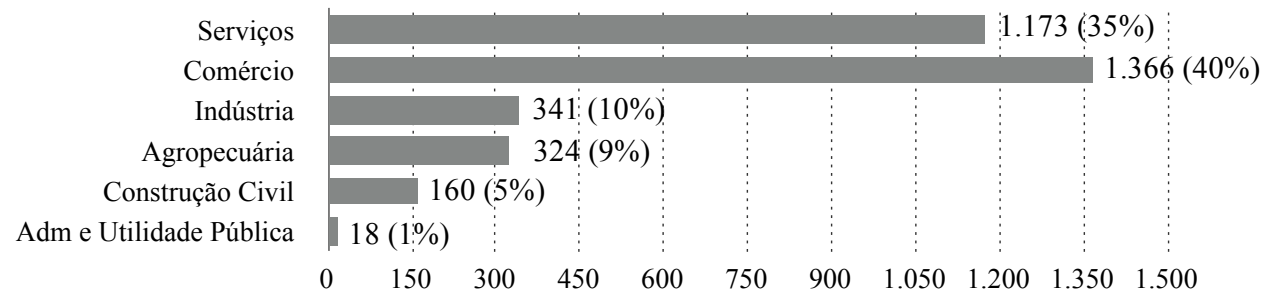

Gráfico 3 - Micro, Pequenas e Médias por setor de atividade - 2010 (em mil) Fonte: MTE/CAGED, 2012

Em termos de distribuição geográfica (Figura 3), observa-se que metade das empresas, independentemente do porte, estão localizadas na região sudeste. Ao se considerar apenas as 
micro e pequenas empresas, em torno de $70 \%$ delas estão localizadas nas regiões sul $(22 \%$ e $20 \%)$ e sudeste $(49 \%$ e $53 \%)$.
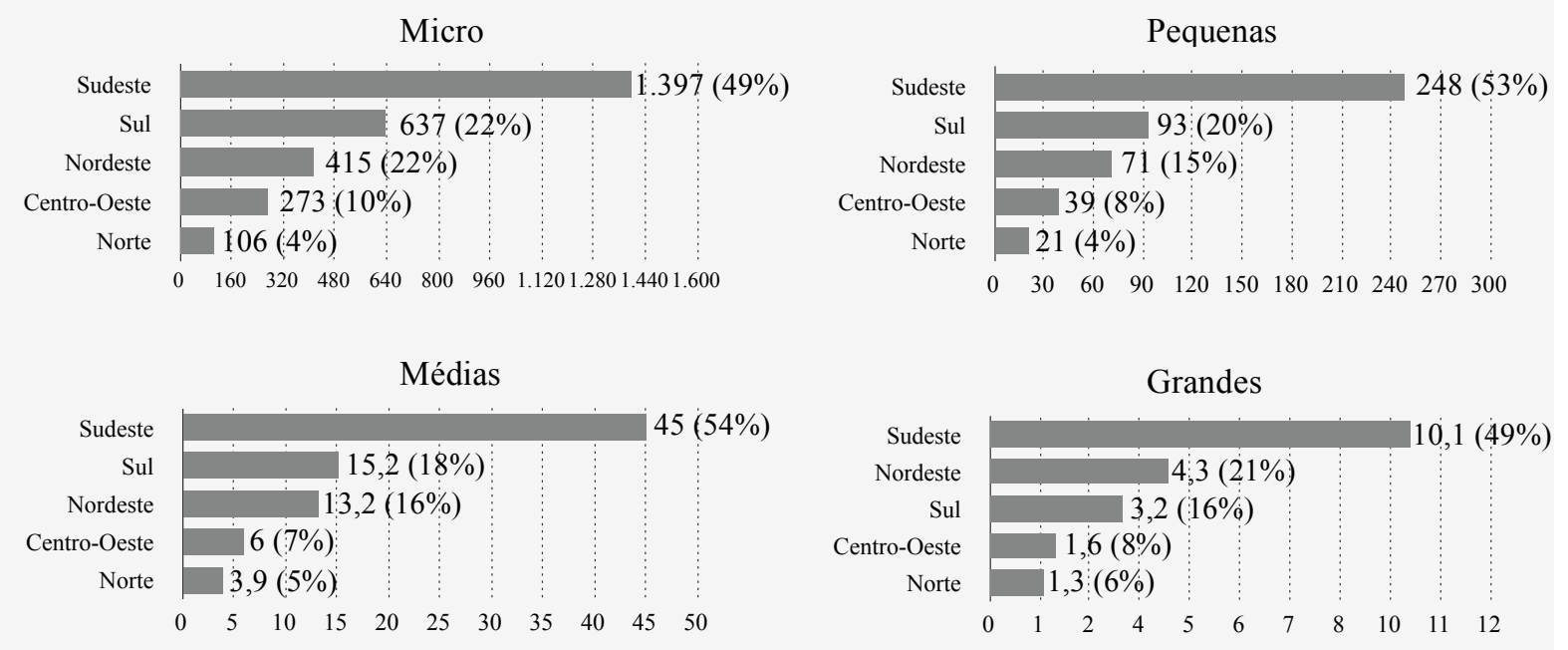

Figura 3 - Distribuição das empresas por tamanho e região - 2010 (em mil)

Fonte: MTE/CAGED, 2012

À medida que aumenta o tamanho das empresas, a região nordeste tem sua representatividade aumentada.

\subsubsection{Porte das empresas}

As variáveis comumente utilizadas para a classificação do porte das empresas gira em torno do número de empregados, faturamento bruto e total de ativos. Ainda que não haja uma discrepância muito grande, os critérios são ligeiramente divergentes entre países, blocos e comunidades.

Tabela 9 - Porte das empresas - Comissão Europeia

\begin{tabular}{l|c|c|c|c|c}
\hline \multicolumn{1}{c|}{ Classificação } & $\begin{array}{c}N^{\text {o de }} \\
\text { Empregados }\end{array}$ & & $\begin{array}{c}\text { Faturamento } \\
\text { (milhões de } € \text { ) }\end{array}$ & & $\begin{array}{c}\text { Ativos Totais } \\
\text { (milhões de } € \text { ) }\end{array}$ \\
\hline Micro & $<10$ & e & $\leq 2$ & ou & $\leq 2$ \\
Pequena & $<50$ & e & $\leq 10$ & ou & $\leq 10$ \\
Média & $<250$ & e & $\leq 50$ & ou & $\leq 43$ \\
\hline
\end{tabular}

Fonte: ANNUAL REPORT ON EU SMEs 2010/2011, 2011 
Para a zona do euro, a recomendação da Comissão da União Europeia estabelece que a classificação do porte das empresas se dê pela combinação do número de empregados, faturamento bruto e ativo total conforme descritos na Tabela 9.

No Canadá a classificação é definida unicamente com base no número de empregados, onde as micro empresas são aquelas com menos de 5 empregados. As pequenas empresas do setor industrial são aquelas com 5 a 50 empregados, enquanto no setor de serviços a faixa para esse porte é de 5 a 100 empregados. As médias empresas são aquelas com menos de 500 empregados, respeitados os critérios anteriores (INDUSTRY CANADÁ, 2012).

No Brasil a classificação é baseada basicamente no faturamento ou no número de empregados. Entretanto, observa-se que as classificações dos vários organismos são ligeiramente divergentes entre si.

Tabela 10 - Porte das empresas - BNDES

\begin{tabular}{l|c}
\hline \multicolumn{1}{c|}{ Classificação } & $\begin{array}{c}\text { Receita Operacional } \\
\text { Bruta anual (em R\$ milhões) }\end{array}$ \\
\hline Micro & $\leq 2,4$ \\
Pequena & $2,4<\mathrm{e} \leq 16$ \\
Média & $16<\mathrm{e} \leq 90$ \\
Média-Grande & $90<\mathrm{e} \leq 300$ \\
Grande & $300<$ \\
\hline FONTE: BNDES, 2012.
\end{tabular}

O Banco Nacional de Desenvolvimento Econômico e Social (BNDES) classifica o porte das empresas tendo por base a receita operacional bruta anual (Tabela 10). Observa-se que a classificação do BNDES, para as três primeiras faixas, é aderente com o perfil de faturamento e classificação utilizado pela União Europeia.

Para o Comitê de Pronunciamentos Contábeis (CPC, 2009), de acordo com o pronunciamento técnico - contabilidade para pequena e média empresa (CPC PME), uma PME é definida como a entidade "que não possui obrigação pública de prestação de contas" e "elabora demonstrações contábeis para fins gerais para usuários externos”. É importante ressaltar que o objetivo do CPC não é classificar, especificamente, o porte das empresas, mas regular e padronizar os procedimentos contábeis para as empresas que não possuem capital aberto, sobretudo com relação à evidenciação das informações financeiras. 
A Lei Geral da Pequena e Média Empresa (Lei Complementar ${ }^{0}$ 11/2011), baseada no faturamento bruto anual (Tabela 12), tem por objetivo apenas estabelecer as faixas de receitas para efeitos de interesses fiscais (Imposto SIMPLES). Órgãos como o SEBRAE, IBGE e MTE pouco tem utilizado essa classificação.

Tabela 11 - Porte das empresas - Lei Geral da MPE (PLC 11/2011)

\begin{tabular}{l|l}
\multicolumn{1}{c|}{ Classificação } & \multicolumn{1}{c}{ Receita Operacional Bruta anual } \\
\hline Microempresa & Menor ou igual a R\$ 360 mil \\
Pequena Empresa & Maior que R\$ 360 mil e menor ou igual a R\$ 3,6 milhões \\
\hline
\end{tabular}

FONTE: Lei Complementar 11/2011

A metodologia de classificação utilizada pelo SEBRAE (2012) considera dois grupos: a) Indústria e construção civil, e; b) comércio e serviços (Tabela 13).

Tabela 13 - Porte das empresas - SEBRAE

\begin{tabular}{l|c|c}
\hline \multirow{2}{*}{ Classificação } & \multicolumn{2}{|c}{ Número de Empregados } \\
\cline { 2 - 3 } & $\begin{array}{c}\text { Indústria e } \\
\text { Construção Civil }\end{array}$ & $\begin{array}{c}\text { Comércio e } \\
\text { Serviços }\end{array}$ \\
\hline Micro & até 19 & até 9 \\
Pequena & 20 a 99 & 10 a 49 \\
Média & 100 a 499 & 50 a 99 \\
Grande & 500 ou mais & 100 ou mais \\
\hline FONTE: SEBRAE, 2012.
\end{tabular}

Apesar das divergências entre as diversas metodologias, é possível obter convergências associando-se as metodologias, ou seja, combinando o número de empregados e faturamento. Outro aspecto a ser observado é a nomenclatura para este contingente empresarial. A denominação internacional amplamente utilizada inclui micro, pequenas e médias empresas no termo "Pequenas e Médias Empresas - PMEs" (Small and Medium sized Enterprises $S M E s)$. Também é recorrente, sobretudo na literatura acadêmica, o uso do termo "pequenos negócios" (small business) (PRAAG, 2003; HABER e REICHEL, 2005; BATES, 1995; LUSSIER e PFEIFER, 2001; WATSON et. al., 1998; LeCORNU et. al., 1996; CARTER e VAN AUKEN, 2006; LUK, 1996; GORGIEVSKI et. al., 2011), e do termo "pequenas empresas" (small firm) (ROBINSON, et. al., 1984; MATA e PORTUGAL, 1984).

Neste trabalho prevalece o conceito de empreendedorismo de negócios, onde a PME é constituída com finalidade econômica e o seu proprietário ou fundador é seu agente, o empreendedor. De modo a uniformizar com a prática recorrente na literatura da área, neste 
trabalho o conjunto de micro, pequenas e médias empresas foi denominado "Pequenas e Médias Empresas (PMEs)". A classificação do porte foi dada pela combinação das metodologias do BNDES e União Europeia, incluindo as empresas que possuem de 1 a 249 pessoas ocupadas assalariadas e tem faturamento bruto anual inferior à 90 milhões de reais.

\subsection{A Teoria de Finanças}

A teoria de finanças rege um importante conjunto de instrumentos presentes na tomada de decisão de investimento e durante a atividade operacional das PMEs. No momento da criação da empresa, as finanças oferecem suporte na compreensão da análise do risco, na determinação das variáveis que constituirão os fluxos de caixa, como previsão de receitas, custos, tributos e despesas, e na determinação da rentabilidade exigida. Estão apoiados nas finanças os termos chaves da decisão de investir ou não investir, a partir do tradeoff construído tendo por base, de um lado, os fluxos de caixa líquidos projetados e, de outro, o custo de capital, o risco e o retorno proporcionado pelo negócio.

Durante a atividade operacional, o planejamento e o controle financeiros são constantes do dia a dia da empresa, como acompanhamento das necessidades de capital giro, controle de contas a receber e a pagar, financiamentos de curto prazo, acompanhamento de custos e formação de preços, planejamento tributário, inadimplência, salários e encargos trabalhistas.

Por fim, o sucesso da empresa é traduzido pelo êxito obtido em um conjunto de indicadores, incluindo-se os financeiros. Porter (1992) destaca que o desempenho econômico consubstancia-se numa das principais razões de uma atividade empresarial. No contexto das grandes corporações, indicadores como lucro, retorno sobre o ativo, retorno sobre o patrimônio líquido, liquidez, índice preço lucro, constituem elementos sobre os quais pairam a maior parte das expectativas e tomada de decisões de investidores. No contexto de PMEs, mesmo se reconhecendo a elevada assimetria informacional, a medição do desempenho pautase, com adaptações, em inúmeros indicadores econômico-financeiros, como percepção de lucro e crescimento das vendas (DESS e ROBINSON, 1984; WEST III e NOEL, 2009).

Não obstante, as evidências da literatura têm apontado a disponibilidade de recursos (capital) e o registro e controle financeiros com maior frequência na determinação ou explicação do 
desempenho de PMEs (BARSLEY; KLEINER,1990; BRUNO et. al., 1987; VAN GELDEREN et al, 2006; WIGHT, 1985; VESPER, 1990; LUSSIER; CORMAN, 1996; LAUZEN, 1985; BATES, 1995; YUSUF, 1995; WATSON et al, 1998; SCHAEFER, 2012; FOTOPOULOS; LOURI, 2000; HEADD, 2003; CARTER; VAN AUKEN, 2006).

\subsubsection{Decisão de investimento em ambiente de incerteza}

A decisão de constituir uma empresa, qualquer que seja seu porte, consiste, a priori, no processo administrativo de organização e alocação de recursos.

De acordo com a teoria da utilidade, as pessoas possuem comportamento racional e suas escolhas baseiam-se na maximização da utilidade dos seus recursos ou, em outras palavras, na maximização de suas riquezas (COPELAND et. al., 2005). O uso da teoria da utilidade na avaliação de alternativas que envolvem incertezas foi sugerido por Bernoulli (1738), seguindo sua demonstração da futilidade de se utilizar o valor esperado como guia de orientação na avaliação de apostas (Paradoxo de São Petersburgo). Bernoulli sugeriu que as pessoas escolhem, entre duas alternativas de risco, aquela que maximiza a utilidade esperada. A utilidade esperada E(U) é dada por (Seitz e Ellison, 1999):

$$
\mathrm{E}(\mathrm{U})=\mathrm{p}_{1} \mathrm{U}\left(\mathrm{X}_{1}\right)+\mathrm{p}_{2} \mathrm{U}\left(\mathrm{X}_{2}\right)+\mathrm{p}_{3} \mathrm{U}\left(\mathrm{X}_{3}\right)+\ldots+\mathrm{p}_{\mathrm{n}} \mathrm{U}\left(\mathrm{X}_{\mathrm{n}}\right)
$$

onde $\mathrm{p}_{1}$ é a probabilidade do resultado $1, \mathrm{X}_{1}$ é o pagamento recebido se o resultado 1 ocorrer, e $U\left(X_{1}\right)$ é o índice extraído que reflete a atratividade do pagamento $X_{1}$ em relação a outros possíveis pagamentos.

A teoria da utilidade esperada, dois séculos mais tarde, foi fundamentada nos axiomas de Von Neumann e Morgenstern (1947). Assim, se os axiomas são satisfeitos, estão é possível determinar uma função utilidade que represente as preferências de um indivíduo. A base axiomática da teoria da utilidade esperada representou uma grande contribuição para a teoria da decisão. Basicamente, os axiomas propostos por Von Neumann e Morgenstern é o que diferenciavam o modelo original da teoria da utilidade esperada proposta por Bernoulli, no século XVIII. 
A função utilidade em ambiente de incerteza classifica os agentes em três tipos: a) avessos ao risco; b) neutros ao risco; c) propensos ao risco.

Na Ilustração 4, a curva A é a curva de utilidade total de um tomador de decisão avesso ao risco. Ela demonstra uma utilidade marginal decrescente, ou seja, cada unidade adicional de riqueza oferece menos utilidade que a unidade anterior. Nesse caso, o tomador de decisão requererá payoffs com valores esperados suficientemente em excesso para que seja estimulado a aceitar o risco. A curva B é a curva de utilidade na qual cada unidade de riqueza adicional possui a mesma utilidade anterior. As decisões tomadas nessa curva revelam-se neutras de risco. Nesse caso o tomador de decisão será indiferente se, em uma aposta, o valor esperado for igual ao custo, e aceitará todas as apostas no qual o valor esperado exceda os custos por menor que seja esta margem. Na curva $\mathrm{C}$ observa-se que cada unidade adicional de riqueza é maior que a utilidade marginal da unidade anterior. Nessa curva, o tomador de decisão é propenso ao risco, e aceitaria algumas apostas em que o valor esperado é menor o custo.

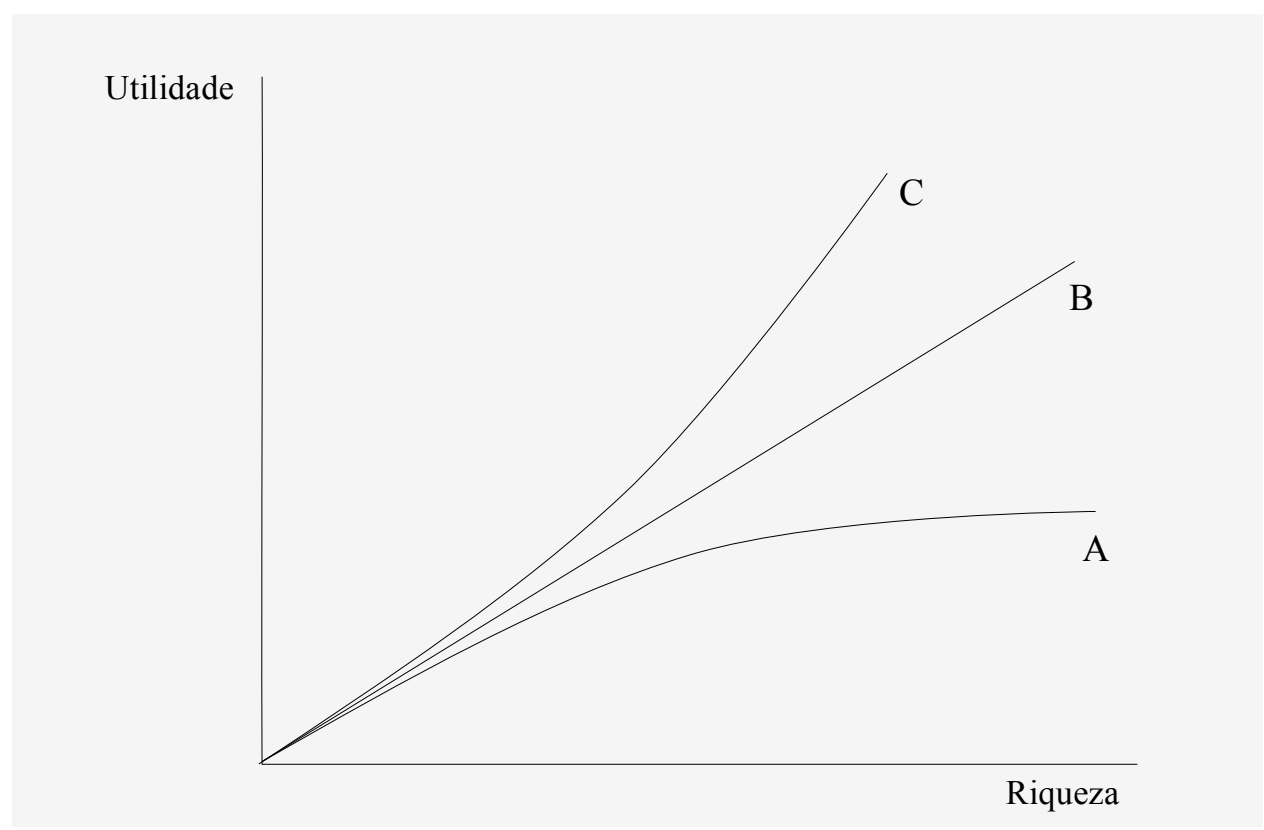

Figura 4 - Curva de utilidade da riqueza FONTE: SEITZ; ELLISON, 1999, p. 352.

A teoria de finanças, de maneira geral, considera que o indivíduo sensato é avesso ao risco (ROSS et. al., 1993; BRIGHAM e EHRHARDT, 2002). Assim, se o indivíduo estiver frente a uma decisão de mesmo valor esperado, ele preferirá a opção menos arriscada, ou se as opções 
forem de mesmo risco, ela optará por aquela que oferecer melhor compensação pelo risco assumido. Entretanto, como será visto no próximo subitem deste capítulo, Kahnemann e Tversky (1979) encontraram evidências empíricas de que as pessoas são avessas ao risco no domínio dos ganhos e propensas ao risco no domínio das perdas.

O risco, na linguagem comum, é a exposição à chance de um prejuízo ou perda. Em finanças, o termo risco é geralmente utilizado para explicar a probabilidade de perdas de dinheiro. Adicionalmente refere-se à possibilidade da obtenção de um retorno menor do que o esperado (SEITZ e ELLISON, 1999). Para Brigham e Ehrhardt (2002) risco é a exposição a um perigo, perda ou dano. Refere-se à probabilidade de ocorrência de algum evento desfavorável.

O risco de um investimento no mercado de ações é medido pela dispersão dos resultados possíveis. Usualmente essa dispersão é medida pelo desvio-padrão ou pela variância (BREALEY; MYERS, 1996). Weston e Brigham (2000) apresentam duas classificações para o risco: a) sistemático, de mercado ou não diversificável, e; b) não-sistemático, isolado ou diversificável.

De acordo com Ross et. al. (1993), o risco sistemático afeta, ao mesmo tempo, um grande número de ativos em iguais ou diferentes intensidades e não pode ser minimizado ou eliminado pela diversificação, enquanto o risco não sistemático afeta especificamente um ativo ou pequeno grupo de ativos e pode ser eliminado pela diversificação. Weston e Brigham (2000) observam que o risco de mercado e o risco específico geralmente estão correlacionados.

Nas decisões de investimento o risco exerce papel preponderante uma vez que os investidores exigem recompensas pela aceitação deles (ROSS et al., 1993). No esforço de equacionar a relação entre risco e retorno, estudos importantes foram apresentados, como a teoria de portfólio de Markowitz (1952), a teoria do modelo de precificação de ativos de capital (Capital Assets Price Model - CAPM) de Sharpe (1964) e Lintner (1965); a teoria de precificação por arbitragem (Arbitrage Pricing Model - APT) de Ross (1976) e o modelo de precificação de três fatores de Fama e French (1992).

O CAPM, bastante utilizado no campo prático, relaciona o retorno esperado de um ativo com o seu coeficiente de risco não diversificável em um mercado em equilíbrio (SHARPE, 1964; 
LINTNER, 1965; MOSSIN, 1966). Estabelece a relação entre o risco e taxa de retorno esperada, quando os ativos são mantidos em carteiras bem diversificadas.

O tradeoff risco-retorno guarda relação com a curva da utilidade esperada do tomador de decisão avesso ao risco, à medida que o modelo estabelece um prêmio pelo risco específico do ativo.

A decisão de investimento de criação de uma empresa consiste na tomada de decisão em ambiente de incerteza, com alocação de recursos em ativos reais. Bodie et. al. (2004) destacam que todos os ativos reais possuem risco. Bodie e Merton (2003) observam que os principais riscos enfrentados pelas empresas são os riscos de produção, preço dos produtos, preço dos insumos, demanda e, tamanho e forma da estrutura organizacional.

Entretanto, modelos como CAPM e APT têm sido largamente aplicados em grandes corporações com ativos negociados em bolsas de valores. Sua aplicação encontra restrições de aplicação em empresas de capital fechado, ainda que grandes, e é substancialmente limitado para ser aplicado em pequenas e médias empresas.

Então, como determinar o risco específico ou de mercado de uma PME? Relembrando, de acordo com as estatísticas nacionais e internacionais, de cada cinco empresas constituídas, quatro são encerradas. Em um horizonte de cinco anos, a chance de sobrevivência é de aproximadamente $35 \%$ ou, pelo avesso, a chance de insucesso é de $65 \%$. Estudos do SEBRAE/SP (2008) apontam que, das empresas encerradas, houve perda total dos recursos em $52 \%$ dos casos, e total ou parcial em $77 \%$ dos casos. Nesse sentido, qual deveria ser o retorno exigido e esperado para que esse risco seja justa e adequadamente remunerado?

Integrando a teoria da utilidade e os modelos de precificação de ativos com o empreendedorismo, observa-se que, ao se criar uma empresa, a utilidade esperada são os retornos representados pelos fluxos de caixa líquidos do investimento, e a curva de custo é representada pelos investimentos associados à taxa de retorno ajustada pelo risco no negócio.

Assim, o valor esperado de uma decisão estratégica de investimento é obtido, ex ante, pela análise de viabilidade baseada nos fluxos de caixa líquidos e investimentos necessários durante a vida econômica do negócio. Brigham e Ehrhardt (2005) destacam três indicadores 
chave para essa análise: a) Período de recuperação do investimento (payback); b) Valor Presente Líquido (VPL), e; c) Taxa Interna de Retorno (TIR).

Em tese, estes indicadores são amplamente reconhecidos e utilizados na literatura de finanças (BRIGHAM e EHRHARDT, 2005; BREALEY e MYERS, 1996; WESTON e BRIGHAM, 2000; ROSS et. al., 1993). O payback determina o tempo necessário para que o investimento originalmente efetuado seja totalmente recuperado. O VPL caracteriza-se pelo valor líquido resultante do valor presente dos fluxos de caixa líquidos (FCLs) do projeto deduzido do investimento original. A TIR estabelece a relação entre o valor investido e os FCLs. Ao se considerar que os FCLs não serão reinvestidos no projeto sendo, portanto, ajustados pelo custo de capital. Nesse caso a TIR constitui a rentabilidade efetiva esperada da decisão de investimento.

\subsubsection{Teoria dos Custos de Transação e as Finanças Comportamentais}

Os custos de transação tiveram sua origem quando Coase (1937) defendeu que, às vezes, o custo de gerenciar transações econômicas por meio de mercados é maior que fazê-lo internamente nas organizações. Williamson (1975) desenvolveu o núcleo central da Teoria dos Custos de Transação (TCT). Para ele, mercados e hierarquias constituíam-se de mecanismos alternativos para um determinado conjunto de transações. Os pressupostos comportamentais que sustentam a TCT é a racionalidade limitada e o oportunismo.

Kupfer e Haesenclever (2002), destacam que a TCT pressupõe que o comportamento humano, ainda que intencionalmente racional, é limitado. Essa limitação sustenta-se em dois fundamentos: o neurofisiológico - limitação no processamento e acumulação informações, e; de linguagem - limitação na capacidade de transmitir a informação. Para Williamson (1987), se não houvesse limitação cognitiva dos agentes, as transações poderiam ser completamente conduzidas por meio do planejamento.

A racionalidade é classificada em três níveis: racionalidade forte - consiste na visão maximizadora de que os agentes econômicos são suficientemente hábeis para receber, absorver, e processar toda a informação disponível; racionalidade limitada - adotada pela TCT, onde os custos de transação resultam de contratos incompletos decorrentes da limitação 
dos agentes, e; racionalidade orgânica - presume que os indivíduos não são capazes de produzir elementos para antecipar a adaptação aos problemas ex-post (Williamson, 1985).

O oportunismo preconizado por Williamson (1987) inclui mentir, roubar, trapacear sob o ponto de vista da revelação incompleta ou distorcida das informações, cujos esforços voltamse a enganar, alterar, disfarçar, ofuscar ou confundir parceiros nas transações. Entretanto, Kupfer e Hasenclever (2002) destacam que o oportunismo defendido na TCT está fundamentalmente associado à manipulação de assimetrias da informação, visando à apropriação de fluxo de lucros.

Os pressupostos comportamentais da TCT são elementos potencialmente presentes na tomada de decisão de investimentos de pequenas e médias empresas, apoiando-se em dois aspectos: a) Oportunidade - de acordo com o relatório do Global Entrepreneurship Monitor (2010), no ano de 2010,68\% dos empreendedores responderam que constituíram suas empresas porque identificaram uma oportunidade, enquanto apenas $32 \%$ o fizerem por necessidade; b) a racionalidade limitada - que se reveste da limitação de receber e processar as informações na sua completude. Em condições de assimetria de informação e limitação cognitiva do agente, a oportunidade pode não representar um provável cenário de apropriação de lucros, e sim, uma inadequada decisão de investimento.

No contexto de PMEs presume-se que os pressupostos da TCT coincidem com o arcabouço teórico das finanças comportamentais.

As Finanças Comportamentais consistem em uma área recente de pesquisas no campo das finanças e da psicologia, que nasceu a partir dos estudos de Kahnemann e Tversky (1979). Os autores, em seu trabalho seminal intitulado Prospect Theory (Teoria do Prospecto), encontraram evidências empíricas de que as decisões do indivíduo apoiam-se mais em como uma decisão é estruturada, e menos sobre a racionalidade preconizada na teoria da utilidade. Mais tarde, em 1992, os autores receberam o Prêmio Nobel de Economia pela contribuição de suas pesquisas.

No desenvolvimento dos estudos, Kahnemann e Tversky (id) construíram alternativas de escolhas com resultados idênticos em questões distintas e as submeteram para escolha dos 
indivíduos. Por exemplo, um dos cenários utilizados nas pesquisas consistia no seguinte conjunto de questões e escolhas:

1) Considere que você recebeu $\$ 1.000$ e por isso deve escolher apenas uma das opções abaixo:

a) Ganhar $\$ 500$ com certeza;

b) Você tem $50 \%$ de chance de ganhar mais $\$ 1.000$ e 50\% de chance de não ganhar nada

2) Considere que você recebeu $\$ 2.000$ e por isso deve escolher apenas uma das opções abaixo:

a) Perder $\$ 500$ com certeza;

b) Você tem $50 \%$ de chance de perder $\$ 1.000$ e $50 \%$ de chance de não perder nada

Tanto para a questão 1 , como para a questão 2, o valor da escolha da alternativa "a" era $\$$ 1.500 e da alternativa " $b$ " era $\$ 1.000$ ou $\$ 2.000$. Entretanto, na questão $1,82 \%$ dos respondentes optaram pela questão "a" enquanto que, na questão 2, apenas $48 \%$ optaram pela alternativa "a". Utilizando-se de diversas questões que envolviam termos antagônicos e com resultados equivalentes ao acima exposto, os autores concluíram que as decisões dos indivíduos eram afetadas pela forma como a decisão (argumento) estava estruturada. Termos como "ganho" e "perda", "vida" e "morte", "saúde" e "doença" exercem efeitos psicológicos distintos e, dependendo da forma como estiverem estruturados produzem decisões enviesadas e racionalmente distorcidas. Os indivíduos tendem a ser avessos ao risco no domínio dos ganhos e propensos ao risco no domínio das perdas.

Kahnemann e Tversky (1979b) observaram que os indivíduos incorrem em vieses cognitivos. Um desses vieses destacado pelos autores (id.) é denominado overconfidence. Esse termo nem sempre tem sido corretamente traduzido/interpretado na língua portuguesa. Comumente a expressão overconfidence é dada como "excesso de confiança". Entretanto é importante ressaltar que o termo também inclui o entendimento de um superdimensionamento do intervalo de confiança. Kahneman e Tversky explicam que, quando não se tem conhecimento, dados e padrões confiáveis sobre um determinado fenômeno, o intervalo de confiança para prevê-lo no futuro aumenta naturalmente.

Com relação à tomada de decisão em ambiente de incerteza, Khnemann e Tversky (1979b) destacam que os indivíduos tendem a subestimar a incerteza, selecionando impulsivamente cenários mais favoráveis. 
Dunne et. al. (1988) identificaram a presença do viés de excesso de confiança em uma amostra de pequenas empresas encerradas do setor industrial, nos Estados Unidos. Os autores ressaltam que os cenários desenhados sob o efeito do viés de excesso de confiança pode não se concretizar na prática, levando ao desestímulo e ao abandono do empreendimento.

\subsubsection{Planejamento e Controle Financeiro}

O planejamento financeiro constitui as diretrizes centrais da empresa para (1) identificar as metas financeiras da empresa, (2) estabelecer uma análise comparativa entre a situação financeira atual e as metas financeiras pretendidas e, (3) construir e descrever o conjunto de medidas e ações necessárias para que a empresa, partindo da situação atual, atinja as metas estabelecidas (ROSS et al, 1993).

Brealey e Myers (1996) destacam que o processo de planejamento financeiro envolve fundamentalmente a (1) análise das opções de investimentos e de financiamento de que a empresa dispõe, (2) a construção dos cenários futuros a partir das decisões presentes de modo a evitar surpresas e conciliar as ações presentes e resultados futuros, (3) a escolha dentre múltiplas alternativas, aquelas que serão implementadas e, (4) a construção de mecanismos de avaliação entre o desempenho esperado e o desempenho alcançado. Ross et al (id) ainda acrescentam que o processo de planejamento (a) explicita as vinculações entre propostas de investimentos distintas e opções de financiamento, (b) oferece oportunidade para empresa examinar diversas opções de investimento e financiamento, (c) auxilia na escolha dos planos que melhor coadunam com os interesses dos proprietários e, (d) evita que a empresa seja apanhada de surpresa frente à possíveis eventos no futuro.

O processo de planejamento financeiro engloba os planos estratégicos (longo prazo) e operacionais (curto prazo). Os planos financeiros de longo prazo (estratégicos) descrevem as medidas financeiras e o impacto esperado delas em um horizonte de dois a dez anos, enquanto os planos operacionais englobam as ações financeiras de um a dois anos, como orçamento de caixa, planos de produção, compras e estocagem, acompanhamento do capital de giro, etc. Os planos de curto e longo prazo precisam estar integrados (GITMAN, 2003). 
Com relação às PMEs como qualquer outra empresa, a ação de planejar começa muito antes da abertura do negócio mediante a elaboração do plano de negócio. Neste instrumento os passos iniciais são pormenorizados, como a aquisição de máquinas e equipamentos, formação de estoques, ajustes das políticas de crédito e de prazos com fornecedores, necessidades permanentes e não permanentes de recursos circulantes, cronograma de caixa etc. Schaefer (2012) ainda lembra que um crescimento desordenado, sem o devido equilíbrio entre fontes e usos de recursos, pode levar à falência uma empresa com sucesso em potencial.

O plano de negócio tem sido evidenciado empiricamente como um importante fator determinante de sucesso de PMEs (BARSLEY; KLEINER, 1990; BRUNO et al, 1987; GASKILL et al, 1993; VAN GELDEREN et al, 2006; LUSSIER, 1995; WOOD, 1989; LUSSIER; CORMAN, 1996; LAUZEN, 1985; LUSSIER, 1996; LUSSIER; PFEIFER , 2001; WATSON et al, 1998; SCHAEFER, 2012).

No levantamento de 16 estudos que identificaram pelo menos uma variável explicativa para o desempenho de pequenos negócios, em 13 deles a variável "plano de negócio" foi representativa, enquanto a variável "registros e controles financeiros" foi significativa em 10 estudos.

Não obstante, em outro levantamento que incluiu 20 artigos, em 16 deles a variável "capital" foi representativa na determinação do sucesso nos pequenos negócios. É importante destacar que essa variável está ligada com a disponibilidade de recursos, seja no ato da constituição da empresa, seja no decorrer de sua atividade.

Gaskill et. al. (1993), utilizando-se de uma amostra de 110 pequenas empresas, encontraram que o planejamento e o capital de giro configuraram-se significativos na sobrevivência dessas empresas. Sullivan et. al. (1998), utilizando-se de uma amostra de 3.377 empresas, identificaram aspectos de financiamento como determinantes de sobrevivência. 


\subsection{Avaliação de desempenho}

O termo “desempenho" é amplamente utilizado no campo da administração, mas seu significado nem sempre é claramente explicitado. Frequentemente "desempenho" é considerado como eficiência ou efetividade. Adicionalmente como competitividade, redução de custos, criação de valor e emprego, crescimento e, sobrevivência das empresas no longo prazo (LEBAS e EUSKE, 2002).

Assim como a amplitude de utilização, também são amplos os significados que podem ser atribuídos ao termo desempenho. Lebas e Euske (2002) identificaram as definições mais utilizadas para o termo, podendo ser:

a) a consecução de alguma intenção específica;

b) o resultado de uma ação (por ex.: valor criado e avaliado);

c) a capacidade de realizar ou o potencial de criar um resultado;

d) a comparação de um resultado com um benchmark ou referência escolhidos - ou determinados - seja interna ou externamente;

e) um resultado inesperado comparado com as expectativas;

f) um julgamento por comparação.

Desempenho é um construto social com conceito complexo. A complexidade aumenta tanto a dificuldade de definição do conceito como a probabilidade de que indicadores de desempenho tornem-se contraditórios ao longo do tempo (LEBAS e EUSKE, 2002).

No mercado de capitais, onde comumente figuram as grandes organizações, os indicadores financeiros são os preferidos para se avaliar desempenho, por se basearem em informações contábeis padronizadas e auditadas. Entretanto, muitos usuários utilizam informações não financeiras, como produtividade, participação de mercado, indicadores socioambientais etc.

\subsubsection{Indicadores Financeiros}

Os indicadores de situação financeira historicamente exerceram um papel importante na análise da saúde das empresas. Os modelos de previsão de falência, como Altman (1968), Kanitz (1978), Matias (1976) e Silva (1983) baseavam-se intensivamente em indicadores 
econômicos financeiros. Não obstante, estes modelos discriminantes apresentaram razoável capacidade de classificar corretamente empresas solventes e insolventes.

Os indicadores financeiros tradicionalmente utilizados na literatura de finanças (BRIGHAM e ERHARDT, 2005; WESTON e BRIGHAM, 2000; ROSS et. al., 1993; GITMAN, 2003; ASSAF NETO, 2003; MATARAZZO, 1998) são classificados em: a) Liquidez; b) Atividade;

c) Capital de Giro; d) Rentabilidade, e; e) Estrutura de Capital. Entretanto, dada a assimetria informacional e indisponibilidade das informações financeiras de PMEs, os pesquisadores têm procurado, dentro do possível, aproximarem-se em torno dos indicadores de capital de giro e de rentabilidade.

\section{a) Indicadores de capital de giro}

Os indicadores de capital de giro permitem observar a eficiência operacional e financeira da empresa e visualizar a dimensão das necessidades de investimentos em capital de giro (ASSAF NETO, 2003; MATARAZZO, 1998). Prazos elevados de estocagem e de recebimento sem a respectiva compensação nos prazos de pagamento implicam em necessidades de financiamento de capital de giro, assim como efeitos exógenos, como a sazonalidade, tem impactos efetivos sobre esta classe de recursos.

O capital de giro representa o montante de recursos envolvidos nas atividades operacionais do dia a dia. Apesar de comumente serem caracterizados como circulantes, o ciclo financeiro pode demandar recursos permanentes em capital de giro. $\mathrm{O}$ nível de $\mathrm{CG}$ que uma empresa deve manter deve ser compatível com a própria essência do seu negócio (GITMAN, 2003).

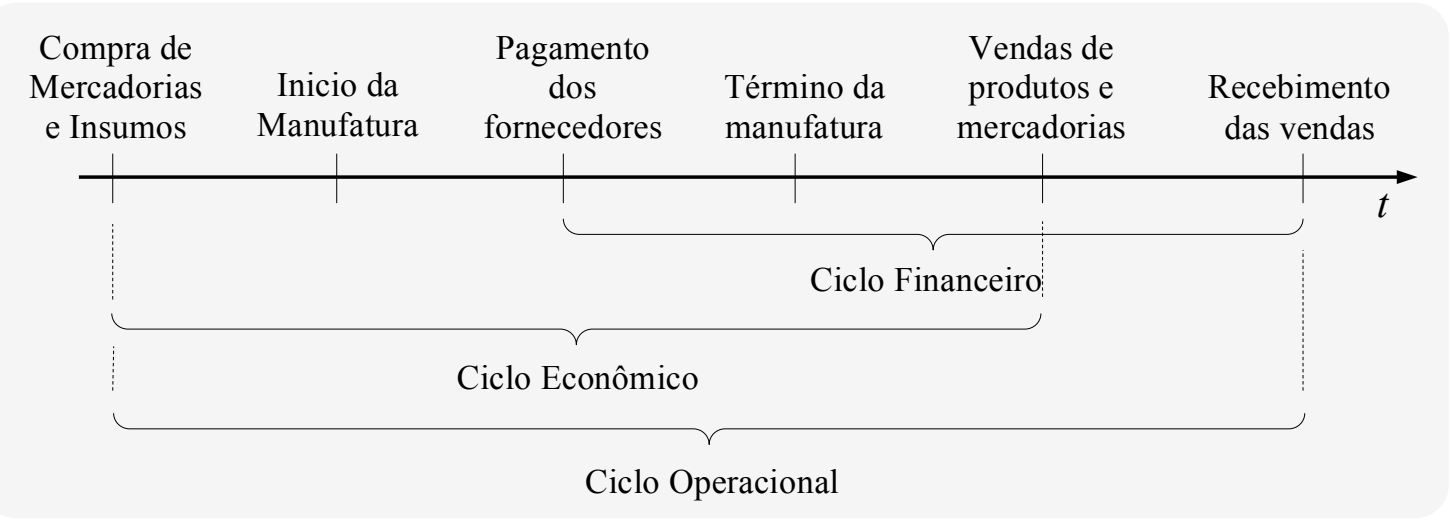

Figura 5 - Ciclos empresariais no tempo 
Na Figura 5 estão apresentados os principais ciclos da atividade empresarial. Na premência de ciclos financeiros positivos, tem-se que cada unidade adicional vendida requer uma fonte adequada de financiamento. Ressalta-se que esta deveria ser uma estimativa inclusa quando da elaboração do plano de negócio, assim como durante a atividade operacional na forma de registros e controles financeiros.

Shaefer (2012) aponta que uma das principais causas do insucesso nas PMEs é o crescimento muito rápido. Nesse caso, dependendo do tamanho do ciclo financeiro, rapidamente a empresa passa a depender de montantes elevados para cobrir suas necessidades correntes e, na presença de restrição de fontes de capital, passa a utilizar passivos altamente onerosos como antecipação de recebíveis, contas garantidas, cheque especial etc.

Sousa et. al. (1996) salientam que a gestão dos recursos de curto prazo inclui o confronto detalhado e contínuo das contas circulantes, preservando a manutenção de saldos satisfatórios de capital circulante líquido.

Resumindo, ainda que os indicadores de atividade e de capital de giro não guardem relação direta com o desempenho, a adequada gestão baseada nesses indicadores culmina com melhor desempenho. Por exemplo, uma política de crédito conciliada com a política de compra e com a disponibilidade e custos das fontes de financiamento permitem que a empresa opere com níveis adequados de capital de giro e constitua uma estratégia de crescimento dentro de suas capacidades.

\section{b) Indicadores de rentabilidade}

Indicadores como Margem Bruta (Operacional/Líquida), Lucro por Ação, Retorno sobre o Ativo, Retorno sobre o Patrimônio Líquido, Retorno sobre o Capital Investido, têm sido largamente empregados como medidas de desempenho de organizações econômicas. O objetivo é avaliar a eficiência das firmas no emprego e na remuneração de suas fontes de financiamento (capital próprio e de terceiros). Essa categoria é útil para avaliar a capacidade das empresas em obter lucros nos exercícios futuros, sobreviver no longo prazo, pagar seus credores e recompensar seus proprietários (acionistas). 


\subsubsection{Indicadores de Desempenho para Pequenas e Médias Empresas}

O desafio envolvido na criação de uma empresa, assim como as incertezas, falta de recursos e a instabilidade, que caracterizam os pequenos negócios, levaram alguns pesquisadores a definir a sobrevivência como uma primeira dimensão do sucesso (VAN DE VEN, et. al., 1984). Entretanto, Kalleberg e Leicht (1991) separam sucesso e sobrevivência em aspectos distintos de desempenho, que são determinados por diferentes fatores.

Dada complexidade para se definir uma medida de desempenho, é frequentemente recomendado utilizar múltiplas medidas de desempenho (GORGIEVSKI et. al., 2011; HABER e REICHEL, 2005; WESTHEAD et. al., 2001; KALLEBERG e LEICHT, 1991). De fato, uma única medida singular, como o lucro, pode não refletir a realidade organizacional, mas uma situação de momento, ou ainda, devido a dificuldade de compreensão da expressão "lucro", as informações obtidas podem estar enviesadas (KOS et. al., 2011). Além disso, essa medida pode não refletir, necessariamente, a habilidade de a empresa sobreviver ou prosperar no longo prazo (BARNEY, 1997).

Kaplan e Norton (1992), por meio do Balanced Scorecard, materializaram uma ferramenta que procurou reunir o desempenho de uma organização sob o prisma de quatro perspectivas: a) financeira; b) clientes; c) processos internos e; d) aprendizado e crescimento. Ainda, de acordo com os autores, o efetivo desempenho das empresas deve ser medido sob a ótica financeira e não financeira.

Adams e Sykes (2003), em uma amostra com empresas Afro-Americanas, observaram que os proprietários consideravam as medidas financeiras como as mais importantes na mensuração do desempenho. Entretanto, Foley (2003), em uma pesquisa com proprietários de pequenos negócios na Austrália concluiu que as medidas financeiras, dentre todas, eram as menos importantes. Para eles a continuidade do negócio consistia o indicador representativo do sucesso. Newby et. al. (2003) encontraram que o principal objetivo dos empreendedores era a satisfação pessoal, seguida dos retornos financeiros.

Haber e Reichel (2005) testaram um conjunto de medidas de desempenho para a indústria turística e os resultados obtidos foram discriminados numa matriz com medidas objetivas e subjetivas de curto e longo prazo (Figura 6). 


\begin{tabular}{|c|c|c|}
\hline $\begin{array}{l}\text { LONGO } \\
\text { PRAZO }\end{array}$ & $\begin{array}{l}\text { - Crescimento nas vendas } \\
\text { - Crescimento no número de } \\
\text { empregados }\end{array}$ & $\begin{array}{l}\text { - Desenvolvimento e Crescimento } \\
\text { - Turismo e a força do negócio } \\
\text { - Sucesso na geração de lucros em } \\
\text { períodos de crise }\end{array}$ \\
\hline \multirow[t]{2}{*}{$\begin{array}{l}\text { CURTO } \\
\text { PRAZO }\end{array}$} & $\begin{array}{l}\text { - Receitas } \\
\text { - Número de Empregados } \\
\text { - Vendas por Empregado }\end{array}$ & $\begin{array}{l}\text { - Ocupação e satisfação do cliente } \\
\text { - Lucro comparado com os } \\
\text { competidores }\end{array}$ \\
\hline & OBJETIVA & SUBJETIVA \\
\hline
\end{tabular}

Figura 6 - Matriz de medidas de desempenho na indústria do turismo FONTE: HABER; REICHEL, 2005

Gorgievski et. al. (2011), utilizando-se de levantamentos na literatura sobre pequenos negócios e entrevistas com proprietários de empresas, definiram dez critérios para determinação do sucesso empresarial (Quadro 1)

Quadro 1 - Critérios de sucesso empresarial

\begin{tabular}{|l|l|}
\hline \multicolumn{1}{|c|}{ Critério } & \multicolumn{1}{c|}{ Descrição } \\
\hline Lucratividade & Elevados dividendos; altas margens de lucro. \\
\hline Crescimento & $\begin{array}{l}\text { Crescimento no número de empregados; vendas; participação no } \\
\text { mercado e/ou distribuição. }\end{array}$ \\
\hline Inovação & Introdução de novos produtos ou métodos de produção. \\
\hline Sobrevivência / continuidade & Permite a transferência geracional ou pode ser vendida com lucro. \\
\hline $\begin{array}{l}\text { Contribuições para a } \\
\text { Sociedade }\end{array}$ & Consciência Social; métodos de produção sustentáveis. \\
\hline Satisfação Pessoal & $\begin{array}{l}\text { Alcance de aspectos importantes, como autonomia, desafios, segurança, } \\
\text { força, criatividade, etc. }\end{array}$ \\
\hline Satisfação dos Stakeholders & Empregados satisfeitos e engajados; clientes satisfeitos. \\
\hline $\begin{array}{l}\text { Balanço positivo: trabalho } \\
\text { versus vida privada }\end{array}$ & $\begin{array}{l}\text { Influência positiva mútua entre trabalho e vida privada, permitindo } \\
\text { tempo para si próprio, família e amigos. }\end{array}$ \\
\hline Reconhecimento Público & Boa reputação, premiação. \\
\hline Utilidade & $\begin{array}{l}\text { A organização cumpre uma necessidade da sociedade; proporciona um } \\
\text { importante serviço ou produto. }\end{array}$ \\
\hline
\end{tabular}

FONTE: GORGIEVSKI et. al., 2011

Três critérios foram considerados, a priori, essenciais na determinação do sucesso dos empreendimentos: lucratividade, crescimento e inovação. Entretanto, na literatura pode ser observado que a lucratividade e crescimento são mais frequentes que inovação. A ordem dos demais critérios também seguiram as investigações realizadas na literatura (ADAMS e SYKES, 2003; PAIGE e LITTRELL, 2002; ENGELEN, 2002; HITT et. al., 2001). 
Como resultado, Gorgievski et. al. concluíram que, claramente, a satisfação pessoal foi a medida de desempenho mais citada pelos proprietários de negócios, seguida pela lucratividade, satisfação dos stakeholders e balanço positivo entre o trabalho e a vida privada. Entretanto, os critérios de desempenho diferem quando levado em conta a idade dos proprietários e o tamanho da empresa. Os mais jovens destacaram mais enfaticamente a lucratividade como medida de sucesso que aqueles de mais idade. Com relação ao tamanho da empresa, os proprietários de empresas maiores enfatizaram a continuidade e a sobrevivência do negócio, enquanto que os de menor porte destacaram o balanço positivo entre o trabalho e a vida privada.

West III e Noel (2009), utilizando a teoria baseada nos recursos, mediram o desempenho de empresas recém-instaladas mediante três questões relacionadas, onde o respondente informava: a) o estágio (percentual) de desempenho que a empresa se encontrava em comparação com o ideal desejado (equivalente a 100\%); b) crescimento percebido na empresa em relação aos principais competidores, e; c) o nível de desempenho geral comparado aos principais competidores. Para o autor, as medidas de desempenho tradicionais, como as financeiras, ou não são apropriadas, ou não estão disponíveis.

Dess e Robinson (1984) testaram a correlação entre variáveis objetivas e subjetivas de desempenho. As variáveis objetivas foram: retorno sobre os ativos (ROA) e, crescimento das vendas, tendo por base as informações contábeis. As variáveis subjetivas de desempenho basearam-se nas objetivas e foram respondidas por pessoas ocupantes de cargos $1^{\mathrm{a}}$ e $2^{\mathrm{a}}$ linhas da hierarquia das empresas da amostra, mediante escala de likert de cinco pontos para as seguintes questões: a) Percepção do retorno sobre os ativos comparado com os competidores do setor; b) Percepção do crescimento das vendas comparado com os competidores do setor e, c) Percepção do desempenho atual (em porcentagem) com relação ao desempenho ideal esperado da empresa (equivalente a 100\%). Os autores encontraram elevada relação entre as medidas objetivas e subjetivas, concluindo que medidas subjetivas são substitutas adequadas na ausência ou inadequação de medidas objetivas. 
Tabela 14 - Variáveis identificadas como medidas de desempenho de PMEs.

\begin{tabular}{|c|c|c|c|c|c|c|}
\hline Autor(es) &  &  & 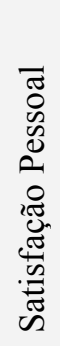 & 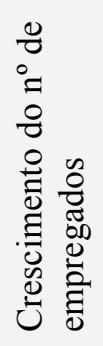 &  & 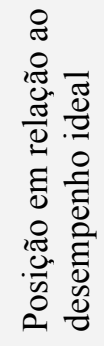 \\
\hline $\begin{array}{l}\text { Robinson (1984) } \\
\text { Gorgievski, Ascalan e Stephan (2011) } \\
\text { Wijewardena, Nanayakkara e Zoysa (2008) } \\
\text { Wang e Lian Ang (2004) } \\
\text { Haber e Reichel (2005) } \\
\text { West III e Noel (2009) } \\
\text { Dess e Robinson (1984) } \\
\text { Wijiwardena e Tibbits (1999) } \\
\text { Kalleberg e Leicht (1991) } \\
\text { Schumpeter (1911, 1934) } \\
\text { Allen (2012) }\end{array}$ & $\begin{array}{l}\bullet \\
\bullet \\
\bullet \\
\bullet \\
\bullet \\
\bullet \\
\bullet\end{array}$ & $\begin{array}{l}\bullet \\
\bullet \\
\bullet\end{array}$ & $\bullet$ & $\stackrel{\bullet}{\bullet}$ & $\stackrel{\bullet}{\bullet}$ & $\bullet$ \\
\hline
\end{tabular}

Dentre o conjunto de variáveis utilizadas nas pesquisas como medida de desempenho, o crescimento das vendas é a que mais tem sido evidenciado empiricamente, seguida da percepção de retornos ou de lucros (Tabela 14).

\subsection{Determinantes de Desempenho de Pequenas e Médias Empresas}

Neste estudo foram identificadas mais de 200 pesquisas que buscaram evidenciar os determinantes (variáveis explicativas) da sobrevivência ou do desempenho de pequenas e médias empresas.

Van Praag (2003) sumarizou inúmeras variáveis explicativas testadas como determinante de de desempenho, vinculando-as aos seus pressupostos teóricos (Tabela 15).

Schaefer (2012), utilizando dados da SBA (Small Business Administration), elencou sete razões que levam uma empresa ao insucesso:

1) Iniciar um negócio tendo por base uma motivação inadequada

2) Administração pobre 
3) Capital insuficiente

4) Localização

5) Falta de planejamento

6) Crescimento extraordinário

7) Falta de website

Tabela 15 - Determinantes de desempenho: clássicos e modernos.

\begin{tabular}{|c|c|c|c|c|c|}
\hline Variáveis & $\begin{array}{l}\text { Evidência } \\
\text { Empírica }\end{array}$ & Say & Marshall & Schumpeter & Knight \\
\hline Idade & $\begin{array}{l}\text { Empreendedores } \\
\text { jovens }\end{array}$ & $\begin{array}{l}\text { Conhecimento } \\
\text { do mundo }\end{array}$ & Liderança & Liderança & \\
\hline $\begin{array}{l}\text { Experiência } \\
\text { empreendedora } \\
\text { própria }\end{array}$ & $\begin{array}{l}\text { Experiência } \\
\text { relevante }\end{array}$ & $\begin{array}{l}\text { Conhecimento } \\
\text { de negócios }\end{array}$ & & & \\
\hline $\begin{array}{l}\text { Experiência no } \\
\text { setor de atuação }\end{array}$ & $\begin{array}{l}\text { Experiência } \\
\text { relevante }\end{array}$ & $\begin{array}{l}\text { Conhecimento } \\
\text { do setor }\end{array}$ & $\begin{array}{l}\text { Conhecimento } \\
\text { comercial }\end{array}$ & & \\
\hline $\begin{array}{l}\text { Experiência } \\
\text { ocupacional }\end{array}$ & $\begin{array}{l}\text { Experiência } \\
\text { relevante }\end{array}$ & $\begin{array}{l}\text { Conhecimento } \\
\text { da ocupação }\end{array}$ & & & \\
\hline Educação & Educação & & & & $\begin{array}{l}\text { Capacidade } \\
\text { intelectual }\end{array}$ \\
\hline Ativos & Capital próprio & & Capital próprio & & $\begin{array}{l}\text { Capital } \\
\text { (habilidade } \\
\text { para obter) }\end{array}$ \\
\hline $\begin{array}{l}\text { Background } \\
\text { familiar }\end{array}$ & & & Background & & \\
\hline $\begin{array}{l}\text { Iniciar como } \\
\text { desempregado }\end{array}$ & & & & Motivação & \\
\hline Autoestima & & & & & $\begin{array}{l}\text { Auto- } \\
\text { confiança }\end{array}$ \\
\hline
\end{tabular}

Fonte: Van Praag, 2003.

Para o presente estudo foram sondadas variáveis potencialmente explicativas em mais de uma centena de pesquisas publicadas nos principais periódicos nacionais e internacionais. Dentre as variáveis utilizadas nos estudos foram identificadas 31 que se mostram estatisticamente significativas, as quais estão descritas e ranqueadas na Tabela 16. 
Tabela 16 - Variáveis explicativas significantes na determinação da sobrevivência ou desempenho de pequenas e médias empresas.

\begin{tabular}{rlr}
\hline Ordem & \multicolumn{1}{c}{ Variável Explicativa } & Frequência \\
\hline 1 & Capital & 15 \\
2 & Experiência no setor / Experiência Ocupacional & 14 \\
2 & Plano de Negócio / Planejamento & 14 \\
4 & Educação & 11 \\
4 & Registros e Controles Financeiros & 11 \\
6 & Liderança & 9 \\
6 & Utilização de serviço especializado & 9 \\
8 & Qualificação do staff & 7 \\
8 & Capacitação Gerencial & 7 \\
10 & Capital investido (tamanho) & 6 \\
10 & Fatores de Marketing & 6 \\
12 & Idade do Empreendedor & 4 \\
12 & Número de empregados (tamanho) & 4 \\
12 & Momento econômico (crescimento x recessão) & 4 \\
12 & Motivação para abertura (oportunidade x necessidade) & 4 \\
16 & Experiência Empreendedora & 3 \\
16 & Cultura Familiar Empreendedora & 3 \\
16 & Estrutura Societária & 3 \\
16 & Gênero do Empreendedor & 3 \\
16 & Problemas / Razões Pessoais & 3 \\
21 & Acesso a Instituições & 2 \\
21 & Generalidade versus especialidade & 2 \\
21 & Grau de independência & 2 \\
21 & Problemas Financeiros & 2 \\
21 & Concorrência & 2 \\
21 & Suporte Governamental & 1 \\
21 & Grau de expectativas & 1 \\
28 & Localização & 1 \\
28 & Idade da empresa & 2 \\
28 & Risco de Mercado & 2 \\
\hline & & 2 \\
\hline
\end{tabular}

$\mathrm{Na}$ Tabela 16 pode ser constatado que as cinco primeiras variáveis foram evidenciadas 65 vezes, representando $43 \%$ do total das observações. De modo a facilitar a construção teórica dessas variáveis, os determinantes de sobrevivência ou de desempenho de PMEs foram classificados em oito grupos:
a) Capital humano
b) Capital social
c) Capacitação gerencial
d) Características organizacionais
e) Condições do ambiente
f) Motivação e nível de risco
g) Tamanho da empresa
h) Demografia pessoal 


\subsubsection{Impacto do Capital Humano}

O capital humano consiste em um conjunto de atributos pessoais do empreendedor, como a própria educação e a experiência de vida adquirida ao longo dos anos de trabalho, que lhe conferem know-how técnico e gerencial, incrementando suas habilidades para lidar com os problemas empresariais, buscar soluções e desenvolver estratégias (COOPER et. al., 1991, 1994). É o estoque de conhecimentos e experiências acumulados ao longo dos anos (BECKER, 1964).

Tabela 17 - Variáveis de Capital Humano identificadas como determinantes de desempenho de PMEs.

\begin{tabular}{|c|c|c|c|c|c|c|}
\hline Autor(es) & 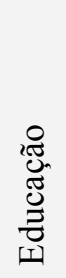 & 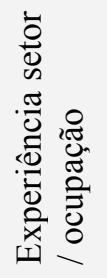 & 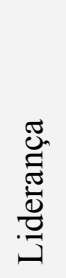 & 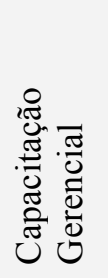 & 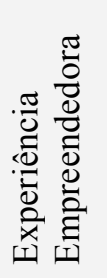 & 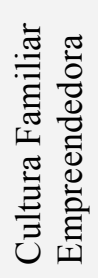 \\
\hline $\begin{array}{l}\text { Barsley e Kleiner (1990) } \\
\text { Cooper, Gascon e Woo (1991) } \\
\text { Flahvin (1985) } \\
\text { Gaskill, Van Auken e Manning (1993) } \\
\text { Brüderl, Preisendörfer e Ziegler (1992) } \\
\text { Lussier (1995) } \\
\text { Wood (1989) } \\
\text { Wight (1985) } \\
\text { Vesper (1980) } \\
\text { Lussier e Corman (1996) } \\
\text { Lauzen (1985) } \\
\text { Lussier (1996) } \\
\text { Bates (1995) } \\
\text { Yusuf (1995) } \\
\text { Lussier e Pfeifer (2001) } \\
\text { Watson, Hogarth-Scott e Wilson (1998) } \\
\text { Schaefer (2012) } \\
\text { Fairlie e Robb (2009) } \\
\text { Misumoto et. al. (2010) } \\
\text { Kozan, Öksoy e Ozsoy (2006) } \\
\text { Headd (2003) } \\
\text { Van Praag (2003) } \\
\text { Haswell e Holmes (1989) } \\
\text { SEBRAE/SP (2008) } \\
\text { Carter e Van Auken (2006) }\end{array}$ & $\begin{array}{l}\bullet \\
\bullet \\
\bullet\end{array}$ & $\begin{array}{l}\bullet \\
\bullet \\
\bullet \\
\bullet \\
\bullet \\
\bullet \\
\bullet \\
\bullet \\
\bullet\end{array}$ & $\begin{array}{l}\bullet \\
\bullet \\
\bullet \\
\bullet \\
\bullet \\
\bullet \\
\bullet \\
\bullet \\
\bullet\end{array}$ & $\begin{array}{l}\bullet \\
\bullet \\
\bullet\end{array}$ & • & • \\
\hline
\end{tabular}

Empresas melhor posicionadas em termos de disponibilidades destes recursos estarão em melhores condições de sobreviver em ambientes hostis e diante de más decisões. Empreendedores com sólida formação e experiência serão mais hábeis para lidar com os 
problemas que surgem no decurso das atividades da empresa, do que aqueles com pouco ou nenhum preparo (COOPER et. al., 1991, 1994).

Conforme apresentado na Tabela 17, os principais fatores de capital humano utilizados na literatura para testar a capacidade discriminatória de sobrevivência ou desempenho são: a) educação; b) experiência ocupacional (empregos que o indivíduo possuiu ao longo da vida); c) experiência na setor de atuação no qual está constituindo o negócio; d) liderança; e) capacitação (experiência) gerencial; f) experiência empreendedora, e; g) cultura familiar empreendedora.

\section{a) Educação}

A educação consiste na formação acadêmica, compreendendo o ensino fundamental e médio, a formação universitária, e a pós-graduação lato e stricto sensu. Cooper et. al. (1991) destacam que a educação é a variável mais estudada no campo do empreendedorismo. Presumivelmente educação esteja relacionada com conhecimento, habilidades, competência para resolver problemas, disciplina, motivação e autoconfiança.

Cooper et. al. (1994) testaram o impacto das variáveis de capital humano na sobrevivência e desempenho de PMEs utilizando uma amostra de 2.994 proprietários, em um período longitudinal de 3 anos. Encontraram que a educação esteve apenas fracamente relacionada com o vetor de sobrevivência marginal $(\alpha<0,10)$, porém fortemente associada com o vetor de alto crescimento $(\alpha<0,01)$. Em outro estudo (id., 1991), a experiência do empreendedor apresentou capacidade foi discriminante da sobrevivência.

Brüderl et. al. (1992) encontraram um índice de $29 \%$ de descontinuidade de empresas até o seu segundo ano de vida, quando os proprietários possuíam menos de 12 anos de estudo. Esse índice diminuía para 17\% quando a escolaridade subia para 15 anos. A experiência e a liderança também foram fatores significativamente determinantes (Tabela 18). 
Tabela 18 - Impacto de fatores de capital humano na descontinuidade de PMEs.

\begin{tabular}{|c|c|c|c|}
\hline \multirow{2}{*}{ Variáveis } & \multicolumn{3}{|c|}{ Percentual de empresas descontinuadas } \\
\hline & Até 2 anos & Até 5 anos & Casos \\
\hline \multicolumn{4}{|l|}{ Escolaridade do fundador* } \\
\hline Menos que 12 anos & 29,1 & 44,7 & 747 \\
\hline 12 a 15 anos & 22,9 & 35,9 & 508 \\
\hline 15 anos ou mais & 17,2 & 28,0 & 530 \\
\hline \multicolumn{4}{|c|}{ Experiência do fundador como trabalhador* } \\
\hline Menos de 10 anos & 33,4 & 48,9 & 638 \\
\hline 10 a 20 anos & 21,0 & 33,7 & 573 \\
\hline 20 a 30 anos & 15,0 & 26,6 & 381 \\
\hline 30 anos ou mais & 16,7 & 28,9 & 192 \\
\hline \multicolumn{4}{|c|}{ Experiência do fundador no ramo de atuação* } \\
\hline Não & 36,9 & 54,5 & 716 \\
\hline Sim & 14,9 & 25,5 & 1.077 \\
\hline \multicolumn{4}{|c|}{ Experiência empreendedora do fundador* } \\
\hline Não & 27,9 & 42,0 & 1.201 \\
\hline Sim & 15,1 & 27,0 & 593 \\
\hline \multicolumn{4}{|c|}{ Experiência do fundador em função de liderança* } \\
\hline Não & 25,6 & 40,1 & 1.101 \\
\hline Sim & 17,8 & 29,7 & 978 \\
\hline
\end{tabular}

(*) Diferença entre os subgrupos é significativa ao nível de $5 \%(\alpha<0,05)$.

FONTE: BRÜDERL et al, 1992

Lussier e Pfeifer (2001) replicaram um estudo originalmente feito com empresas dos Estados Unidos em uma amostra com 350 empresas na Croácia. De 15 variáveis testadas, apenas educação e o staff (colaboradores) demonstraram-se significativos. O modelo conseguiu classificar corretamente as empresas sobreviventes (72\%), porém foi menos eficiente na classificação das empresas descontinuadas (31\%). Lussier e Halabi (2010) utilizaram a metodologia em uma amostra com 234 empresas no Chile, mas não encontraram fatores significativamente discriminantes.

\section{b) Experiência ocupacional / experiência no setor de atuação}

A experiência tem sido explorada sob várias vertentes: a) experiência na mesma atividade do negócio; b) experiência ocupacional (vários empregos ao longo da vida); c) experiência como empreendedor ou profissional autônomo, e; d) experiência gerencial (VAN PRAAG, 2003; VAN GELDEREN et. al., 2006; BRÜDERL et. al., 1992).

\section{c) Liderança}

Na escola da liderança Cunningham e Lisheron (1991) destacam que um empreendedor não pode realizar seus objetivos apenas com o seu esforço. Ele depende de outras pessoas. E a 
virtude fundamental do líder não é adaptar as pessoas ao seu estilo, mas adaptar o seu estilo às necessidades das pessoas, assegurando a motivação e direção na busca dos objetivos.

A liderança também se destaca nas contribuições de Schumpeter (1911, 1934), que consolidou o empreendedorismo como área de estudos. $\mathrm{O}$ autor estabelece que o empreendedor é o agente que rompe o equilíbrio entre oferta e demanda por meio da inovação. As empresas que não inovarem, não sobreviverão. Para Van Praag (2003), a liderança é um atributo indispensável para o sucesso no esforço da inovação. Brüderl et. al. (1992) esclarecem que a habilidade da liderança ganha importância à medida que aumenta o número de empregados.

\section{d) Capacitação / Experiência Gerencial}

A capacitação e/ou a experiência gerencial proporciona ao gestor habilidades na utilização de ferramentas de organização, planejamento e controle. Haswell e Holmes (1989), utilizando-se de uma amostra de 418 empresas na Austrália, identificou que 90\% das falências dos pequenos negócios ocorreram pela inadequada ou insuficiente competência na gestão do negócio. Os estudos de Flahvin (1980) apontaram um índice de falência de 80\% das empresas australianas no período de cinco anos. Bortoli Neto (1980, p. 138) encontrou que $80 \%$ dos problemas de PMEs estão relacionados com aspectos estratégicos e que, por sua vez, estão "estritamente relacionados com a conduta do dirigente-lider".

Bates (1995), a partir de uma amostra de empresas franqueadas dos Estados Unidos criadas no período de 1984 a 1987, testou os determinantes de sobrevivência no período de 1987 a 1991. Ao considerar todas as empresas, evidenciou o impacto da educação como discriminante de sobrevivência. Entretanto, ao especificar a amostra apenas com as pequenas empresas de varejo, a educação e a experiência/capacidade de gestão do proprietário evidenciaram-se significativas.

Van Praag (2003), utilizando-se de uma amostra de 271 jovens empreendedores, do sexo masculino e idade entre 20 e 32 anos, cujas empresas foram fundadas no período de 1985 a 1989, observou que a experiência, seja ela no ramo do negócio ou em qualquer outra atividade ocupacional, proporciona maiores chances de sobrevivência. 


\section{e) Experiência Empreendedora}

$\mathrm{Na}$ teoria econômica clássica Say (1971) destaca que a experiência empreendedora proporciona ao indivíduo o conhecimento da essência do negócio. $\mathrm{O}$ autor salienta, ainda, que a capacidade de inovação depende de um domínio profundo do negócio e das variáveis a ele relacionadas. Brüderl et. al. (1992) observaram que quando o proprietário possuía experiência empreendedora anterior, o nível de insucesso após dois anos diminuía de $28 \%$ para $15 \%$, e após quatro anos diminuía de $42 \%$ para 27\%. A Delloite (2013), em seu trabalho anual intitulado "as PMEs que mais crescem no Brasil" identificaram que 41\% $(N=333)$ já tiveram outro negócio no passado. Mendes (2006) identificou um índice de 37,5\% de empreendedores, na sua amostra, que já possuíram outra empresa anteriormente.

\section{f) Cultura Empreendedora Familiar}

Apesar de não incorporar a literatura tanto quanto as variáveis educação e experiência, a cultura empreendedora familiar pode oferecer subsídios determinantes na sobrevivência de pequenas e médias empresas. Em PMEs geracionais com sucessão familiar, a aprendizagem e experiência ocorrem gradativa e continuamente. Gorgievski et. al. (2011) observaram que à medida que a empresa se tornava maior um dos focos de desempenho dos proprietários era a continuidade dos negócios para as futuras gerações. Bruderl et. al. (id.) encontram evidências do impacto da cultura empreendedora familiar ao concluir que a chance de insucesso do proprietário diminuía significativamente quando seus pais eram o tinham sido empresários.

\subsubsection{Impacto do Capital Social}

O Capital Social consiste na eficiência que o indivíduo possui para acessar os recursos necessários para sua atividade econômica, por meio de uma rede de contatos, relacionamentos e parcerias (LIN, 2001). Bordieu (1986) e Coleman (1988) deram destaque à importância do capital social salientando os benefícios que os agentes podem obter por meio das redes sociais. Putnam (1993) popularizou o termo com o seu estudo em que evidenciou fortemente a presença de normas sociais e padrões de confiança interpessoal. 
Na Tabela 20 estão descritas as variáveis de capital social que se demonstraram significativas na determinação do desempenho de PMEs, onde foram evidenciados três aspectos: a) capital; b) acesso a instituições / parcerias, e; c) utilização de serviço especializado.

\section{a) Capital}

Reconhecidamente a variável "capital" é amplamente utilizada nos modelos quantitativos para testar a sobrevivência e o desempenho de PMEs, sendo que, em inúmeras pesquisas, demonstrou-se significativa (Tabela 19). O capital refere-se à disponibilidade de recursos na constituição da empresa e durante sua vida econômica.

Tabela 19 - Variáveis de capital social determinantes do desempenho de PMEs

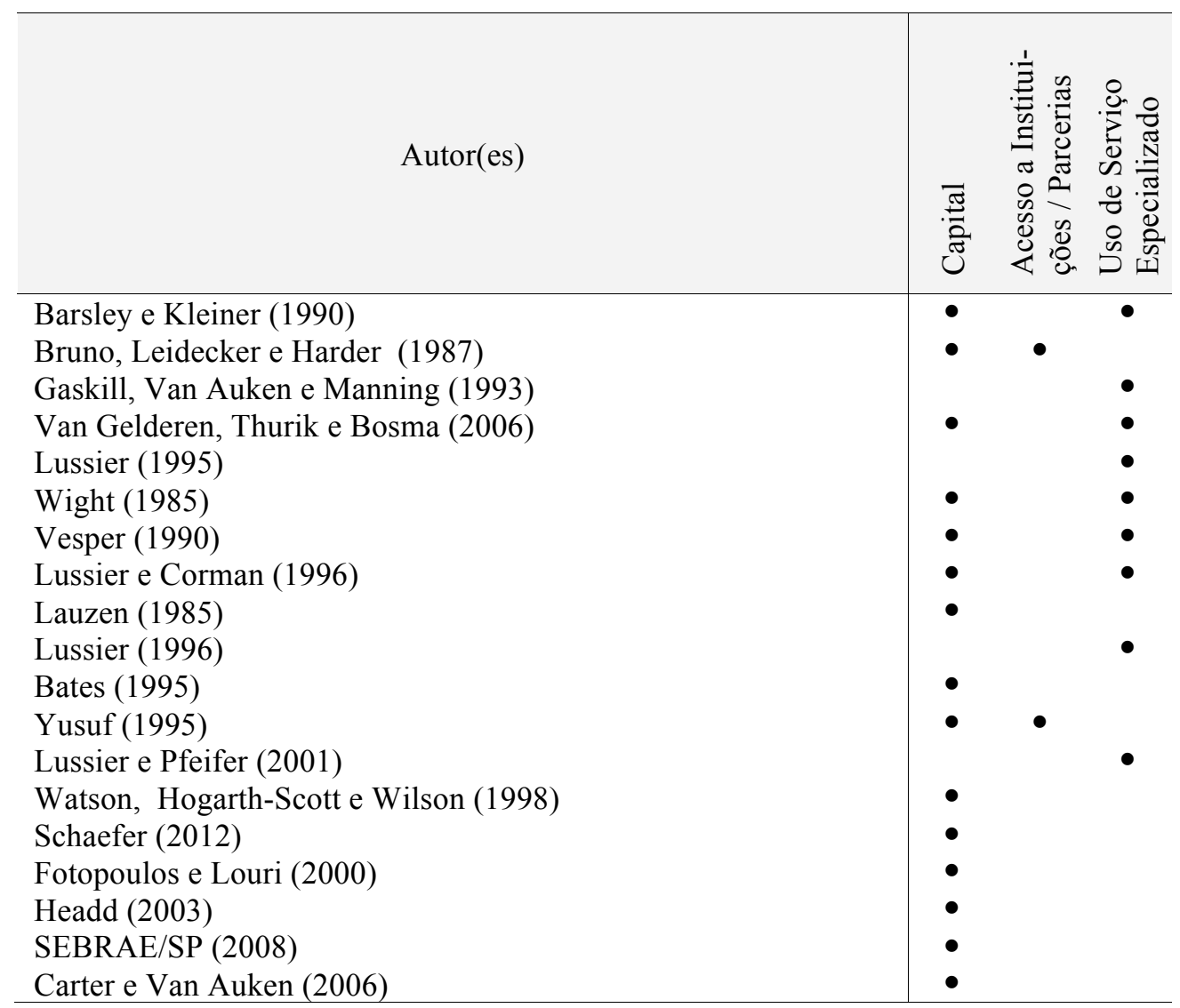

Carter e Van Auken (2006), em um estudo com 57 PMEs, identificaram sete variáveis significantes relacionadas com capital: a) disponibilidade de empréstimos; b) disponibilidade de capital próprio; c) disponibilidade para obtenção de empréstimos pessoais; d) alto custo dos empréstimos; e) elevadas taxas de juros; f) falta de dinheiro; g) falta de garantias para obtenção de empréstimos. 
Bruno et. al. (1987) observam que a subcapitalização tem sido um dos principais determinantes de falência das empresas. Outros estudos, como de Almeida et. al. (2004), Guney et. al. (2000), Opler et. al. (1999), Dittmar et. al. (2002), Kim et. al. (1998) e, Pinkowitz e Williamson (2001) evidenciaram que as empresas com elevado potencial de crescimento mantinham excessos de caixa, ainda que isso prejudicasse a sua rentabilidade. A presença da assimetria informacional e de incertezas associadas à restrição de capital tem levado essas empresas a acreditarem que não terão acesso a recursos em tempo de suas demandas ou que estes teriam um custo elevado.

Em estudo do SEBRAE/SP (2008), com empresas encerradas, dentre os motivos alegados para a descontinuidade do negócio, $20 \%$ dos pesquisados responderam ter sido a "falta de capital". Em seguida quando perguntados o que levaria a não ter fechado o negócio, o fator mais frequente (28\%) apontado pelos respondentes foi “empréstimos bancários".

\section{b) Acesso a Instituições / Parcerias}

A rede de relacionamentos consubstancia o núcleo do capital social (LIN, 2001). Esses relacionamentos podem ser atribuídos aos principais stakeholders da empresa, como clientes, fornecedores, bancos, prestadores de serviços, empregados e instituições públicas. Bruno et. al., (1987) ressaltam que a rede baseia-se no acesso aos recursos no momento da constituição da empresa e no seu decurso, como parcerias com clientes e fornecedores. Destacam, ainda (ibid), que inúmeras empresas foram descontinuadas por estarem concentradas em um ou poucos clientes.

É importante destacar que inúmeras situações relacionadas com capital poderiam ser equacionadas ou minimizadas por meio da rede de relacionamentos ou parcerias.

\section{c) Utilização de serviço especializado}

Inúmeras expertises podem ser obtidas por meio de consultas a administradores, economistas, advogados, banqueiros e contadores. Em geral, as informações decorrentes de contatos proporciona obtenção de dados e informações especializadas, minimizando os pontos cegos na tomada de decisão. A disponibilidade de informações adequadas refletem, em um 
planejamento mais compreensivo, um nível mais sofisticado de gestão e a probabilidade de um start up mais promissor (COOPER et. al., 1991).

As pesquisas têm apresentado a utilização de serviços especializados como um importante fator de sobrevivência e desempenho de PMEs (BARSLEY; KLEINER, 1990; GASKILL et. al., 1993; VAN GELDEREN, 2006; LUSSIER, 1995, 1996).

\subsubsection{Impacto das Características Gerenciais}

Este construto reveste-se propriamente do estilo de gestão do proprietário ou fundador.

Cunningham e Lischeron (1991), nas abordagens sobre empreendedorismo, observam que, sob a ótica da escola de gestão, o pressuposto é que os empreendedores podem ser desenvolvidos ou treinados por meio de funções técnicas e de gestão. Sob o escopo de que os empreendedores são agentes econômicos que organizam, apropriam e gerenciam recursos em ambientes de risco, habilidades de planejamento, organização de pessoas, capitalização e orçamentação são essenciais no desempenho das empresas. Nesta abordagem, a literatura tem apresentado evidências abundantes do impacto do plano de negócios (planejamento) e dos registros e controles financeiros.

Na Tabela 20 estão apresentadas as principais evidências dos impactos dos fatores de gestão no desempenho de PMEs, desdobrando-se em cinco pontos principais:
a) Plano de negócio / planejamento;
b) Registros e controles financeiros;
c) Fatores de marketing
c) Inadimplência;
d) Problemas financeiros: fontes e custos de financiamento 
Tabela 20 - Características gerenciais determinantes do desempenho de PMEs

\begin{tabular}{|c|c|c|c|c|c|}
\hline Autor(es) & 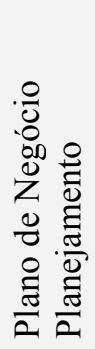 & 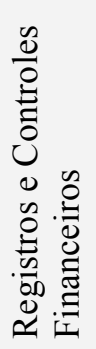 & 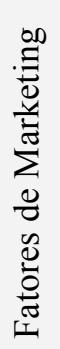 & 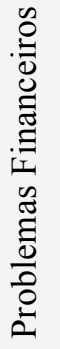 & 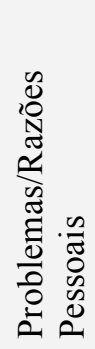 \\
\hline $\begin{array}{l}\text { Barsley e Kleiner (1990) } \\
\text { Bruno, Leidecker e Harder (1987) } \\
\text { Gaskill, Van Auken e Manning (1993) } \\
\text { Van Gelderen, Thurik e Bosma (2006) } \\
\text { Lussier (1995) } \\
\text { Wood (1989) } \\
\text { Wight (1985) } \\
\text { Vesper (1990) } \\
\text { Lussier e Corman (1996) } \\
\text { Lauzen (1985) } \\
\text { Lussier (1996) } \\
\text { Lussier e Pfeifer (2001) } \\
\text { Watson, Hogarth-Scott e Wilson (1998) } \\
\text { Schaefer (2012) } \\
\text { Kozan, Öksoy e Ozsoy (2006) } \\
\text { Mizumoto et. al. (2010) } \\
\text { SEBRAE/SP (2008) }\end{array}$ & $\begin{array}{l}\bullet \\
\bullet \\
\bullet \\
\bullet \\
\bullet \\
\bullet \\
\bullet \\
\bullet \\
\bullet\end{array}$ & $\begin{array}{l}\bullet \\
\bullet \\
\bullet \\
\bullet \\
\bullet \\
\bullet \\
\bullet\end{array}$ & • & • & $\bullet$ \\
\hline
\end{tabular}

\section{a) Plano de Negócio / Planejamento}

Como visto anteriormente, o plano de negócio ou planejamento foi o fator mais evidenciado nas pesquisas consultadas. Schaefer (2012) destaca que o plano de negócio consiste em um elemento crítico para todos os negócios. Muitos dos pequenos empreendimentos falham devido a deficiências fundamentais do seu plano de negócio. Ela ainda acrescenta que um plano deve ser realístico estar apoiado em informações acuradas e correntes, além de incluir projeções calculadas com relação ao futuro.

\section{b) Registros e controle financeiros}

Os registros e controles financeiros permitem acompanhar o desempenho das empresas por meio de indicadores financeiros, como lucratividade e crescimento. Nos estudos de Carter e Van Auken (2006), controles financeiros e fluxos de caixa pobres e a falta de habilidade na formação de preços mostraram-se significantes na determinação da sobrevivência de PMEs. 


\section{c) Problemas financeiros}

Os problemas financeiros, geralmente, são o desfecho do conjunto de circunstâncias já observadas, como a subcapitalização, uso de empréstimos muito rapidamente, deficiências nos registros e controles financeiros, utilização de fontes "emergenciais" de financiamento excessivamente onerosas.

A OCDE/CEPAL (2012) destacam que as taxas de juros de longo prazo para as PMEs da América Latina são muito discrepantes em relação às grandes empresas (Figura 7). Observase que na maioria dos países o custo de financiamento para as PMEs é mais que o dobro da taxa cobrada das grandes empresas.
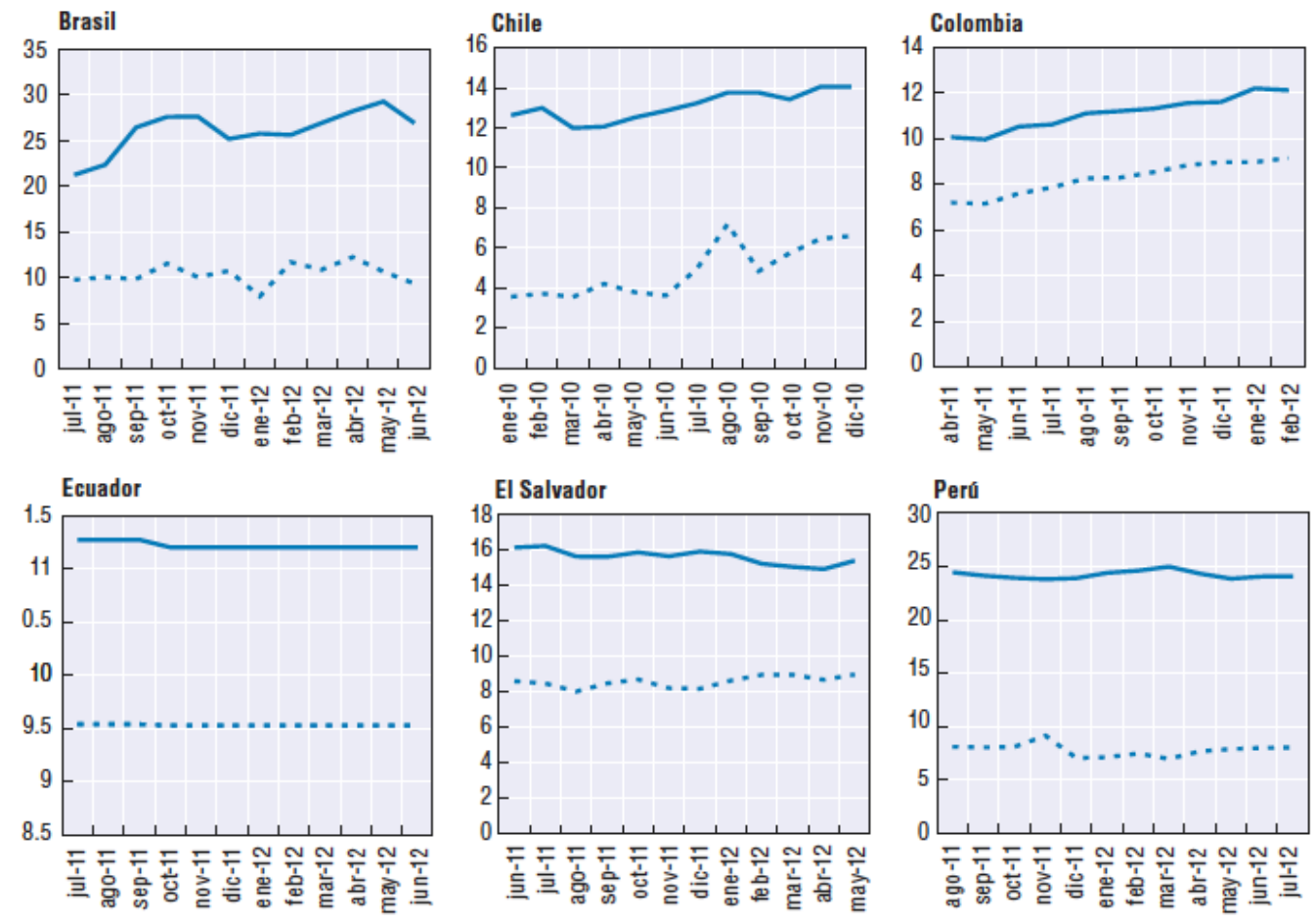

PMEs

. " . . . . . . . Grandes Empresas

Figura 7 - Taxas de juros de longo prazo entre PMEs e grandes empresas FONTE: OCDE/CEPAL, 2012, p. 76.

Schaefer (2012) observa que o primeiro entrave à sobrevivência está na subcapitalização, pois é um estágio em que a empresa não possui histórico operacional e garantias para obtenção de recursos no tempo em que são demandados. Carter e Van Auken (2006) identificaram a "falta de dinheiro", "disponibilidade de empréstimos pessoais", "altos custos dos empréstimos" e "falta de garantias pessoais" como indicadores de sobrevivência das empresas. 


\subsubsection{Impacto das Características Organizacionais}

Estudos envolvendo as características organizacionais de PMEs tem recebido menos atenção se comparados aos pontos tratados anteriormente. Brüderl et. al. (1992) encontraram que decisões em torno de escolhas estratégicas foram determinantes na sobrevivência e desempenho. As evidências apontaram que as empresas com produtos/serviços generalistas tiveram índices de sobrevivência significativamente menores que empresas especializadas em um único ou poucos produtos/serviços. Outra evidência significativa foi o escopo de mercado, onde empresas que visam mercados muito restritos (locais) são mais propensas à descontinuidade que aquelas com mercado mais abrangente. Igualmente, negócios independentes apresentaram taxas de sobrevivência menores que os afiliados (por exemplo, franquias).

Conforme detalhado na Tabela 21, as características organizacionais impactantes do desempenho de PMEs desdobram-se nos seguintes pontos: a) generalidade versus especialidade; b) escopo de abrangência; c) grau de independência; d) qualidade do staff; e) estrutura societária, e; f) localização.

Tabela 21 - Variáveis de Caracterização Organizacional determinantes do desempenho de PMEs

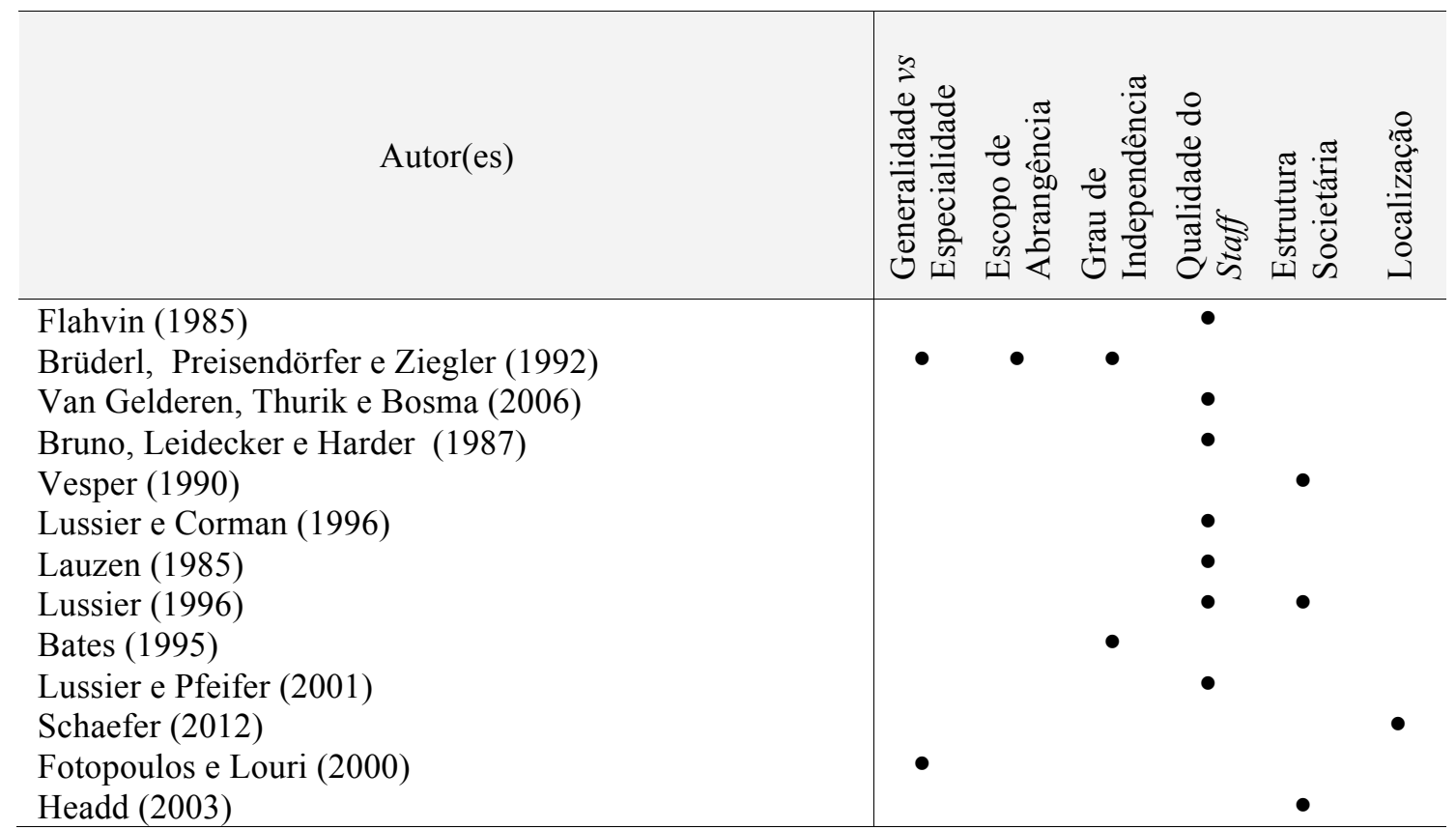




\section{a) Generalidade versus especialidade}

Brüderl et. al. (1992) observaram que a longevidade das empresas que operavam com uma única ou pequena gama de produtos ou serviços é maior do que aquelas com um portfólio mais amplo.

\section{b) Escopo de abrangência}

A natureza econômica de um negócio pode delimitar seu escopo de abrangência. Empresas prestadoras de serviços comumente tem seu mercado pelos clientes locais, localizados no bairro, quando muito a região. Outras empresas, principalmente no ramo comercial e industrial, têm maiores possibilidades de atender um escopo mais abrangente como vários munícipios, estados, e até o mercado internacional. Brüderl et. al. (id) identificaram que as empresas com escopo mais delimitado tinham índices de sobrevivência significativamente menores do que aquelas com escopo mais amplo. Nesse sentido Schaefer (2012) destaca o avanço de e-commerce, lembrando que nos EUA 77\% da população é usuária da internet e, em 2010, 165 bilhões de dólares foram transacionados pela internet. Essa ferramenta é uma forma de ampliar o escopo de mercado e clientes para muitos produtos e serviços.

\section{c) Grau de independência}

Brüderl et. al. (id), diferentemente do que pressupõe a teoria, identificou que os negócios afiliados, como franquias e representações, apresentaram índices de sobrevivência significativamente menores do que os negócios independentes. Bates (1995) chegou às mesmas conclusões, ressaltando que esse fato ocorre porque as pequenas franquias tem pouca flexibilidade e uma baixa capacidade de se adaptar a uma competição com a presença de concorrentes assemelhados independentes.

\section{d) Qualidade do staff}

Do conjunto de características organizacionais, a qualificação do staff é a que apresentou mais evidências empíricas determinantes da sobrevivência e do desempenho de PMEs. Lussier e Pfeifer (2001) ressaltam que empresas que conseguem atrair e reter empregados mais 
qualificados tem mais chances de desepempenho do que aquelas menos atrativas. Em uma amostra em que foram testadas 15 variáveis, a qualidade do staff foi a única estatisticamente representativa do modelo.

Bruno et. al. (1987) entrevistaram proprietários de empresas descontinuadas e $90 \%$ deles informou que a ineficiência do staff foi determinante na falência. A Delloite (2013, p. 15) perguntou aos empreendedores da amostra $(N=333)$ o que eles fariam de diferente em suas trajetórias, sendo que dentre os quatro aspectos de maior frequência consta que "investiriam mais na formação de um grupo de pessoas altamente qualificadas e preparadas para administrar uma empresa de alta performance".

\section{e) Estrutura societária}

A estrutura societária apresenta a situação paradoxal: a) mais sócios permitem divisão de tarefas, decisões menos impulsivas e mais colegiadas, mas; b) por outro lado, pode apresentar conflitos de interesses e problemas de relacionamento. Lussier e Halabi (2010) destacam que negócios iniciados com apenas um proprietário tem menos chance de sobreviver do que aqueles com mais de um. Headd (2001) concluiu empiricamente que o aumento do número de sócios proporcionava maiores chances de sobrevivência das empresas.

\section{f) Localização}

Schaefer (2012) observou que a localização constitui-se em fator determinante de sobrevivência das PMEs. Segundo ela, a localização é um elemento chave no plano de negócio e na tomada de decisão, pois conjuga clientes, fornecedores e competidores, considera as condições de tráfego, acessibilidade e estacionamento, além de incorporar aspectos como cultura local, disponibilidade de infraestrutura e serviços.

\subsubsection{Impacto das condições do ambiente}

As condições do ambiente tem sido amplamente utilizadas na construção metodológica de pesquisas relacionadas com a sobrevivência de pequenas e médias empresas, porém poucas evidências representativas foram identificadas (Tabela 22). Brüderl et. al. (1992) observaram que empresas situadas em ambientes altamente competitivos e com elevadas sazonalidades 
apresentaram índices significativamente menores de sobrevivência. Entretanto, o timming econômico tem sido o fator mais frequente e significante na sobrevivência dessas empresas (BRUNO et. al., 1987; VESPER, 1990; LUSSIER e CORMAN, 1996; BATES, 1995).

Tabela 22 - Características do ambiente determinantes do desempenho de PMEs

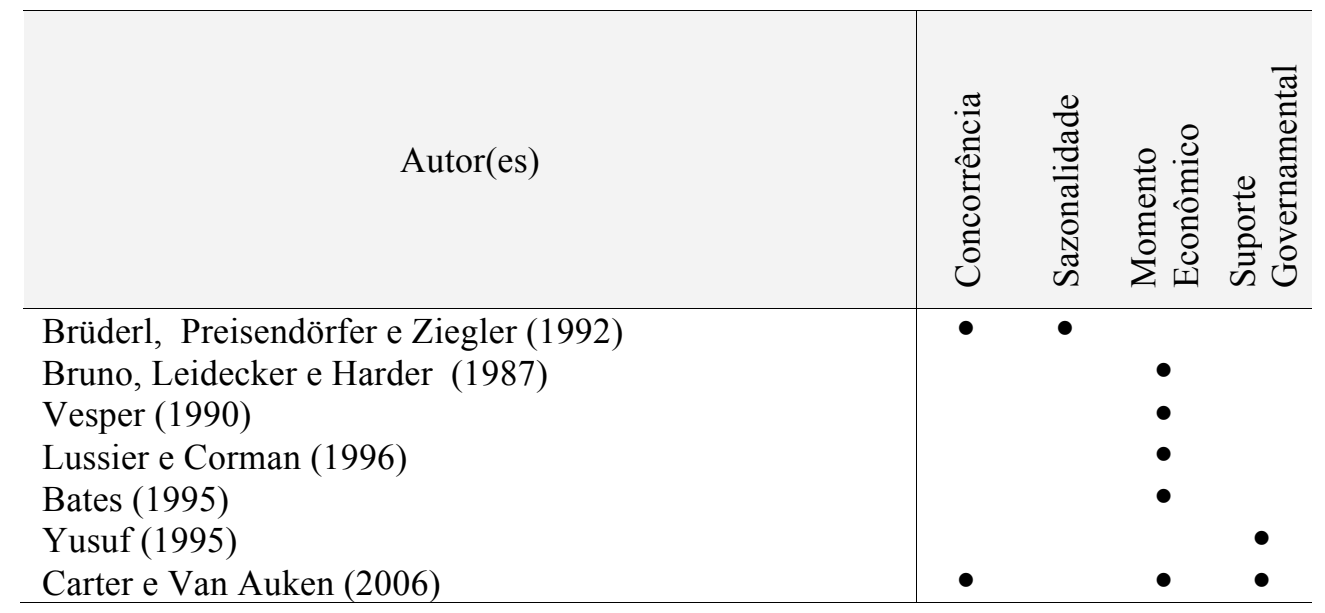

\subsubsection{Impacto dos fatores de motivação e percepção do risco}

A motivação para abertura de uma empresa geralmente é analisada sob dois ângulos: oportunidade ou necessidade (GEM, 2010). No primeiro, a decisão baseia-se na descoberta de uma oportunidade a ser explorada. No segundo, o negócio decorre de uma necessidade comumente imperativa, como obtenção de renda ou atendimento de formalidades documentais.

Schaefer (2012) elenca a razão para abertura da empresa como um dos sete fatores críticos de sucesso. A autora destaca alguns equívocos de expectativas envolvidos na abertura de empresa, como: ganhar muito dinheiro; que por determinar seu próprio horário de trabalho, terá mais tempo para a família; que por ser o proprietário, não terá que dar satisfação a ninguém - se forem estes os motivos para abertura da empresa, a decisão deverá ser seriamente repensada, destaca a autora.

Na Tabela 23 estão apresentados os fatores determinantes de sobrevivência e de desempenho observados sob a ótica das pesquisas e da teoria das finanças comportamentais. 
Tabela 23 - Variáveis de motivação e percepção do risco determinantes do desempenho de PMEs

\begin{tabular}{|c|c|c|c|c|}
\hline Autor(es) & 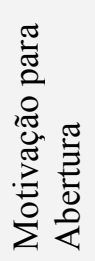 &  & 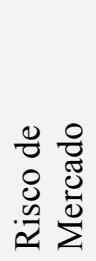 & 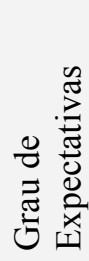 \\
\hline $\begin{array}{l}\text { Watson, Hogarth-Scott e Wilson (1998) } \\
\text { Shaefer (2012) } \\
\text { Mizumoto et. al. (2010) } \\
\text { Headd (2003) } \\
\text { Kahnemann e Tversky (1979) } \\
\text { Dunne et. al. (1985) } \\
\text { Van Praag (2003) } \\
\text { Van Gelderen et al (2006) }\end{array}$ & $\begin{array}{l}\bullet \\
\bullet \\
\bullet \\
\bullet\end{array}$ & $\bullet$ & $\bullet$ & • \\
\hline
\end{tabular}

Dunne et. al. (1985) identificaram a presença do viés cognitivo do "excesso de confiança" das empresas entrantes. Na presença deste viés o indivíduo tende a construir cenários irreais e a se desmotivar diante das frustrações destas expectativas. A teoria dos custos de transação suporta que a oportunidade percebida pode decorrer da assimetria de informações.

\subsubsection{Impacto do tamanho da empresa}

As pesquisas fundamentalmente baseadas em dados censitários tem evidenciado o tamanho da empresa como determinante de sobrevivência de PMEs (BRUNO et. al., 1987; BRUDERL et. al., 1992; HEADD, 2003).

Tabela 24 - Variáveis de Tamanho identificadas como determinantes do desempenho de PMEs

\begin{tabular}{|c|c|c|}
\hline Autor(es) & 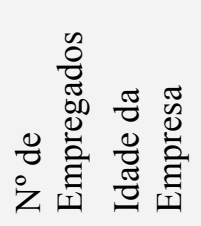 &  \\
\hline $\begin{array}{l}\text { Bruno, Leidecker e Harder (1987) } \\
\text { Brüderl, Preisendörfer e Ziegler (1992) } \\
\text { Mata e Portugal (1994) } \\
\text { Bates (1995) } \\
\text { Fotopoulos e Louri } \\
\text { Fairlie e Robb } \\
\text { Mizumoto et. al. (2010) } \\
\text { Headd (2003) } \\
\text { Wijiwardena e Tibbits (1999) }\end{array}$ & • & $\begin{array}{l}\bullet \\
\bullet \\
\bullet \\
\bullet \\
\bullet \\
\bullet \\
\bullet\end{array}$ \\
\hline
\end{tabular}


À medida que uma empresa aumenta de tamanho, consequentemente consegue atrair um staff mais qualificado, mais acesso ao crédito. Nesse sentido, alguns estudos (MIZUMOTO et. al., 2010) tem utilizado o tamanho da empresa como variável de controle. As principais medidas de tamanho utilizadas é o capital investido e o número de empregados (Tabela 24).

\subsubsection{Impacto da demografia pessoal}

Algumas pesquisas têm incluído variáveis demográficas em seus modelos, como gênero (VAN GELDEREN et. al., 2006; WATSON et. al., 1998; FAIRLIE e ROBB, 2009), idade (VAN GELDEREN et. al., 2006; BATES, 1995; HEADD, 2003) e estado civil (VAN PRAAG, 2003), conforme apresentado na Tabela 25.

Tabela 25 - Variáveis demográficas pessoais determinantes do desempenho de PMEs

\begin{tabular}{|c|c|c|c|}
\hline Autor(es) &  & 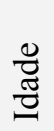 & 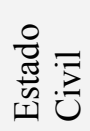 \\
\hline $\begin{array}{l}\text { Van Gelderen, Thurik e Bosma (2006) } \\
\text { Bates (1995) } \\
\text { Watson, Hogarth-Scott e Wilson (1998) } \\
\text { Fairlie e Robb (2009) } \\
\text { Head (2003) } \\
\text { Van Praag (2003) } \\
\text { Cooper et al (1994) }\end{array}$ & $\begin{array}{l}\bullet \\
\bullet \\
\bullet\end{array}$ & $\begin{array}{l}\bullet \\
\bullet \\
\bullet \\
\bullet \\
\bullet\end{array}$ & \\
\hline
\end{tabular}

\section{a) Gênero}

Fairlie e Robb (2009), interessados em analisar a participação acelerada das mulheres em empreendimentos empresariais, identificaram coeficientes positivos para a falência e negativos para indicadores como lucro, volume de receitas e número de empregados, concluindo que as chances de sobrevivência e desempenho eram diferentes em função do gênero. Watson et. al. (1998) encontraram as mesmas evidências de Fairlie e Robb. Cooper et. al. (1994) identificaram relação significativa entre alto crescimento e gênero. 


\section{b) Idade}

Lussier e Pfeifer (2001) consideram que as pessoas mais jovens tem menos chance de sobrevivência e desempenho, por possuírem menos know how e experiência que os empreendedores com mais idade. Entretanto, Van Praag (2003) e Van Gelderen et. al. (2006) ressaltam que os mais jovens possuem mais energia, atributo importante principalmente nos primeiros anos de vida da empresa.

Em termos de pesquisas empíricas, Van Praag (2003) e Bates (1995) identificaram uma relação negativa e significativa entre idade e sobrevivência, confirmando os pressupostos iniciais de que a chance de sobrevivência diminui à medida que a idade aumenta.

\section{c) Estado Civil}

Bates (1995) ressalta que existe diferença entre pessoas solteiras e casadas em termos de maturidade, disponibilidade de tempo e responsabilidades. E essa condição pode ter impactos significativos na sobrevivência ou desempenho de PMEs, entretanto não conseguiu comprovar empiricamente seus pressupostos. 



\section{Capítulo 3}

\section{METODOLOGIA DA PESQUISA}

\subsection{Caracterização do Método de Pesquisa}

Com relação aos procedimentos de pesquisa, de acordo com Kerlinger (1980), o primeiro passo é definir se a pesquisa será experimental ou não experimental. $\mathrm{Na}$ pesquisa experimental uma ou mais variáveis são manipuladas. Caso contrário, ou seja, se não houver manipulação das variáveis independentes, o procedimento caracteriza-se como "ex post facto". Como o objetivo de pesquisa foi identificar os fatores (variáveis) determinantes da sobrevivência e desempenho das PMEs, os dados utilizados foram estáticos e pré-existentes ou em condições de rotina real, sendo, no entanto, a pesquisa caracterizada, em seu procedimento, como não experimental.

Na dimensão de tempo uma pesquisa pode ser transversal (cross section) ou longitudinal. Em um estudo transversal a unidade amostral é considerada em um único momento no tempo. No estudo longitudinal uma mesma unidade amostral é analisada ou testada em vários períodos de tempo (COOPER; SCHINDLER, 2004). Como cada um dos respondentes constituiu uma única unidade amostral e em um único período de tempo, o estudo possui dimensão temporal transversal.

Com relação ao ambiente de pesquisa, os respondentes foram empresários ou ex-empresários que responderam ao instrumento tendo por base dados objetivos pessoais e da sua empresa, mas também retrataram suas percepções subjetivas, cujas circunstâncias que o cercam podem exercido influência na resposta. Dessa forma, o ambiente de pesquisa caracteriza-se como de campo com rotina real (ibid).

\subsection{Definição do universo e amostra da pesquisa}

O universo da pesquisa foi formado por pequenas e médias empresas inativas (encerradas) e ativas (em funcionamento). Dada a dificuldade de acesso e a necessidade de uso de estratégias 
de abordagem do respondente, normalmente pessoais, o universo foi delimitado à microrregião centro sul do Estado do Paraná, conforme área delimitada na Figura 8.

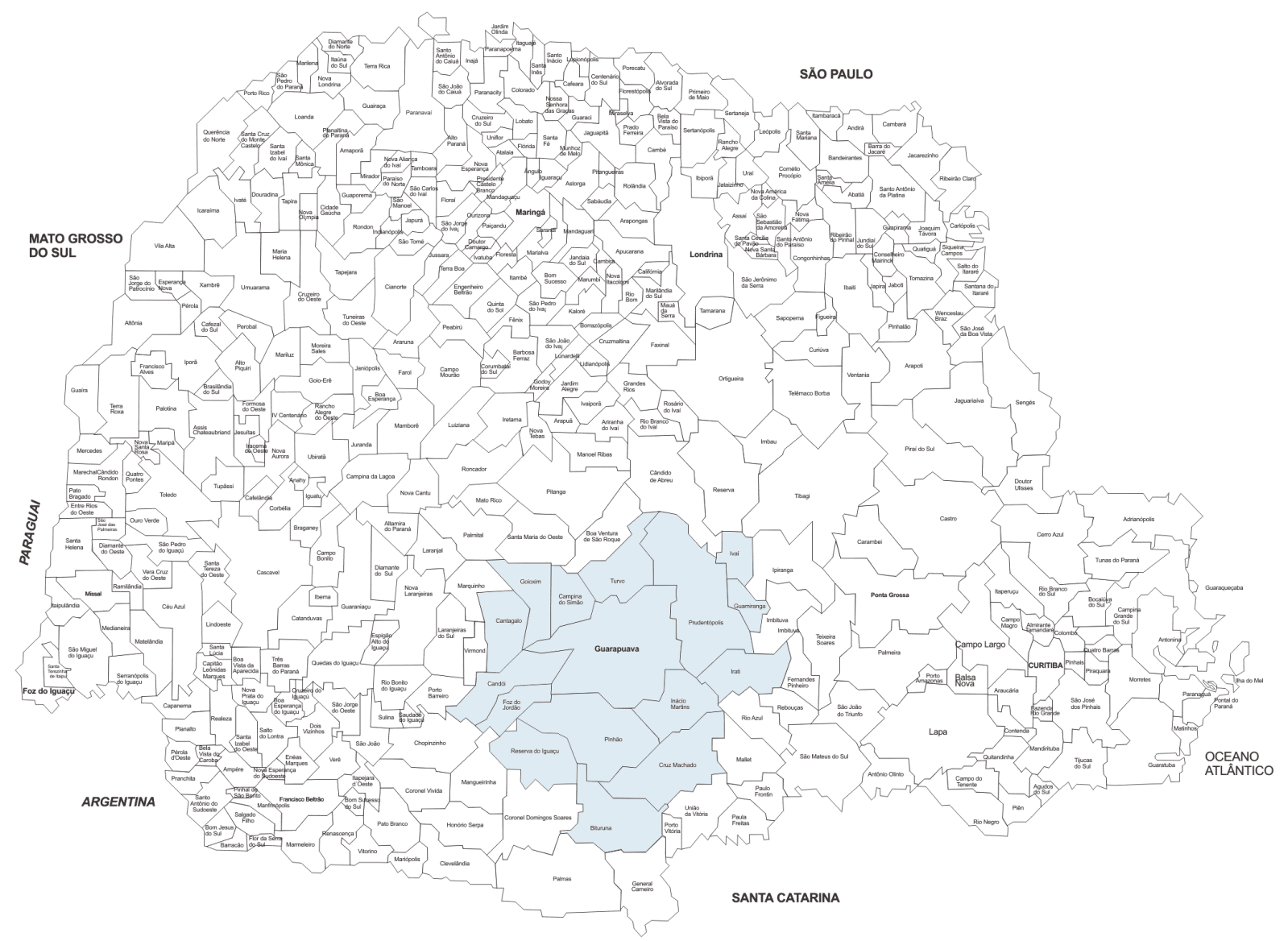

Figura 8 - Delimitação da área da pesquisa

A amostra foi formada por 410 empresas, sendo: a) 336 empresas em atividade (sobreviventes) e 74 empresas inativas (não sobreviventes). Com relação à amostragem, a pesquisa foi constituída incluindo duas formas:

a) Amostra por adesão: formada pelos respondentes do questionário enviado e recebido de forma online. O questionário foi enviado para 6.827 empresas acessadas por cadastros de e-mails disponibilizados pelas Associações Comerciais e mailing list de pesquisadores. Foram respondidos 108 questionários, perfazendo um índice de retorno de 1,3\%. Para as empresas que não responderam a pesquisa no primeiro envio, houve um reenvio 7 a 10 dias posteriormente. Após os dois envios verificou-se que 618 empresas abriram o e-mail com o questionário, 166 iniciaram o preenchimento e não completaram e 108 responderam integralmente. 
b) Amostra por conveniência: os questionários foram impressos e entregues pessoalmente ao respondente. Foi considerado principalmente a facilidade de acesso e a disponibilidade e interesse do empresário em participar da pesquisa. Para empresas em atividade foram entregues 270 questionários e 228 foram respondidos, perfazendo um retorno de $85 \%$. Para empresas inativas foram entregues 90 questionários, obtendo-se um retorno de 74 $(82 \%)$. Para efeito do estudo, foram consideradas apenas as empresas descontinuadas no período de 2003 a 2013.

\subsection{Modelo Conceitual Teórico}

O modelo descrito na Figura 9 representa o design central da pesquisa, que teve por base o arcabouço teórico descrito anteriormente.



Figura 9 - Modelo Conceitual Teórico 


\subsubsection{Variáveis explicativas}

Para explicar o desempenho de PMEs (variável dependente) foram utilizados os fatores (construtos) e os respectivos indicadores (variáveis independentes) com seus pressupostos conceituais e sinais esperados em relação a variável dependente.

Quadro 2 - Variáveis explicativas, sinal esperado e pressupostos conceituais de Capital Humano

\begin{tabular}{|c|c|c|c|}
\hline $\begin{array}{c}\text { Fator } \\
\text { (Construto) }\end{array}$ & $\begin{array}{l}\text { Indicadores / } \\
\text { Variáveis explicativas }\end{array}$ & Sinal & Pressupostos conceituais \\
\hline \multirow{6}{*}{ Capital Humano } & Escolaridade & + & $\begin{array}{l}\text { O nível educacional está positivamente associado } \\
\text { com o desempenho de PMEs. }\end{array}$ \\
\hline & $\begin{array}{l}\text { Experiência ocupacional } \\
\text { Experiência no setor }\end{array}$ & + & $\begin{array}{l}\text { A experiência em empregos anteriores e em } \\
\text { atividades assemelhadas ao negócio proporcionam } \\
\text { maiores chances de sucesso. }\end{array}$ \\
\hline & Liderança & + & $\begin{array}{l}\text { Pessoas com mais aptidão e experiência em } \\
\text { liderança têm mais condições de atingirem melhores } \\
\text { resultados. }\end{array}$ \\
\hline & Experiência Gerencial & + & $\begin{array}{l}\text { Empreendedores com formação e experiência } \\
\text { gerencial terão mais habilidade em lidar com os } \\
\text { problemas empresariais, tomando decisões mais } \\
\text { orientadas ao desempenho. }\end{array}$ \\
\hline & $\begin{array}{l}\text { Experiência } \\
\text { Empreendedora }\end{array}$ & + & $\begin{array}{l}\text { Empreendedores que já experimentaram a prática } \\
\text { empreendedora anteriormente possuem mais } \\
\text { conhecimentos acerca dos desafios e problemas do } \\
\text { que os estreantes, conferindo-lhes mais chances de } \\
\text { sucesso. }\end{array}$ \\
\hline & $\begin{array}{l}\text { Cultura Familiar } \\
\text { Empreendedora }\end{array}$ & + & $\begin{array}{l}\text { O empreendedorismo na família proporciona a } \\
\text { convivência e a aquisição de conhecimentos e } \\
\text { experiências sobre o negócio e sobre gestão, } \\
\text { aumentando as chances de sucesso. }\end{array}$ \\
\hline
\end{tabular}

O Capital Humano define-se como o conjunto de habilidades, conhecimentos e experiências que o empreendedor detém, fornecendo mecanismos que podem ser influentes no processo de tomada de decisões e de gestão do negócio.

Tabela 26 - Caracterização operacional dos indicadores de Capital Humano

\begin{tabular}{llcc}
\hline Indicador & \multicolumn{1}{c}{ Descrição } & Tipo & Escala \\
\hline ESCOL & Escolaridade & Ordinal & 5 \\
EXP_OCUP & Experiência ocupacional & Ordinal & 6 \\
EXP_R & Experiência ocupacional no ramo do negócio & Ordinal & 6 \\
EXP_LID & Experiência em funções de liderança & Ordinal & 6 \\
TREIN & Média anual de treinamento pessoal & Ordinal & 6 \\
HIST_FAM & Histórico Familiar & Dummy & 2 \\
EXP_ANT & Experiência anterior em outra empresa & Dummy & 2 \\
\hline
\end{tabular}


No Quadro 2 estão discriminados os pressupostos conceituais do Capital Humano com as influências (sinal) esperadas, enquanto na Tabela 26 estão descritos os indicadores que foram utilizados para operacionalizar os testes desta dimensão.

Quadro 3 - Variáveis explicativas, sinal esperado e pressupostos conceituais do Capital Social

\begin{tabular}{|c|l|c|l|}
\hline $\begin{array}{c}\text { Fator } \\
\text { (Dimensão) }\end{array}$ & $\begin{array}{c}\text { Indicadores / } \\
\text { Var. explicativas }\end{array}$ & Sinal & \multicolumn{1}{c|}{ Pressupostos conceituais } \\
\hline Capital & + & $\begin{array}{l}\text { Quanto maiores forem os recursos disponíveis na fase } \\
\text { inicial e durante a atividade operacional, maior é a } \\
\text { probabilidade de sucesso da empresa }\end{array}$ \\
\hline Capital Social & $\begin{array}{l}\text { Acesso a Instituições } \\
\text { / Parcerias }\end{array}$ & + & $\begin{array}{l}\text { Indivíduos/empresas com uma adequada rede de } \\
\text { relacionamentos com as entidades que proveem os } \\
\text { recursos necessários aos negócios terão melhores } \\
\text { condições de desempenho. }\end{array}$ \\
\hline $\begin{array}{l}\text { Uso de serviços } \\
\text { especializados }\end{array}$ & + & $\begin{array}{l}\text { Os proprietários que buscam e têm acesso a serviços } \\
\text { especializados como consultorias, têm mais chances de } \\
\text { obterem informações mais acuradas, permitindo } \\
\text { tomada de decisões mais eficientes em resultados. }\end{array}$ \\
\hline
\end{tabular}

O Capital Social constitui-se do conjunto de recursos que o empreendedor possui e da gama de acessos para obtê-los, incluindo relacionamento com bancos, fornecedores, instituições etc. No Quadro 3 estão expressados os pressupostos conceituais e a influência esperada, enquanto na Tabela 27 estão descritos os indicadores utilizados para testar o efeito desta dimensão no desempenho das PMEs.

Tabela 27 - Caracterização operacional dos indicadores de Capital Social

\begin{tabular}{llcc}
\hline Indicador & \multicolumn{1}{c}{ Descrição } & Tipo & Escala \\
\hline D_CAP & Disponibilidade de capital para constituição da empresa & Ordinal & 5 \\
EMP_C & Uso de empréstimos na constituição da empresa & Ordinal & 5 \\
FORN & Quantidade de fornecedores & Ordinal & 5 \\
G_FORN & Giro dos fornecedores & Ordinal & 5 \\
R_BANK & Relacionamento da empresa com bancos & Likert & 5 \\
SERV_ESP & Uso de serviços especializados & Likert & 4 \\
REC_CRED & Receptividade nas demandas de crédito & Likert & 6 \\
VOL_CRED & Volume de crédito atendido nas demandas & Likert & 6 \\
DIF_CRED & Dificuldade de obtenção de crédito & Likert & 6 \\
IMP_CRED & Impacto do crédito na expansão do negócio & Likert & 6 \\
\hline
\end{tabular}

As características gerenciais constituem o uso dos elementos da função de gestão: planejar, organizar, coordenar, executar e controlar. Nessa dimensão, as principais evidências empíricas mostram, de maneira mais recorrente, os aspectos relacionados ao "plano de negócio / planejamento" e aos "registros e controles financeiros" (BARSLEY; KLEINER, 1990; GASKILL et. al., 1993; VAN GELDEREN et. al., 2006). 
Quadro 4 - Variáveis explicativas e pressupostos conceituais de Características Gerenciais

\begin{tabular}{|c|c|c|c|}
\hline $\begin{array}{c}\text { Fator } \\
\text { (Dimensão) }\end{array}$ & $\begin{array}{c}\text { Indicadores / } \\
\text { Var. explicativas }\end{array}$ & Sinal & Pressupostos conceituais \\
\hline \multirow{3}{*}{$\begin{array}{l}\text { Características } \\
\text { Gerenciais }\end{array}$} & $\begin{array}{l}\text { Plano de Negócio } \\
\text { Planejamento }\end{array}$ & + & $\begin{array}{l}\text { Decisões de investimento baseadas em plano de } \\
\text { negócio previamente elaborado e a utilização de } \\
\text { práticas de planejamento proporcionam mais } \\
\text { chances de sobrevivência e alto desempenho. }\end{array}$ \\
\hline & $\begin{array}{l}\text { Registros e controles } \\
\text { financeiros }\end{array}$ & + & $\begin{array}{l}\text { As empresas que conhecem e controlam os fluxos } \\
\text { financeiros do dia a dia estarão em melhores } \\
\text { condições de obterem sucesso. }\end{array}$ \\
\hline & Custos financeiros & - & $\begin{array}{l}\text { Empreendimentos que enfrentam uma maior gama } \\
\text { de problemas financeiros terão mais dificuldades } \\
\text { para alcançar o sucesso. }\end{array}$ \\
\hline
\end{tabular}

No Quadro 4 estão explicitados os pressupostos conceituais e as influências esperadas. $\mathrm{Na}$ Tabela 28 estão descritos os indicadores que foram utilizados nesta dimensão. Dadas as evidências empíricas em relação ao "plano de negócio", os cinco primeiros indicadores procuraram medir os principais aspectos de planejamento realizados antes da abertura da empresa.

Tabela 28 - Caracterização operacional dos indicadores das Características Gerenciais

\begin{tabular}{llcc}
\hline Indicador & \multicolumn{1}{c}{ Descrição } & Tipo & Escala \\
\hline PESQ_MERC & Nível de pesquisa de mercado realizado antes da abertura & Likert & 6 \\
PESQ_FORN & Pesquisa e contatos prévios com os principais fornecedores & Likert & 6 \\
PESQ_AMB & Análise do ambiente: concorrentes, preços etc & Likert & 6 \\
PESQ_LOC & Pesquisa sobre a localização do negócio & Likert & 6 \\
PESQ_VEF & Estudo sobre a viabilidade econômico-financeira & Likert & 6 \\
CONT_FCX & Conhecimento e controle do fluxo de caixa & Likert & 6 \\
ANT_REC & Frequência de uso de antecipação de recebíveis & Likert & 6 \\
INAD & Problemas com inadimplentes & Likert & 6 \\
JURO & Pagamento de juros elevados & Likert & 6 \\
\hline
\end{tabular}

A dimensão "Condições do Ambiente" consiste no conjunto dos elementos sistêmicos e exógenos que podem ser percebidos e sentidos de forma diferente pelas empresas. Neste contexto incluem-se os aspectos de competição, sazonalidade, suportes institucionais e governamentais (Quadro 5).

Brüderl et. al. (1992) concluíram que ambientes mais competitivos e com elevada sazonalidade apresentaram índices significativamente menores de sobrevivência. No entanto, a evidência mais recorrente é o timming econômico (BRUNO, et. al., 1987; LUSSIER; CORMAN, 1996). 
Quadro 5 - Variáveis explicativas e pressupostos conceituais das Condições do Ambiente

\begin{tabular}{|c|c|c|c|}
\hline $\begin{array}{c}\text { Fator } \\
\text { (Dimensão) }\end{array}$ & $\begin{array}{c}\text { Indicadores / } \\
\text { Var. explicativas }\end{array}$ & Sinal & Pressupostos conceituais \\
\hline \multirow{4}{*}{$\begin{array}{l}\text { Condições do } \\
\text { Ambiente }\end{array}$} & Competição & - & $\begin{array}{l}\text { Ambientes altamente competitivos tendem a ser } \\
\text { mais arriscados em termos de sobrevivência. } \\
\text { Entretanto, podem proporcionar aprendizagem e } \\
\text { desempenho superior. }\end{array}$ \\
\hline & Sazonalidade & - & $\begin{array}{l}\text { Condições sazonais proeminentes impactam o } \\
\text { desempenho negativamente. }\end{array}$ \\
\hline & Momento econômico & + & $\begin{array}{l}\text { Variando entre recessão e prosperidade, o momento } \\
\text { econômico, sobretudo na entrada da empresa, tem } \\
\text { efeitos positivos sobre o desempenho. }\end{array}$ \\
\hline & Suporte Governamental & + & $\begin{array}{l}\text { O suporte governamental fornece melhores } \\
\text { condições de obtenção de sucesso. }\end{array}$ \\
\hline
\end{tabular}

Os testes desta dimensão foram desenvolvidos tendo por base os indicadores apresentados na Tabela 29.

Tabela 29 - Caracterização operacional dos indicadores de Condições do Ambiente

\begin{tabular}{llcc}
\hline Indicador & \multicolumn{1}{c}{ Descrição } & Tipo & Escala \\
\hline SAZON & Grau de sazonalidade no segmento da empresa & Likert & 5 \\
COMPET & Grau de competição no ambiente da empresa & Likert & 5 \\
CRED_LA & Suporte governamental em relação a linhas e acesso ao crédito & Likert & 6 \\
SERV_PUB & Nível de avaliação dos serv. públicos relacionados com PMEs & Likert & 6 \\
INST & Nível de avaliação de suporte de instituições & Likert & 6 \\
AMB_COMP & Ambiente competitivo: grau de lealdade e formalidade & Likert & 6 \\
\hline
\end{tabular}

Outro aspecto que as pesquisas têm revelado como influenciador do desempenho são as características organizacionais, que inclui o conjunto de formatações que vai deste o ramo, escolhas estratégicas, qualificação do staff até o grau de inovação percebido pelo empreendedor.

Nesta dimensão foram explorados sete aspectos, que estão apresentados no Quadro 6. Brüderl et. al. (1992) encontraram que as empresas que tem seu escopo de abrangência delimitado em poucos produtos ou serviços tiveram maior longevidade. Os autores (id) também identificaram que as empresas afiliadas (como franquias, representações etc.) possuem mais chances de sobrevivência que as independentes (autônomas).

Entretanto, o aspecto que apresentou de forma mais recorrente evidências de impactos no desempenho foi a qualidade do staff (FLAHVIN, 1985; BRUNO et. al, 1987; LUSSIER e CORMAN, 1996; HEAD, 2003). 
Quadro 6 - Variáveis explicativas e pressupostos conceituais - Características Organizacionais

\begin{tabular}{|c|c|c|c|}
\hline $\begin{array}{c}\text { Fator } \\
\text { (Construto) }\end{array}$ & $\begin{array}{c}\text { Indicadores / } \\
\text { Var. explicativas }\end{array}$ & Sinal & Pressupostos conceituais \\
\hline \multirow{7}{*}{$\begin{array}{l}\text { Características } \\
\text { Organizacionais }\end{array}$} & $\begin{array}{l}\text { Generalidade versus } \\
\text { especialidade }\end{array}$ & $\begin{array}{l}+ \\
?\end{array}$ & $\begin{array}{l}\text { Atividades pautadas pela especialidade têm mais } \\
\text { chances de serem dominadas e conhecidas, tornando- } \\
\text { se mais eficientes e competitivas, favorecendo o } \\
\text { desempenho. Entretanto, alternativas diversificadas } \\
\text { podem ser igualmente favoráveis. }\end{array}$ \\
\hline & $\begin{array}{l}\text { Escopo de } \\
\text { abrangência }\end{array}$ & + & $\begin{array}{l}\text { À medida que aumenta o escopo de abrangência, } \\
\text { diminuí a concentração de clientes e podem surgir } \\
\text { alternativas mais eficientes e lucrativas, favorecendo } \\
\text { o sucesso. }\end{array}$ \\
\hline & $\begin{array}{l}\text { Grau de } \\
\text { independência }\end{array}$ & + & $\begin{array}{l}\text { As evidências empíricas têm demonstrado que, } \\
\text { sobretudo devido à menor flexibilidade, os negócios } \\
\text { afiliados tem menos chances de sobrevivência. }\end{array}$ \\
\hline & Qualidade do staff & + & $\begin{array}{l}\text { A capacidade da empresa em atrair e reter } \\
\text { empregados qualificados proporciona melhores } \\
\text { condições de obtenção de sucesso. }\end{array}$ \\
\hline & Estrutura Societária & + & $\begin{array}{l}\text { As evidências empíricas demonstraram que à medida } \\
\text { que aumenta o quadro social, melhoram as chances de } \\
\text { sobrevivência e desempenho. }\end{array}$ \\
\hline & $\begin{array}{l}\text { Utilização da } \\
\text { internet }\end{array}$ & + & $\begin{array}{l}\text { As pessoas estão cada mais conectadas na internet, e } \\
\text { as empresas que a utilizam tem mais chances de } \\
\text { apresentar ou vender seus produtos ou serviços }\end{array}$ \\
\hline & Inovação & + & $\begin{array}{l}\text { Um ambiente intensivo em inovação pode representar } \\
\text { oportunidade para a empresa tornar-se mais criativa e } \\
\text { readaptar-se. }\end{array}$ \\
\hline
\end{tabular}

Além dos aspectos tradicionalmente pesquisados, Schaefer (2012) lembra que há um crescimento muito intenso de usuários da internet. Ela é a base do e-commerce, que em 2010 movimentou 165 bilhões de dólares em negócios. Este estudo se propôs a verificar e testar o uso de ferramentas de internet (SITE, CONS_W e VND_W) como determinantes de desempenho.

Na Tabela 30 estão descritos os indicadores utilizados para testar a influência desta dimensão no desempenho das PMEs. 
Tabela 30 - Caracterização operacional dos indicadores das Características Organizacionais

\begin{tabular}{llcc}
\hline Indicador & \multicolumn{1}{c}{ Descrição } & Tipo & Escala \\
\hline ESP_GEN & Escopo de abrangência: especialidade versus generalidade & Dummy & 2 \\
AF_IND & Afiliação ou independência do negócio & Dummy & 2 \\
QUAL_E & Nível de qualificação do staff & Likert & 4 \\
TREIN_E & Nível de treinamento disponibilizado ao staff & Likert & 4 \\
SÓCIOS & Número de sócios da empresa & Razão & \\
REL_SOC & Relacionamento entre os sócios & Likert & 5 \\
INOV & Grau de inovação exigido no setor de atuação & Likert & 5 \\
SITE & Se a empresa possui site (sítio) & Dummy & 2 \\
CONS_W & Se os produtos/serviços podem ser consultados no sítio & Dummy & 2 \\
VND_W & Se a empresa comercializa prod./serviços pela internet & Dummy & 2 \\
\hline
\end{tabular}

No Quadro 7 estão descritos os pressupostos conceituais e influência esperada dos indicadores de motivação para empreender e percepção do risco. Mendes (2006) identificou que o risco envolvido nos pequenos negócios não afetou a decisão de empreender.

Quadro 7 - Variáveis explicativas e pressupostos conceituais - Motivação e percepção de risco

\begin{tabular}{|l|l|c|l|}
\hline $\begin{array}{c}\text { Fator } \\
\text { (Dimensão) }\end{array}$ & $\begin{array}{c}\text { Indicadores / } \\
\text { Var. explicativas }\end{array}$ & Sinal & \multicolumn{1}{|c|}{ Pressupostos conceituais } \\
\hline $\begin{array}{l}\text { Motivação para } \\
\text { abertura }\end{array}$ & + & $\begin{array}{l}\text { Decisão de investimentos baseada em } \\
\text { oportunidades têm proporciona mais chances de } \\
\text { Perfil de Risco } \\
\text { sobrevivência e de sucesso em comparação com } \\
\text { aqueles iniciados por necessidade. }\end{array}$ \\
\cline { 2 - 4 } & Percepção de risco & + & $\begin{array}{l}\text { As empresas mais conscientes do nível de risco no } \\
\text { qual estão inseridas tendem a tomar decisões } \\
\text { compatíveis com esse grau de risco e terem mais } \\
\text { chances de melhor desempenho }\end{array}$ \\
\hline
\end{tabular}

Schaefer (2012) salienta que se o motivo para abrir uma empresa for "ganhar muito dinheiro", seria melhor repensar a decisão. Na Tabela 31 estão apresentados os indicadores operacionais utilizados para testar os impactos sobre o desempenho.

Tabela 31 - Caracterização operacional dos indicadores de motivação e percepção risco

\begin{tabular}{llcc}
\hline Indicador & \multicolumn{1}{c}{ Descrição } & Tipo & Escala \\
\hline OP_NEC & Decisão de empreender: oportunidade versus necessidade & Nominal & 2 \\
MOT_EMP & Motivação para a decisão de empreender & Nominal & 3 \\
RISCO & Percepção do grau de risco envolvido nas PMEs & Likert & 5 \\
\hline
\end{tabular}

No Quadro 8 estão descritos os pressupostos conceituais e efeitos esperados do tamanho da empresa e aspectos pessoais do empreendedor, como gênero, estado civil e idade. O efeito do tamanho e da idade da empresa tem sido especificamente utilizado como variáveis de 
controle, uma vez que um conjunto de fatores vão sendo adquiridos em decorrência deles. Nesta pesquisa, ainda que tenham sido utilizados como variáveis de controle, dada a caracterização da amostra, a variável tamanho implica menores influências na obtenção de outros fatores.

Quadro 8 - Variáveis explicativas, e pressupostos conceituais de tamanho e demografia pessoal

\begin{tabular}{|c|c|c|c|}
\hline $\begin{array}{c}\text { Fator } \\
\text { (Dimensão) }\end{array}$ & $\begin{array}{c}\text { Indicadores / } \\
\text { Variáveis explicativas }\end{array}$ & Sinal & Pressupostos conceituais \\
\hline \multirow{3}{*}{$\begin{array}{l}\text { Tamanho da } \\
\text { Empresa }\end{array}$} & Capital investido & \multirow{3}{*}{+} & \multirow{3}{*}{$\begin{array}{l}\text { Em detrimento do tamanho, a empresa, por ter } \\
\text { mais condições de obter outros fatores, tem } \\
\text { associação positiva com o desempenho. }\end{array}$} \\
\hline & Número de empregados & & \\
\hline & Faturamento anual bruto & & \\
\hline \multirow{3}{*}{$\begin{array}{l}\text { Demografia } \\
\text { Pessoal }\end{array}$} & Gênero & $?$ & $\begin{array}{l}\text { Pesquisas com PMEs tem demonstrado que } \\
\text { pessoas do gênero feminino têm menos chances } \\
\text { de sucesso. Entretanto, não há sustentação teórica } \\
\text { robusta com relação a essa influência. }\end{array}$ \\
\hline & Idade & - & $\begin{array}{l}\text { As evidências empíricas demonstram que a idade } \\
\text { está negativamente associada com o desempenho } \\
\text { da empresa }\end{array}$ \\
\hline & Estado Civil & $?$ & $\begin{array}{l}\text { Pessoas casadas contam com mais senso de } \\
\text { equilíbrio e de responsabilidade. Indivíduos } \\
\text { solteiros têm mais tempo para se dedicar ao } \\
\text { negócio. }\end{array}$ \\
\hline
\end{tabular}

Na Tabela 32 estão caracterizados os indicadores empregados para testar a influência do tamanho e da demografia pessoal sobre o desempenho da empresa.

Tabela 32 - Caracterização operacional dos indicadores de tamanho e demografia pessoal

\begin{tabular}{llcc}
\hline Indicador & \multicolumn{1}{c}{ Descrição } & Tipo & Escala \\
\hline INV & Capital gasto para constituir o negócio & Ordinal & 8 \\
FAT & Faturamento anual bruto do último ano & Ordinal & 9 \\
EMP_A & Número atual de empregados & Razão & - \\
Gênero & Gênero do empreendedor & Nominal & 2 \\
IDADE & Idade do empreendedor & Razão & - \\
CIVIL & Estado civil do empreendedor & Nominal & 4 \\
\hline
\end{tabular}




\subsubsection{Variável explicada: Desempenho}

O desempenho foi testado sob três ângulos: 1) teste binário: sobrevivência $v s$ não sobrevivência; 2) teste multinomial: não sobrevivência $v s$ sobrevivência $v s$ alto desempenho, e; 3) teste de regressão com escala contínua. O desempenho foi determinado por uma escala métrica com intervalo entre 8 e 40 pontos, resultante da soma das respostas de seis assertivas do tipo likert com intensidade final de 5 pontos, como segue:
a) Percepção do lucro
b) Crescimento das vendas
c) Crescimento do número de empregados
d) Percepção do desempenho em comparação com empresas do mesmo setor
e) Satisfação pessoal
f) Impacto na qualidade de vida
g) Grau de confirmação da decisão acerca do negócio
h) Grau de efetivação das expectativas

Tabela 33 - Definição dos indicadores para determinação do Desempenho

\begin{tabular}{lllcc}
\hline Indicador & \multicolumn{1}{c}{ Descrição } & Tipo & Pontos & Ajuste* \\
\hline LUCRO & Margem de Lucro & Likert & 7 & 5 \\
V_FAT & Crescimento da Receita & Likert & 5 & 5 \\
V_EMP & Crescimento do quadro de empregados & Likert & 5 & 5 \\
PERC_D & Percepção comparativa de desempenho & Likert & 5 & 5 \\
SAT_PES & Satisfação pessoal com a empresa & Likert & 5 & 5 \\
QV & Impacto da empresa sobre a QV familiar & Likert & 5 & 5 \\
CONF_DEC & Nível de confirmação da decisão & Likert & 4 & 5 \\
EXPEC & Grau de efetivação das expectativas & Likert & 4 & 5 \\
\hline
\end{tabular}

(*) Os variáveis LUCRO e CONF_DEC foram reponderadas para escala de cinco pontos.

Na Figura 10 são apresentadas as faixas de classificação das empresas em função do escore resultante das combinações das respostas da Tabela 33.

\section{a) Sobrevivência Marginal:}

As PMEs cujo escore for de 8 a 24 pontos foram classificadas como marginalmente sobreviventes. Essa faixa de escore inclui, em sua maioria, a parte inferior da escala de cada indicador (questão) do construto; 


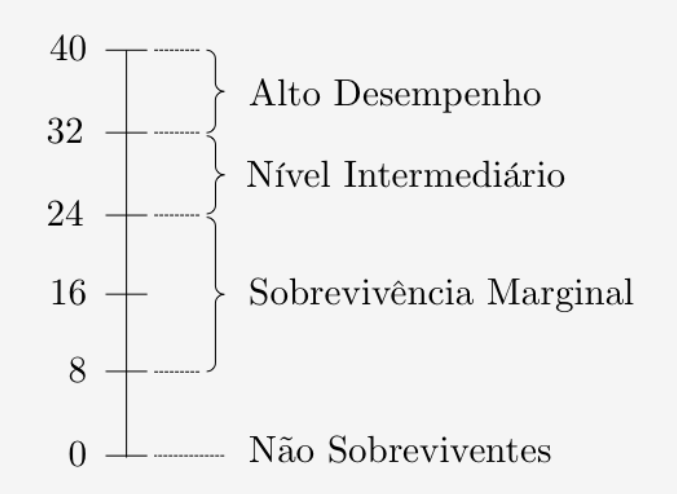

Figura 10 - Escore de Desempenho

\section{b) Nível Intermediário}

Nessa faixa encontram-se as empresas com pontuação superior a 24 e menor ou igual a 32. Essa pontuação constitui a combinação de indicadores com escala média e acima da média.

\section{c) Alto Desempenho}

Para obtenção dessa faixa de pontuação (maior que 32 até 40) é necessário que a combinação de todos os indicadores produzam mais de um nível acima da média.

As variáveis (construtos/fatores) resultantes dos agrupamentos de indicadores foram validadas pelo coeficiente Alfa de Cronbach. Este coeficiente procura medir a confiabilidade interna de um conjunto de questões que se destinam a medir um mesmo construto ou uma mesma dimensão. O teste é dado por:

$$
\alpha=\frac{k}{k-1}\left(1-\frac{\sum_{i=1}^{k} S_{i}^{2}}{S_{T}^{2}}\right)
$$

onde $k$ é o número de indicadores (perguntas) do construto/dimensão; $S_{i}^{2}$ é a variância do $i$ ésimo indicador $(i=1,2, \ldots, k)$, e; $S_{T}^{2}$ é a variância do total da escala de cada indivíduo $j$ nos $k$ indicadores.

Na literatura são observadas pequenas divergências com relação aos níveis do coeficiente $\alpha$ para aceitação da confiabilidade, conforme Tabela 34. 
Tabela 34 - Níveis de alfa de Cronbach $(\alpha)$ para aceitação da confiabilidade

\begin{tabular}{l|l|r}
\hline \multicolumn{1}{c|}{ Autor } & \multicolumn{1}{c|}{ Condição } & $\boldsymbol{\alpha}$ aceitável \\
\hline \multirow{2}{*}{ Hair et. al. (2005) } & Pesquisa Exploratória & 0,6 a 0,7 \\
& Pesquisa Básica & $>0,7$ \\
\hline \multirow{2}{*}{ Davis (1964) } & Previsão Individual & $>0,75$ \\
& Previsão para grupos (25-50 indivíduos) & $>0,65$ \\
\hline \multirow{2}{*}{ Kaplan; Sacuzzo (1982) } & Pesquisa Básica & 0,7 a 0,8 \\
& Pesquisa Aplicada & $>0,95$ \\
\hline \multirow{3}{*}{ Murphy; Davidsholder (1988) } & Confiabilidade inaceitável & $<0,6$ \\
& Confiabilidade baixa & 0,6 a 0,7 \\
& Confiabilidade aceitável & 0,7 a 0,8 \\
& Confiabilidade moderada a elevada & 0,8 a 0,9 \\
& Confiabilidade elevada & $>0,9$ \\
\hline \multirow{3}{*}{ Nunnally (1978) } & Pesquisa Preliminar & 0,7 \\
& Pesquisa Básica & 0,8 \\
& Pesquisa Aplicada & 0,9 a 0,95 \\
\hline
\end{tabular}

Dadas as características de investigação presentes neste estudo, foi estabelecido um coeficiente alfa de Cronbach mínimo de 0,7 para validação da consistência do construto ou dimensão.

Com o objetivo de evitar perda da observação (unidade amostral) caso da empresa não tenha respondido todos os oito indicadores desta dimensão, optou-se por apurar o $D S P$ (escore de desempenho) de acordo com o modelo descrito pela equação 3 .

$$
D S P_{j}=\sum_{i=1}^{n_{j} \mid n_{j} \succeq 5} \frac{I_{i j}(p)}{n_{j}}
$$

onde: $D S P_{j}=$ Escore (desempenho) calculado para a empresa $j ; I_{i, j}=$ valor de escala ( 1 a 5 pontos) atribuído ao Indicador $i$, pela empresa $j ; n_{j}=$ número de Indicadores validados / respondidos pela empresa $j$, tal que $n_{j} \quad 5 ; p=8=$ total de indicadores retidos no modelo.

\subsection{Instrumento e estratégia de coleta de dados}

A coleta de dados foi operacionalizada por meio de questionários com questões estruturadas que foram respondidos por empresas (empresários) encerradas e em atividade (Apêndices $1 \mathrm{e}$ 2). A forma de acesso dos respondentes ocorreu de duas maneiras: a) via e-mail, onde foi disponibilizado o link do servidor onde o questionário esteve hospedado para que fossem respondidos na forma online; b) entrega pessoal de questionário no formato impresso. 
Para o caso das empresas encerradas, devido ao possível ambiente de desconforto, a abordagem inicial foi mediada por escritórios de contabilidade ou pessoas próximas dos respondentes.

\subsection{Procedimentos estatísticos para teste das hipóteses}

A Hipótese central que foi testada é se existe pelo menos um fator (indicador) capaz de explicar o desempenho (variável dependente) de pequenas e médias empresas. Assim, o modelo geral testado é de que o desempenho de PMEs $(y)$ é uma função de uma ou mais variáveis independentes $(x)$.

Para testar o modelo foram utilizados os seguintes testes estatísticos: análise fatorial, regressão linear múltipla, regressão logística binária e regressão logística multinomial.

Os testes mais recorrentes na literatura, conforme apresentado na Tabela 35, são a regressão logística, a regressão linear múltipla e a análise de sobrevivência.

No caso das duas primeiras dimensões de teste, com dois grupos (não sobreviventes e sobreviventes) e três grupos (não sobreviventes, sobrevivência marginal e alto desempenho) foi utilizada a regressão logística (FOTOPOULOS e LOURI, 2000; VAN PRAAG, 2003; LUSSIER, 1995); LUSSIER e PFEIFER, 2001; SADLER-SMITH et. al., 2003; WATSON et. al., 1998; SCHERR, 1989). No caso em que a variável dependente foi analisada em escala contínua, os testes de hipóteses foram realizados com o uso mais recorrentes dos métodos de análise fatorial (BENZING et. al., 2009; HABER e REICHEL, 2005; WANG e ANG, 2004; KOZAN et. al., 2006; CARTER e VAN AUKEN, 2006) e regressão linear múltipla (WEST III e NOEL, 2009; WIJIWARDENA e TIBBITS, 1999; WANG e ANG, 2004). 
Tabela 35 - Testes estatísticos utilizados para analisar sobrevivência e/ou desempenho

\begin{tabular}{|c|c|c|}
\hline Variável Dependente & Estatística de Teste & Autor(es) \\
\hline Sobrevivência versus não Sobrevivência & Análise de Sobrevivência & $\begin{array}{l}\text { Fotopoulos e Louri (2000) } \\
\text { Van Praag (2003) }\end{array}$ \\
\hline Desempenho & Análise Fatorial & $\begin{array}{l}\text { Benzing et. al. (2009) } \\
\text { Haber e Reichel (2005) }\end{array}$ \\
\hline Desempenho & Regressão Linear Múltipla & West III e Noel (2009) \\
\hline Desempenho (crescimento das Vendas) & Regressão Linear Múltipla & Wijiwardena e Tibbits (1999) \\
\hline Sobrevivência versus não Sobrevivência & Regressão Logística & $\begin{array}{l}\text { Bates (1990) } \\
\text { Bates (1995) } \\
\text { Lussier (1995) } \\
\text { Lussier e Pfeifer (2001) } \\
\text { Watson et. al. (1998) }\end{array}$ \\
\hline Sobrevivência e Desempenho & Regressão Logística & Cooper et. al. (1994) \\
\hline Desempenho (crescimento das Vendas) & Regressão Logística & Sadler-Smith et. al. (2003) \\
\hline Sobrevivência versus não Sobrevivência & Regressão Probit & Dunne e Hughes (1986) \\
\hline Sobrevivência versus não Sobrevivência & $\begin{array}{l}\text { Probabilidade Linear } \\
\text { Análise Discriminante }\end{array}$ & Scherr (1989) \\
\hline Desempenho & $\begin{array}{l}\text { Análise Fatorial } \\
\text { Regressão Linear Múltipla }\end{array}$ & Wang e Ang (2004) \\
\hline Sobrevivência versus não Sobrevivência & $\begin{array}{l}\text { Regressão Linear Múltipla } \\
\text { Regressão Logística }\end{array}$ & Fairlie e Robb (2009) \\
\hline Desempenho & $\begin{array}{l}\text { Análise Fatorial } \\
\text { Correlação Canônica }\end{array}$ & Kozan et. al. (2006) \\
\hline Desempenho & $\begin{array}{l}\text { Correlação de Ordem Zero } \\
\text { Análise de Variância }\end{array}$ & Dess e Robinson (1984) \\
\hline Sobrevivência versus não Sobrevivência & $\begin{array}{l}\text { Regressão Logística } \\
\text { Análise de Sobrevivência }\end{array}$ & Mizumoto et. al. (2010) \\
\hline Sobrevivência versus não Sobrevivência & $\begin{array}{l}\text { Análise Fatorial } \\
\text { Análise de Sobrevivência }\end{array}$ & Carter e Van Auken (2006) \\
\hline
\end{tabular}

\subsubsection{Análise Fatorial}

A análise fatorial (AF) é uma técnica multivariada que tem por objetivo reduzir um número grande de variáveis em um conjunto reduzido de fatores (dimensões) assegurando que uma parte significativa da variância seja explicada. Outra vantagem do uso desse método é a eliminação da multicolinearidade entre as variáveis explicativas, incluindo as intercorrelações e aproveitando a contribuição do conjunto máximo de indicadores para o modelo. De outra forma, parte das variáveis explicativas multicolineares precisariam ser excluídas da análise (HAIR et. al., 2005). 
Neste estudo, a AF procurou minimizar o número de indicadores originalmente incluídos em cada uma das dimensões incluindo a variável dependente. Os escores fatoriais permitiram a apropriação adequada de cada indicador no fator em função da carga fatorial, além de dar mais densidade ao seu uso (fator) por se tratar de uma variável com escala contínua.

Os pressupostos principais assegurados na análise fatorial foram: KMO, $M S A, R M S R$, Comunalidade e Variância Total explicada.

O teste de KMO (Kaiser-Meyer-Olkin) confronta as correlações entre pares de indicadores com as correlações residuais. Para validar a AF é necessário que $K M O$ seja maior que 0,5 com a significância dada pelo teste de Bartlett $(\alpha<0,05)$. A estatística de teste é:

$$
K M O=\frac{\sum_{i=1}^{p-1} \sum_{j=i+1}^{p} r_{x_{i} x_{j}}^{2}}{\sum_{i=1}^{p-1} \sum_{j=i+1}^{p} r_{x_{i} x_{j}}^{2}+\sum_{i=1}^{p-1} \sum_{j=i+1}^{p} r^{2}{ }_{x_{i} x_{j} \mid x_{k}}}
$$

Onde $r^{2}{ }_{x_{i} x_{j}}$ é o quadrado da correlação de Pearson entre as variáveis $X_{i}$ e $X_{j}$, e $r^{2}{ }_{x_{i} x_{j}} \mid x_{k}$ é o quadrado das correlações parciais ${ }^{4}$ de $X_{i}$ e $X_{j}$, descontados os efeitos de $X_{k}(k \quad i \quad j=1$, $\ldots, p)$ variáveis.

O teste MSA (Measures Sample Adequacy) determina individualmente a adequação de cada uma das variáveis (indicadores) na amostra. Pode também ser entendida como uma particularização do $K M O$, e é dada por:

$$
K M O_{i}=\frac{\sum_{j \neq i+1}^{p} r_{x_{i} x_{j}}^{2}}{\sum_{j \neq i+1}^{p} r_{x_{i} x_{j}}^{2}+\sum_{j \neq i+1}^{p} r^{2}{ }_{x_{i} x_{j} \mid x_{k}}}
$$

O RMSR (Root Mean Square Residual) é utilizado para calcular a qualidade do ajuste do modelo. Este índice resulta do quadrado médio entre as diferenças das variâncias-covariâncias

\footnotetext{
${ }^{4}$ Correlação parcial é a correlação entre duas variáyẹis $x_{i}$ e $x_{r_{j}}$ descontados os efeitos de outras variáveis, $x_{k}$, que

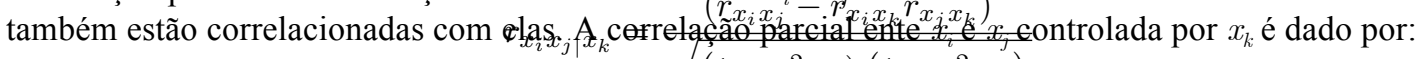
$\sqrt{\left(1-r_{x_{i} x_{j}}^{2}\right)\left(1-r_{x_{i} x_{k}}^{2}\right)}$
} 
estimadas pelo modelo e as variâncias-covariâncias observadas (SCHUMACKER e LOMAX, 1996):

$$
R M S R=\sqrt{\frac{\sum_{i=1}^{p} \sum_{j=1}^{p}\left(\sigma_{i j}-s_{i j}\right)^{2}}{\frac{p(p+1)}{2}}}
$$

onde $\sigma_{i j}$ são as variâncias-covariâncias estimadas pelo modelo, $s_{i j}$ são as variânciascovariâncias observadas e $p$ o número de variâncias-covariâncias não redundantes.

A Comunalidade é a quantidade de variância de um indicador explicada pelo(s) fatore(s) extraído(s). Comunalidade menor que 0,5 significa que mais de $50 \%$ da variância do indicador (variável) não foi captada pelo(s) fator(es), devendo ser excluído do modelo. A Variância Total Explicada inclui a variância de todos os indicadores explicada pela variável latente. Recomenda-se um índice de pelo menos $60 \%$ ou dois terços.

A análise fatorial utilizada neste estudo é baseada na matriz de correlações e no método de análise de componentes principais. Não foi utilizado o critério de autovalores para determinação do número de fatores e sim, adotado o número certo de um (1) fator, portanto não houve rotação dos eixos.

\subsubsection{Regressão Linear Múltipla - Ordinary Least Square (OLS)}

O modelo de estimação por regressão $(O L S)$, dentre os métodos estatísticos, é um dos mais propícios para análise ceteribus paribus porque permite explicitamente controlar simultaneamente o conjunto de fatores que afetam a variável dependente (WOOLDRIDGE, 2003).

Maroco (2010) destaca que para validação do modelo $O L S$, alguns pressupostos precisam ser atendidos:

a) Os erros possuem distribuição normal, média nula e variância constante $-\varepsilon_{\mathrm{j}} \sim N(0, \sigma)$;

b) As covariações dos erros são independentes - $\operatorname{Cov}\left(\varepsilon_{\mathrm{k}}, \varepsilon_{\mathrm{l}}\right)=0(k \quad l ; k, l=1, \ldots, n)$;

c) Os Preditores não são correlacionados (ortogonalidade das variáveis independentes). 
O modelo genérico da regressão linear é dado por:

$$
Y_{j}=\alpha+\beta_{1} X_{1 j}+\beta_{2} X_{2 j}+\cdots+\beta_{n} X_{n j}+\varepsilon_{j}
$$

onde: $Y_{\mathrm{j}}=$ variável dependente; $\alpha=$ termo constante; $\beta=$ estimativa do parâmetro relacionado com uma variável independente $X ; X_{j}=$ Variáveis independentes; $\varepsilon_{j}=$ erro aleatório da observação $j$.

A inferência da validade do modelo de regressão linear é dado por:

$$
F=\frac{S Q R}{p} \cdot \frac{(n-p-1)}{S Q E}=\frac{Q M R}{Q M E}
$$

onde $S Q R=$ Soma dos quadrados da regressão; $S Q E=$ Soma dos quadrados dos erros; $p=$ número de variáveis independentes do modelo; $Q M R=$ Quadrados médios da regressão; $Q M E=$ Quadrado Médio dos Erros; $n=$ número de observações. Sob $\mathrm{H}_{0}$ a estatística $F$ possui distribuição $F$-Snedecor com $p$ e $(n-p-1)$ graus de liberdade.

O coeficiente de explicação (comumente denominado $r^{2}$ ) mede a dimensão do efeito das variáveis independentes sobre a variável dependente no modelo de regressão. $\mathrm{O} r^{2}$ é dado por:

$$
r^{2}=\frac{S Q R}{S Q T}
$$

onde $S Q T$ é a soma dos quadrados totais da regressão. No entanto, Zar (1999) observa que a inclusão de mais uma variável no modelo tende a aumentar o $r^{2}$, ainda que sua influência seja pequena. Dessa forma, sugere-se que o $r^{2}$ seja ajustado em função do número de variáveis $(p)$

$$
r_{a}^{2}=r^{2}-\frac{p-\left(1-r^{2}\right)}{n-p-1}
$$

Como o número de variáveis incluídas neste estudo é relativamente grande, foi utilizada a análise fatorial exploratória como forma de agrupar aquelas correlacionadas entre si e para incorporar sua contribuição no conjunto da análise, ratificando ou retificando os construtos estimados no modelo teórico. Nesse caso, os indicadores com confiabilidade assegurada serão substituídos pelo fator que os representa. 
O modelo estimador foi dado por :

$$
\begin{aligned}
D S P_{j}= & \alpha+\beta_{1}(\mathrm{CH})+\beta_{2}(\mathrm{CS})+\beta_{3}(\mathrm{CG})+\beta_{4}(\mathrm{CA})+\beta_{5}(\mathrm{MPR}) \\
& +\beta_{6}(\mathrm{CO})+\beta_{7}(\mathrm{Tam})+\beta_{8}(\mathrm{Id})+\beta_{9}(\mathrm{G})+\beta_{10}(\mathrm{EC})+\varepsilon_{j}
\end{aligned}
$$

onde: $D S P_{j}=$ desempenho esperado da empresa $j ; \alpha=$ termo constante; $\beta=$ coeficiente de correlação parcial; construtos ou indicadores: $\mathrm{CH}=$ Capital Humano; $\mathrm{CS}=$ Capital Social; $\mathrm{CG}=$ Características Gerenciais; $\mathrm{CA}=$ Condições do Ambiente; $\mathrm{CO}=$ Características Organizacionais; MPR = Motivação e Percepção do Risco; Tam = Tamanho (variável de controle); $\mathrm{Id}=$ Idade do proprietário; $\mathrm{G}=$ Gênero do proprietário (dummy); EC = Estado civil do proprietário; $\varepsilon_{j}=$ resíduo aleatório para a observação $j$.

\subsubsection{Regressão Logística Binária}

A regressão logística é indicada quando a variável dependente é não métrica, e quando não há relação linear entre a variável dependente e as variáveis independentes. Hair et. al. (2005) destacam ainda que a regressão logística não depende de suposições rígidas (como normalidade multivariada e igualdade de matrizes de variâncias e covariâncias), tornando-a mais robusta quando esses pressupostos não possam ser atendidos. A equação de regressão logística expressa uma equação de regressão linear múltipla em termos logarítmicos, resolvendo o problema da violação da linearidade.

Esse modelo estatístico assume um conjunto distinto de variações: a) binária - quando a variável de teste é dicotômica: 1 = sucesso; 0 = insucesso; b) multinomial - quando a variável dependente possui mais de dois grupos, e; c) ordinal - quando os grupos da variável dependente assumem uma ordem (crescente ou decrescente). Neste tópico serão abordados apenas os aspectos alusivos à regressão logística binária, onde será testado se (1) a empresa sobreviveu ou se (0) não sobreviveu.

Hair et. al. (2005) observam que a regressão logística tem seu nome derivado da transformação logística, onde os coeficientes resultam da razão de desigualdade da probabilidade de um evento ocorrer em comparação com ele não ocorrer. Essa razão pode ser expressa como:

$$
\frac{P(\text { evento ocorrer })}{P(\text { evento } \text { nao ocorrer })}=e^{\beta_{0}+\beta_{1} X_{1}+\cdots+\beta_{n} X_{n}}
$$


A função utilizada na regressão logística para estimar a probabilidade da $j$-ésima $(j=1, \ldots$, $n$ ) ocorrência da variável dependente ser "sucesso" $P\left[Y_{j}=1\right]=\hat{\pi}_{j}$, é a função cujo modelo genérico para um conjunto de variáveis é (MAROCO, 2010):

$$
\widehat{\pi}_{j}=\frac{e^{\beta_{0}+\beta_{1} X_{1} j+\cdots+\beta_{n} X_{n} j}}{1+e^{\beta_{0}+\beta_{1} X_{1} j+\cdots+\beta_{n} X_{n} j}}
$$

ou na forma matricial

$$
\widehat{\pi}_{j}=\frac{e^{\mathrm{X} \beta}}{1+e^{\mathrm{X} \beta}}
$$

onde $\hat{\pi}$ é o vetor das probabilidades estimadas, $X$ é a matriz das variáveis independentes e $\beta$ é o vetor dos coeficientes da regressão logística. Nota-se que consiste de modelo não linear, e a solução tradicional consiste em linearizá-la por meio da transformação Logit $(\hat{\pi})$.

$$
\operatorname{Logit}(\widehat{\pi})=\operatorname{Ln}\left[\frac{\widehat{\pi}}{1-\widehat{\pi}}\right]
$$

A razão $\hat{\pi} /(1-\widehat{\pi})$ é conhecida como razão de verossimilhança ou chances, que constitui o conceito chave da regressão logística, explicitando a razão entre a probabilidade do sucesso $(\pi)$ face a probabilidade de insucesso $(1-\pi)$. Dessa forma o modelo de regressão logística é dado por:

$$
\operatorname{Logit}(\widehat{\pi})=\beta_{0}+\beta_{1} X_{1 j}+\beta_{2} X_{2 j}+\cdots \beta_{n} X_{n j}
$$

Onde: $\operatorname{Logit}(\widehat{\pi})=$ probabilidade linearizada de $y, P\left[Y_{j}=1\right]=\widehat{\pi}_{j} ; \beta_{0}=$ valor de $\operatorname{Ln}[\widehat{\pi} /(1-\widehat{\pi})]$ quando todos os $X_{i}=0(i=1, \ldots, p) ; \beta_{1}, \beta_{2}, \ldots, \beta_{p}=$ são os coeficientes Logit, ou seja, a variação do Logit ( $\widehat{\pi})$ quando $\Delta X_{i}=1 \mathrm{e} ; X_{1}, X_{2}, \ldots, X_{p}=$ variáveis independentes.

Os valores de $\beta$, diferentemente da regressão linear, são difíceis de interpretar, sendo usual a interpretação do exponencial destes coeficientes $-\operatorname{Exp}(\beta)$, ou $e^{\beta}(i d)$, conforme dado na equação:

$$
\operatorname{Exp}\left(\beta_{i}\right)=e^{\beta_{i}}=\frac{\frac{P\left[Y=1 \mid X_{i}=x+1\right]}{1-\left(P\left[Y=1 \mid X_{i}=x+1\right]\right)}}{\frac{P\left[Y=1 \mid X_{i}=x\right]}{1-P\left[Y=1 \mid X_{i}=x\right]}}
$$


Este coeficiente é uma estimativa da razão das chances de "sucesso" em comparação com "insucesso", a cada unidade de variação da variável independente $X_{\mathrm{i}}$. Ou seja, quando $X_{\mathrm{i}}$ varia uma unidade, as chances de obter sucesso variam $\beta_{\mathrm{i}}$ unidades.

Maroco (2010) ainda destaca que o modelo de regressão logística deve obedecer os seguintes pressupostos:

a) Linearidade e aditividade: a escala de $\operatorname{Logit}(\pi)$ é aditiva e linear (mas a de $\pi$ não);

b) Proporcionalidade: a contribuição de cada $X_{\mathrm{i}}$ é proporcional ao seu valor com um fator $\beta_{\mathrm{i}} ;$

c) Constância de efeito: a contribuição de uma variável independente é constante, e independe da contribuição das outras variáveis independentes;

d) Os erros são independentes e apresentam distribuição binomial;

e) Os Preditores não são multicolineares.

Como os erros da regressão logística não seguem distribuição normal e não apresentam variância constante, a avaliação da adequação do modelo é realizado com base no método da maximização da verossimilhança (HAIR et. al., 2005; MAROCO, 2010). A função de verossimilhança, considerando variáveis quantitativas, é dada por:

$$
L L=\operatorname{Ln}(L)=\sum_{j=1}^{n}\left[y_{j} \operatorname{Ln}\left(\widehat{\pi}_{j}\right)-\left(1-y_{j}\right) \operatorname{Ln}\left(1-\widehat{\pi}_{j}\right)\right]
$$

onde $L L$ é o log da verossimilhança. Entretanto, se o modelo incluir variáveis qualitativas, a função é ajustada para (HOSMER e LEMESHOW, 2000):

$$
L L=\operatorname{Ln}(L)=\sum_{j=1}^{n}\left[y_{j} \operatorname{Ln}\left(\widehat{\pi}_{j}\right)+\left(n_{j}-y_{j}\right) \operatorname{Ln}\left(1-\widehat{\pi}_{j}\right)\right]
$$

onde $n$ é o número de elementos que pertencem a cada subpopulação $j, y$ é o número de sucessos em cada subpopulação $j$, e $\pi$ é a probabilidade de ocorrência de $j$.

Maroco (2010) observa que os estimadores obtidos pelo método da máxima verossimilhança são eficientes e produzem estimativas com distribuição normal assintótica.

A significância do modelo, que na regressão linear é dada pela soma dos quadrados do erros, na regressão logística é fornecida pela verossimilhança $(-2 L L$ ou -2 vezes o log da 
verossimilhança) (HAIR et. al., 2005). Maroco (id) ressalta que significância do modelo $\left(G^{2}\right)$ é dada a partir das estatísticas para modelo nulo ou reduzido $\left(X_{0}^{2}\right)$ :

$$
X_{0}^{2}=-2 L L_{0} \stackrel{a}{\rightarrow} \chi_{n-1}^{2}
$$

e para o modelo completo

$$
X_{c}^{2}=-2 L L_{c} \stackrel{a}{\rightarrow} \chi_{n-1-p}^{2}
$$

sendo a estatística de significância $\left(G^{2}\right)$ dada por:

$$
G^{2}=X_{0}^{2}-X_{c}^{2}=-2 L L_{0}-\left(-2 L L_{c}\right)=-2 L n\left[\frac{L_{0}}{L_{c}}\right] \stackrel{a}{\rightarrow} \chi_{(p)}^{2}
$$

Adicionalmente ao teste de significância $\left(G^{2}\right)$, requer-se também o teste de adequação dos dados ao modelo, obtidos pelo teste de Hosmer e Lemeshow e o teste de Deviance, descritos

\begin{tabular}{|c|c|}
\hline Teste de Hosmer e Lemeshow & Teste de Deviance \\
\hline$X_{H L}^{2}=\sum_{i=1}^{g} \frac{\left(O_{i}-E_{i}\right)^{2}}{E_{i}}$ & $D=-2 \operatorname{Ln}\left[\frac{L_{c}}{L_{s}}\right]$ \\
\hline $\begin{array}{l}\text { onde: } g=\text { número de grupos; } O=\text { valores } \\
\text { observados; } E=\text { valores esperados. }\end{array}$ & $\begin{array}{l}\text { onde: } L_{C}=\text { verossimilhança do modelo ajustado; } L_{S} \\
=\text { verossimilhança do modelo saturado }\end{array}$ \\
\hline
\end{tabular}
no Quadro 8. Sob $\mathrm{H}_{0}$ tem-se que os dados se ajustam ao modelo.

Quadro 8 - Testes de ajustamento: Hosmer e Lemeshow; Deviance

Na regressão logística utiliza-se o pseudo- $R^{2}$ como medida da qualidade do modelo. Os principais testes são os pseudo- $R^{2}$ de Cox e Snell, Nagelkerke e McFadden, descritos no

\begin{tabular}{|c|c|c|c|c|}
\hline Cox \& Snell & Nagelkerke & & McFadden & \\
\hline$R_{C S}^{2}=1-e^{\frac{2\left(L L_{c}-L L_{0}\right)}{n}}$ & $R_{N}^{2}=\frac{R_{C S}^{2}}{1-e^{\frac{2 L L_{0}}{n}}}$ & $(26)$ & $R_{M F}^{2}=1-\frac{L L_{C}}{L L_{0}}$ & $(27)$ \\
\hline
\end{tabular}
Quadro 9.

Quadro 9: Testes de qualidade do modelo logístico 
Os testes de qualidade na regressão logística devem ser interpretados com precaução, já que eles não explicam o efeito e sim, estabelecem a relação de proporção da verossimilhança do modelo completo em relação ao modelo nulo.

Após concluído que o modelo é significativo e ajustado, é necessário identificar as variáveis influentes do modelo. Para testar a se uma variável independente é significativamente discriminante recorre-se ao teste de Wald (equivalente ao teste t na regressão $O L S$ ). A estatística de teste é:

$$
\chi_{\text {Wald }_{i}}^{2}=\left(\frac{\widehat{\beta}_{i}}{\widehat{S E}\left(\widehat{\beta}_{i}\right)}\right)^{2} \stackrel{a}{\rightarrow} \chi_{(1)}^{2}
$$

onde $\hat{\beta}_{i}$ é o estimador de $\beta_{i}$ e $\widehat{S E}$ é o estimador do erro-padrão de $\beta_{i}$. O teste de Wald possui distribuição assintótica qui-quadrado com um (1) grau de liberdade.

Quadro 10 - Poder discriminatório do modelo logístico - Curva ROC

\begin{tabular}{|c|l|}
\hline Área sob a curva ROC & Poder discriminante do modelo \\
\hline$\leq 0,5$ & Sem poder discriminante \\
$>0,5 \mathrm{e}<0,7$ & Discriminação fraca \\
$\geq 0,7 \mathrm{e}<0,8$ & Discriminação aceitável \\
$\geq 0,8 \mathrm{e}<0,9$ & Discriminação boa \\
$\geq 0,9$ & Discriminação excepcional \\
\hline
\end{tabular}

FONTE: MAROCO, 2007, p. 839.

Adicionalmente aos testes de qualidade, utiliza-se o teste da área sob a curva $R O C(c)$, que tem como variável de teste a probabilidade prevista. Sob $\mathrm{H}_{0}(c \leq 0,5)$ tem-se que o modelo não apresentou poder discriminante e sob $\mathrm{H}_{1}$ o modelo é discriminante, cujo poder de discriminação sugeridos por Hosmer e Lemeshow (2000) são descritos no Quadro 10.

\subsubsection{Regressão Logística Multinomial}

Neste estudo, para testar a discriminação dos grupos (0) não sobreviventes, (1) sobrevivência marginal e (2) alto desempenho foi utilizada a regressão logística multinomial. Este modelo, comparativamente à regressão logística binária, apenas considera que um determinado sujeito $j$ pode ser classificado em mais do que dois grupos da variável dependente. Neste caso a 
variável dependente pode assumir um valor dentre três grupos. A probabilidade de $Y$ assumir qualquer um dos grupos é dado por (HOSMER e LEMESHOW, 2000):

$$
\begin{aligned}
& P(Y=0 \mid \mathbf{X})=\frac{e^{\beta_{00}+\beta_{01} X_{1}+\cdots+\beta_{0 n} X_{n}}}{e^{\beta_{00}+\beta_{01} X_{1}+\cdots+\beta_{0 n} X_{n}}+e^{\beta_{10}+\beta_{11} X_{1}+\cdots+\beta_{1 n} X_{n}}+e^{\beta_{20}+\beta_{21} X_{1}+\cdots+\beta_{2 n} X_{n}}} \\
& P(Y=1 \mid \mathbf{X})=\frac{e^{\beta_{10}+\beta_{11} X_{1}+\cdots+\beta_{1 n} X_{n}}}{e^{\beta_{00}+\beta_{01} X_{1}+\cdots+\beta_{0 n} X_{n}}+e^{\beta_{10}+\beta_{11} X_{1}+\cdots+\beta_{1 n} X_{n}}+e^{\beta_{20}+\beta_{21} X_{1}+\cdots+\beta_{2 n} X_{n}}} \\
& P(Y=2 \mid \mathbf{X})=\frac{e^{\beta_{20}+\beta_{21} X_{1}+\cdots+\beta_{2 n} X_{n}}}{e^{\beta_{00}+\beta_{01} X_{1}+\cdots+\beta_{0 n} X_{n}}+e^{\beta_{10}+\beta_{11} X_{1}+\cdots+\beta_{1 n} X_{n}}+e^{\beta_{20}+\beta_{21} X_{1}+\cdots+\beta_{2 n} X_{n}}}
\end{aligned}
$$

Ou seja, a probabilidade de se observar um determinado grupo $(g)$ em relação ao grupo de referência (0) no sujeito $j$ é dado por (MAROCO, 2010):

$$
P\left(Y_{j}=g \mid \mathbf{x}_{j}\right)=\frac{e^{\beta_{g 0}+\beta_{g 1} X_{1 j}+\cdots+\beta_{g n} X_{n j}}}{1+\sum_{i=1}^{g} e^{\beta_{i 0}+\beta_{i 1} X_{1 j}+\cdots+\beta_{i 1} X_{1 j}}}
$$

e para o grupo de referência:

$$
P\left(Y_{j}=0 \mid \mathbf{x}_{j}\right)=\frac{1}{1+\sum_{i=1}^{g} e^{\beta_{i 0}+\beta_{i 1} X_{1 j}+\cdots+\beta_{i 1} X_{1 j}}}
$$

As suposições dos testes de ajustamento, de qualidade e de significância são os mesmos descritos no modelo logístico binário. 


\section{Capítulo 4}

\section{APRESENTAÇÃO E ANÁLISE DE DADOS}

\subsection{Descrição da Amostra}

\subsubsection{Descrição dos Empreendedores}

A amostra final foi constituída por 410 empresas, sendo 74 inativas (18\%) e 336 em atividade (82\%). Com relação ao gênero, participaram da pesquisa 226 homens (55\%) e 184 mulheres (45\%). Das empresas inativas, a participação masculina foi de $67 \%$, enquanto das mulheres foi de 33\%. Das empresas em atividade houve equilíbrio com relação ao gênero, sendo 52\% de homens, e $48 \%$, de mulheres (Tabela 36 ).

Tabela 36 - Perfil da amostra por status e gênero

\begin{tabular}{lccc}
\hline \multirow{2}{*}{ Gênero } & \multicolumn{2}{c}{ Status da empresa } & \multirow{2}{*}{ TOTAL } \\
\cline { 2 - 3 } & Não Sobrevivente & Sobrevivente & \\
\hline Masculino & 50 & 176 & $\mathbf{2 2 6}$ \\
Feminino & 24 & 160 & $\mathbf{1 8 4}$ \\
TOTAL & $\mathbf{7 4}$ & $\mathbf{3 3 6}$ & $\mathbf{4 1 0}$ \\
\hline
\end{tabular}

$\mathrm{Na}$ Tabela 37 verifica-se que os casados constituíram $70 \%$ da amostra, enquanto a participação dos solteiros foi de $20 \%$. Entre os solteiros, a participação das mulheres foi maior (59\%), enquanto entre os casados a participação dos homens foi mais elevada (58\%).

Tabela 37 - Perfil: Estado Civil e Gênero

\begin{tabular}{lccc}
\hline \multirow{2}{*}{ Estado Civil } & \multicolumn{2}{c}{ Gênero } & \multirow{2}{*}{ TOTAL } \\
\cline { 2 - 3 } & Masculino & Feminino & \\
\hline Solteiro & 33 & 47 & $\mathbf{8 0}$ \\
Casado & 167 & 120 & $\mathbf{2 8 7}$ \\
Divorciado & 17 & 10 & $\mathbf{2 7}$ \\
Outro & 7 & 6 & $\mathbf{1 3}$ \\
TOTAL & $\mathbf{2 2 4}$ & $\mathbf{1 8 3}$ & $\mathbf{4 0 7}$ \\
\hline
\end{tabular}

Com relação ao status de atividade, $65 \%$ dos respondentes das empresas não sobreviventes são casados, $19 \%$ solteiros e $16 \%$ divorciados. Das empresas sobreviventes, $72 \%$ são casados, e $20 \%$, solteiros. 
Tabela 38 - Perfil de Idade

\begin{tabular}{|c|c|c|c|c|}
\hline \multirow{2}{*}{ Idade } & \multicolumn{2}{|c|}{ Sobreviventes } & \multicolumn{2}{|c|}{ Não Sobreviventes } \\
\hline & $F_{i}$ & $\%$ & $\mathbf{F}_{\mathbf{i}}$ & $\%$ \\
\hline Até 25 anos & 19 & 5,7 & 4 & 5,4 \\
\hline De 26 a 35 anos & 76 & 22,8 & 20 & 27,0 \\
\hline De 36 a 45 anos & 106 & 31,8 & 26 & 35,1 \\
\hline De 46 a 60 anos & 108 & 32,4 & 20 & 27,0 \\
\hline Acima de 60 anos & 24 & 7,2 & 4 & 5,4 \\
\hline TOTAL & 333 & 100,0 & 74 & 100,0 \\
\hline
\end{tabular}

Com relação à faixa etária, do total da amostra, 63,8\% dos respondentes possuem entre $36 \mathrm{e}$ 60 anos, 5,7\%, até 25 anos, enquanto $6,9 \%$ possuem mais de 60 anos. Das empresas não sobreviventes, $89 \%$ situam-se na faixa etária entre 26 e 60 anos, com distribuição equilibrada entre as três faixas. Das empresas sobreviventes, 64\% dos respondentes possuem entre 36 e 60 anos, sendo aproximadamente $32 \%$ em cada uma das duas classes (Tabela 38).

Tabela 39 - Perfil: Escolaridade e status da empresa

\begin{tabular}{|c|c|c|c|c|c|c|}
\hline \multirow{3}{*}{ Escolaridade } & \multicolumn{4}{|c|}{ Status da empresa } & \multirow{2}{*}{\multicolumn{2}{|c|}{ TOTAL }} \\
\hline & \multicolumn{2}{|c|}{ Não Sobrevivente } & \multicolumn{2}{|c|}{ Sobrevivente } & & \\
\hline & $\mathbf{F}_{\mathbf{i}}$ & $\%$ & $\mathbf{F}_{\mathbf{i}}$ & $\%$ & $F_{i}$ & $\%$ \\
\hline Ensino Fundamental & 4 & 5,4 & 33 & 9,9 & 37 & 9,1 \\
\hline Ensino Médio & 34 & 45,9 & 108 & 32,5 & 142 & 35,0 \\
\hline Ensino Superior & 16 & 21,6 & 107 & 32,2 & 123 & 30,3 \\
\hline Especialização & 16 & 21,6 & 74 & 22,3 & 90 & 22,2 \\
\hline Mestrado/Doutorado & 4 & 5,4 & 10 & 3,0 & 14 & 3,4 \\
\hline TOTAL & 74 & 100,0 & 332 & 100,0 & 406 & 100,0 \\
\hline
\end{tabular}

Na Tabela 39 observa-se que o nível escolar de maior frequência é o ensino médio, tanto nas empresas não sobreviventes (46\%), como nas empresas sobreviventes (33\%). Nas primeiras os níveis fundamental e médio somam $51 \%$, enquanto nas outras essa faixa é de $42 \%$.

\subsubsection{Descrição das Empresas}

Constituíram a amostra 56 empresas do setor industrial (13,7\%), 223 do comércio (54,3\%) e 131 de serviços $(32 \%)$.

Com relação à idade das empresas sobreviventes (Tabela 40), 24,6\% estão em funcionamento em período inferior à 5 anos enquanto $21,3 \%$ possuem entre 5 e 10 anos. Ou seja, $46 \%$ das 
empresas da amostra possuem até 10 anos. A maior frequência do conjunto das empresas sobreviventes é a faixa de 11 a 20 anos de idade (29\%). A idade média dessas empresas é de 14,5 anos (desvio-padrão de 12,3 anos).

Tabela 40 - Idade das Empresas

\begin{tabular}{lrr}
\hline \multicolumn{1}{c}{ Idade } & $\mathbf{F}_{\mathbf{i}}$ & \multicolumn{1}{c}{$\mathbf{\%}$} \\
\hline Menos de 5 anos & 82 & 24,6 \\
De 5 a 10 anos & 71 & 21,3 \\
De 11 a 20 anos & 97 & 29,0 \\
De 21 a 30 anos & 48 & 14,4 \\
Acima de 30 anos & 36 & 10,8 \\
TOTAL & $\mathbf{3 3 4}$ & $\mathbf{1 0 0 , 0}$ \\
\hline
\end{tabular}

Na Tabela 41 observa-se que das empresas não sobreviventes, 29,7\% delas encerraram suas atividades nos dois primeiros anos. No período de 5 anos esse índice atingiu 62,1\%. Estas evidências coincidem com os estudos do SEBRAE (2008) que identificou um nível de não sobrevivência de $27 \%$ nos dois primeiros anos e de $62 \%$ em 5 anos, em uma amostra com 400 empresas paulistas. Dunne et. al. (1988) evidenciaram um índice de não sobrevivência de $61,5 \%$ em 5 anos para uma amostra de empresas industriais dos EUA.

Tabela 41 - Índice de não sobrevivência

\begin{tabular}{lrrr}
\hline \multicolumn{1}{c}{ Idade } & $\mathbf{F}_{\mathbf{i}}$ & \% & \%ac \\
\hline Até 2 anos & 22 & 29,7 & 29,7 \\
De 3 a 5 anos & 24 & 32,4 & 62,1 \\
De 6 a 10 anos & 21 & 28,4 & 90,5 \\
De 11 a 15 anos & 6 & 8,1 & 98,6 \\
Mais de 15 anos & 1 & 1,4 & 100,0 \\
TOTAL & $\mathbf{3 3 4}$ & $\mathbf{1 0 0 , 0}$ & - \\
\hline
\end{tabular}

Comparativamente a países europeus (Tabela 42) observa-se que o índice de sobrevivência das empresas da amostra equipara-se, no primeiro ano, aos índices obtidos por Alemanha, Itália e Reino Unido, superando França e Portugal. No período de dois anos a taxa de sobrevivência observada na amostra é igual às obtidas por Alemanha e Irlanda e superior as demais nações. Entretanto, após 5 anos, as empresas da amostra tiveram uma taxa de sobrevivência significativamente menor que as demais nações. A idade média das empresas não sobreviventes foi de 5,16 anos (desvio padrão de 3,6 anos). 
Tabela 42 - Taxa de sobrevivência de empresas - Europa e Brasil (amostra)

\begin{tabular}{lccc}
\hline \multirow{2}{*}{\multicolumn{1}{c}{ País }} & \multicolumn{3}{c}{ Taxa de sobrevivência após (\%) } \\
\cline { 2 - 4 } & \multicolumn{1}{c}{$\mathbf{1}$ ano } & 2 anos & $\mathbf{5}$ anos \\
\hline França & 84 & 62 & 48 \\
Alemanha & 86 & 70 & 63 \\
Irlanda & 91 & 70 & 57 \\
Itália & 87 & 66 & 54 \\
Portugal & 76 & 56 & 47 \\
Reino Unido & 87 & 62 & 47 \\
Brasil (amostra desta pesquisa) & $\mathbf{8 7}$ & $\mathbf{7 0}$ & $\mathbf{3 8}$ \\
\hline
\end{tabular}

FONTE: BRIDGE et. at., 2003, p. 208 e dados da pesquisa.

O regime fiscal predominante nas empresas da amostra é o Simplificado (80\%), seguido do Lucro Presumido (14\%) e do Lucro Real (6\%).

Quando da constituição, 16,7\% das empresas eram gerenciadas exclusivamente pelo proprietário(a), enquanto outras $20,8 \%$ além do proprietário(a) incluíam os familiares diretos. Ou seja, 37,5\% das empresas iniciadas não geraram outros empregos senão aos próprios familiares. Na constituição de 32,4\% das iniciantes foram contratados entre 1 a 2 empregados, enquanto em 15,9\% delas foram gerados de 3 a 5 empregos. Em resumo, 85\% das empresas geraram, em média, um (1) emprego no momento em que foram constituídas (Tabela 43).

Tabela 43 - Empregos gerados na constituição da empresa

\begin{tabular}{lrr}
\hline Quadro de empregados na constituição & $\mathbf{F}_{\mathbf{i}}$ & $\mathbf{~ \%}$ \\
\hline Nenhum. Eu gerenciava a empresa sozinho & 68 & 16,7 \\
Eu e familiares diretos (esposa e/ou filhos) & 85 & 20,8 \\
1 a 2 empregados & 132 & 32,4 \\
3 a 5 empregados & 65 & 15,9 \\
6 a 10 empregados & 32 & 7,8 \\
Mais de 10 empregados & 26 & 6,4 \\
TOTAL & $\mathbf{4 0 8}$ & $\mathbf{1 0 0 , 0}$ \\
\hline
\end{tabular}

Das empresas não sobreviventes, $27 \%$ delas não possuíam nenhum empregado no momento da descontinuação. Em 10,8\% dos casos havia 1 empregado, enquanto em 16,2\% haviam 2 empregados. Em 54\% das empresas não sobreviventes perdeu-se um emprego a cada duas empresas descontinuadas (Tabela 44). 
Tabela 44 - Quadro de empregados no momento da descontinuidade da empresa

\begin{tabular}{lrc}
\hline Quadro de empregados na descontinuação & $\mathbf{F}_{\mathbf{i}}$ & $\mathbf{\%}$ \\
\hline Nenhum & 20 & 27,0 \\
1 empregado & 8 & 10,8 \\
2 empregados & 12 & 16,2 \\
3 empregados & 10 & 13,5 \\
4 a 5 empregados & 12 & 16,2 \\
Mais de 5 empregados & 12 & 16,2 \\
TOTAL & $\mathbf{7 4}$ & $\mathbf{1 0 0 , 0}$ \\
\hline
\end{tabular}

Das empresas que permaneceram em atividade, atualmente um terço (34\%) possuem até 2 empregados, enquanto 71,3\% delas possuem até 10 empregados (Tabela 45). O número atual de empregados não foram informados por 33 empresas. $\mathrm{O}$ número médio de empregados dessas empresas é de 15,6 (desvio-padrão de 40,8).

Tabela 45 - Quadro atual de empregados das empresas sobreviventes

\begin{tabular}{lcr}
\hline Número de Empregados & $\mathbf{F}_{\mathbf{i}}$ & $\mathbf{~ \% ~}$ \\
\hline Nenhum & 29 & 9,6 \\
1 a 2 empregados & 74 & 24,4 \\
3 a 5 empregados & 58 & 19,1 \\
6 a 10 empregados & 55 & 18,2 \\
11 a 20 empregados & 42 & 13,9 \\
21 a 50 empregados & 31 & 10,2 \\
Mais de 50 empregados & 14 & 4,6 \\
TOTAL & $\mathbf{3 0 3}$ & $\mathbf{1 0 0 , 0}$ \\
\hline
\end{tabular}

O valor gasto (em valores atuais) para constituir a empresa (inclui-se a compra de equipamentos, edificações, reformas, capital de giro etc.) foi inferior a 10 mil reais em 27,9\% dos casos, de 10 até 25 mil em 25,7\% dos casos e, de 25 a 120 mil, em 27,4\%.

Tabela 46 - Valor gasto para constituir a empresa

\begin{tabular}{lrr}
\hline Valor gasto para constituir a empresa & $\mathbf{F}_{\mathbf{i}}$ & $\mathbf{~ \%}$ \\
\hline Menos de 10 mil & 112 & 27,9 \\
De 10 mil até 25 mil & 103 & 25,7 \\
De 25 mil até 120 mil & 110 & 27,4 \\
De 120 mil até 240 mil & 41 & 10,2 \\
De 240 mil até 720 mil & 21 & 5,2 \\
De 720 mil até 2,4 milhões & 14 & 3,5 \\
TOTAL & $\mathbf{4 0 1}$ & $\mathbf{1 0 0 , 0}$ \\
\hline
\end{tabular}

Das empresas sobreviventes, $52,9 \%$ das empresas da amostra faturam menos de 360 mil reais 
anuais. Em 13,2\% dos casos o faturamento é entre 360 e 720 mil, enquanto em $12 \%$ é entre 720 mil a 1,2 milhões e apenas $21,7 \%$ das empresas da amostra faturam mais de 1,2 milhões por ano (Tabela 47).

Tabela 47 - Faturamento bruto anual das empresas sobreviventes

\begin{tabular}{lrr}
\hline Faturamento bruto anual & $\mathbf{F}_{\mathbf{i}}$ & $\mathbf{\%}$ \\
\hline Menos de 360 mil & 172 & 52,9 \\
De 360 mil a 720 mil & 43 & 13,2 \\
De 720 mil até 1,2 milhões & 39 & 12,0 \\
De 1,2 milhões até 2,4 milhões & 29 & 8,9 \\
De 2,4 milhões até 5 milhões & 19 & 5,8 \\
De 5 milhões a 20 milhões & 19 & 5,8 \\
De 20 milhões a 50 milhões & 4 & 1,2 \\
TOTAL & $\mathbf{3 2 5}$ & $\mathbf{1 0 0 , 0}$ \\
\hline
\end{tabular}

Das empresas não sobreviventes, 59,5\% faturavam menos de 360 mil quando foram descontinuadas, $27 \%$ faturavam entre 360 e 720 mil e, os $13,5 \%$ restantes, entre 720 mil e 1,2 milhões anuais.

\subsubsection{Descrição dos indicadores de Desempenho}

Os indicadores de desempenho foram respondidos apenas pelas empresas sobreviventes.

Tabela 48 - Perfil do Lucro

\begin{tabular}{llrr}
\hline \multicolumn{1}{c}{ Variável } & \multicolumn{1}{c}{ Classe } & $\mathbf{F}_{\mathbf{i}}$ & $\mathbf{\%}$ \\
\hline & Menos de 3\% & 8 & 2,5 \\
& De 3\% a 5\% & 47 & 14,9 \\
Qual o lucro médio atual & De 6\% a 10\% & 79 & 25,1 \\
obtido pela empresa em & De 11\% a 15\% & 42 & 13,3 \\
relação ao faturamento & De 16\% a 20\% & 43 & 13,7 \\
bruto? & De 21\% a 25\% & 24 & 7,6 \\
& Mais de 25\% & 72 & 22,9 \\
& TOTAL & $\mathbf{3 1 5}$ & $\mathbf{1 0 0 , 0}$ \\
\hline
\end{tabular}

Na Tabela 48 observa-se que $25,1 \%$ dos respondentes informaram que o lucro médio anual da empresa situa-se entre $6 \%$ e $10 \%$. No entanto, outros $22,9 \%$ apontaram um lucro superior a $25 \%$ das vendas. Vale lembrar que o lucro é um termo contábil que pode acarretar confusão com relação à sua interpretação. Kos et. al. (2011) concluíram que as micro e pequenas empresas não compreendem o termo "lucro", podendo este indicador estar enviesado. 
Tabela 49 - Variação do Faturamento

\begin{tabular}{llrr}
\hline \multicolumn{1}{c}{ Variável } & \multicolumn{1}{c}{ Classe } & F $_{\mathbf{i}}$ & \multicolumn{1}{c}{$\mathbf{\%}$} \\
\hline \multirow{2}{*}{ Com relação ao } & Aumentou mais de 20\% & 51 & 15,9 \\
faturamento bruto, & Aumentou até 20\% & 109 & 34,0 \\
levando em conta os & Permaneceu estável & 142 & 44,2 \\
últimos 12 meses, & Diminuiu até 20\% & 11 & 3,4 \\
você diria que: & Diminuiu mais de 20\% & 8 & 2,5 \\
& TOTAL & $\mathbf{3 2 1}$ & $\mathbf{1 0 0 , 0}$ \\
\hline
\end{tabular}

Com relação ao crescimento das vendas (Tabela 49) observou-se que a maior parte dos respondentes $(44,2 \%)$ responderam que permaneceu estável, enquanto $34 \%$ informaram que houve crescimento de até $20 \%$ e, para $15,9 \%$, o crescimento foi superior a $20 \%$. Esta medida é a mais recorrente na literatura, tendo sido usado em inúmeras pesquisas sobre desempenho (WAN e LIANG ANG, 2004; HABER e REICHEL, 2005; ALLEN, 2012; WIJIWARDENA, 2008).

Tabela 50 - Variação no quadro de empregados

\begin{tabular}{llrr}
\hline \multicolumn{1}{c}{ Variável } & \multicolumn{1}{c}{ Classe } & $\mathbf{F}_{\mathbf{i}}$ & $\mathbf{\%}$ \\
\hline \multirow{2}{*}{ Com relação ao $\mathrm{n}^{\mathbf{0}}$ de } & Aumentou mais de 20\% & 27 & 8,5 \\
empregados, levando & Aumentou até 20\% & 58 & 18,3 \\
em conta os últimos & Permaneceu estável & 218 & 68,8 \\
12 meses, você diria & Diminuiu até 20\% & 8 & 2,5 \\
que: & Diminuiu mais de 20\% & 6 & 1,9 \\
& TOTAL & $\mathbf{3 1 7}$ & $\mathbf{1 0 0 , 0}$ \\
\hline
\end{tabular}

O crescimento do número de empregados como medida de desempenho foi utilizada por Haber e Reichel (2005), Robinson et. al. (1984) e Gorvieski et. al. (2011). Neste estudo observou-se que o quadro de empregados não apresentou variação em 68,8\% das empresas, enquanto em $18,3 \%$ houve crescimento de até $20 \%$.

Tabela 51 - Percepção do desempenho

\begin{tabular}{llrr}
\hline \multicolumn{1}{c}{ Variável } & \multicolumn{1}{c}{ Classe } & $\mathbf{F}_{\mathbf{i}}$ & \multicolumn{1}{c}{$\%$} \\
\hline & Muito acima da média & 33 & 10,1 \\
Comparativamente com outras & Um pouco acima da média & 120 & 36,7 \\
empresas do seu setor de atuação, & Igual a média do setor & 141 & 43,1 \\
como você avalia o desempenho & Um pouco abaixo da média & 32 & 9,8 \\
da sua empresa? & Muito abaixo da média & 1 & 0,3 \\
& TOTAL & $\mathbf{3 2 7}$ & $\mathbf{1 0 0 , 0}$ \\
\hline
\end{tabular}

Como as medidas objetivas tradicionais, por complexidades semânticas (principalmente as econômico-financeiras), podem levar à produção de dados distorcidos, Dess e Robinson (1984), West III e Noel (2009) e Haber e Reichel (2005) sugeriram que o desempenho seja 
uma medida subjetiva de domínio do empreendedor. Nesta pesquisa 43,1\% dos respondentes avaliaram o desempenho de suas empresas como dentro da médio do setor, enquanto $36,7 \%$ disseram estar um pouco acima da média e 10,1\% afirmaram que têm desempenho muito acima da média.

Tabela 52 - Satisfação Pessoal com o negócio

\begin{tabular}{llrr}
\hline \multicolumn{1}{c}{ Variável } & \multicolumn{1}{c}{ Classe } & $\mathbf{F}_{\mathbf{i}}$ & $\mathbf{\%}$ \\
\hline & Muito satisfeito & 51 & 15,6 \\
Quanto à satisfação & Satisfeito & 200 & 61,2 \\
pessoal com relação à & Nem satisfeito, nem insatisfeito & 67 & 20,5 \\
sua empresa, você diria & Insatisfeito & 9 & 2,8 \\
que está: & Muito insatisfeito & 0 & 0 \\
& TOTAL & $\mathbf{3 2 7}$ & $\mathbf{1 0 0 , 0}$ \\
\hline
\end{tabular}

As Tabelas 52 e 53 descrevem o desempenho sob a ótica da satisfação pessoal e do impacto na qualidade de vida causado/proporcionado pelo negócio. Gorgievski et. al. (2011) incluem essas medidas dentre o conjunto de critérios de sucesso empresarial. Com relação à satisfação pessoal em relação ao negócio, a avaliação revelou-se positiva para três quartos dos entrevistados, onde $61,2 \%$ disseram que estão satisfeitos, e $15,6 \%$, muito satisfeitos.

Tabela 53 - Impacto na qualidade de vida pessoal e familiar

\begin{tabular}{llrc}
\hline \multicolumn{1}{c}{ Variável } & \multicolumn{1}{c}{ Classe } & $\mathbf{F}_{\mathbf{i}}$ & \multicolumn{1}{c}{$\mathbf{\%}$} \\
\hline & Muito Positivamente & 44 & 13,6 \\
Com relação à qualidade de & Positivamente & 208 & 64,4 \\
vida pessoal e da família, & Não teve impacto & 44 & 13,6 \\
você diria que o negócio & Negativamente & 25 & 7,7 \\
impactou: & Muito Negativamente & 2 & 0,6 \\
& TOTAL & $\mathbf{3 2 3}$ & $\mathbf{1 0 0 , 0}$ \\
\hline
\end{tabular}

Em termos de impacto na qualidade de vida pessoal e familiar (Tabela 53), 64,4\% informaram que o impacto foi positivo, para $13,6 \%$ foi muito positivo enquanto para outros $13,6 \%$ não teve impacto. Menos de $10 \%$ disseram que o impacto foi negativo.

Tabela 54 - Grau de confirmação na decisão

\begin{tabular}{|c|c|c|c|c|}
\hline Variável & Classe & Seq* & $\mathbf{F}_{\mathbf{i}}$ & $\%$ \\
\hline \multirow{5}{*}{$\begin{array}{l}\text { Se você pudesse voltar } \\
\text { no tempo imediatamente } \\
\text { anterior à seu ingresso } \\
\text { no negócio atual, você: }\end{array}$} & Não abriria uma empresa & 4 & 15 & 4,6 \\
\hline & esmo negócio & 1 & 139 & 42,5 \\
\hline & $\begin{array}{l}\text { Investiria no mesmo negócio, porém } \\
\text { faria um planejamento mais minucioso }\end{array}$ & 2 & 137 & 41,9 \\
\hline & Investiria em outro tipo/ramo de negócio & 3 & 36 & 11,0 \\
\hline & TOTAL & & 327 & 100,0 \\
\hline
\end{tabular}

(*) Sequência de ordem para grau confirmação da decisão no negócio atual 
Ainda, em termos de medidas subjetivas, foi aferido quão afiliado e satisfeito o empreendedor está acerca da sua decisão de empreender (Tabela 54). Observou-se que aproximadamente $85 \%$ dos empreendedores, caso tivessem a oportunidade de voltar atrás e tomar a decisão novamente, investiriam no mesmo negócio.

\subsubsection{Descrição dos indicadores de Capital Humano}

Além da Escolaridade já apresentada no item 4.1.1, esta dimensão procurou identificar outros indicadores que constituem o Capital Humano do Empreendedor, sendo:
a) Experiência Ocupacional
b) Experiência no ramo em que abriu o negócio
c) Experiência em funções ou cargos de liderança
d) Participação em cursos e eventos relacionados com o negócio
e) Histórico familiar em atividade empresarial
f) Experiência empreendedora anterior (já teve empresa anteriormente)

Da amostra total, 17,6\% informaram nunca terem exercido uma atividade ocupacional como empregado. Outros 7,1\% disseram que possuíam menos de um ano de experiência, enquanto $30,9 \%$ possuíam de 1 a 5 anos (Tabela 55).

Levando-se em conta somente as empresas não sobreviventes, 48,6\% responderam que possuíam de 1 a 5 anos de experiência, e 32,4\%, de 6 a 10 anos de experiência.

Tabela 55 - Experiência Ocupacional antes de Empreender

\begin{tabular}{|c|c|c|c|c|c|}
\hline \multirow{2}{*}{ Indicador } & \multirow{2}{*}{$\begin{array}{l}\text { Experiência } \\
\text { Ocupacional }\end{array}$} & \multicolumn{2}{|c|}{ Sobreviventes } & \multicolumn{2}{|c|}{ Não Sobreviventes } \\
\hline & & $\mathbf{F}_{\mathbf{i}}$ & $\%$ & $\mathbf{F}_{\mathbf{i}}$ & $\%$ \\
\hline \multirow{7}{*}{$\begin{array}{l}\text { Antes de ser empresário(a), } \\
\text { você já tinha trabalhado } \\
\text { como empregado? }\end{array}$} & Não (nenhuma) & 72 & 17,6 & 6 & 8,1 \\
\hline & Menos de 1 ano & 29 & 7,1 & 2 & 2,7 \\
\hline & De 1 a 5 anos & 126 & 30,9 & 36 & 48,6 \\
\hline & De 6 a 10 anos & 95 & 23,3 & 24 & 32,4 \\
\hline & De 11 a 20 anos & 60 & 14,7 & 6 & 8,1 \\
\hline & Mais de 20 anos & 26 & 6,4 & - & - \\
\hline & TOTAL & 408 & 100,0 & 74 & 100,0 \\
\hline
\end{tabular}


Com relação à experiência no ramo e considerando apenas as empresas sobreviventes, 53\% disseram que não haviam trabalhado no ramo quando constituíram o negócio. Outros 7,4\% possuíam menos de um ano de experiência, enquanto $6,9 \%$ contavam com 1 a 2 anos.

Tabela 56 - Experiência anterior no ramo

\begin{tabular}{|c|c|c|c|c|c|}
\hline \multirow{2}{*}{ Indicador } & \multirow{2}{*}{ Experiência no Ramo } & \multicolumn{2}{|c|}{ Sobreviventes } & \multicolumn{2}{|c|}{ Não Sobreviventes } \\
\hline & & $F_{i}$ & $\%$ & $\mathbf{F}_{\mathbf{i}}$ & $\%$ \\
\hline \multirow{7}{*}{$\begin{array}{l}\text { Antes de ser empresário(a), } \\
\text { você já tinha trabalhado no } \\
\text { ramo em que abriu o } \\
\text { negócio? }\end{array}$} & Não (nenhuma) & 177 & 53,0 & 50 & 67,6 \\
\hline & Menos de 1 ano & 20 & 6,0 & 10 & 13,5 \\
\hline & De 1 a 2 anos & 22 & 6,6 & 6 & 8,1 \\
\hline & De 3 a 5 anos & 51 & 15,3 & 6 & 8,1 \\
\hline & De 6 a 10 anos & 22 & 6,6 & 2 & 2,7 \\
\hline & Mais de 10 anos & 42 & 12,6 & - & - \\
\hline & TOTAL & 334 & 100,0 & 74 & 100,0 \\
\hline
\end{tabular}

Das empresas não sobreviventes, $67,6 \%$ disseram que não possuíam nenhuma experiência no ramo, e 13,5\%, menos de 1 ano quando constituíram suas empresas.

Tabela 57 - Experiência em cargo de liderança

\begin{tabular}{llrrrrrr}
\hline \multirow{2}{*}{ Indicador } & Experiência em & & \multicolumn{2}{c}{ Sobreviventes } & & \multicolumn{2}{c}{ Não Sobreviventes } \\
& Liderança & \multicolumn{1}{c}{$\mathbf{F}_{\mathbf{i}}$} & $\mathbf{\%}$ & & $\mathbf{F}_{\mathbf{i}}$ & \% \\
\hline & Não (nenhuma) & 171 & 51,2 & & 44 & 59,5 \\
Antes de ser empresário(a), & Menos de 1 ano & & 21 & 6,3 & & 10 & 13,5 \\
você ocupou função na qual & De a anos & & 31 & 9,3 & & 8 & 10,8 \\
possuía pessoas/empregados & De a 5 anos & 55 & 16,5 & & 8 & 10,8 \\
sob seu comando? & De 6 a 10 anos & 16 & 4,8 & & 4 & 5,4 \\
& Mais de 10 anos & 40 & 12,0 & & - & - \\
& TOTAL & $\mathbf{3 3 4}$ & $\mathbf{1 0 0 , 0}$ & & $\mathbf{7 4}$ & $\mathbf{1 0 0 , 0}$ \\
\hline
\end{tabular}

De forma similar à experiência no ramo, também foi elevado o índice de inexperiência em funções de liderança (Tabela 57). Das empresas sobreviventes, 51,2\% responderam que não tiveram nenhuma experiência em funções/cargos de liderança antes de abrir a empresa, 6,3\% disseram que a experiência foi menor que um ano, enquanto outros $9,3 \%$ tiveram entre um a dois anos de experiência.

No caso das empresas não sobreviventes, os índices apresentaram apenas uma pequena diferença, onde 59,5\% informaram não possuir nenhuma experiência em liderança, e 13,5\%, menos de um ano. 
Tabela 58 - Qualificação (cursos, eventos etc.) - Empresas sobreviventes

\begin{tabular}{llrr}
\hline Indicador & Treinamento & $\mathbf{F}_{\mathbf{i}}$ & $\mathbf{\%}$ \\
\hline & Menos de 12 horas por ano & 146 & 43,7 \\
Considerando os últimos 24 & De 12 a 24 horas & 55 & 16,5 \\
meses, indique a média anual & De 25 a 36 horas & 31 & 9,3 \\
de horas em cursos técnicos, & De 36 a 48 horas & 27 & 8,1 \\
palestras, feiras, seminários & De 48 a 60 horas & 10 & 3,0 \\
etc., relacionados com o seu & Mais de 60 horas & 65 & 19,5 \\
negócio dos quais participou & TOTAL & $\mathbf{3 3 4}$ & $\mathbf{1 0 0 , 0}$ \\
\hline
\end{tabular}

Observa-se, Tabela 58, que 43,7\% dos proprietários de empresas sobreviventes realizaram menos de 12 horas anuais médias de treinamento ou participação de atividades relacionadas à seu negócio, 16,5\% disseram que realizaram de 12 a 24 horas, enquanto apenas 19,5\% informaram terem realizado mais de 60 horas por ano.

Com relação às empresas não sobreviventes foi perguntado a quantia de treinamento realizado no último ano antes da descontinuidade. Dos respondentes deste grupo, 64,9\% responderam que fizeram menos de 12 horas por ano, $18,9 \%$ de 12 a 24 horas, e 10,8\%, de 25 a 36 horas.

Com relação ao histórico familiar em atividade empreendedora, 44,6\% das empresas sobreviventes disseram que os pais são ou foram empresários, enquanto para as empresas não sobreviventes esse índice caiu para 29,7\% (Tabela 58).

Tabela 59 - Histórico Familiar na atividade empresarial

\begin{tabular}{llcccc}
\hline \multirow{2}{*}{ Histórico Familiar } & \multicolumn{2}{c}{ Sobreviventes } & \multicolumn{2}{c}{ Não Sobreviventes } \\
\cline { 3 - 6 } & Fi & $\mathbf{\%}$ & $\mathbf{F}_{\mathbf{i}}$ & $\mathbf{\%}$ \\
\hline \multirow{2}{*}{ Seus pais são ou } & Sim & 149 & 44,6 & 22 & 29,7 \\
foram empresários? & Não & 185 & 55,4 & 52 & 70,3 \\
& TOTAL & $\mathbf{3 3 4}$ & $\mathbf{1 0 0 , 0}$ & $\mathbf{7 4}$ & $\mathbf{1 0 0 , 0}$ \\
\hline
\end{tabular}

Na Tabela 59 verifica-se que das empresas em atividade, 23,7\% dos empreendedores já tiveram outra(s) empresa(s) anteriormente à atual. Para o caso das empresas não sobreviventes, esse índice foi de 18,9\%. 
Tabela 60 - Experiência em negócio anterior

\begin{tabular}{|c|c|c|c|c|c|}
\hline \multirow{2}{*}{$\begin{array}{c}\text { Experiência anterior em } \\
\text { outra empresa }\end{array}$} & & \multicolumn{2}{|c|}{ Sobreviventes } & \multicolumn{2}{|c|}{ Não Sobreviventes } \\
\hline & & $F_{i}$ & $\%$ & $F_{i}$ & $\%$ \\
\hline \multirow{3}{*}{$\begin{array}{l}\text { Antes da empresa atual, } \\
\text { você já teve outra(s) } \\
\text { empresa(s)? }\end{array}$} & Sim & 79 & 23,7 & 14 & 18,9 \\
\hline & Não & 255 & 76,3 & 60 & 81,1 \\
\hline & TOTAL & 334 & 100,0 & 74 & 100,0 \\
\hline
\end{tabular}

Ainda constatou-se que 23,7\% dos empreendedores de empresas em atividade já tiveram uma outra empresa anteriormente à essa, enquanto no grupo das não sobreviventes esse índice foi de $18,9 \%$.

\subsubsection{Descrição dos indicadores de Capital Social}

Os indicadores de Capital Social utilizados nesta dimensão foram:

a) Disponibilidade de capital para abertura da empresa;

b) Nível de utilização de empréstimos para abertura da empresa

c) Estrutura de fornecedores

d) Giro de fornecedores

e) Relacionamento com os bancos

f) Utilização de serviços especializados

g) Receptividade creditícia

h) Volume de crédito acessado

i) Nível de dificuldade (obstrução) de obtenção de crédito

j) Impactos da dificuldade e do custo do crédito na expansão do negócio

O capital tem sido o fator de impacto sobre o desempenho de PMEs de maior frequência na literatura (BARSLEY e KLEINER, 1990; VAN GELDEREN et. al, 2006; VESPER, 1990; FOTOPOULOS e LOURI, 2000, HEAD, 2003; SHAEFER, 2012) Carter e Van Auken (2006) e Bruno et. al. (1987) destacam os efeitos da subcapitalização como os principais responsáveis pela falência das empresas. 
Tabela 61 - Disponibilidade de capital para constituição do negócio

\begin{tabular}{|c|c|c|c|c|}
\hline \multirow{2}{*}{$\begin{array}{l}\text { Com relação à disponibilidade de capital para } \\
\text { abertura da empresa, você diria que possuía: }\end{array}$} & \multicolumn{2}{|c|}{ Sobreviventes } & \multicolumn{2}{|c|}{ Não Sobreviventes } \\
\hline & $\mathbf{F}_{\mathbf{i}}$ & $\%$ & $\mathbf{F}_{\mathbf{i}}$ & $\%$ \\
\hline $\begin{array}{l}\text { Todos os recursos inclusive uma sobra para as } \\
\text { necessidades inesperadas na fase inicial }\end{array}$ & 36 & 11,0 & 2 & 2,7 \\
\hline A quantia suficiente para abertura da empresa & 80 & 24,5 & 20 & 27,0 \\
\hline $\begin{array}{l}\text { Uma boa parte dos recursos, mas ao final faltou um } \\
\text { pouco de dinheiro }\end{array}$ & 66 & 20,2 & 18 & 24,3 \\
\hline Aproximadamente metade dos recursos necessários & 22 & 6,7 & 16 & 21,6 \\
\hline Apenas uma pequena parte dos recursos & 122 & 37,4 & 18 & 24,3 \\
\hline TOTAL & 326 & 100,0 & 74 & 100,0 \\
\hline
\end{tabular}

No conjunto da amostra observou-se que aproximadamente $45 \%$ das empresas possuíam menos da metade dos recursos necessários para constituição do negócio, sendo que, das empresas sobreviventes, 37,4\% possuíam apenas uma pequena parte, enquanto nas empresas não sobreviventes o índice dessa categoria foi de $24,3 \%$ (Tabela 61).

Tabela 62 - Utilização de empréstimos na abertura da empresa

\begin{tabular}{|c|c|c|c|c|}
\hline \multirow{2}{*}{$\begin{array}{c}\text { Empréstimos para constituição } \\
\text { da empresa }\end{array}$} & \multicolumn{2}{|c|}{ Sobreviventes } & \multicolumn{2}{|c|}{ Não Sobreviventes } \\
\hline & $\mathbf{F}_{\mathbf{i}}$ & $\%$ & $\mathbf{F}_{\mathbf{i}}$ & $\%$ \\
\hline Não utilizou empréstimos & 173 & 51,5 & 32 & 43,2 \\
\hline Menos de $20 \%$ & 71 & 21,1 & 18 & 24,3 \\
\hline Entre 21 e $40 \%$ & 43 & 12,8 & 16 & 21,6 \\
\hline Entre $41 \%$ e $70 \%$ & 31 & 9,2 & 8 & 10,8 \\
\hline Mais de $70 \%$ & 14 & 4,2 & - & - \\
\hline TOTAL & 326 & 100,0 & 74 & 100,0 \\
\hline
\end{tabular}

O efeito da subcapitalização logo no início do negócio leva o empreendedor a buscar alternativas para suprir essas exigências de recursos. Sob a ótica do capital social, uma boa rede de contatos e relacionamentos pode auxiliar na obtenção desses recursos sem que haja necessidade de se recorrer à empréstimos de bancos, instituições ou pessoas físicas. Entretanto, na maior parte das vezes essa rede parece não ter sido eficiente, convergindo para índices de insucessos e baixo desempenho (SEBRAE, 2008; CARTER e VAN AUKEN, 2006; BRUNO et. al., 1987).

Nas empresas da amostra (Tabela 63) observou-se que, aproximadamente metade delas, utilizaram empréstimos para complementar os recursos exigidos na constituição da empresa. 
Tabela 63 - Giro de fornecedores

\begin{tabular}{lrrrrrrr}
\hline \multirow{2}{*}{ Com relação aos fornecedores, você diria que: } & \multicolumn{2}{c}{ Sobreviventes } & & \multicolumn{2}{c}{ Não Sobreviventes } \\
& $\mathbf{F}_{\mathbf{i}}$ & $\mathbf{\%}$ & & $\mathbf{F}_{\mathbf{i}}$ & $\mathbf{\%}$ \\
\hline Raramente ocorrem alterações no quadro de fornecedores & & 131 & 39,9 & & 28 & 37,8 \\
Uma pequena parte (em torno de 25\%) é substituída & & 95 & 29,0 & & 22 & 29,7 \\
Tenho trocado em torno da metade dos fornecedores & 33 & 10,1 & & 10 & 13,5 \\
Há um rodizio, mas tenho parceria firme com 25\% & 26 & 7,9 & & 2 & 2,7 \\
Tenho muito poucos fornecedores firmes (contínuos) & 43 & 12,8 & & 12 & 16,2 \\
TOTAL & $\mathbf{3 2 8}$ & $\mathbf{1 0 0 , 0}$ & & $\mathbf{7 4}$ & $\mathbf{1 0 0 , 0}$ \\
\hline
\end{tabular}

Não raras vezes, os fornecedores de matérias-primas, mercadorias e insumos tornam-se importantes aliados no espectro estratégico da empresa, seja como financiadores das necessidades de capital de giro ou nas suas capacidades de operar com o binômio preçoqualidade. Empresas industriais, principalmente, tem cerca de $50 \%$ a $70 \%$ da sua estrutura de resultados associada a este stakeholder, levando a situações em que o fornecedor passa a integrar o próprio processo operacional da organização. Sob esta ótica, o grau de aproximação e integração entre empresa e fornecedor revela-se em um importante capital social.

Neste estudo observou-se que existe elevada estabilidade entre as empresas e seus fornecedores, onde cerca de $70 \%$ disseram que raramente ou poucas vezes substituem os fornecedores.

No entanto, na dimensão do "capital social", o principal intermediador de recursos é a instituição financeira, sobretudo porque o mercado de capitais é uma realidade distante de PMEs do Brasil.

Com o passar dos anos, a tendência é que ocorra um estreitamento das relações entre instituição financeira e empresa. Entretanto, fatores como a saúde financeira da empresa e a rentabilidade que ela proporciona podem reforçar ou deteriorar essa relação. No Gráfico 4 observaram-se diferenças significativas entre as empresas sobreviventes e não sobreviventes na avaliação de suas relações com bancos. Enquanto nas empresas sobreviventes o índice de “excelente" e "ótimo" é de 51\%, nas outras esse índice alcança 26\%. Na parte inferior ocorre o contrário, enquanto nas empresas não sobreviventes o índice de "regular" e "ruim" é de $35 \%$, nas sobreviventes é de apenas $8 \%$. 


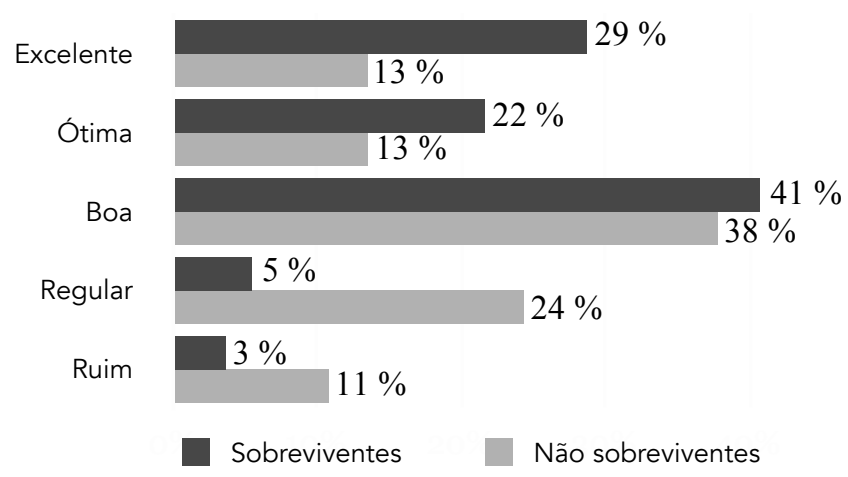

\section{Grafico 4 - Avaliação do relacionamento com bancos}

Com relação ao volume de crédito, $59 \%$ das empresas sobreviventes disseram que o banco sempre ou quase sempre aprova integralmente suas solicitações de recursos, caindo para $15 \%$ para o caso das não sobreviventes.

Quanto à obstrução ao crédito, 62\% das empresas sobreviventes responderam que raramente ou nunca tiveram seu processo de crédito dificultado pelo banco, índice que cai para 31\% quando analisadas as empresas não sobreviventes. O mesmo efeito ocorre na parte superior, onde o índice de sempre, quase sempre e muitas vezes é de $21 \%$ para as sobreviventes e de $47 \%$ para as não sobreviventes.

Tabela 64 - Reciprocidade bancária e acesso ao crédito

\begin{tabular}{|c|c|c|c|c|c|c|c|}
\hline $\begin{array}{l}\text { Marque a intensidade equivalente para cada uma } \\
\text { das assertivas abaixo: }\end{array}$ & $\begin{array}{l}\text { Status da } \\
\text { atividade }\end{array}$ & $\begin{array}{l}0 \\
\stackrel{0}{0} \\
\text { ప }\end{array}$ &  & 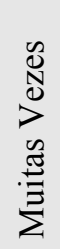 & 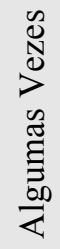 & 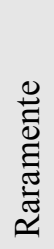 & $\begin{array}{l}\text { J } \\
\text { Z }\end{array}$ \\
\hline \multirow{2}{*}{$\begin{array}{l}\text { Quando preciso de um empréstimo, o banco é } \\
\text { atencioso comigo }\end{array}$} & Sobrevivente & 47 & 24 & 12 & 11 & 4 & 2 \\
\hline & Não Sobrevivente & 10 & 13 & 26 & 26 & 19 & 6 \\
\hline \multirow{2}{*}{$\begin{array}{l}\text { Quando preciso de um empréstimo, o banco } \\
\text { aprova integralmente a quantia solicitada }\end{array}$} & Sobrevivente & 37 & 22 & 7 & 19 & 7 & 7 \\
\hline & Não Sobrevivente & 6 & 9 & 19 & 25 & 34 & 6 \\
\hline \multirow{2}{*}{$\begin{array}{l}\text { Quando preciso de um empréstimo, sinto que o } \\
\text { dificulta a aprovação e liberação dos recursos }\end{array}$} & Sobrevivente & 4 & 6 & 11 & 16 & 33 & 29 \\
\hline & Não Sobrevivente & 3 & 22 & 22 & 22 & 16 & 15 \\
\hline \multirow{2}{*}{$\begin{array}{l}\text { A dificuldade e o custo do crédito têm } \\
\text { atrapalhado a expansão do negócio }\end{array}$} & Sobrevivente & 17 & 13 & 11 & 23 & 19 & 17 \\
\hline & Não Sobrevivente & 10 & 23 & 27 & 17 & 13 & 10 \\
\hline
\end{tabular}

Entretanto, com relação ao impacto causado pelo custo e dificuldade de crédito na expansão 
dos negócios, observa-se que basicamente não há diferenças entre os grupos de empresas. Enquanto o índice de sempre e quase sempre das sobreviventes é de $30 \%$, das não sobreviventes é de 33\%. Na parte inferior porém, observa-se uma diferença mais acentuada entre essas empresas.

O infográfico (Figura 11) permite uma observação visual mais adequada com relação aos aspectos comparativos dessas empresas em cada um dos indicadores.

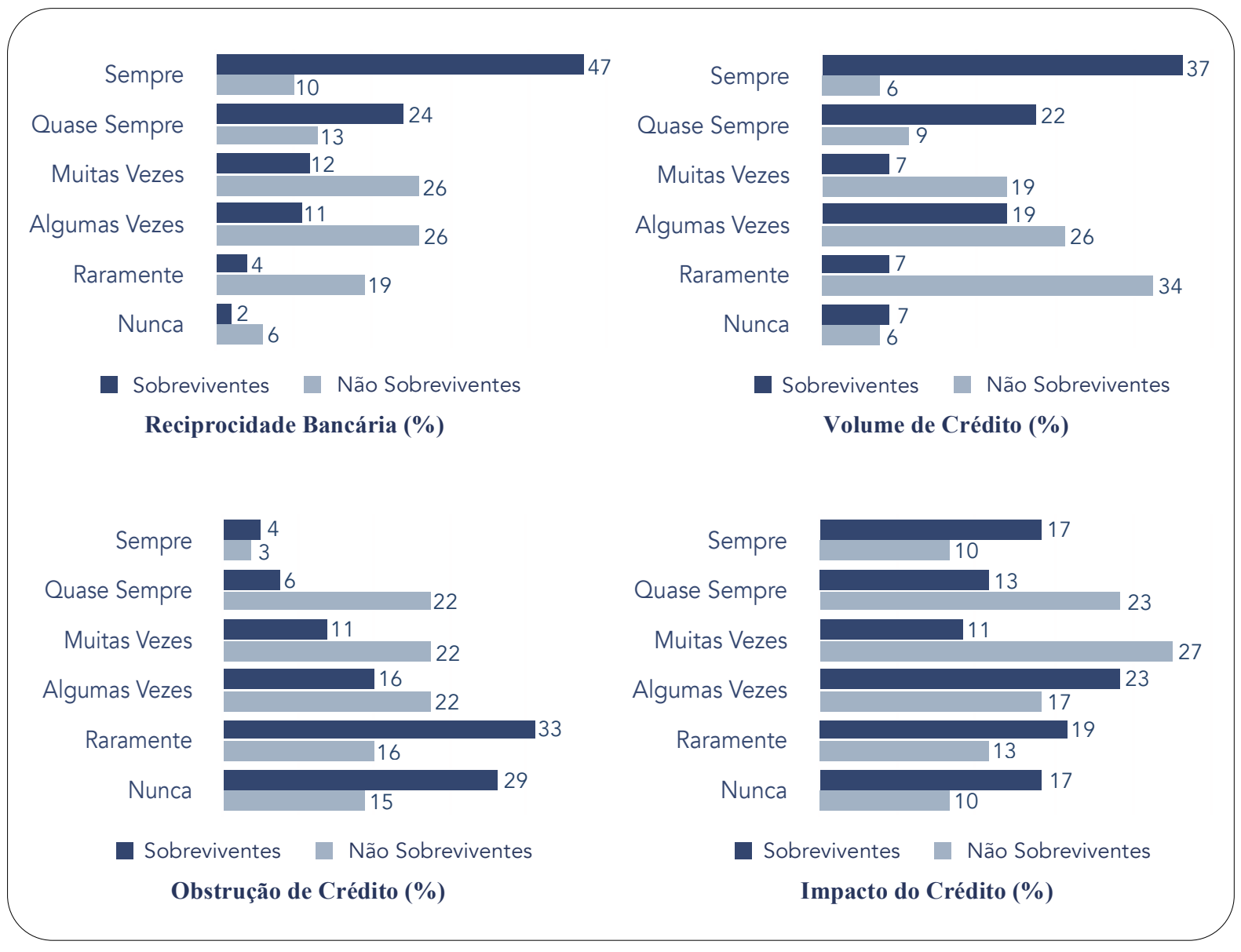

Figura 11 - Infográfico - Crédito: reciprocidade, acesso e impactos

Com relação à parcerias ou utilização de serviços especializados como Sebrae, Universidades, Associações, Federações, Consultorias etc., observou-se (Gráfico 5) que a frequência é bastante baixa. Das empresas sobreviventes, apenas 25\% disseram que utilizam esses com muita ou razoável frequência. No caso das não sobreviventes esse índice cai para $5 \%$. Na parte inferior, $40 \%$ das sobreviventes informaram que raramente ou nunca utilizou os serviços, enquanto nas não sobreviventes esse índice foi de $73 \%$. 


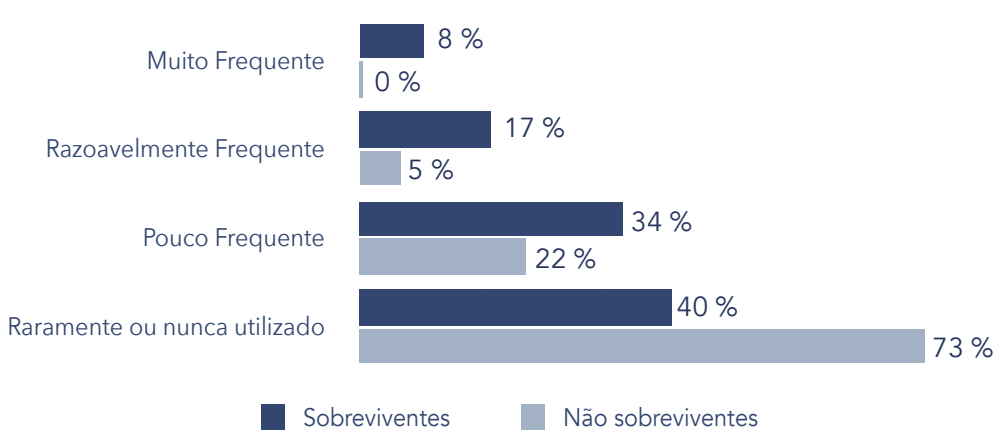

Gráfico 5 - Uso de Serviços Especializados

Na Tabela 64 observam-se diferenças entre as empresas sobreviventes e não sobreviventes em vários aspectos. Um primeiro ponto é a receptividade do banco, aspecto que $71 \%$ das empresas sobreviventes avaliaram positivamente como o banco sendo sempre ou quase sempre atenciosos diante das demandas da empresa. Enquanto para o caso das não sobreviventes este índica cai para 26\%. O uso de serviços especializados como fator de sobrevivência e desempenho das empresas foram relatados por Barsley e Kleiner (1990), Gaskill et. al. (1993), Van Gelderen et. al. (2006) e Lussier (1995, 1996).

\subsubsection{Descrição dos indicadores de Características Gerenciais}

Esta dimensão inclui aspectos relacionados à mecanismos de gestão utilizados pelo empreendedor, principalmente aqueles relacionados à planejamento e registros e controles financeiros. Indicadores incluídos neste construto:

a) Nível de planejamento realizado antes da abertura do negócio

- Pesquisa de mercado e dos clientes potenciais;

- Identificação e contato com os principais fornecedores;

- Análise do ambiente: concorrentes, preços, atendimento, competição etc.

- Análise da localização do negócio

- Realização de estudos de viabilidade financeira e econômica

b) Planejamento e controle dos fluxos de caixa

c) Nível de utilização de antecipação de recebíveis

d) Gestão e controle da inadimplência

e) Gestão e controle de custos financeiros 
Na literatura, o Plano de Negócio tem sido descrito como um dos instrumentos chave no processo de planejamento e viabilização de um negócio, sendo determinante da sobrevivência e desempenho de PMEs (BARSLEY e KLEINER, 1990; WOOD, 1989; LUSSIER e PFEIFER, 2001; SHAEFER, 2012).

Tabela 65 - Nível de planejamento antes da abertura do negócio

\begin{tabular}{|c|c|c|c|c|c|c|c|}
\hline Antes de abrir a empresa, você: & $\begin{array}{l}\text { Status da } \\
\text { atividade }\end{array}$ & 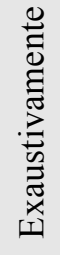 & 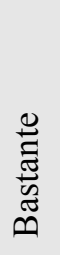 & 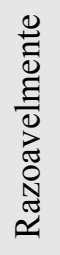 & 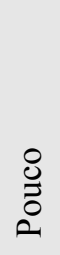 & $\begin{array}{l}\stackrel{0}{0} \\
0 \\
0 \\
\stackrel{0}{\varrho} \\
\stackrel{\Xi}{\Xi}\end{array}$ & $\frac{\pi}{\tilde{J}}$ \\
\hline \multirow{2}{*}{$\begin{array}{l}\text { Pesquisou o mercado de atuação e o perfil dos } \\
\text { potenciais clientes }\end{array}$} & Sobrevivente & 6 & 24 & 25 & 23 & 9 & 12 \\
\hline & Não Sobrevivente & 3 & 5 & 35 & 19 & 19 & 19 \\
\hline \multirow{2}{*}{$\begin{array}{l}\text { Identificou e estabeleceu contato com os } \\
\text { principais fornecedores }\end{array}$} & Sobrevivente & 7 & 35 & 21 & 13 & 11 & 12 \\
\hline & Não Sobrevivente & - & 14 & 19 & 22 & 17 & 28 \\
\hline \multirow{2}{*}{$\begin{array}{l}\text { Analisou os principais concorrentes, preços, } \\
\text { atendimento, competitividade }\end{array}$} & Sobrevivente & 7 & 33 & 24 & 14 & 10 & 11 \\
\hline & Não Sobrevivente & 6 & 8 & 22 & 31 & 14 & 19 \\
\hline \multirow{2}{*}{ Fez estudos sobre a localização do negócio } & Sobrevivente & 12 & 32 & 16 & 15 & 7 & 18 \\
\hline & Não Sobrevivente & 3 & 8 & 11 & 24 & 30 & 19 \\
\hline \multirow{2}{*}{$\begin{array}{l}\text { Fez estudos atestando a viabilidade econômica e } \\
\text { financeira do negócio }\end{array}$} & Sobrevivente & 6 & 29 & 22 & 17 & 7 & 19 \\
\hline & Não Sobrevivente & 3 & 3 & 11 & 25 & 25 & 33 \\
\hline
\end{tabular}

Obs.: Os valores das frequências estão apresentadas em percentual (\%)

Na Tabela 65 estão apresentados os indicadores relacionados ao nível de planejamento antes da abertura. Observou-se que existem diferenças no comportamento entre as empresas sobreviventes e não sobreviventes. Fazendo comparações nas intensidades superiores (exaustivamente e bastante), destacam-se elevadas diferenças nos dois grupos.

Em termos de pesquisa de mercado observou-se que, das empresas sobreviventes, $30 \%$ disseram que pesquisaram exaustivamente ou bastante, enquanto no grupo das não sobreviventes esse índice foi de $8 \%$.

O maior contraste entre os grupos de empresas pode ser observado no indicador "análise da viabilidade econômica e financeira" onde, das empresas sobreviventes, $35 \%$ responderam que se dedicaram exaustivamente ou bastante nesse aspecto do planejamento, enquanto no segundo grupo o índice caiu para $6 \%$. Na parte inferior ocorre o inverso, onde $58 \%$ da 
empresas não sobreviventes informaram ter se dedicado muito pouco ou nada com relação à este indicador, enquanto para o primeiro grupo esta faixa incluiu $26 \%$ das empresas.

Outro conjunto de indicadores avaliados nessa dimensão estão relacionados com o planejamento em controle financeiro. Carter e Van Auken (2006) encontraram que controles financeiros e fluxos de caixa pobres demonstraram-se significativos na sobrevivências das empresas.

Tabela 66 - Registros, controles e custos financeiros

\begin{tabular}{|c|c|c|c|c|c|c|c|}
\hline $\begin{array}{l}\text { Marque a intensidade equivalente para cada uma } \\
\text { das assertivas abaixo: }\end{array}$ & $\begin{array}{l}\text { Status da } \\
\text { atividade }\end{array}$ & 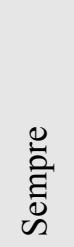 &  & 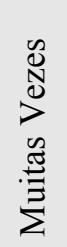 &  & 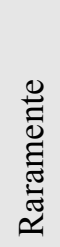 & $\stackrel{\tilde{\Xi}}{\Xi}$ \\
\hline \multirow{2}{*}{$\begin{array}{l}\text { Conheço detalhadamente as entradas e saídas de } \\
\text { caixa que ocorrerão no mês }\end{array}$} & Sobrevivente & 55 & 21 & 8 & 8 & 5 & 3 \\
\hline & Não Sobrevivente & 24 & 30 & 30 & 16 & - & - \\
\hline \multirow{2}{*}{$\begin{array}{l}\text { Utilizo antecipação de recebíveis (desconto de } \\
\text { duplicatas, cheques pré etc.) para fazer caixa }\end{array}$} & Sobrevivente & 11 & 12 & 6 & 14 & 18 & 39 \\
\hline & Não Sobrevivente & 18 & 18 & 18 & 8 & 6 & 32 \\
\hline \multirow{2}{*}{ Tenho problemas com inadimplência } & Sobrevivente & 8 & 6 & 11 & 32 & 29 & 13 \\
\hline & Não Sobrevivente & - & 8 & 32 & 27 & 22 & 11 \\
\hline \multirow{2}{*}{ Tenho pago juros elevados ao(s) banco(s) } & Sobrevivente & 6 & 7 & 7 & 24 & 25 & 31 \\
\hline & Não Sobrevivente & 9 & 17 & 20 & 29 & 11 & 14 \\
\hline
\end{tabular}

Obs.: Valores das frequências estão apresentados em percentual (\%)

Observa-se, na Tabela 66, que as empresas sobreviventes mantém um planejamento e controle dos fluxos de caixa, onde 55\% disse que sempre conhece as entradas e saídas de caixa, enquanto $21 \%$ disseram conhece-lo quase sempre. Do grupo das empresas não sobreviventes, $24 \%$ disseram que conheciam "sempre" os fluxos de caixa, e $30 \%$, quase sempre. Juntando as duas primeiras categorias observou-se nível ligeiramente maior de controles financeiros nas empresas sobreviventes (76\%) em comparação com as não sobreviventes (54\%).

A antecipação de recebíveis é uma forma muito recorrente de financiamento das necessidades de curto prazo, apoiando-se substancialmente em duas situações: a) as empresas não dispõe de outras fontes de financiamento, e; b) o planejamento não foi realizado com a devida antecedência, demandando (como improviso) o uso desse mecanismo de crédito. Operacionalmente trata-se de uma linha de crédito disponibilizada por instituições financeiras caucionadas (garantidas) por recebíveis com vencimentos futuros. Observou-se que essa 
prática, no âmbito das empresas sobreviventes, é sempre utilizada em 11\% das situações, quase sempre, $12 \%$ e, muitas vezes, em outros $6 \%$ dos casos. Do conjunto das empresas não sobreviventes, $18 \%$ reportaram que sempre utilizam a antecipação de recebíveis, outros $18 \%$, quase sempre, e ainda outros 18\%, muitas vezes. Ou seja, mais da metade (54\%) desse conjunto de empresas utilizaram com certa frequência essa fonte de recursos para suas necessidades de caixa.

Os problemas com inadimplência parecem estar equacionados na sua forma mais agressiva, principalmente com o uso de cartões de débito/crédito, de modo que a recorrência nas intensidades sempre e quase sempre foi inferior a $15 \%$ em ambos os grupos.

Como na maioria das vezes financiar-se de forma não planejada pode custar caro, foi perguntado às empresas com relação ao custo financeiro que elas vinham tendo. Observou-se ligeira diferença entre os grupos de empresas, onde $20 \%$ das empresas sobreviventes disseram que sempre, quase sempre ou muitas vezes têm pago juros elevados. Para a mesma faixa de intensidade, o índice das não sobreviventes foi de $46 \%$.

\subsubsection{Descrição dos indicadores das Condições do Ambiente}

As condições do ambiente consistem na estrutura institucional ou conjuntural na qual o negócio está inserido, a qual pode ser percebida e sentida de forma diferente entre as empresas. Brüderl et. al. (1992) observaram que empresas situadas em ambientes altamente competitivos e com elevadas sazonalidades apresentaram índices significativamente menores de sobrevivência. Para constituir esta dimensão foram considerados os seguintes indicadores:
a) Sazonalidade
b) Nível de competição
c) Suporte institucional

- Linhas de crédito e acesso ao crédito

- Qualidade dos serviços públicos

- Apoio de instituições (Sebrae, associações, escolas etc.)

- Ambiente competitivo (lealdade dos competidores, grau de formalidade) 
Tabela 67 - Sazonalidade

\begin{tabular}{lrrrrrr}
\hline \multirow{2}{*}{ Sazonalidade do negócio } & \multicolumn{2}{c}{ Sobreviventes } & & \multicolumn{2}{c}{ Não Sobreviventes } \\
\cline { 2 - 3 } \cline { 6 - 7 } & $\mathbf{F}_{\mathbf{i}}$ & $\mathbf{\%}$ & & $\mathbf{F}_{\mathbf{i}}$ & $\mathbf{\%}$ \\
\hline Muito sazonal & 26 & 7,9 & & 10 & 13,5 \\
Bastante sazonal & 60 & 18,3 & & 20 & 27,0 \\
Razoavelmente sazonal & 134 & 40,9 & & 24 & 32,4 \\
Pouco sazonal & 97 & 29,6 & & 14 & 18,9 \\
Nada sazonal & 11 & 3,4 & & 6 & 8,1 \\
TOTAL & $\mathbf{3 2 6}$ & $\mathbf{1 0 0 , 0}$ & & $\mathbf{7 4}$ & $\mathbf{1 0 0 , 0}$ \\
\hline
\end{tabular}

A sazonalidade é um mecanismo que pode afetar a estabilidade da atividade empresarial, principalmente quando demandas de caixa coincidem com momentos de baixa das receitas. Observa-se, na Tabela 67 , que 40,5\% das empresas não sobreviventes classificaram sua atividade como muito ou bastante sazonal. Nas empresas sobreviventes este índice foi de $26,2 \%$.

Tabela 68 - Competividade

\begin{tabular}{lrrrrrr}
\hline \multirow{2}{*}{ Nível de Competição } & \multicolumn{2}{c}{ Sobreviventes } & & \multicolumn{2}{c}{ Não Sobreviventes } \\
\cline { 2 - 3 } \cline { 6 - 7 } & $\mathbf{F}_{\mathbf{i}}$ & $\mathbf{\%}$ & & $\mathbf{F}_{\mathbf{i}}$ & $\mathbf{\%}$ \\
\hline Altamente competitivo & 103 & 31,0 & & 22 & 29,7 \\
Competitivo & 145 & 43,7 & & 22 & 29,7 \\
Competitividade média & 134 & 17,8 & & 18 & 24,3 \\
Pouco competitivo & 22 & 6,6 & & 12 & 16,3 \\
Nada competitivo & 3 & 0,9 & & - & - \\
TOTAL & $\mathbf{3 3 2}$ & $\mathbf{1 0 0 , 0}$ & & $\mathbf{7 4}$ & $\mathbf{1 0 0 , 0}$ \\
\hline
\end{tabular}

Um outro fator que pode revestir-se de inúmeras facetas em relação ao desempenho das empresas é o nível de competição. Ambientes altamente competitivos podem revelar-se como oportunidades para empresas mais capacitadas prosperarem, enquanto aquelas menos estruturadas e ainda não consolidadas sofrem impactos maiores. Na Tabela 68 observou-se que a distribuição do perfil de competição são equivalentes entres as empresas sobreviventes e não sobreviventes.

Nesta dimensão ainda observaram-se indicadores relacionados ao suporte governamental / institucional. Pequenas e Médias Empresas comumente ressentem-se de quadros capacitados com relação à inúmeras demandas da empresa, como questões tributárias, trabalhistas, jurídicas, isto é, todo o conjunto de burocracias à que a empresa está submetida. Neste sentido, a disponibilidade de suporte institucional (como Sebrae, Universidades, Associações Comerciais, Federações industriais) e de serviços públicos com oferta de um escopo de ações 
que amparem essas carências podem tornar as empresas mais preparadas e sólidas em seus desafios. Especificamente em relação ao suporte governamental, Yusuf (1995) e Van Auken (2006) encontraram evidências de que esse indicador tem papel relevante na sobrevivência e desempenho de PMEs.

Tabela 69 - Suporte Institucional / Governamental

\begin{tabular}{|c|c|c|c|c|c|c|c|}
\hline $\begin{array}{l}\text { No seu setor, ou em termos gerais quando se } \\
\text { refere à pequenas e médias empresas, como você } \\
\text { avalia o suporte governamental / institucional. }\end{array}$ & $\begin{array}{l}\text { Status da } \\
\text { atividade }\end{array}$ & 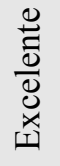 & $\stackrel{\circ}{\varrho}$ & ణ̊ & 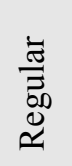 & $\stackrel{\Xi}{\check{\Xi}}$ & $\begin{array}{l}\stackrel{\Xi}{\Xi} \\
\infty \\
\infty\end{array}$ \\
\hline \multirow{2}{*}{ Linhas de crédito e acesso ao crédito } & Sobrevivente & 4 & 4 & 35 & 33 & 14 & 11 \\
\hline & Não Sobrevivente & - & - & 14 & 17 & 46 & 23 \\
\hline \multirow{2}{*}{ Qualidade dos serviços públicos } & Sobrevivente & - & 4 & 26 & 30 & 26 & 14 \\
\hline & Não Sobrevivente & - & - & 3 & 47 & 25 & 25 \\
\hline \multirow{2}{*}{$\begin{array}{l}\text { Apoio de Instituições (Sebrae, Associações, } \\
\text { Federações, Escolas etc.) }\end{array}$} & Sobrevivente & 3 & 14 & 39 & 34 & 7 & 3 \\
\hline & Não Sobrevivente & - & 3 & 43 & 32 & 20 & 3 \\
\hline \multirow{2}{*}{$\begin{array}{l}\text { Ambiente competitivo (lealdade dos } \\
\text { competidores; grau de formalidade) }\end{array}$} & Sobrevivente & 2 & 2 & 27 & 39 & 20 & 10 \\
\hline & Não Sobrevivente & - & - & 28 & 47 & 19 & 6 \\
\hline
\end{tabular}

Obs.: Valores apresentados na forma de frequências relativas (\%)

De forma geral esse conjunto de indicadores (Tabela 69) foi mal avaliado nas escalas "excelente" e "ótimo", obtendo, em três dos quatro indicadores, índices inferiores à 5\%. O indicador "serviços públicos" teve o pior desempenho, onde $40 \%$ das empresas sobreviventes e $50 \%$ das empresas não sobreviventes o avaliaram como "ruim" ou "péssimo". Em termos de suportes institucionais ou governamentais, observa-se que a diferença mais destacada entre os grupos de empresas relaciona-se com "linhas de crédito e acesso ao crédito". Das empresas sobreviventes, $68 \%$ considerou este indicador como bom ou regular, enquanto das não sobreviventes $69 \%$ avaliou como ruim ou péssimo. Quantos aos serviços públicos, ainda que paire ligeira diferença entre os grupos nos critérios excelente, ótimo e bom, de forma geral este indicador foi negativamente avaliado, onde $40 \%$ do primeiro grupo considerou-o ruim ou péssimo, enquanto o índice do segundo grupo foi de $50 \%$.

\subsubsection{Descrição dos indicadores de Motivação e Percepção do Risco}

Shaefer (2012), em um estudo com 10 mil pequenas e médias empresas no Reino Unido, incluiu a razão (motivo) da abertura do negócio como um fator crítico de sucesso. Abrir uma empresa pensando em ganhar muito dinheiro, determinar seu próprio horário de trabalho ou 
não ter que dar satisfação à ninguém revestem-se em equívocos de expectativas, destaca a autora.

Allen (2012) prefere separar os empreendimentos em "empreendedorismo empresarial" e "empreendedorismo de subsistência". Para a autora, os empreendimentos cuja finalidade é garantir a renda do proprietário e da família tendem a rapidamente adquirir um nível operacional e permanecerem estabilizados nele, onde são baixos o crescimento e a inovação. Já o empreendedorismo empresarial pauta-se na inovação, criação de valor e alto crescimento.

Na Tabela 70 observa-se que, das empresas sobreviventes, 62,8\% disseram que sua decisão de empreender pautou-se em uma "oportunidade", enquanto para 37,2\% a "necessidade" melhor representou sua decisão. Estes percentuais estão bastante próximos dos estudos do $\operatorname{GEM}(2010)$, que apresentou índice de 70\% para oportunidade e de 30\% para necessidade. No entanto, este mesmo estudo já havia apresentado uma relação $62 \%$ - 38\% no ano de 2002 .

Tabela 70 - Decisão de empreender: oportunidade versus necessidade

\begin{tabular}{lrrrrrr}
\hline \multirow{2}{*}{$\begin{array}{l}\text { Qual das situações melhor representa } \\
\text { decisão de empreender? }\end{array}$} & sua & \multicolumn{2}{c}{ Sobreviventes } & & \multicolumn{2}{c}{ Não Sobreviventes } \\
\cline { 2 - 3 } \cline { 6 - 7 } Oportunidade & $\mathbf{F}_{\mathbf{i}}$ & $\mathbf{\%}$ & & $\mathbf{F}_{\mathbf{i}}$ & $\mathbf{\%}$ \\
\hline Necessidade & 204 & 62,8 & & 34 & 45,9 \\
TOTAL & 122 & 37,2 & & 40 & 54,1 \\
\hline
\end{tabular}

Entretanto, ao se considerar as empresas não sobreviventes observou-se uma inversão nessa relação, ou seja, 45,9\% disseram que sua decisão de empreender baseou-se em uma oportunidade, enquanto que para 54,1 baseou-se na necessidade.

Tabela 71 - Motivação e decisão de empreender - sobreviventes

\begin{tabular}{|c|c|c|c|c|c|c|}
\hline \multirow{3}{*}{$\begin{array}{l}\text { Motivador de maior destaque na } \\
\text { decisão de empreender }\end{array}$} & \multicolumn{4}{|c|}{ Decisão de Empreender } & \multirow{2}{*}{\multicolumn{2}{|c|}{ TOTAL }} \\
\hline & \multicolumn{2}{|c|}{ Oportunidade } & \multicolumn{2}{|c|}{ Necessidade } & & \\
\hline & $\mathbf{F}_{\mathbf{i}}$ & $\%$ & $\mathbf{F}_{\mathbf{i}}$ & $\%$ & $\mathbf{F}_{\mathbf{i}}$ & $\%$ \\
\hline Garantir a renda e a subsistência familiar & 49 & 24,0 & 64 & 52,5 & 113 & 34,7 \\
\hline Explorar uma oportunidade em potencial & 119 & 58,3 & 34 & 27,4 & 153 & 46,9 \\
\hline Ganhar dinheiro & 36 & 17,6 & 24 & 19,7 & 60 & 18,4 \\
\hline TOTAL & 204 & 100,0 & 122 & 100,0 & 326 & 100,0 \\
\hline
\end{tabular}

Na Tabela 71 é analisada a relação entre decisão e motivação para empreender das empresas sobreviventes. Dos respondentes cuja decisão baseou-se na oportunidade, 58,3\% disseram que 
a motivação principal foi a exploração de uma oportunidade em potencial, $24 \%$ foi motivado pela busca de renda e subsistência da família enquanto 17,6\% tiveram sua motivação centrada em "ganhar dinheiro". Daqueles que pautaram sua decisão na necessidade, $52,5 \%$ foi motivado pela busca da renda e subsistência familiar, 27,4\% intencionava explorar uma oportunidade em potencial enquanto $19,7 \%$ foram motivados pela expectativa de ganhar dinheiro.

Tabela 72 - Motivação e decisão de empreender - não sobreviventes

\begin{tabular}{|c|c|c|c|c|c|c|}
\hline \multirow{3}{*}{$\begin{array}{l}\text { Motivador de maior destaque na } \\
\text { sua decisão de empreender }\end{array}$} & \multicolumn{4}{|c|}{ Decisão de Empreender } & \multirow{2}{*}{\multicolumn{2}{|c|}{ TOTAL }} \\
\hline & \multicolumn{2}{|c|}{ Oportunidade } & \multicolumn{2}{|c|}{ Necessidade } & & \\
\hline & $\mathbf{F}_{\mathbf{i}}$ & $\%$ & $\mathbf{F}_{\mathbf{i}}$ & $\%$ & $\mathbf{F}_{\mathbf{i}}$ & $\%$ \\
\hline Garantir a renda e a subsistência familiar & - & - & 36 & 90,0 & 36 & 48,6 \\
\hline Explorar uma oportunidade em potencial & 22 & 64,7 & 2 & 5,0 & 24 & 32,4 \\
\hline Ganhar dinheiro & 12 & 35,3 & 2 & 5,0 & 14 & 18,9 \\
\hline TOTAL & 34 & 100,0 & 40 & 100,0 & 74 & 100,0 \\
\hline
\end{tabular}

Nas empresas não sobreviventes (Tabela 72), daqueles que pautaram sua decisão na oportunidade, $64,7 \%$ teve como motivador explorar uma oportunidade em potencial, enquanto os $35,5 \%$ restantes pretendiam "ganhar dinheiro". Daqueles que empreenderam por necessidade, $90 \%$ tiveram por motivador a "garantia de renda e a subsistência familiar".

A "percepção de risco" é um indicador que teve por objetivo verificar o grau de risco que os empreendedores atribuem à atividade empresarial. O pressuposto conceitual é de que à medida que aumenta a percepção do risco, as decisões passam a ser mais cautelosas e calculadas, proporcionado melhores chances de sobrevivência. No entanto, a falta de agressividade e de ousadia pode limitar o crescimento da empresa.

Tabela 73 - Percepção de risco

\begin{tabular}{lrrrrrr}
\hline \multirow{2}{*}{ Nível de risco } & \multicolumn{2}{c}{ Sobreviventes } & & \multicolumn{2}{c}{ Não Sobreviventes } \\
\cline { 2 - 3 } \cline { 6 - 7 } & $\mathbf{F}_{\mathbf{i}}$ & $\mathbf{\%}$ & & $\mathbf{F}_{\mathbf{i}}$ & $\mathbf{\%}$ \\
\hline Muito alto & 66 & 20,0 & & 28 & 37,8 \\
Alto & 183 & 55,5 & & 36 & 48,6 \\
Nem alto, nem baixo & 74 & 22,4 & & 10 & 13,5 \\
Baixo & 7 & 2,1 & & - & - \\
Muito baixo & - & - & & - & - \\
TOTAL & $\mathbf{3 3 0}$ & $\mathbf{1 0 0 , 0}$ & & $\mathbf{7 4}$ & $\mathbf{1 0 0 , 0}$ \\
\hline
\end{tabular}


Na Tabela 73 observa-se, de forma geral, que os empreendedores classificaram o risco, na atividade empresarial, como elevado. $\mathrm{Na}$ faixa "muito alto" constatou-se um índice ligeiramente maior das empresas não sobreviventes $(37,8 \%)$ em relação às sobreviventes (20\%). Parte da diferença dessa percepção atribui-se ao efeito ex post facto, decorrente da experiência vivida pelas não sobreviventes.

Tabela 74 - Expectativa de desempenho: antes versus após a abertura

\begin{tabular}{lrrrrrr}
\hline \multicolumn{1}{c}{$\begin{array}{c}\text { Desempenho após abertura } \\
\text { da empresa }\end{array}$} & \multicolumn{2}{c}{ Sobreviventes } & & \multicolumn{2}{c}{ Não Sobreviventes } \\
\cline { 7 - 7 } \cline { 6 - 7 } & $\mathbf{F}_{\mathbf{i}}$ & $\mathbf{\%}$ & & $\mathbf{F}_{\mathbf{i}}$ & $\mathbf{\%}$ \\
\hline Muito acima das expectativas & 88 & 26,9 & & 2 & 2,7 \\
Um pouco acima das expectativas & 50 & 15,3 & & 8 & 10,8 \\
Dentro das expectativas & 152 & 46,5 & & 16 & 21,6 \\
Um pouco abaixo das expectativas & 28 & 8,6 & & 26 & 35,1 \\
Muito baixo das expectativas & 9 & 2,7 & & 22 & 29,7 \\
TOTAL & $\mathbf{3 2 7}$ & $\mathbf{1 0 0 , 0}$ & & $\mathbf{7 4}$ & $\mathbf{1 0 0 , 0}$ \\
\hline
\end{tabular}

Outro fator abordado neste estudo foi o grau de efetivação de expectativas. Dunne et. al. (1985) salientam que as empresas iniciantes podem ter sido constituídas diante de cenários irreais, levando à níveis de desmotivação dependendo do grau de frustração das expectativas.

Com relação à confrontação das expectativas entre antes e depois da constituição da empresa, das sobreviventes $46,5 \%$ disseram que o desempenho obtido depois da abertura esteve dentro do esperado, para $30 \%$ o desempenho foi muito acima da expectativas enquanto para $15,3 \%$ os resultados foram um pouco acima do esperado. Com relação às empresas não sobreviventes, $29,7 \%$ informou que o desempenho esteve muito abaixo do esperado, enquanto para $35,1 \%$ a performance pós abertura ficou um pouco abaixo das expectativas.

\subsubsection{Descrição dos indicadores de Características Organizacionais}

As características organizacionais constituem o perfil intrínseco da organização, incluindo um conjunto de atributos que dá a particularidade à organização, como escolha estratégica, ramo, escopo de abrangência (generalidade versus especialidade), grau de afiliação (empresas afiliadas versus independentes / autônomas), qualidade do staff, relacionamento entre os sócios e nível de inovação. 
Na Tabela 75 verifica-se ligeira predominância de especialidade de escopo, onde $57 \%$ das empresas sobreviventes disseram que o negócio é baseado em produto/serviço especializado. No caso das empresas não sobreviventes esse índice foi de 62,2\%. Brüderl et. al. (1992) concluíram que a sobrevivência das empresas que operavam com uma única ou pequena gama de produtos ou serviços é maior do que aquelas com um portfólio mais amplo.

Tabela 75 - Expectativa de desempenho: antes versus após a abertura

\begin{tabular}{|c|c|c|c|c|}
\hline \multirow{2}{*}{ Escopo de abrangência } & \multicolumn{2}{|c|}{ Sobreviventes } & \multicolumn{2}{|c|}{ Não Sobreviventes } \\
\hline & $\mathbf{F}_{\mathbf{i}}$ & $\%$ & $\mathbf{F}_{\mathbf{i}}$ & $\%$ \\
\hline Produto/serviço especializado & 185 & 57,0 & 46 & 62,2 \\
\hline Diversificado & 140 & 43,0 & 28 & 37,8 \\
\hline TOTAL & 325 & 100,0 & 74 & 100,0 \\
\hline
\end{tabular}

Com relação ao grau de afiliação, Brüderl et. al. (1992) constataram que os negócios afiliados apresentavam maiores chances de longevidade. Nesta pesquisa (Tabela 76), a baixa presença de empresas com características de afiliação dificulta inferências neste quesito. $\mathrm{Na}$ amostra, de forma geral, em torno de $90 \%$ das empresas são caracterizadas como independentes.

Tabela 76 - Afiliação ou Independência do Negócio

\begin{tabular}{lrrrrrr}
\hline \multirow{2}{*}{ Afiliação / Independência } & \multicolumn{2}{c}{ Sobreviventes } & & \multicolumn{3}{c}{ Não Sobreviventes } \\
\cline { 2 - 3 } \cline { 5 - 6 } & $\mathbf{F}_{\mathbf{i}}$ & $\mathbf{\%}$ & & & $\mathbf{F}_{\mathbf{i}}$ & $\mathbf{\%}$ \\
\hline Afiliado (franquia, representação etc.) & 32 & 10,0 & & 5 & 6,9 \\
Independente & 290 & 90,0 & & 67 & 93,1 \\
TOTAL & $\mathbf{3 2 2}$ & $\mathbf{1 0 0 , 0}$ & & $\mathbf{7 4}$ & $\mathbf{1 0 0 , 0}$ \\
\hline
\end{tabular}




\subsection{Teste de Hipóteses - Inferências Parciais}

\subsubsection{Validação do construto "Desempenho"}

A medida de Desempenho de PMEs resultou dos indicadores: LUCRO (percepção do lucro); V_FAT (variação no faturamento); V_EMP (variação no quadro de empregados); PERC_D (percepção do desempenho); SAT_PES (satisfação pessoal); QV (impacto na qualidade de vida pessoal e familiar), CONF (grau de confirmação da escolha do negócio), e; EXPECT (grau de efetivação das expectativas). No teste de alfa de Cronbach obteve-se o coeficiente igual a 0,755 , tornando o construto válido.

Tabela 77 - Matriz de Correlações - Indicadores de Desempenho

\begin{tabular}{|c|c|c|c|c|c|c|c|c|}
\hline & & LUCRO & V_FAT & V_EMP & PERC_D & SAT_P & QV & EXPECT \\
\hline V_FAT & $\begin{array}{l}\rho \\
p \text {-valor } \\
\mathrm{N}\end{array}$ & $\begin{array}{r}0,391^{* *} \\
0,000 \\
313\end{array}$ & & & & & & \\
\hline V_EMP & $\begin{array}{l}\rho \\
p \text {-valor } \\
\mathrm{N}\end{array}$ & $\begin{array}{r}0,028 \\
0,621 \\
309\end{array}$ & $\begin{array}{r}0,390^{* *} \\
0,000 \\
316\end{array}$ & & & & & \\
\hline PERC_D & $\begin{array}{l}\rho \\
p \text {-valor } \\
\mathrm{N}\end{array}$ & $\begin{array}{r}0,074 \\
0,191 \\
315\end{array}$ & $\begin{array}{r}0,341^{* *} \\
0,000 \\
322\end{array}$ & $\begin{array}{r}0,182^{* *} \\
0,001 \\
318\end{array}$ & & & & \\
\hline SAT_PES & $\begin{array}{l}\rho \\
p \text {-valor } \\
\mathrm{N}\end{array}$ & $\begin{array}{r}0,218^{* *} \\
0,000 \\
315\end{array}$ & $\begin{array}{r}0,308^{* *} \\
0,000 \\
322\end{array}$ & $\begin{array}{r}0,276^{* *} \\
0,000 \\
318\end{array}$ & $\begin{array}{r}0,441^{* *} \\
0,000 \\
328\end{array}$ & & & \\
\hline QV & $\begin{array}{l}\rho \\
p \text {-valor } \\
\mathrm{N}\end{array}$ & $\begin{array}{r}0,164^{* *} \\
0,004 \\
311\end{array}$ & $\begin{array}{r}0,284^{* *} \\
0,000 \\
318\end{array}$ & $\begin{array}{r}0,154^{* *} \\
0,006 \\
314\end{array}$ & $\begin{array}{r}0,330^{* *} \\
0,000 \\
324\end{array}$ & $\begin{array}{r}0,478^{* *} \\
0,000 \\
324\end{array}$ & & \\
\hline EXPECT & $\begin{array}{l}\rho \\
p \text {-valor } \\
\mathrm{N}\end{array}$ & $\begin{array}{r}0,174^{* *} \\
0,002 \\
312\end{array}$ & $\begin{array}{r}0,179^{* *} \\
0,001 \\
319\end{array}$ & $\begin{array}{r}0,132^{*} \\
0,019 \\
315\end{array}$ & $\begin{array}{r}0,258^{* *} \\
0,000 \\
325\end{array}$ & $\begin{array}{r}0,437^{* *} \\
0,000 \\
325\end{array}$ & $\begin{array}{r}0,350^{* *} \\
0,000 \\
321\end{array}$ & \\
\hline CONF & $\begin{array}{l}\rho \\
p \text {-valor } \\
\mathrm{N}\end{array}$ & $\begin{array}{r}0,174^{* *} \\
0,002 \\
313 \\
\end{array}$ & $\begin{array}{r}0,217^{* *} \\
0,000 \\
320 \\
\end{array}$ & $\begin{array}{r}0,150^{* *} \\
0,008 \\
316 \\
\end{array}$ & $\begin{array}{r}0,297^{* *} \\
0,000 \\
326 \\
\end{array}$ & $\begin{array}{r}0,401^{* *} \\
0,000 \\
326\end{array}$ & $\begin{array}{r}0,453^{* *} \\
0,000 \\
322 \\
\end{array}$ & $\begin{array}{r}0,355^{* *} \\
0,000 \\
327 \\
\end{array}$ \\
\hline
\end{tabular}

Na matriz de correlações (Tabela 77) observa-se que, dos 27 pares associados, apenas dois não apresentaram significância estatística: V_EMP versus LUCRO e PERC_D versus LUCRO. Isso significa que à medida que o lucro aumenta não necessariamente há aumento do quadro de empregados ou que implique na percepção de melhor desempenho em comparação com as demais empresas.

A partir da validação da confiabilidade da dimensão "desempenho" $(\alpha=0,755)$, onde os oito 
indicadores foram retidos, calcularam-se os escores de cada uma das empresas da amostra. Conforme descrito no capítulo 3, o modelo para obtenção do desempenho de cada uma das empresas foi dado por (equação 3 reapresentada):

$$
D S P_{j}=\sum_{i=1}^{n_{j} \mid n_{j} \succeq 5} \frac{I_{i j}(p)}{n_{j}}
$$

Na Tabela 78 encontra-se a estatística descritiva para a variável "DSP”. Observou-se que o escore (DSP) médio obtido pelas empresas foi 28,8, com desvio-padrão de 4,4. Tem-se, tendo por base a distribuição normal, que cerca de $68 \%$ das empresa amostra estão distribuídas no nível intermediário (entre os grupos "sobrevivência marginal" e "alto desempenho"). O escore mínimo foi de 16 pontos e o máximo de 39 pontos.

Tabela 78 - Estatística descritiva da variável dependente

\begin{tabular}{lr}
\hline \multicolumn{1}{c}{ Estatística } & Valor \\
\hline Média & 28,8 \\
Mediana & 29 \\
Variância & 19,2 \\
Desvio padrão & 4,4 \\
Mínimo & 16 \\
Máximo & 39 \\
Range & 23 \\
Amplitude interquartil & 5,7 \\
Teste de Normalidade (K-S) - p-value & 0,434 \\
\hline
\end{tabular}

Pela distribuição dos escores (Tabela 79) observa-se que 61,5\% das empresas encontram-se na faixa de 24,1 até 32 pontos.

Tabela 79 - Distribuição dos Escores

\begin{tabular}{lrr}
\hline $\begin{array}{c}\text { Classe de Escore } \\
\text { (pontos) }\end{array}$ & \multicolumn{2}{c}{ Sobreviventes } \\
\cline { 2 - 3 } & $\mathbf{F}_{\mathbf{i}}$ & \multicolumn{1}{c}{$\%$} \\
\hline De 8 até 16 & 1 & 0,3 \\
De 16,1 até 24 & 51 & 15,5 \\
De 24,1 até 28 & 92 & 27,9 \\
De 28,1 até 32 & 113 & 33,6 \\
De 32,1 até 36 & 60 & 18,2 \\
Acima de 36 & 13 & 3,9 \\
TOTAL & $\mathbf{3 3 0}$ & $\mathbf{1 0 0 , 0}$ \\
\hline
\end{tabular}


No grupo de empresas com escore igual a 24 pontos ou menos foram classificadas 51 empresas. Como forma de deixar os grupos mais equilibrados, optou-se por classificar como "sobrevivência marginal" as empresas com escore inferior à 25 pontos (ou seja, acrescentando-se 9 décimos à faixa). Assim, os grupos de teste foram definidos conforme Tabela 80.

Tabela 80 - Classificação das empresas

\begin{tabular}{|c|c|c|c|c|}
\hline & mpenho & $\begin{array}{c}\text { Faixa de Escore } \\
\text { (Pontos) }\end{array}$ & $\begin{array}{c}\text { Qtde de } \\
\text { Empresas }\end{array}$ & Cód. \\
\hline \multirow{2}{*}{ Sobreviventes } & Alto Desempenho & 32,1 a 40,0 & 73 & 2 \\
\hline & Sobrevivência Marginal & 8,0 a 24,9 & 66 & 1 \\
\hline \multicolumn{2}{|c|}{ Não Sobreviventes } & 0 & 74 & 0 \\
\hline
\end{tabular}

Na nova configuração verifica-se que foram produzidos grupos mais equilibrados em termos do número de indivíduos incluídos em cada grupo, sendo 74 (18\%) classificadas como "não sobreviventes", 66 (16\%) como "sobrevivência marginal", e 73 (18\%) como "alto desempenho".

\subsubsection{Teste da Hipótese $\mathrm{H}_{0,1}$ - Capital Humano}

Os indicadores considerados neste construto (ESCOL; EXP_OC; EXP_R; EXP_LID; TREIN; HIST_FAM e EXP_ANT) não puderam ser validados no teste de confiabilidade. Dessa forma, cada indicador foi testado individualmente, tanto em relação ao desempenho como em relação ao modelo geral, com uso das estatísticas: regressão linear múltipla [variável de teste: DSP (escala contínua)], regressão logística binária [variável de teste - grupos: $0=$ empresa não sobrevivente; 1 = empresa sobrevivente (escala binária)] e regressão logística multinomial [variável de teste - grupos: 0 = "não sobrevivente"; 1 = "sobrevivência marginal", e: 2 = "alto de desempenho" (escala nominal)].

Nenhum dos indicadores desta dimensão demonstrou-se significativo para explicar o desempenho mediante uso da regressão linear múltipla.

Para realização da Regressão Logística as variáveis foram recodificadas (Tabela 81). Com isso todas as variáveis do modelo assumiram escala "nominal". 
Tabela 81 - Ajuste dos indicadores de Capital Humano para regressão logística

\begin{tabular}{|c|c|c|c|c|c|}
\hline Indicador & Classe & Ordem & Dummy & \multicolumn{2}{|c|}{ Código } \\
\hline \multirow{3}{*}{ Escolaridade } & Fundamental & 1 & ESCOL(1) & 1 & 0 \\
\hline & Ensino Médio & 2 & $\operatorname{ESCOL}(2)$ & 0 & 1 \\
\hline & Superior ou mais & 3 & ESCOL & 0 & 0 \\
\hline \multirow{3}{*}{$\begin{array}{l}\text { Experiência } \\
\text { Ocupacional }\end{array}$} & Nada até 1 ano & 1 & EXP_OC(1) & 1 & 0 \\
\hline & De 1 a 5 anos & 2 & EXP_OC(2) & 0 & 1 \\
\hline & Mais de 5 anos & 3 & EXP_OC & 0 & 0 \\
\hline \multirow{3}{*}{$\begin{array}{l}\text { Experiência no } \\
\text { Ramo }\end{array}$} & Nada até 1 ano & 1 & EXP_R & 1 & 0 \\
\hline & De 1 a 5 anos & 2 & EXP_R(1) & 0 & 1 \\
\hline & Mais de 5 anos & 3 & EXP_R(2) & 0 & 0 \\
\hline \multirow{3}{*}{$\begin{array}{l}\text { Experiência em } \\
\text { Liderança }\end{array}$} & Nada até 1 ano & 1 & EXP_LID(1) & 1 & 0 \\
\hline & De 1 a 5 anos & 2 & EXP_LID(2) & 0 & 1 \\
\hline & Mais de 5 anos & 3 & EXP_LID & 0 & 0 \\
\hline \multirow{3}{*}{ Treinamento } & Até 12 horas/ano & 1 & TREIN & 1 & 0 \\
\hline & De 12 a 36 horas & 2 & TREIN(1) & 0 & 1 \\
\hline & Mais de 36 horas & 3 & TREIN(2) & 0 & 0 \\
\hline Histórico Familiar & Binária (Sim/Não) & 1 & HIST_FAM & 1 & 0 \\
\hline Experiência Anterior & Binária (Sim/Não) & 1 & EXP_ANT & 1 & 0 \\
\hline
\end{tabular}

No modelo final do teste de regressão logística binária $(1=$ sobrevivência; $0=$ não sobrevivência) foram retidos os indicadores: EXP_OC; EXP_R e HIST_FAM. Pelo teste de coeficientes de Omnibus, o modelo mostrou-se válido $\left(G^{2}=40,366 ; p<0,001\right)$. No teste de Hosmer e Lemeshow verificou-se que os dados estiveram aderentes ao modelo $\left(x^{2}=6,569 ; p\right.$ $=0,475)$. Os pseudo- $R^{2}$ de Cox $\&$ Snell $(0,094)$ e Nagelkerke $(0,154)$ proporcionam potência fraca ao modelo.

Tabela 82 - Coeficientes do modelo logístico - Capital Humano

\begin{tabular}{|c|c|c|c|c|c|c|c|c|}
\hline \multirow{2}{*}{ Modelo } & \multirow{2}{*}{$\boldsymbol{\beta}$} & \multirow{2}{*}{$\begin{array}{c}\text { Erro } \\
\text { Padrão }\end{array}$} & \multirow{2}{*}{ Wald } & \multirow{2}{*}{$g l$} & \multirow{2}{*}{ Sig. } & \multirow{2}{*}{$e^{\beta}$} & \multicolumn{2}{|c|}{$95 \%$ IC para $e^{\beta}$} \\
\hline & & & & & & & Inferior & Superior \\
\hline EXP_R & & & 13,062 & 2 & 0,001 & & & \\
\hline EXP_R(1) & $-2,139$ & 0,751 & 8,120 & 1 & 0,004 & 0,118 & 0,027 & 0,513 \\
\hline EXP_R(2) & $-1,258$ & 0,797 & 2,489 & 1 & 0,115 & 0,284 & 0,060 & 1,356 \\
\hline HIST_FAM & 0,586 & 0,299 & 3,844 & 1 & 0,050 & 1,796 & 1,000 & 3,225 \\
\hline EXP_OC & & & 12,769 & 2 & 0,002 & & & \\
\hline EXP_OC(1) & 1,001 & 0,442 & 5,132 & 1 & 0,023 & 2,721 & 1,144 & 6,468 \\
\hline EXP_OC(2) & $-0,505$ & 0,303 & 2,786 & 1 & 0,045 & 0,603 & 0,333 & 1,092 \\
\hline Constante & 3,076 & 0,727 & 17,897 & 1 & 0,000 & 21,671 & & \\
\hline
\end{tabular}

Na Tabela 82 pode ser observado que se o empreendedor possui histórico familiar, as chances de sobrevivência aumentam 79,6\%. Brüderl et. al. (1992) encontraram que essa experiência aumenta em $85 \%$ as chances de sobrevivência nos dois primeiros anos e de $55 \%$ nos cinco primeiros anos. Lussier (1995) também identificou influência significativa do histórico familiar na sobrevivência e desempenho dos negócios. Fairlie e Robb (2009) apontam que a 
experiência em negócio da família é determinante do desempenho, tanto para o gênero masculino, como feminino.

De forma semelhante, as chances de sobrevivência da empresa diminuem $88,2 \%$ se a experiência no ramo (EXP_R) passa da categoria 3 (Mais de 5 anos) para a categoria 1 (Nada ou menos de 1 ano). Brüderl et. al. (1992), em estudo com amostra de 716 empresas não sobreviventes e 1.077 sobreviventes, identificaram que se o empreendedor não possui experiência no ramo, suas chances de sobrevivência diminuem em 59,6\% nos dois primeiros anos de vida da empresa, e de 53,7\% nos cinco anos iniciais. Van Gelderen et. al. (2006) identificaram que a experiência no ramo mostrou-se determinante no sucesso da empresa.

Ainda na dimensão do Capital Humano, se a experiência ocupacional variar da categoria 3 (mais de 10 anos) para a categoria 2 (de 1 a 10 anos) as chances de sobrevivência diminuem em 39,7\%. Entretanto, a variação entre EXP_OC e EXP_OC(1) apresentou probabilidade não esperada, ou seja, se o tempo de experiência no ramo passar da categoria 3 (mais de 10 anos) para a categoria 1 (nada ou menos de 1 ano), as chances de sobrevivência aumentam em 172\%. Watson et. al. (1998) encontraram evidências da influência da experiência ganha no emprego anterior, como ter trabalhado mais de 10 anos em tempo integral no último emprego.

No Gráfico 6 verifica-se um índice maior de sobreviventes (28\%) em relação aos não sobreviventes (11\%) na faixa que inclui nenhuma experiência ocupacional ou menor que um ano.

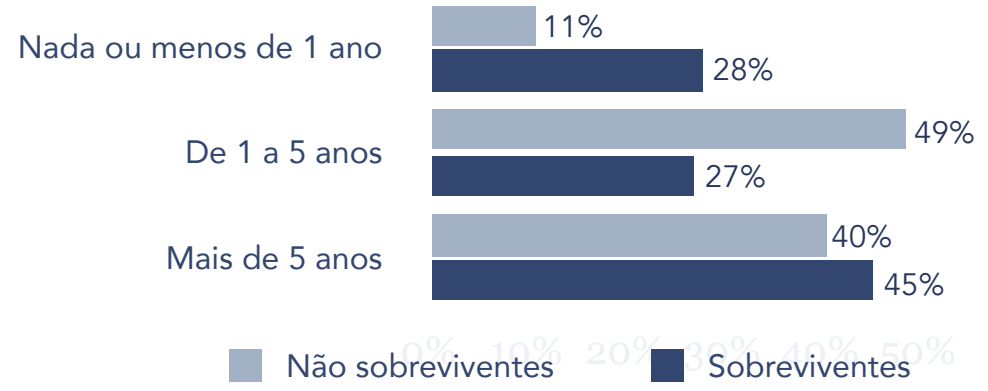

Gráfico 6 - Experiência ocupacional e sobrevivência

O modelo conseguiu classificar corretamente $82,7 \%$ dos casos. A área sob a curva ROC foi 0,714 ( $p<0,001$ ), demonstrando que o modelo discrimina em grau aceitável os sobreviventes dos não sobreviventes. 
Tendo por base os resultados analisados, rejeita-se a hipótese nula para os indicadores EXP_OC, EXP_R e HIST_FAM, nos testes de sobrevivência e não sobrevivência.

Para testar o efeito destes indicadores sobre o desempenho (grupos), foi utilizada a regressão logística multinominal incluindo as categorias de desempenho: a) não sobrevivência; b) sobrevivência marginal, e; c) alto desempenho. A estrutura de dados de entrada desse modelo é a mesma utilizada na regressão logística binária (vide Tabela 81).

Tabela 83 - Informações de ajuste do modelo multinominal - Capital Humano

\begin{tabular}{lcccccc}
\hline \multirow{2}{*}{ Modelo } & $\begin{array}{c}\text { Critérios de ajuste } \\
\text { de modelo }\end{array}$ & & \multicolumn{3}{c}{$\begin{array}{c}\text { Testes de razão de } \\
\text { verossimilhança }\end{array}$} \\
\cline { 2 - 3 } & $\begin{array}{c}\text { Verossimilhança } \\
\text { de log }-2\end{array}$ & & $\begin{array}{c}\text { Qui- } \\
\text { quadrado }\end{array}$ & gl & Sig. \\
\hline Modelo nulo & 413,371 & & & & \\
Modelo completo & 317,864 & & 95,507 & 24 & 0,000 \\
\hline
\end{tabular}

Na Tabela 83 observa-se que existe pelo menos um indicador capaz de discriminar os grupos: 0 = não sobrevivente; 1 = sobrevivência marginal, e; 2 = alto desempenho. $\mathrm{O}$ dados apresentaram-se ajustados ao modelo nos testes de Qui-quadrado de Pearson $\left(x^{2}=32,29 ; p=\right.$ $0,249)$ e Deviance $\left(x^{2}=12,29 ; p=0,249\right)$. Os pseudo- $R^{2}$ de Cox e Snell $(0,367)$, Nagelkerke $(0,413)$ e McFadden $(0,209)$ proporcionam poder intermediário ao modelo.

Tabela 84 - Teste de razão de verossimilhança

\begin{tabular}{|c|c|c|c|c|}
\hline \multirow{2}{*}{ Efeito } & \multirow{2}{*}{$\begin{array}{c}\begin{array}{c}\text { Critérios de ajuste de } \\
\text { modelo }\end{array} \\
-2 \text { LL do modelo } \\
\text { reduzido }\end{array}$} & \multicolumn{3}{|c|}{$\begin{array}{l}\text { Testes de razão de } \\
\text { verossimilhança }\end{array}$} \\
\hline & & $\begin{array}{c}\text { Qui- } \\
\text { quadrado }\end{array}$ & $g l$ & Sig. \\
\hline Constante & $317,864^{\mathrm{a}}$ & 0,000 & 0 & - \\
\hline ESCOL & 321,735 & 3,871 & 4 & 0,424 \\
\hline EXP_OC & 352,821 & 34,957 & 4 & 0,000 \\
\hline EXP_R & 338,199 & 20,335 & 4 & 0,000 \\
\hline EXP_LID & 323,943 & 6,080 & 4 & 0,193 \\
\hline TREIN & 333,951 & 16,088 & 4 & 0,003 \\
\hline HIST_FAM & 332,966 & 15,102 & 2 & 0,001 \\
\hline EXP_ANT & 320,348 & 2,485 & 2 & 0,289 \\
\hline
\end{tabular}

Obs.: A estatística de qui-quadrado é a diferença nas verossimilhanças de log -2 entre o modelo final e um modelo reduzido. O modelo reduzido é formado pela omissão de um efeito do modelo final. A hipótese nula significa que todos os parâmetros desse efeito são nulos.

a) Esse modelo reduzido é equivalente ao modelo final porque a omissão do efeito não aumenta os graus de liberdade.

Pelo teste de razão de verossimilhança (Tabela 84) constatou-se que a experiência ocupacional (EXP_OC), a experiência no ramo (EXP_R), o nível de treinamento (TREIN) e o 
histórico familiar (HIST_FAM) apresentam capacidade discriminante para os grupos.

Tabela 85 - Coeficientes do modelo logístico multinominal - Capital Humano

\begin{tabular}{|c|c|c|c|c|c|c|c|c|c|}
\hline \multirow{2}{*}{\multicolumn{2}{|c|}{ Grupo / Modelo }} & \multirow[b]{2}{*}{$\beta$} & \multirow[b]{2}{*}{$\begin{array}{l}\text { Erro } \\
\text { padrão }\end{array}$} & \multirow[b]{2}{*}{ Wald } & \multirow[b]{2}{*}{ gl } & \multirow[b]{2}{*}{ Sig. } & \multirow[b]{2}{*}{$e^{\beta}$} & \multicolumn{2}{|c|}{ IC $95 \%$ para $e^{\beta}$} \\
\hline & & & & & & & & $\begin{array}{c}\text { Limite } \\
\text { inferior }\end{array}$ & $\begin{array}{c}\text { Limite } \\
\text { superior }\end{array}$ \\
\hline \multirow{8}{*}{ 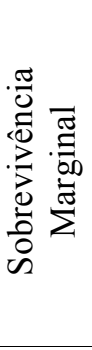 } & Constante & 3,008 & 1,034 & 8,460 & 1 & 0,004 & & & \\
\hline & EXP_OC(1) & 0,286 & 0,579 & 0,244 & 1 & 0,621 & 1,331 & 0,428 & 4,142 \\
\hline & EXP_OC(2) & $-2,836$ & 0,623 & 20,744 & 1 & 0,000 & 0,059 & 0,017 & 0,199 \\
\hline & EXP_R(1) & $-1,593$ & 0,864 & 3,401 & 1 & 0,045 & 0,203 & 0,037 & 1,105 \\
\hline & $\mathrm{EXP}^{-} \mathrm{R}(2)$ & $-0,734$ & 0,933 & 0,619 & 1 & 0,431 & 0,480 & 0,077 & 2,988 \\
\hline & TREĪN(1) & $-2,080$ & 0,723 & 8,273 & 1 & 0,004 & 0,125 & 0,030 & 0,516 \\
\hline & TREIN(2) & $-2,417$ & 0,798 & 9,174 & 1 & 0,002 & 0,089 & 0,019 & 0,426 \\
\hline & HIST_FAM & 1,856 & 0,483 & 14,754 & 1 & 0,000 & 6,398 & 2,482 & 16,496 \\
\hline \multirow{8}{*}{ 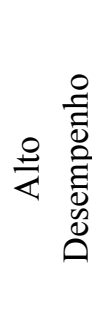 } & Constante & 3,538 & 988 & 12,824 & 1 & 0,000 & & & \\
\hline & EXP_OC(1) & 1,242 & 0,583 & 4,545 & 1 & 0,033 & 3,463 & 1,105 & 10,850 \\
\hline & EXP_OC(2) & $-0,812$ & 0,508 & 2,557 & 1 & 0,110 & 0,444 & 0,164 & 1,201 \\
\hline & $\mathrm{EXP}^{-} \mathrm{R}(1)$ & $-2,594$ & 0,846 & 9,408 & 1 & 0,002 & 0,075 & 0,014 & 0,392 \\
\hline & $\mathrm{EXP}_{-}^{-} \mathrm{R}(2)$ & $-1,221$ & 0,888 & 1,891 & 1 & 0,169 & 0,295 & 0,052 & 1,680 \\
\hline & TREIN(1) & $-2,281$ & 0,671 & 11,548 & 1 & 0,001 & 0,102 & 0,027 & 0,381 \\
\hline & TREIN(2) & $-1,886$ & 0,727 & 6,741 & 1 & 0,009 & 0,152 & 0,036 & 0,630 \\
\hline & HIST_FAM & 1,179 & 0,445 & 7,029 & 1 & 0,008 & 3,251 & 1,360 & 7,773 \\
\hline
\end{tabular}

Obs.: Categoria de referência: [0] não sobreviventes

Na Tabela 85 observa-se que as chances de uma empresa não sobrevivente (0) passar para a classe sobrevivência marginal (1) aumenta 5,4 vezes $\left(e^{\beta}=6,398 ; p<0,001\right)$ se o empreendedor possuir histórico familiar na atividade empreendedora. $\mathrm{O}$ indicador também apresenta discriminação significativa para o grupo alto desempenho $\left(e^{\beta}=3,251 ; p=0,008\right)$. Cooper et. al. (1994) encontraram evidências de poder de discriminação do histórico familiar apenas para o grupo "sobrevivência marginal", enquanto para o grupo "alto desempenho" a variável não foi discriminante.

Não possuir experiência ocupacional ou se ela for menor que 1 ano não afeta a probabilidade de se passar do grupo não sobrevivente para sobrevivência marginal. Entretanto, se o empreendedor possuir de um a cinco anos de experiência ocupacional ao invés de mais de 5 anos, as chances de que a empresa passe do grupo 0 para o grupo 1 diminuem $4,15 \%\left(e^{\beta}=\right.$ 0,059; $p<0,001)$. Para o caso do treinamento, se a média anual de treinamento for de até 12 horas comparativamente com "mais de 36 horas", as chances (de passagem do grupo 0 para 1 ) diminuem em $87,5 \%\left(e^{\beta}=0,125 ; p=0,004\right)$ e, se estiver na classe 12 a 36 horas as chances diminuem 91\% $\left(e^{\beta}=0,089 ; p=0,008\right)$. Ainda, possuir menos de 1 anos de experiência no ramo comparativamente à possuir mais de cinco anos diminuem em $80 \%\left(e^{\beta}=0,203 ; p=\right.$ $0,045)$ as chances de passagem do grupo 0 para grupo 1 . 
A experiência ocupacional, ao se comparar grupo não sobreviventes (0) com o grupo alto desempenho (2) não apresentou os efeitos esperados (as chances de alto desempenho aumentam quando diminui a experiência ocupacional). Quanto ao indicador experiência no ramo, possuir menos de 1 ano ao invés de possuir mais de 5 anos reduz em $92,5 \%\left(e^{\beta}=0,075\right.$; $p=0,002)$ a probabilidade de passagem do grupo 0 ao grupo 2 . Ainda, possuir média anual de treinamento menor que 12 horas, ou menor que 36 horas, comparativamente com mais de 36 horas, diminui em $90 \%\left(e^{\beta}=0,102 ; p=0,001\right)$ e $85 \%\left(e^{\beta}=0,15 ; p=0,009\right)$, respectivamente, a chance da empresa passa de não sobrevivente para alto desempenho.

Tabela 86 - Sumário dos testes de hipótese - Capital Humano

\begin{tabular}{|c|c|c|c|c|c|c|}
\hline \multirow[t]{2}{*}{ Indicador } & \multicolumn{3}{|c|}{$\begin{array}{l}\text { Sobrevivência versus } \\
\text { Não Sobrevivência }\end{array}$} & \multicolumn{3}{|c|}{ Desempenho } \\
\hline & Teste & $\mathbf{H}_{\mathbf{0}}$ & $\mathrm{H}_{1}$ & Teste & $\mathbf{H}_{\mathbf{0}}$ & $\mathbf{H}_{1}$ \\
\hline Escolaridade & & $\mathbf{\square}$ & & & $\mathbf{\square}$ & \\
\hline Experiência Ocupacional & & & 口 & & & 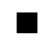 \\
\hline Experiência no Ramo & Regressão & & $\mathbf{\square}$ & Reoressão L ooística & & 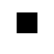 \\
\hline Experiência em Liderança & Logística & $\square$ & & $\begin{array}{c}\text { Regressáo Logistica } \\
\text { Multinomial }\end{array}$ & $\mathbf{\square}$ & \\
\hline Treinamento & Binária & $\mathbf{\square}$ & & & & \\
\hline Histórico Familiar & & & $\boldsymbol{\square}$ & & & $\square$ \\
\hline Experiência Anterior & & $\mathbf{\square}$ & & & $\mathbf{\square}$ & \\
\hline
\end{tabular}

Pela Tabela 86 verifica-se que as hipóteses nulas foram rejeitadas para os indicadores EXP_OC, EXP_R, TREIN e HIST_FAM e mantidas para ESCOL, EXP_LID e EXP_ANT. Como houve pelo menos um indicador significativo, rejeita-se a hipótese nula para Capital Humano $\left(\mathrm{H}_{0,1}\right)$.

\subsubsection{Teste da Hipótese $\mathrm{H}_{0,2}$ - Capital Social}

Neste construto foram incluídos os indicadores relacionados com a disponibilidade, fontes e acesso aos recursos necessários para constituição de desenvolvimento do negócio. Dos 10 indicadores definidos para esta dimensão, cinco foram retidos no teste de confiabilidade interna $(\alpha=0,887)$ :

1) R_BANK - Relacionamento da empresa com banco(s)

2) REC_CRED - Reciprocidade com o banco (qualidade no atendimento)

3) VOL_CRED - Volume de crédito acessado pela empresa

4) DIF_CRED - Grau de obstrução do crédito por parte do banco

5) IMP_CRED - Impacto do custo e da dificuldade de crédito na expansão do negócio 
Pela matriz de correlações (Tabela 87) observou-se elevada associação entre dos indicadores de Capital Social retidos, tornando o construto bastante robusto.

Tabela 87 - Matriz de Correlações - Capital Social

\begin{tabular}{|c|c|c|c|c|c|}
\hline & & R_BANK & REC_CRED & VOL_CRED & DIF_CRED \\
\hline REC_CRED & $\begin{array}{l}\rho \\
p \text {-valor } \\
\mathrm{N}\end{array}$ & $\begin{array}{r}0,557^{* *} \\
0,000 \\
335\end{array}$ & & & \\
\hline VOL_CRED & $\begin{array}{l}\rho \\
p \text {-valor } \\
\mathrm{N}\end{array}$ & $\begin{array}{r}0,592^{* *} \\
0,000 \\
342\end{array}$ & $\begin{array}{r}0,765^{* *} \\
, 000 \\
331\end{array}$ & & \\
\hline DIF_CRED & $\begin{array}{l}\rho \\
p \text {-valor } \\
\mathrm{N}\end{array}$ & $\begin{array}{r}-0,547^{* *} \\
0,000 \\
344\end{array}$ & $\begin{array}{r}-0,752^{* *} \\
0,000 \\
328\end{array}$ & $\begin{array}{r}-0,693^{* *} \\
0,000 \\
337\end{array}$ & \\
\hline IMP_CRED & $\begin{array}{l}\rho \\
p \text {-valor } \\
\mathrm{N}\end{array}$ & $\begin{array}{r}-0,480^{* *} \\
, 000 \\
330\end{array}$ & $\begin{array}{r}-0,550^{* *} \\
000 \\
314\end{array}$ & $\begin{array}{r}-0,557^{* *} \\
0,000 \\
321\end{array}$ & $\begin{array}{r}0,613^{* *} \\
0,000 \\
328\end{array}$ \\
\hline
\end{tabular}

O construto deste conjunto de indicadores foi formado pelo escore resultante da análise fatorial, baseada na matriz de correlações e componentes principais. A medida de KaiserMeyer-Olkin de adequação da amostra $(K M O=0,857)$ e o teste de esfericidade de Bartlet $\left(x^{2}\right.$ $=910,63 ; p<0,001)$ asseguram a validade da AF.

Tabela 88 - Análise Fatorial - Capital Social

\begin{tabular}{lcccc}
\hline Indicadores & Comunalidades & $\begin{array}{c}\text { Anti-imagem } \\
\text { MSA }\end{array}$ & $\begin{array}{c}\text { Componentes } \\
\text { Extraídos }\end{array}$ & $\begin{array}{c}\text { Coeficientes dos } \\
\text { Componentes }\end{array}$ \\
\hline R_BANK & 0,603 & 0,927 & 0,883 & 0,220 \\
REC_CRED & 0,780 & 0,811 & 0,878 & 0,252 \\
VOL_CRED & 0,768 & 0,842 & 0,877 & 0,250 \\
DIF_CRED & 0,772 & 0,848 & 0,770 & 0,251 \\
IMP_CRED & 0,688 & 0,897 & 0,767 & 0,219 \\
\hline
\end{tabular}

Na Tabela 88 observa-se que, em média, mais de 70\% da variância de cada indicador foi explicada pelo modelo (comunalidades). Igualmente verifica-se a adequação de cada indicador no modelo $(M S A>0,5)$. Os componentes extraídos possuem cargas fatoriais elevadas e os coeficientes demonstram que o escore fatorial foi constituído por pesos homogêneos dentre o conjunto de indicadores. 
Tabela 89 - Variância Total Extraída: Capital Social

\begin{tabular}{|c|c|c|c|c|c|c|}
\hline \multirow{2}{*}{ Componente } & \multicolumn{3}{|c|}{ Autovalores iniciais } & \multicolumn{3}{|c|}{$\begin{array}{c}\text { Somas da extração dos } \\
\text { carregamentos ao quadrado }\end{array}$} \\
\hline & Total & $\begin{array}{c}\text { \% de } \\
\text { variância }\end{array}$ & $\begin{array}{c}\% \\
\text { cumulativa }\end{array}$ & Total & $\begin{array}{c}\text { \% de } \\
\text { variância }\end{array}$ & $\begin{array}{c}\% \\
\text { cumulativa }\end{array}$ \\
\hline 1 & 3,501 & 70,028 & 70,028 & 3,501 & 70,028 & 70,028 \\
\hline 2 &, 525 & 10,493 & 80,521 & & & \\
\hline 3 & ,472 & 9,432 & 89,953 & & & \\
\hline 4 & ,304 & 6,079 & 96,032 & & & \\
\hline 5 & , 198 & 3,968 & 100,000 & & & \\
\hline
\end{tabular}

O construto "Capital Social" resultante dos cinco indicadores, explica, individualmente, 70\% da variância total do conjunto dos indicadores (Tabela 89). Como as variáveis estão todas correlacionadas entre si, ainda que se tenha ajustado o software para retenção de um único fator, por propriedade o autovalor determinaria uma única dimensão.

Para testar os efeitos do capital social sobre o desempenho da empresa foi utilizada a regressão múltipla.

Tabela 90: Regressão múltipla: Valores de entrada - Capital Social

\begin{tabular}{lllll}
\hline \multicolumn{2}{c}{ Variáveis } & Tipo & Escala & \multicolumn{1}{c}{ Método } \\
\hline \multirow{2}{*}{ Dependente } & DSP & Construto & Razão & Escala somada \\
& CAP_SOC & Construto & Razão & Escore fatorial \\
\multirow{3}{*}{ Independentes } & D_CAP & Indicador & Likert & Likert (5 pt) \\
& EMP_AB & Indicador & Likert & Likert (5 pt) \\
& FORN & Indicador & Likert & Likert (5 pt) \\
& SERV_ESP & Indicador & Likert & Likert (4 pt) \\
\hline
\end{tabular}

Pelo método de entradas, as variáveis não significativas foram sendo excluídas até a obtenção do modelo final, que apresentou um poder de explicação de $18 \%(F=30,507 ; p<0,001)$.

Tabela 91 - Coeficientes da regressão ${ }^{\mathrm{a}}$ : Capital Social

\begin{tabular}{|c|c|c|c|c|c|}
\hline \multirow{2}{*}{ Modelo } & \multicolumn{2}{|c|}{$\begin{array}{c}\text { Coeficientes não } \\
\text { padronizados }\end{array}$} & \multirow{2}{*}{$\begin{array}{c}\text { Coeficientes } \\
\text { padronizados } \\
\text { Beta }\end{array}$} & \multirow{2}{*}{$\mathbf{t}$} & \multirow{2}{*}{ Sig. } \\
\hline & $\boldsymbol{\beta}$ & $\begin{array}{c}\text { Erro } \\
\text { padrão }\end{array}$ & & & \\
\hline (Constante) & 31,731 & 2,379 & & 13,337 & 0,000 \\
\hline CAP_SOC & $-3,906$ & 0,682 & $-0,325$ & $-5,725$ & 0,000 \\
\hline SERV ESP & $-2,820$ & 0,727 & $-0,220$ & $-3,880$ & 0,000 \\
\hline
\end{tabular}

a) Variável dependente: DSP 
Na Tabela 91 verifica-se que o construto "capital social" (CAP_SOC) explica 32,5\% das variâncias, enquanto o nível de uso de serviço especializado explica $22 \%$. Como o construto e o indicador estão na escala inversa, o sinal obtido está de acordo com o esperado. $\mathrm{O}$ modelo estimado é expresso por:

$$
D S P=31,73-3,91\left(\mathrm{CAP} \_\mathrm{SOC}\right)-2,82\left(\mathrm{SERV} \_\mathrm{ESP}\right)
$$

Os resultados demonstraram que à medida que aumenta o relacionamento com bancos e o acesso ao crédito, melhora o desempenho da empresa. Os estudos realizados pelo SEBRAE (2008) destacam que a falta de crédito foi apontado, pelas empresas não sobreviventes, como o principal motivo da descontinuidade. Bruno et. al. (1987) relatam que um dos principais motivos de falência das empresas foi "tomar dinheiro emprestado muito cedo". Carter e Van Auken (2006), em um estudo com 25 variáveis com potencial explicação sobre os problemas nos negócios, concluíram que a disponibilidade de (a) "empréstimos para negócios", (b) "capital próprio" e (c) "empréstimos pessoais", além dos "altos custos dos empréstimos" são determinantes da sobrevivência das empresas. As evidências sobre dos efeitos do capital social sobre o desempenho foram reportados também por Barsley e Kleiner (1990), Wight (1985), Vesper (1990), Lussier e Corman (1996), Lauzen (1985), Fotopoulos e Louri (2000), Headd (2003), Schaefer (2012).

Além da regressão linear, em que a variável dependente foi dada na escala contínua, utilizouse a regressão logística considerando dois estados para a variável dependente: 0 (não sobrevivente); 1 ( sobrevivente). Os indicadores tipo likert de 5 ou 4 pontos foram ajustados para escala de 3 pontos. Após os ajustes iniciais extraíram-se os indicadores aprovados pelos testes do modelo de Omnibus $\left(x^{2}=46,521 ; p<0,001\right)$. Os dados se ajustam ao modelo, conforme teste de Hosmer e Lemeshow $\left(x^{2}=13,837 ; p=0,122\right)$.

Tabela 92 - Coeficientes do modelo logístico - Capital Social

\begin{tabular}{lrcrccccc}
\hline & $\boldsymbol{\beta}$ & $\begin{array}{c}\text { Erro } \\
\text { Padrão }\end{array}$ & Wald & gl & Sig. & $\boldsymbol{e}^{\boldsymbol{\beta}}$ & \multicolumn{2}{c}{ IC 95\% para $\boldsymbol{e}^{\boldsymbol{\beta}}$} \\
\cline { 6 - 9 } & & & & & & Inferior & Superior \\
\hline SERV_ESP (1)* & 1,165 & 0,553 & 4,441 & 1 & 0,035 & 3,205 & 1,085 & 9,465 \\
CAP_SOC & $-0,893$ & 0,164 & 29,513 & 1 & 0,000 & 0,409 & 0,297 & 0,565 \\
Constante & 1,476 & 0,184 & 64,390 & 1 & 0,000 & 4,375 & & \\
\hline
\end{tabular}

(*) SERV_ESP(1): Muito Frequente 
O teste $-2 L L(258,102)$, os pseudo- $R^{2}$ de Cox e Snell $(0,139)$ e de Nagelkerke $(0,223)$ e o teste de Wald $\left(\right.$ Wald $\left.=98,548 ; p<0,001 ; e^{\beta}=4,167\right)$ sugerem que o modelo é valido porém com potência limitada.

Na Tabela 92 observa-se que a cada unidade de piora de avaliação da dimensão de Capital Social (CAP_SOC) a chances de sobrevivências são reduzidas em $60 \%\left(e^{\beta}=0,409 ; p<\right.$ 0,001). Com relação ao uso de serviços especializados (SERV_ESP) como o Sebrae, Universidades, Escolas e Associações, verifica-se que quando o empreendedor utiliza com muita frequência as chances de sobrevivência aumentam 2,2 vezes $\left(e^{\beta}=3,205 ; p=0,035\right)$ comparativamente ao nível de uso "muito pouco ou raramente utilizado". Nos estudos de Cooper et. al. (1994) os serviços profissionais apresentaram capacidade discriminatória entre os grupos "não sobreviventes" e "sobrevivência marginal". Nos estudos de Barsley e Kleiner (1990), Gaskill et. al. (1993), Van Gelderen et. al. (2006), Lussier (1995), Vesper (1990), Wight (1985), Lussier e Pfeifer (2001), os "serviços profissionais (especializados)" foram discriminantes da sobrevivência das empresas.

O modelo, no teste da curva $R O C$, apresentou bom poder discriminatório $(c=0,779 ; p<$ 0,001). A equação estimada é dada por:

$$
\operatorname{Logit}(\pi)=1,476+1,165\left[\operatorname{SERV} \_\operatorname{ESP}(1)\right]-0,893\left(\mathrm{CAP} \_\mathrm{SOC}\right)
$$

Os impactos dos indicadores de capital social também foram medidos levando em consideração os três grupos de desempenho: a) não sobreviventes; b) sobrevivência marginal, e; c) alto desempenho. A estatística de teste utilizada foi a regressão logística multinominal. As variáveis de entrada foram as mesmas utilizadas no modelo binário. Pelos coeficientes dos testes de verossimilhança $\left(G^{2}=58,855 ; \mathrm{p}<0,001\right)$ contatou-se que existe pelo menos um indicador capaz de discriminar os grupos: não sobrevivente (0), sobrevivência marginal (1) e alto desempenho (2). O dados apresentaram-se ajustados ao modelo nos testes de Pearson $\left(x^{2}\right.$ $=12,35 ; p=0,176)$ e Deviance $\left(x^{2}=10,51 ; p=0,219\right)$. Os pseudo- $\mathrm{R}^{2}$ de Cox e Snell $(0,326)$, Nagelkerke $(0,368)$ e McFadden $(0,182)$ proporcionam poder de fraco à intermediário ao modelo. 
Tabela 93 - Teste de $G^{2}$ de significância das variáveis

\begin{tabular}{|c|c|c|c|c|}
\hline \multirow[b]{2}{*}{ Efeito } & \multirow{2}{*}{$\begin{array}{c}\text { Critérios de ajuste } \\
-2 L L\end{array}$} & \multicolumn{3}{|c|}{ Testes de razão de verossimilhança } \\
\hline & & $G^{2}$ & df & Sig. \\
\hline Constante & $264,851^{\mathrm{a}}$ & 0,000 & 0 & \\
\hline CAP_SOC & 290,787 & 25,936 & 2 & 0,000 \\
\hline SERV_ESP & 266,353 & 1,502 & 2 & 0,472 \\
\hline EMP $\bar{C}$ & 278,591 & 13,740 & 4 & 0,008 \\
\hline D CĀP & 278,215 & 13,364 & 4 & 0,010 \\
\hline
\end{tabular}

Obs.: A estatística de qui-quadrado é a diferença nas verossimilhanças de $\log -2$ entre o modelo final e um modelo reduzido. O modelo reduzido é formado pela omissão de um efeito do modelo final. A hipótese nula significa que todos os parâmetros desse efeito são nulos.

a) Esse modelo reduzido é equivalente ao modelo final porque a omissão do efeito não aumenta os graus de liberdade.

Constatou-se que o construto capital social (CAP_SOC), o nível de empréstimos (EMP_C) e a disponibilidade de capital (D_CAP) para constituição do negócio apresentaram capacidade discriminante para os grupos.

Tabela 94 - Coeficientes do modelo multinominal - Capital Social

\begin{tabular}{|c|c|c|c|c|c|c|c|c|c|}
\hline \multirow{2}{*}{\multicolumn{2}{|c|}{ Grupo/Modelo }} & \multirow{3}{*}{$\begin{array}{c}\boldsymbol{\beta} \\
0,463\end{array}$} & \multirow{3}{*}{$\begin{array}{c}\begin{array}{c}\text { Erro } \\
\text { padrão }\end{array} \\
0,449\end{array}$} & \multirow{3}{*}{$\begin{array}{c}\text { Wald } \\
1,061\end{array}$} & \multirow{3}{*}{$\begin{array}{c}\text { gl } \\
1\end{array}$} & \multirow{3}{*}{$\begin{array}{c}\text { Sig. } \\
0,303\end{array}$} & \multirow{3}{*}{$e^{\boldsymbol{\beta}}$} & \multicolumn{2}{|c|}{ IC de $95 \%$ para $\mathrm{e}^{\beta}$} \\
\hline & & & & & & & & \multirow{2}{*}{$\begin{array}{c}\text { Limite } \\
\text { inferior }\end{array}$} & \multirow{2}{*}{$\begin{array}{c}\text { Limite } \\
\text { superior }\end{array}$} \\
\hline \multirow{6}{*}{ 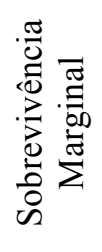 } & Constante & & & & & & & & \\
\hline & CAP_SOC & $-0,616$ & 0,221 & 7,749 & 1 & 0,005 & 0,540 & 0,350 & 0,833 \\
\hline & EMP_C(1) & 1,739 & 0,580 & 8,995 & 1 & 0,003 & 5,689 & 1,827 & 17,721 \\
\hline & EMP_C(2) & $-0,070$ & 0,620 & 0,013 & 1 & 0,910 & 0,932 & 0,276 & 3,144 \\
\hline & D_CAP(1) & $-1,459$ & 0,664 & 4,826 & 1 & 0,028 & 0,232 & 0,063 & 0,854 \\
\hline & D_CAP(2) & 0,207 & 0,524 & 0,156 & 1 & 0,693 & 1,230 & 0,441 & 3,433 \\
\hline \multirow{6}{*}{ 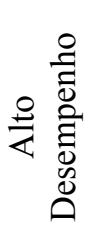 } & Constante & $-0,612$ & 0,522 & 1,375 & 1 & 0,241 & & & \\
\hline & CAP_SOC & $-1,172$ & 0,255 & 21,160 & 1 & 0,000 & 0,310 & 0,188 & 0,510 \\
\hline & EMP_C(1) & 2,034 & 0,720 & 7,971 & 1 & 0,005 & 7,641 & 1,862 & 31,349 \\
\hline & EMP_C(2) & 0,900 & 0,696 & 1,674 & 1 & 0,196 & 2,461 & 0,629 & 9,626 \\
\hline & D_CAP(1) & $-1,412$ & 0,678 & 4,331 & 1 & 0,037 & 0,244 & 0,064 & 0,921 \\
\hline & D_CAP(2) & $-1,431$ & 0,652 & 4,817 & 1 & 0,028 & 0,239 & 0,067 & 0,858 \\
\hline
\end{tabular}

Obs.: Categoria de referência: [0] não sobreviventes

Na Tabela 94 verifica-se que a probabilidade de uma empresa não sobrevivente (0) passar para o grupo sobrevivência marginal (1) diminui $46 \%\left(e^{\beta}=0,54 ; p=0,005\right)$ a cada unidade de deterioração do capital social (CAP_SOC). Com relação à utilização de empréstimos constata-se que as chances de mudança de grupo (0 para 1) aumentam 4,7 $\left(e^{\beta}=5,689 ; p=\right.$ 0,003) vezes se o empreender não utilizou nada de empréstimos [EMP_C(1)] em comparação com aquele que utilizou mais de 40\% (EMP_C). Em termos de disponibilidade de capital para abertura do negócio verifica-se que as chances de passagem de grupo ( 0 para 1$)$ diminuem $76,8 \%\left(e^{\beta}=0,232 ; p=0,028\right)$ se o empreendedor possuía apenas uma parte dos recursos para abertura do negócio (D_CAP) em comparação com aqueles que possuíam todos os recursos [D_CAP(1)]. 
$\mathrm{Na}$ análise do grupo de não sobreviventes (0) com o grupo de alto desempenho (2), verifica-se que as chances de mudança de grupo (0 para 2$)$ diminuem em $69 \%\left(e^{\beta}=0,31 ; p<0,001\right)$ a cada unidade de deterioração do capital social (CAP_SOC). Outro impacto significativo é com relação ao uso de empréstimos para abertura do negócio, cuja probabilidade de passagem de "não sobreviventes" para "alto desempenho" aumenta 6,6 vezes $\left(e^{\beta}=7,641 ; p=0,005\right)$ se o empreendedor não utilizou nada de empréstimos comparativamente àquele que usou mais de $40 \%$. Esse ponto está diretamente associado com o nível de disponibilidade de recursos para abertura da empresa, onde se observa que as chances da empresa mudar de grupo (0 para 2) diminuem $75,6 \%\left(e^{\beta}=0,244 ; p=0,037\right)$ se a empresa possuir apenas uma parte dos recursos em comparação com àquela que possui todos os recursos.

As constatações desta pesquisa, no contexto do capital social, convergem com as evidências descritas na literatura (BARSLEY e KLEINER, 1990; BRUNO et. al, 1987; VAN GELDEREN et. al., 2006; LUZEN, 1985; WATSON et. al, 1998). Schaefer (2012) ressalta que a insuficiência de capital é um "erro fatal comum" na descontinuidade de inúmeras empresas. Os empreendedores subestimam a necessidade de recursos, e quando estes são requisitados, as chances de obtê-los em tempo são reduzidas. Outro viés são as expectativas não realísticas de obtenção de receitas e lucros no início da atividade (id). Cooper et. al. (1994) analisaram o capital investido em relação às receitas obtidas no primeiro ano e concluíram que as chances de sobrevivência e de desempenho melhoram à medida que essa relação aumenta.

Tabela 95 - Classificações corretas - Capital Social

\begin{tabular}{lcccc}
\hline \multirow{2}{*}{ Observado } & \multicolumn{4}{c}{ Previsto } \\
\cline { 2 - 5 } & $\begin{array}{c}\text { Não } \\
\text { Sobreviventes }\end{array}$ & $\begin{array}{c}\text { Sobrevivência } \\
\text { Marginal }\end{array}$ & $\begin{array}{c}\text { Alto } \\
\text { Desempenho }\end{array}$ & $\begin{array}{c}\text { Porcentagem } \\
\text { correta }\end{array}$ \\
\hline Não Sobreviventes & 44 & 8 & 8 & $73,3 \%$ \\
Sobrevivência Marginal & 19 & 19 & 10 & $39,6 \%$ \\
Alto Desempenho & 11 & 7 & 25 & $58,1 \%$ \\
Porcentagem global & $49,0 \%$ & $22,5 \%$ & $28,5 \%$ & $58,3 \%$ \\
\hline
\end{tabular}

Na Tabela 95 verifica-se que o modelo classificou corretamente 58,3\% das empresas, sendo 5,4 vezes mais eficiente que as classificações por acaso (10,77\%). O grupo de melhor classificação foi o "não sobreviventes", onde de 60 empresas 44 foram classificadas corretamente, 8 foram classificadas no grupo "sobrevivência marginal" e 8 no grupo alto 
desempenho. A menor eficiência na classificação foi o grupo "sobrevivência marginal", onde um total de 48 empresas apenas 19 foram classificadas corretamente. No entanto, outras 19 $(39,6 \%)$ foram classificadas no grupo "não sobreviventes" que muitas vezes apresentam perfis muito próximos.

Tabela 96 - Sumário dos testes de hipótese - Capital Social

\begin{tabular}{|c|c|c|c|c|c|c|}
\hline \multirow[t]{2}{*}{ Indicador } & \multicolumn{3}{|c|}{$\begin{array}{l}\text { Sobrevivência versus } \\
\text { Não Sobrevivência }\end{array}$} & \multicolumn{3}{|c|}{ Desempenho } \\
\hline & Teste & $\mathbf{H}_{0}$ & $\mathrm{H}_{1}$ & Teste & $\mathbf{H}_{\mathbf{0}}$ & $\mathrm{H}_{1}$ \\
\hline Disponibilidade de Capital na abertura do negócio & RLB $^{1}$ & a & & $\mathrm{RLM}^{2}$ & & $\mathbf{\square}$ \\
\hline Uso de empréstimos na abertura & RLB & a & & RLM & & [ \\
\hline Nível de Fornecedores & RLB & - & & RLM & a & \\
\hline Giro de Fornecedores & RLB & घ & & RLM & घ & \\
\hline Relacionamento com banco(s) & RLB & & घ & RLM, OLS ${ }^{3}$ & & घ \\
\hline Grau de uso de serviços especializados & RLB & & $\mathbf{\square}$ & RLM, OLS & & $\mathbf{\square}$ \\
\hline Reciprocidade de crédito & RLB & & घ & RLM, OLS & & घ \\
\hline Volume de crédito acessado & RLB & & घ & RLM, OLS & & घ \\
\hline Nível de obstrução do crédito & RLB & & घ & RLM, OLS & & घ \\
\hline Impacto do acesso e custo do crédito & RLB & & a & RLM, OLS & & a \\
\hline
\end{tabular}

1) RLB: Regressão Logística Binária; 2) Regressão Logística Multinomial; 3) Ordinary Least Squares

Pela Tabela 96 verifica-se que do conjunto de 10 indicadores, oito demonstraram-se significantes na determinação da sobrevivência e desempenho das PMEs (rejeitou-se $\mathrm{H}_{0}$ ). Não foi possível rejeitar a hipótese nula dos indicadores nível de fornecedores (FORN) e giro de fornecedores (G_FORN).

\subsubsection{Teste da Hipótese $\mathrm{H}_{0,3}$ - Características Gerenciais}

Do conjunto de nove indicadores definidos para constituir a dimensão "Características Gerenciais", cinco foram retidos pelo teste de confiabilidade $(\alpha=0,859)$ e estão estreitamente relacionados com os aspectos do planejamento antes da abertura do negócio (PLAN_AB):

a) PESQ_MERC - Pesquisa de mercado e potenciais clientes

b) PESQ_FORN - Identificação e contato com os principais fornecedores

c) PESQ_AMB - Pesquisa do ambiente: concorrentes, preços etc.

d) PESQ_LOC - Análise da adequação da localização

e) PESQ_VEF - Estudos de viabilidade econômica e financeira 
Tabela 97 - Matriz de Correlações dos indicadores de Planejamento antes da abertura

\begin{tabular}{|c|c|c|c|c|c|}
\hline & & PESQ_MERC & PESQ_FORN & PESQ_AMB & PESQ_LOC \\
\hline PESQ_FORN & $\begin{array}{l}\rho \\
p \text {-valor } \\
\mathrm{N}\end{array}$ & $\begin{array}{r}0,586^{* *} \\
0,000 \\
381\end{array}$ & & & \\
\hline PESQ_AMB & $\begin{array}{l}\rho \\
p \text {-valor } \\
\mathrm{N}\end{array}$ & $\begin{array}{r}0,584^{* *} \\
0,000 \\
379\end{array}$ & $\begin{array}{r}0,564^{* *} \\
0,000 \\
379\end{array}$ & & \\
\hline PESQ_LOC & $\begin{array}{l}\rho \\
p \text {-valor } \\
\mathrm{N}\end{array}$ & $\begin{array}{r}0,543^{* *} \\
0,000 \\
368\end{array}$ & $\begin{array}{r}0,493^{* *} \\
0,000 \\
366\end{array}$ & $\begin{array}{r}0,575^{* *} \\
0,000 \\
364\end{array}$ & \\
\hline PESQ_VEF & $\begin{array}{l}\rho \\
p \text {-valor } \\
\mathrm{N}\end{array}$ & $\begin{array}{r}0,544^{* *} \\
0,000 \\
377\end{array}$ & $\begin{array}{r}0,490^{* *} \\
0,000 \\
375\end{array}$ & $\begin{array}{r}0,547^{* *} \\
0,000 \\
373\end{array}$ & $\begin{array}{r}0,647^{* *} \\
0,000 \\
364\end{array}$ \\
\hline
\end{tabular}

O construto "Planejamento antes da abertura - PLAN_AB" foi determinado pelo escore resultante da análise fatorial, validada pelo $K M O(0,853)$ e Bartlet $\left(x^{2}=741,08 ; p<0,001\right)$.

Tabela 98 - Análise Fatorial: PLAN_AB

\begin{tabular}{lcccc}
\hline Indicadores & Comunalidades & $\begin{array}{c}\text { Anti-imagem } \\
\text { MSA }\end{array}$ & $\begin{array}{c}\text { Componentes } \\
\text { Extraídos }\end{array}$ & $\begin{array}{c}\text { Coeficientes dos } \\
\text { Componentes }\end{array}$ \\
\hline PESQ_MERC & 0,653 & 0,863 & 0,822 & 0,252 \\
PESQ_FORN & 0,694 & 0,868 & 0,808 & 0,241 \\
PESQ_AMB & 0,651 & 0,868 & 0,807 & 0,252 \\
PESQ_LOC & 0,675 & 0,828 & 0,793 & 0,257 \\
PESQ_VEF & 0,629 & 0,843 & 0,771 & 0,248 \\
\hline
\end{tabular}

Na Tabela 98 observa-se que aproximadamente 65\% das variâncias de cada um dos indicadores foram captadas. O teste de MSA confirmou a adequação de cada um dos itens à dimensão testada, resultando em cargas fatoriais elevadas e coeficientes homogêneos.

Tabela 99 - Variância Total Extraída: PLAN_AB

\begin{tabular}{|c|c|c|c|c|c|c|}
\hline \multirow{2}{*}{ Componente } & \multicolumn{3}{|c|}{ Autovalores iniciais } & \multicolumn{3}{|c|}{$\begin{array}{c}\text { Somas da extração dos } \\
\text { carregamentos ao quadrado }\end{array}$} \\
\hline & Total & $\begin{array}{c}\text { \% de } \\
\text { variância }\end{array}$ & $\begin{array}{c}\% \\
\text { cumulativa }\end{array}$ & Total & $\begin{array}{c}\text { \% de } \\
\text { variância }\end{array}$ & $\begin{array}{c}\% \\
\text { cumulativa }\end{array}$ \\
\hline 1 & 3,202 & 64,048 & 64,048 & 3,202 & 64,048 & 64,048 \\
\hline 2 & 0,594 & 11,879 & 75,928 & & & \\
\hline 3 & 0,446 & 8,918 & 84,845 & & & \\
\hline 4 & 0,414 & 8,273 & 93,119 & & & \\
\hline 5 & 0,344 & 6,881 & 100,000 & & & \\
\hline
\end{tabular}

A variância total explicada pelo construto foi de $64 \%$, que pode ser classificada como de boa representação. 
Dos demais indicadores de Características Gerenciais associados com os aspectos de registro, controle e custos financeiros das PMEs, apenas ANT_REC (grau de utilização de recebíveis) e JURO (grau do custo de financiamento das empresas) apresentaram correlação elevada ( $\rho=$ $0,515 ; p<0,001)$ e tiveram a confiabilidade validada $(\alpha=0,716)$. As correlações dos indicadores estão demonstrado na Tabela 99.

Tabela 100 - Matriz de correlações: registros, controles e custos financeiros

\begin{tabular}{|c|c|c|c|c|c|}
\hline & & DSP & CONT_FCX & ANT_REC & INAD \\
\hline CONT_FCX & $\begin{array}{l}\rho \\
p \text {-valor } \\
\mathrm{N}\end{array}$ & $\begin{array}{r}0,232^{* *} \\
0,000 \\
400\end{array}$ & & & \\
\hline ANT_REC & $\begin{array}{l}\rho \\
p \text {-valor } \\
\mathrm{N}\end{array}$ & $\begin{array}{r}0,150^{* *} \\
0,003 \\
379\end{array}$ & $\begin{array}{r}0,063 \\
0,222 \\
382\end{array}$ & & \\
\hline INAD & $\begin{array}{l}\rho \\
p \text {-valor } \\
\mathrm{N}\end{array}$ & $\begin{array}{r}0,198^{* *} \\
0,000 \\
388\end{array}$ & $\begin{array}{r}0,157^{* *} \\
0,002 \\
391\end{array}$ & $\begin{array}{r}0,167^{* *} \\
0,001 \\
377\end{array}$ & \\
\hline JURO & $\begin{array}{l}\rho \\
p \text {-valor } \\
\mathrm{N}\end{array}$ & $\begin{array}{r}0,329^{* *} \\
0,000 \\
363\end{array}$ & $\begin{array}{r}0,382^{* *} \\
0,000 \\
366\end{array}$ & $\begin{array}{r}0,515^{* *} \\
0,000 \\
359\end{array}$ & $\begin{array}{r}0,264^{* *} \\
0,000 \\
360\end{array}$ \\
\hline
\end{tabular}

Observa-se (Tabela 100) que todos os indicadores de registro, controle e custos financeiros estão significativamente associados com o desempenho (DSP) das empresas. Devido ao teste de confiabilidade todas as escalas foram ajustadas de modo que não se verificam correlações negativas. Os sinais obtidos estão em linha com os pressupostos conceituais.

Como hipoteticamente esperado, a antecipação de recebíveis, não raras vezes, converte-se em uma fonte onerosa de financiamento para a empresa, o que foi confirmado pela associação positiva JURO (custo de financiamento), ou seja, quanto maior a intensidade de uso dessa fonte, mais elevado é seu custo.

Esperava-se que a antecipação de recebíveis resultasse da deficiência de registro e controle dos fluxos de caixa (CONT_FCX), o que acabou não se confirmando. Entretanto, a inadimplência mostrou associação significativa com antecipação, dando evidências de que os problemas com inadimplência podem levar as empresas à utilizarem antecipação de recebíveis.

Para suprimir o problema da multicolinearidade de ANT_REC e JURO, utilizou-se o escore fatorial da combinação desses indicadores (os pressupostos da AF foram atendidos), 
resultante no fator/dimensão FIN_CP (Financiamento de Curto Prazo), cuja variância total explicada foi de $76 \%$.

Para testar a influência conjunta dessas sub-dimensões e indicadores, foi utilizada a regressão linear múltipla, a partir da seguinte estrutura de entrada apresentada na Tabela 101.

Tabela 101: Regressão múltipla: Valores de entrada - Características Gerenciais

\begin{tabular}{lllll}
\hline \multicolumn{2}{c}{ Variáveis } & Tipo & Escala & \multicolumn{1}{c}{ Método } \\
\hline \multirow{2}{*}{ Dependente } & DSP & Construto & Razão & Escala somada \\
& PLAN_AB & Construto & Razão & Escore fatorial \\
\multirow{3}{*}{ Independentes } & FIN_CP & Construto & Razão & Escore fatorial \\
& CONT_FCX & Indicador & Likert & Likert (6 pt) \\
& INAD & Indicador & Likert & Likert $(6 \mathrm{pt})$ \\
\hline
\end{tabular}

No modelo regressor testado, os indicadores CONT_FCX e INAD não apresentaram significância estatística, sendo excluídos.

O poder de explicação do modelo foi de $17,4 \%$, e pode ser validado pelo teste de ANOVA (F $=32,694 ; \mathrm{p}<0,001)$. Na Tabela 102 verifica-se que os construtos PLAN_AB e FIN_CP demonstraram-se significativos e com os sinais esperados.

Tabela 102 - Coeficientes da regressão ${ }^{\mathrm{a}}$ : Características Gerenciais

\begin{tabular}{|c|c|c|c|c|c|}
\hline \multirow{2}{*}{ Modelo } & \multicolumn{2}{|c|}{$\begin{array}{c}\text { Coeficientes não } \\
\text { padronizados }\end{array}$} & \multirow{2}{*}{$\begin{array}{c}\begin{array}{c}\text { Coeficientes } \\
\text { padronizados }\end{array} \\
\text { Beta } \\
\end{array}$} & \multirow{2}{*}{$\mathbf{t}$} & \multirow{2}{*}{ Sig. } \\
\hline & $\boldsymbol{\beta}$ & $\begin{array}{c}\text { Erro } \\
\text { padrão }\end{array}$ & & & \\
\hline (Constante) & 23,236 & 0,628 & & 37,017 & 0,000 \\
\hline FIN_CP & 2,721 & 0,617 & 0,231 & 4,408 & 0,000 \\
\hline PLANN_AB & 3,819 & 0,644 & 0,311 & 5,931 & 0,000 \\
\hline
\end{tabular}

a) Variável dependente: DSP

Pelo resultado conclui-se, levando em conta apenas a dimensão relacionada às características gerenciais, que 17\% do desempenho (DSP) das PMEs pode ser explicado pelo planejamento que o empreendedor realiza antes da abertura do negócio (PLAN_AB) e pelo nível de uso de fontes onerosas no financiamento das necessidades de curto prazo (FIN_CP). Verifica-se, também, que PLAN_AB tem maior poder explicativo (31\%) em relação à FIN_CP (23\%), ou seja, para cada unidade de variância do desempenho (DSP) os construtos PLAN_AB e FIN_CP explicam 0,311 e 0,231 respectivamente. Sendo $\alpha$, PLAN_AB e FIN_CP significantes, o modelo estimado resultante foi: 


$$
D S P=23,24+3,819\left(\mathrm{PLAN}_{-} \mathrm{AB}\right)+2,721\left(\mathrm{FIN} \_\mathrm{CP}\right)
$$

Em estudo com 10 mil pequenas empresas do Reino Unido, Schaefer (2012) identificou sete armadilhas que podem levar a empresa ao insucesso. O plano de negócio, neste conjunto, figura com peça crítica: a falência de muitos dos pequenos negócios está diretamente associada com a deficiência do seu processo de planejamento. Lussier (1995), em uma amostra com 216 empresas (108 sobreviventes e 108 não sobreviventes) concluiu que a chance de falência da empresa decaía a cada nível adicional de detalhamento no processo de planejamento. Misumoto et. al. (2010), a partir de uma amostra com 2.016 empresas paulistas, concluíram que a "busca de informações antes da abertura da empresa" foi um aspecto que discriminante da sobrevivência dos negócios.

Carter e Van Auken (2006), a partir de uma amostra com 110 empresas (55 sobreviventes e 55 não sobreviventes), além das evidências dos impactos do planejamento, também concluíram que "fluxos de caixa pobres", "registros e controles financeiros deficientes" e "altos custos de empréstimos" impactam a sobrevivência das empresas.

Adicionalmente foi testado o poder de discriminação dos indicadores desta dimensão com relação aos grupos de (1) empresas sobreviventes e (2) não sobreviventes, por meio do uso da regressão logística. Os valores de entrada do modelo estão apresentados na Tabela 103.

Tabela 103 - Ajuste dos indicadores para regressão logística binária

\begin{tabular}{|c|c|c|c|c|c|}
\hline Indicador & Classe & Ordem & Variável & \multicolumn{2}{|c|}{ Código } \\
\hline \multirow{3}{*}{$\begin{array}{l}\text { Problemas com } \\
\text { Inadimplência }\end{array}$} & Sempre / quase sempre & 1 & INAD(1) & 1 & 0 \\
\hline & Muitas vezes / algumas vezes & 2 & INAD $(2)$ & 0 & 1 \\
\hline & Raramente / nunca & 3 & INAD & 0 & 0 \\
\hline \multirow{3}{*}{$\begin{array}{l}\text { Controle de Fluxo de } \\
\text { Caixa }\end{array}$} & Sempre / quase sempre & 1 & CONT_CX(1) & 1 & 0 \\
\hline & Muitas vezes / algumas vezes & 2 & CONT_CX(2) & 0 & 1 \\
\hline & Raramente / nunca & 3 & CONT_CX & 0 & 0 \\
\hline Planejamento & Escala razão (escore fatorial) & & PLAN_AB & & \\
\hline Financiamento $\mathrm{CP}$ & Escala razão (escore fatorial) & & FIN CP & & \\
\hline
\end{tabular}

Os testes de coeficientes de Omnibus $\left(G^{2}=45,066 ; p<0,001\right)$ sustentam a adequação do modelo. A estimação de -2LL $(265,629)$ e os pseudo- $R^{2}$ de Cox e Snell $(0,135)$ e Nagelkerke $(0,214)$ indicam que os resultados sejam considerados com parcimônia. O teste de Hosmer e Lemeshow $\left(x^{2}=12,191 ; p=0,143\right)$ demonstrou que os dados se ajustam ao modelo. 
Tabela 104 - Coeficientes do modelo logístico binário - Características Gerenciais

\begin{tabular}{|c|c|c|c|c|c|c|c|c|}
\hline \multirow{2}{*}{ Modelo } & \multirow{2}{*}{$\beta$} & \multirow{2}{*}{$\begin{array}{c}\text { Erro } \\
\text { Padrão }\end{array}$} & \multirow{2}{*}{ Wald } & \multirow{2}{*}{$g l$} & \multirow{2}{*}{ Sig. } & \multirow{2}{*}{$e^{\beta}$} & \multicolumn{2}{|c|}{$95 \%$ IC para $e^{\beta}$} \\
\hline & & & & & & & Inferior & Superior \\
\hline PLAN_AB & $-0,778$ & 0,174 & 19,990 & 1 & 0,000 & 0,459 & 0,326 & 0,646 \\
\hline FIN_CP & 0,432 & 0,156 & 7,684 & 1 & 0,006 & 1,540 & 1,135 & 2,091 \\
\hline INAD & & & 6,840 & 2 & 0,033 & & & \\
\hline INAD(1) & 0,469 & 0,565 & 691 & 1 & 0,406 & 1,599 & 0,529 & 4,836 \\
\hline INAD(2) & $-0,656$ & 0,352 & 3,573 & 1 & 0,050 & 0,519 & 0,261 & 1,034 \\
\hline Constante & 1,972 & 0,292 & 45,490 & 1 & 0,000 & 7,182 & & \\
\hline
\end{tabular}

Na Tabela 104 observa-se que o planejamento antes da abertura (PLAN_AB) apresentou o maior poder de explicação $\left(X^{2}\right.$ Wald $\left.=19,990 ; p<0,001\right)$. As chances de sobrevivência da empresa diminuem $54 \%\left(e^{\beta}=0,459\right)$ a cada unidade de deterioração de PLAN_AB. Com relação às fontes e custo de financiamento de curto prazo, as chances de sobrevivência aumentam em $54 \%\left(e^{\beta}=1,540 ; p=0,006\right)$ a cada unidade de melhora deste indicador (FIN_CP), ou seja, à medida que a empresa diminui o uso de antecipação de recebíveis e pagamento de juros elevados, a probabilidade de sobrevivência aumenta.

Ainda que a forma mais agressiva de problemas com inadimplência tenha sido superada pelo uso de cartões de débito ou crédito, em regiões e municípios menos desenvolvidos é recorrente a prática do crédito direto (como caderninho e cheques pré-datados). $\mathrm{Na}$ amostra esse efeito foi captado e está associado probabilisticamente com a sobrevivência das empresas, onde as chances (de sobrevivência) diminuem em $48 \%\left(e^{\beta}=0,519 ; p=0,050\right)$ se a empresa se encontrar na categoria "muitas vezes ou algumas vezes" $[\operatorname{INAD}(2)]$ ao invés da categoria "raramente ou nunca" [INAD].

O modelo classificou corretamente $83,6 \%$ das observações e, no teste da curva ROC, apresentou bom poder discriminatório $(c=0,755 ; p<0,001)$. A equação estimada é dada por:

$$
\operatorname{Logit}(\widehat{\pi})=1,972-0,778\left(P L A N \_A B\right)+0,432\left[F I N \_(C P)\right]-0,656[I N A D(2)]
$$

Como visto anteriormente, para testar a discriminação por grupos de desempenho (não sobrevivência, sobrevivência marginal e alto desempenho), foi utilizada a regressão logística multinomial. Os valores de entrada foram os mesmos do modelo logístico binário.

Tabela 105 - Informações de ajuste do modelo multinominal - Capital Social

\begin{tabular}{lcccccc}
\hline \multirow{2}{*}{ Modelo } & \multicolumn{2}{c}{ Critérios de ajuste } & & \multicolumn{3}{c}{ Testes de verossimilhança } \\
\cline { 2 - 2 } & $\mathbf{- 2 L \boldsymbol { L }}$ & & $\boldsymbol{G}^{\mathbf{2}}$ & gl & Sig. \\
\hline Somente da constante & 351,604 & & & & \\
Final & 286,721 & & 64,884 & 8 & 0,000 \\
\hline
\end{tabular}


Na Tabela 105 observa-se que existe pelo menos um indicador capaz de discriminar os grupos: não sobrevivente (0), sobrevivência marginal (1) e alto desempenho (2). Os pseudo$R^{2}$ de Cox e Snell $(0,332)$, Nagelkerke $(0,374)$ e McFadden $(0,185)$ proporcionam poder de fraco à intermediário ao modelo, devendo ser considerado com limitações.

Os construtos "planejamento antes da abertura" (PLAN_AB) e "fontes e financiamento de curto prazo" (FIN_CP), e o indicador inadimplência (INAD) apresentaram capacidade discriminante para os grupos.

Tabela 106 - Coeficientes do modelo multinominal - Capital Social

\begin{tabular}{|c|c|c|c|c|c|c|c|c|c|}
\hline \multirow{2}{*}{\multicolumn{2}{|c|}{ Grupo/Modelo }} & \multirow{3}{*}{$\begin{array}{c}\boldsymbol{\beta} \\
0,141\end{array}$} & \multirow{3}{*}{$\begin{array}{c}\begin{array}{c}\text { Erro } \\
\text { padrão }\end{array} \\
0,396\end{array}$} & \multirow{3}{*}{$\begin{array}{l}\text { Wald } \\
0,127\end{array}$} & \multirow{3}{*}{$\begin{array}{c}\boldsymbol{g l} \\
1\end{array}$} & \multirow{3}{*}{$\begin{array}{c}\text { Sig. } \\
0,722\end{array}$} & \multirow{3}{*}{$e^{\beta}$} & \multicolumn{2}{|c|}{ IC de $95 \%$ para $e^{\beta}$} \\
\hline & & & & & & & & \multirow{2}{*}{$\begin{array}{c}\text { Limite } \\
\text { inferior }\end{array}$} & \multirow{2}{*}{$\begin{array}{c}\text { Limite } \\
\text { superior }\end{array}$} \\
\hline \multirow{5}{*}{ 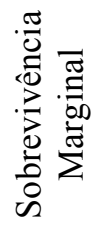 } & Constante & & & & & & & & \\
\hline & PLAN_AB & $-0,652$ & 0,243 & 7,222 & 1 & 0,007 & 0,521 & 0,324 & 0,838 \\
\hline & FIN_CP & 0,141 & 0,206 & 0,466 & 1 & 0,495 & 1,151 & 0,768 & 1,725 \\
\hline & INAD̄ $(1)$ & 0,763 & 0,686 & 1,235 & 1 & 0,266 & 2,145 & 0,558 & 8,235 \\
\hline & $\operatorname{INAD}(2)$ & $-0,466$ & 0,478 & 0,950 & 1 & 0,330 & 0,628 & 0,246 & 1,601 \\
\hline \multirow{5}{*}{  } & Constante & 0,550 & 0,386 & 2,035 & 1 & 0,154 & & & \\
\hline & PLAN AB & $-1,336$ & 0,273 & 23,894 & 1 & 0,000 & 0,263 & 0,154 & 0,449 \\
\hline & FIN_CP & 0,689 & 0,248 & 7,684 & 1 & 0,006 & 1,991 & 1,224 & 3,240 \\
\hline & INAD̄ $(1)$ & $-0,595$ & 0,841 & 0,501 & 1 & 0,479 & 0,551 & 0,106 & 2,866 \\
\hline & INAD(2) & $-1,198$ & 0,499 & 5,766 & 1 & 0,016 & 0,302 & 0,113 & 0,802 \\
\hline
\end{tabular}

Obs.: Categoria de referência: [0] não sobreviventes

Na Tabela 106 constata-se que as chances de passagem do grupo "não sobrevivente" (0) para o grupo "sobrevivência marginal" diminuem 48\% a cada unidade de deterioração dos níveis de planejamento realizado antes da abertura (PLAN_AB). Os demais itens discriminatórios destes dois grupos ( 0 e 1) não apresentaram significância estatística.

Na segunda parte da Tabela 106 verifica-se uma discriminação mais densa. A probabilidade de passagem da empresa do grupo "não sobrevivente" (0) para o grupo "alto desempenho" (2) diminui $73,7 \%$ a cada unidade de deterioração do nível de planejamento realizado antes da abertura (PLAN_AB). No caso dos custos financeiros, a chance dessa passagem (grupo 0 para 2) aumenta 99\% a cada unidade a menos de uso da combinação "antecipação de recebíveis e juros elevados" (FIN_CP). Para o caso dos problemas com inadimplência, se a empresa está na categoria "muitas vezes ou algumas vezes" ao invés da categoria "raramente ou nunca" sua chance de mudança de grupo (0 para 2 ) diminui $70 \%$. 
Tabela 107 - Classificações corretas - Características Gerenciais

\begin{tabular}{lcccc}
\hline \multirow{2}{*}{ Observado } & \multicolumn{4}{c}{ Previsto } \\
\cline { 2 - 5 } & $\begin{array}{c}\text { Não } \\
\text { Sobreviventes }\end{array}$ & $\begin{array}{c}\text { Sobrevivência } \\
\text { Marginal }\end{array}$ & $\begin{array}{c}\text { Alto } \\
\text { Desempenho }\end{array}$ & $\begin{array}{c}\text { Porcentagem } \\
\text { correta }\end{array}$ \\
\hline Não Sobreviventes & 52 & 4 & 6 & $83,9 \%$ \\
Sobrevivência Marginal & 23 & 11 & 13 & $23,4 \%$ \\
Alto Desempenho & 10 & 7 & 35 & $67,3 \%$ \\
Porcentagem global & $52,8 \%$ & $13,7 \%$ & $33,5 \%$ & $60,9 \%$ \\
\hline
\end{tabular}

$\mathrm{Na}$ Tabela 107 verifica-se que o modelo classificou corretamente 60,9\% das empresas. $\mathrm{O}$ grupo de melhor classificação foi "não sobreviventes" onde de 62 empresas 52 (83,9\%) foram classificadas corretamente, 4 foram classificadas no grupo "sobrevivência marginal" e 6 no grupo alto desempenho. A menor eficiência na classificação foi do grupo "sobrevivência marginal", onde de um total de 48 empresas apenas $11(23,4 \%)$ foram classificadas corretamente, enquanto $23(48 \%)$ foram classificadas erroneamente no grupo "não sobreviventes". Na Tabela anterior (106) observou-se que das quatro variáveis selecionadas, três não apresentaram significância estatística ao discriminar o grupo de empresas "não sobreviventes" do grupo "sobrevivência marginal".

Tabela 108 - Sumário dos testes de hipótese - Características Gerenciais

\begin{tabular}{|c|c|c|c|c|c|c|}
\hline \multirow[t]{2}{*}{ Indicador } & \multicolumn{3}{|c|}{$\begin{array}{c}\text { Sobrevivência versus } \\
\text { Não Sobrevivência }\end{array}$} & \multicolumn{3}{|c|}{ Desempenho } \\
\hline & Teste & $\mathbf{H}_{\mathbf{0}}$ & $\mathbf{H}_{1}$ & Teste & $\mathbf{H}_{\mathbf{0}}$ & $\mathbf{H}_{1}$ \\
\hline Pesquisa de mercado e clientes & $\mathrm{RLB}^{1}$ & & $\mathbf{\square}$ & $\mathrm{RLM}^{2}, \mathrm{OLS}^{3}$ & & $\mathbf{\square}$ \\
\hline Identificação e contato com fornecedores & RLB & & $\mathbf{\square}$ & RLM,OLS & & $\mathbf{\square}$ \\
\hline Pesquisa do ambiente & RLB & & $\mathbf{\square}$ & RLM,OLS & & $\mathbf{\square}$ \\
\hline Análise da localização & RLB & & $\mathbf{\square}$ & RLM,OLS & & $\mathbf{\square}$ \\
\hline Estudos de viabilidade econômica e financeira & RLB & & $\mathbf{\square}$ & RLM,OLS & & $\mathbf{\square}$ \\
\hline Registro e controle de caixa & RLB & $\mathbf{\square}$ & & RLM & $\mathbf{\square}$ & \\
\hline Antecipação de recebíveis & RLB & & $\mathbf{\square}$ & RLM, OLS & & $\mathbf{\square}$ \\
\hline Problemas com inadimplência & RLB & & $\mathbf{\square}$ & RLM & & $\mathbf{a}$ \\
\hline Pagamento de juros elevados & RLB & & $\mathbf{\square}$ & RLM, OLS & & $=$ \\
\hline
\end{tabular}

1) RLB: Regressão Logística Binária; 2) Regressão Logística Multinomial; 3) Ordinary Least Squares

Pela Tabela 108 verifica-se que do conjunto de nove indicadores, oito demonstraram-se significantes na explicação dos desempenho das PMEs. Não foi possível rejeitar a hipótese nula do indicador "registro e controle de caixa" (CONTR_CX). 


\subsubsection{Teste da Hipótese $\mathbf{H}_{0,4}$ - Condições do Ambiente}

Nesta dimensão foram incluídos indicadores relacionados a fenômenos externos e que independem da ação da empresa ou do empreendedor. Para constituir este construto foram utilizados os seguintes indicadores:

a) SAZON - Grau de sazonalidade em que o negócio está inserido;

b) COMPET - Nível de competição no ambiente da empresa;

c) CRED_LA - Crédito institucionalizado: linhas e acesso;

d) SERV_PUB - Qualidade dos serviços públicos;

e) INST - Apoio de Instituições (SEBRAE, Associações, escolas etc.);

f) AMB_COMP - Amb. competitivo (lealdade dos competidores, grau de formalidade)

$\mathrm{Na}$ matriz de correlações (Tabela 109) observa-se que os indicadores ligados ao suporte institucional / governamental apresentaram relações mais significativas. Entretanto não possível validar a dimensão com o conjunto dos indicadores, sendo recrutados apenas SERV_PUB e CRED_LA $(\alpha=0,700)$.

Tabela 109 - Matriz de Correlações: Condições do Ambiente

\begin{tabular}{|c|c|c|c|c|c|c|}
\hline & & SAZON & COMPET & CRED_LA & SERV_PUB & INST \\
\hline COMPET & $\begin{array}{l}\rho \\
p \text {-valor } \\
\mathrm{N}\end{array}$ & $\begin{array}{r}0,215^{* *} \\
0,000 \\
402\end{array}$ & & & & \\
\hline CRED_LA & $\begin{array}{l}\rho \\
p \text {-valor } \\
\mathrm{N}\end{array}$ & $\begin{array}{r}0,029 \\
0,583 \\
366\end{array}$ & $\begin{array}{r}0,033 \\
0,528 \\
370\end{array}$ & & & \\
\hline SERV_PUB & $\begin{array}{l}\rho \\
p \text {-valor } \\
\mathrm{N}\end{array}$ & $\begin{array}{r}-0,073 \\
0,155 \\
379\end{array}$ & $\begin{array}{r}-0,025 \\
0,630 \\
383\end{array}$ & $\begin{array}{r}0,540^{* *} \\
0,000 \\
364\end{array}$ & & \\
\hline INST & $\begin{array}{l}\rho \\
p \text {-valor } \\
\mathrm{N}\end{array}$ & $\begin{array}{r}-0,058 \\
0,268 \\
367\end{array}$ & $\begin{array}{r}-0,062 \\
0,235 \\
371\end{array}$ & $\begin{array}{r}0,295^{* *} \\
0,000 \\
358\end{array}$ & $\begin{array}{r}0,263^{* *} \\
0,000 \\
366\end{array}$ & \\
\hline AMB_COMP & $\begin{array}{l}\rho \\
p \text {-valor } \\
\mathrm{N}\end{array}$ & $\begin{array}{r}-0,002 \\
0,963 \\
375\end{array}$ & $\begin{array}{r}-0,205^{* *} \\
0,000 \\
377\end{array}$ & $\begin{array}{r}0,255^{* *} \\
0,000 \\
356\end{array}$ & $\begin{array}{r}0,270^{* *} \\
0,000 \\
368\end{array}$ & $\begin{array}{r}0,115^{*} \\
0,029 \\
361\end{array}$ \\
\hline
\end{tabular}

(*) Correlação significativa ao nível de 5\%; (**) correlação significativa ao nível de 1\%.

Para eliminar o efeito da multicolinearidade, SERV_PUB e CRED_LA foram combinadas de modo a constituir um único fator, denominado SUP_GOV (Suporte Governamental), que explicou $77 \%$ da variância total dos dois indicadores. 
Os impactos das condições do ambiente, no contexto endógeno dessa dimensão, foi testado mediante o uso da regressão múltipla, constituída pelos valores de entrada descritos na Tabela 110.

Tabela 110: Regressão múltipla: Valores de entrada - Condições do Ambiente

\begin{tabular}{lllll}
\hline \multicolumn{2}{c}{ Variáveis } & \multicolumn{1}{c}{ Tipo } & Escala & \multicolumn{1}{c}{ Método } \\
\hline \multirow{2}{*}{ Dependente } & DSP & Construto & Razão & Escala somada \\
& SUP_GOV & Construto & Razão & Escore fatorial \\
& SAZON & Indicador & Likert & Likert $(5 \mathrm{pt})$ \\
\multirow{5}{*}{ Independentes } & COMPET & Indicador & Likert & Likert $(5 \mathrm{pt})$ \\
& INST & Indicador & Likert & Likert $(6 \mathrm{pt})$ \\
& AMB_COMP & Indicador & Likert & Likert $(6 \mathrm{pt})$ \\
\hline
\end{tabular}

A variável INST foi excluída por não se mostrar significativa. O modelo estimado apresentou uma capacidade preditiva de $13 \%(F=13,18 ; p<0,001)$.

Tabela 111 - Coeficientes da regressão ${ }^{a}$ : Condições do Ambiente

\begin{tabular}{|c|c|c|c|c|c|}
\hline \multirow{2}{*}{ Modelo } & \multicolumn{2}{|c|}{$\begin{array}{c}\text { Coeficientes não } \\
\text { padronizados }\end{array}$} & \multirow{2}{*}{$\begin{array}{c}\begin{array}{c}\text { Coeficientes } \\
\text { padronizados }\end{array} \\
\text { Beta }\end{array}$} & \multirow{2}{*}{$\mathbf{t}$} & \multirow{2}{*}{ Sig. } \\
\hline & $\boldsymbol{\beta}$ & $\begin{array}{c}\text { Erro } \\
\text { padrão }\end{array}$ & & & \\
\hline (Constante) & 17,373 & 3,540 & & 4,908 & 0,000 \\
\hline SUP_GOV & 4,020 & 0,633 & 0,338 & 6,346 & 0,000 \\
\hline SAZON & 1,433 & 0,633 & 0,117 & 2,265 & 0,024 \\
\hline COMPET & $-1,795$ & 0,689 & $-0,137$ & $-2,604$ & 0,010 \\
\hline AMB_COMP & 1,266 & 0,637 & 0,108 & 1,989 & 0,048 \\
\hline
\end{tabular}

a) Variável dependente: DSP

Observa-se (Tabela 111), no modelo estimado, que o construto relacionado ao suporte governamental, envolvendo a disponibilidade e acesso à linhas de crédito e a qualidade dos serviços públicos (SUP_GOV), apresentou maior impacto, tendo explicado $34 \%$ das variâncias do desempenho (DSP). Sob esta ótica constata-se que, à medida que as PMEs encontram dificuldade nas ações institucionais/governamentais, seu desempenho se deteriora e aumenta o risco de não sobrevivência. Bates (1995), utilizando-se de uma amostra de 4.213 empresas, observou que o suporte governamental constitui fator crítico de sucesso dos pequenos negócios. Nos estudos de Carter e Van Auken (2006), as regulamentações federais demonstraram-se significativas na explicação do sucesso das empresas.

Com relação a sazonalidade constatou-se que a medida que diminui a sazonalidade (SAZON) 
na qual a empresa está inserida, melhora seu desempenho (DSP). Negócios inscritos em ambientes sazonais requerem ações de planejamento de forma a evitar, principalmente, os contra-fluxos de caixa, ou seja, minimizar as saídas de caixa para o período de diminuição das vendas ou ajustar fontes de recursos para suprir as demandas requeridas nesse período. Neste ponto, os achados desta pesquisa convergem com os estudos de Brüderl et. al. (1992), que identificaram um índice de não sobrevivência 37,5\% maior de empresas situadas em ambientes com elevada sazonalidade, e de Mendes (2006).

No que diz respeito à competição (COMPET), verificou-se que com o aumento da competitividade também melhora o desempenho da empresa. Nos pressupostos conceituais presumiu-se que uma hipótese seria de que as empresas que operam em ambientes altamente competitivos tendem a buscar mecanismos de capacitação e adaptação capazes de torna-las ambientadas ao modus operandi do contexto no qual estão inseridas. Portanto, o sinal obtido era uma hipótese esperada e está em linha com os pressupostos adotados. No entanto, as evidências apresentadas por Büderl et. al. (1992) caminham em sentido contrário. Os autores concluíram que o índice de não sobrevivência aumentava 17,6\% se a empresa estava situada em ambientes altamente competitivos, em comparação com as empresas que operavam em ambiente de baixa competição. Shaefer (2012) salienta que a análise do ambiente de competição é um ponto crítico que deve constar no plano de negócio e nas ações de coleta de informações da empresa em seu processo de planejamento.

Carter e Van Auken (2006) observaram que para as empresas sobreviventes o nível de competição foi relevante, enquanto para as não sobreviventes esse fator não teve significância, convergindo com as evidências deste estudo.

O modelo estimado para as condições do ambiente foi dado por:

$$
D S P=17,37+4,02\left(S U P \_G O V\right)+1,43(S A Z O N)-1,8(C O M P)+1,27\left(A M B \_C O M P\right)
$$

Adicionalmente à regressão linear, em que a variável desempenho foi considerada de forma contínua, também foi testado o poder discriminatório dos indicadores para classificar as empresas sobreviventes das não sobreviventes, por meio da regressão logística binária. $\mathrm{Na}$ Tabela 112 estão apresentados os valores de entrada do modelo. 
Tabela 112 - Ajuste dos indicadores para regressão logística binária

\begin{tabular}{llclll}
\hline \multicolumn{1}{c}{ Indicador } & \multicolumn{1}{c}{ Classe } & Ordem & \multicolumn{1}{c}{ Variável } & \multicolumn{2}{c}{ Código } \\
\hline \multirow{3}{*}{ Sazonalidade } & Muito ou bastante sazonal & 1 & SAZON(1) & 1 & 0 \\
& Razoavelmente Sazonal & 2 & SAZON(2) & 0 & 1 \\
& Pouco ou nada sazonal & 3 & SAZON & 0 & 0 \\
\hline \multirow{3}{*}{ Competição } & Altamente competitivo & 1 & COMP(1) & 1 & 0 \\
& Competitivo & 2 & COMP(2) & 0 & 1 \\
& Competição baixa & 3 & COMP & 0 & 0 \\
\hline Suporte Governamental & Escala razão (escore fatorial) & & SUP_GOV & & \\
\hline
\end{tabular}

Os testes de coeficientes de Omnibus $\left(G^{2}=47,090 ; p<0,001\right)$ sustentam a adequação do modelo. A estimação -2LL $(307,584)$ e os pseudo- $R^{2}$ de Cox e Snell $(0,123)$ e Nagelkerke $(0,196)$ indicam que existem limitações, e o teste de Hosmer e Lemeshow $\left(x^{2}=16,545 ; p=\right.$ 0,093) demonstra que os dados se ajustam ao modelo.

Tabela 113 - Coeficientes do modelo logístico binário - Condições do Ambiente

\begin{tabular}{|c|c|c|c|c|c|c|c|c|}
\hline \multirow{2}{*}{ Modelo } & \multirow{2}{*}{$\boldsymbol{\beta}$} & \multirow{2}{*}{$\begin{array}{c}\text { Erro } \\
\text { Padrão }\end{array}$} & \multirow{2}{*}{ Wald } & \multirow{2}{*}{$g l$} & \multirow{2}{*}{ Sig. } & \multirow{2}{*}{$e^{\beta}$} & \multicolumn{2}{|c|}{ IC $95 \%$ para $e^{\beta}$} \\
\hline & & & & & & & Inferior & Superior \\
\hline SUP_GOV & $-0,847$ & 0,163 & 26,988 & 1 & 0,000 & 0,429 & 0,311 & 0,590 \\
\hline SAZON & & & 5,891 & 2 & 0,053 & & & \\
\hline SAZON(1) & $-0,912$ & 0,387 & 5,537 & 1 & 0,019 & 0,402 & 0,188 & 0,859 \\
\hline SAZON(2) & $-0,280$ & 0,365 & 0,587 & 1 & 0,444 & 0,756 & 0,369 & 1,547 \\
\hline COMP & & & 10,264 & 2 & 0,006 & & & \\
\hline $\operatorname{COMP}(1)$ & 0,997 & 0,388 & 6,612 & 1 & 0,010 & 2,710 & 1,268 & 5,795 \\
\hline $\operatorname{COMP}(2)$ & 1,072 & 0,359 & 8,915 & 1 & 0,003 & 2,922 & 1,445 & 5,907 \\
\hline Constante & 1,320 & 0,325 & 16,479 & 1 & 0,000 & 3,745 & & \\
\hline
\end{tabular}

O construto e os indicadores (Tabela 113) apresentaram poder para discriminar os grupos de empresas. Com relação aos aspectos relacionados ao suporte governamental, tem-se que a cada unidade de deterioração na avaliação deste item, a chances de sobrevivência diminuem em 57\%. Em termos da sazonalidade observa-se que, se a empresa figura na categoria "muito ou bastante sazonal" [SAZON(1)] em comparação com aquelas da categoria "pouco ou nada sazonal" (SAZON), as chances de sobrevivência diminuem em $60 \%$. Com relação a competição, verifica-se que as chances de sobrevivência aumentam com o aumento do grau de competição, sendo de $171 \%$ se o ambiente for "altamente competitivo" $\left[\mathrm{COMP}(1) ; e^{\beta}=\right.$ 2,$710 ; p=0,010$ ] e de $192 \%$ se for "competitivo" [COMP(2); $e^{\beta}=2,922 ; p=0,003$ ], comparativamente às empresas inseridas no ambiente de "competição baixa" (COMP).

O modelo, no teste da área sob a curva ROC apresentou bom poder discriminatório $(c=$ $0,763 ; p<0,001)$. 
Os indicadores também foram testados sob a ótica de (a) não sobreviventes, (b) sobrevivência marginal e (c) alto desempenho, com a utilização da regressão multinomial.

Tabela 114 - Informações de ajuste do modelo multinomial - Condições do Ambiente

\begin{tabular}{lcccccc}
\hline \multicolumn{1}{c}{ Modelo } & Critérios de ajuste & & \multicolumn{3}{c}{ Testes de verossimilhança } \\
\cline { 2 - 2 } \cline { 5 - 7 } & $\mathbf{- 2 L \boldsymbol { L }}$ & & $\boldsymbol{G}^{\mathbf{2}}$ & $\boldsymbol{g l}$ & Sig. \\
\hline Modelo nulo & 344,627 & & & & \\
Modelo Completo & 301,457 & & 43,170 & 10 & 0,000 \\
\hline
\end{tabular}

Na Tabela 114 observa-se que existe pelo menos um indicador capaz de discriminar os grupos: não sobrevivente (0), sobrevivência marginal (1) e alto desempenho (2). Os pseudo$R^{2}$ de Cox e Snell $(0,216)$, Nagelkerke $(0,244)$ e McFadden $(0,112)$ proporcionam poder fraco ao modelo, devendo ser considerado de forma parcimoniosa.

Tabela 115 - Coeficientes do modelo multinominal - Condições do Ambiente

\begin{tabular}{|c|c|c|c|c|c|c|c|c|c|}
\hline \multirow{2}{*}{\multicolumn{2}{|c|}{ Grupo/Modelo }} & \multirow{3}{*}{$\begin{array}{c}\boldsymbol{\beta} \\
-0,503\end{array}$} & \multirow{3}{*}{$\begin{array}{c}\begin{array}{c}\text { Erro } \\
\text { padrão }\end{array} \\
0,438\end{array}$} & \multirow{3}{*}{$\begin{array}{c}\text { Wald } \\
1,316\end{array}$} & \multirow{3}{*}{$\begin{array}{c}g l \\
1\end{array}$} & \multirow{3}{*}{$\begin{array}{c}\text { Sig. } \\
0,251\end{array}$} & \multirow{3}{*}{$e^{\beta}$} & \multicolumn{2}{|c|}{ IC de $95 \%$ para $\mathrm{e}^{\beta}$} \\
\hline & & & & & & & & \multirow[t]{2}{*}{$\begin{array}{l}\text { Limite } \\
\text { inferior }\end{array}$} & \multirow[t]{2}{*}{$\begin{array}{c}\text { Limite } \\
\text { superior }\end{array}$} \\
\hline \multirow{6}{*}{ 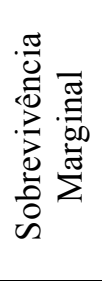 } & Constante & & & & & & & & \\
\hline & SUP_GOV & $-0,354$ & 0,219 & 2,612 & 1 & 0,106 & 0,702 & 0,457 & 1,078 \\
\hline & SAZON(1) & $-0,859$ & 0,507 & 2,870 & 1 & 0,090 & 0,423 & 0,157 & 1,144 \\
\hline & SAZON(2) & $-0,005$ & 0,465 & 0,000 & 1 & 0,992 & 0,995 & 0,400 & 2,476 \\
\hline & COMP(1) & 0,988 & 0,512 & 3,724 & 1 & 0,054 & 2,686 & 0,985 & 7,325 \\
\hline & $\operatorname{COMP}(2)$ & 0,860 & 0,483 & 3,169 & 1 & 0,075 & 2,364 & 0,917 & 6,095 \\
\hline \multirow{6}{*}{ 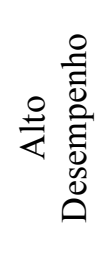 } & Constante & $-0,673$ & 0,469 & 2,062 & 1 & 0,151 & & & \\
\hline & SUP_GOV & $-1,004$ & 0,226 & 19,795 & 1 & 0,000 & 0,367 & 0,236 & 0,570 \\
\hline & SAZ̄̄oN(1) & $-1,324$ & 0,542 & 5,973 & 1 & 0,015 & 0,266 & 0,092 & 0,769 \\
\hline & SAZON(2) & $-0,131$ & 0,480 & 0,074 & 1 & 0,785 & 0,877 & 0,343 & 2,248 \\
\hline & COMP(1) & 1,516 & 0,566 & 7,188 & 1 & 0,007 & 4,555 & 1,504 & 13,803 \\
\hline & COMP(2) & 1,589 & 0,518 & 9,412 & 1 & 0,002 & 4,901 & 1,775 & 13,528 \\
\hline
\end{tabular}

Obs.: Categoria de referência: [0] não sobreviventes

$\mathrm{Na}$ Tabela 115 verifica-se que nenhum indicador selecionado apresentou poder discriminatório para o grupo "sobrevivência marginal", levando o modelo a classificar corretamente apenas $24 \%$ das empresas desse grupo. Com o objetivo de deixar os coeficientes mais densos, procedeu-se a análise apenas com os grupos "não sobreviventes" e "alto desempenho", tornando o modelo multinomial equivalente à um modelo binário.

O novo modelo mostrou-se significativo no teste de coeficientes de Omnibus $\left(G^{2}=36,268 ; p\right.$ $<0,001)$. O teste $-2 L L(138,458)$ e os pseudo- $R^{2}$ de Cox e Snell $(0,248)$ e Nagelkerke $(0,332)$ demonstram que houve sensível melhora nas evidências. $\mathrm{O}$ teste de Hosmer e Lemeshow $\left(x^{2}\right.$ $=8,056 ; p=0,328$ ) confirmou a adequação dos dados ao modelo. 
Tabela 116 - Coeficientes do modelo binário - Condições do Ambiente

\begin{tabular}{lcccccccc}
\hline \multicolumn{1}{c}{ Modelo } & $\boldsymbol{\beta}$ & $\begin{array}{c}\text { Erro } \\
\text { Padrão }\end{array}$ & Wald & $\boldsymbol{g l}$ & Sig. & $\boldsymbol{e}^{\boldsymbol{\beta}}$ & \multicolumn{2}{c}{$\mathbf{9 5 \%}$ para $\boldsymbol{e}^{\boldsymbol{\beta}}$} \\
& & & & & & \\
Inferior & Superior \\
\hline SUP_GOV & $-0,850$ & 0,220 & 14,880 & 1 & 0,000 & 0,428 & 0,278 & 0,658 \\
SAZON & & & 5,615 & 2 & 0,060 & & & \\
SAZON(1) & $-1,227$ & 0,563 & 4,754 & 1 & 0,029 & 0,293 & 0,097 & 0,883 \\
SAZON(2) & $-0,126$ & 0,494 & 0,064 & 1 & 0,800 & 0,882 & 0,335 & 2,324 \\
COMP & & & 9,680 & 2 & 0,008 & & & \\
COMP(1) & 1,390 & 0,578 & 5,791 & 1 & 0,016 & 4,016 & 1,294 & 12,463 \\
COMP(2) & 1,633 & 0,540 & 9,141 & 1 & 0,002 & 5,118 & 1,776 & 14,748 \\
Constante & $-0,721$ & 0,453 & 2,531 & 1 & 0,112 & 0,486 & & \\
\hline
\end{tabular}

Na Tabela 116 verifica-se que apenas a constante e SAZON(2) não obtiveram significância discriminatória. Novamente pode ser observada a influência destacada do suporte governamental $\left(X_{\text {Wald }}^{2}=14,88 ; p<0,001\right)$, onde observa-se que a chance da empresa migrar do grupo "não sobreviventes" (0) para o grupo "alto desempenho" diminui 57,2\% a cada unidade de deterioração na avaliação de SUP_GOV $\left(e^{\beta}=0,428 ; p<0,001\right)$. Com relação a sazonalidade, conclui-se que se a empresa pertence à categoria "muito sazonal" ao invés de "pouco ou nada sazonal" suas chances de ascender do grupo 0 para o grupo 2 diminuem em $70 \%\left(e^{\beta}=0,293 ; p=0,029\right)$. No quesito competição, caso uma empresa pertença à categoria "altamente competitivo" [COMP(1)], comparativamente àquela pertencente à categoria "competição baixa" (COMP), suas chances de ascender ao grupo alto desempenho aumentam 3,0 vezes $\left(e^{\mathrm{B}}=4,016 ; p=0,016\right)$, e se a empresa pertencer ao grupo "competitivo" [COMP(2)], suas chances são aumentadas em 4,1 vezes $\left(e^{\beta}=5,118 ; p=0,002\right)$.

Tabela 117 - Classificações corretas - Condições do Ambiente

\begin{tabular}{lccc}
\hline \multirow{2}{*}{ Observado } & \multicolumn{3}{c}{ Previsto } \\
\cline { 2 - 4 } & $\begin{array}{c}\text { Não } \\
\text { Sobreviventes }\end{array}$ & $\begin{array}{c}\text { Alto } \\
\text { Desempenho }\end{array}$ & $\begin{array}{c}\text { Porcentagem } \\
\text { correta }\end{array}$ \\
\hline Não Sobreviventes & 56 & 14 & $80,0 \%$ \\
Alto Desempenho & 23 & 34 & $59,6 \%$ \\
Porcentagem global & & & $70,9 \%$ \\
\hline
\end{tabular}

$\mathrm{Na}$ Tabela 117 verifica-se que o modelo classificou corretamente 70,9\% das empresas. O grupo de melhor classificação foi o "não sobreviventes" onde de 70 empresas 56 (80\%) foram classificadas corretamente. Do conjunto de 57 empresas de "alto desempenho", 34 (59,6\%) foram classificadas corretamente. No geral, a cada 10 empresas, 7 foram classificadas corretamente. Pelo teste da área sob a curva $R O C$, o poder discriminatório do modelo é considerado bom $(c=0,805 ; p<0,005)$. 
Tabela 118 - Sumário dos testes de hipótese - Condições do Ambiente

\begin{tabular}{|c|c|c|c|c|c|c|}
\hline \multirow[t]{2}{*}{ Indicador } & \multicolumn{3}{|c|}{$\begin{array}{l}\text { Sobrevivência versus } \\
\text { Não Sobrevivência }\end{array}$} & \multicolumn{3}{|c|}{ Desempenho } \\
\hline & Teste & $\mathbf{H}_{\mathbf{0}}$ & $\mathbf{H}_{1}$ & Teste & $\mathbf{H}_{\mathbf{0}}$ & $\mathbf{H}_{1}$ \\
\hline Sazonalidade & RLB $^{1}$ & & $\mathbf{\square}$ & RLB, $\mathrm{OLS}^{3}$ & & $\mathbf{\square}$ \\
\hline Grau de Competição & RLB & & $\mathbf{\square}$ & RLB, OLS & & $\mathbf{\square}$ \\
\hline Linhas e acesso ao crédito & RLB & & $\mathbf{\square}$ & RLB, OLS & & $\mathbf{\square}$ \\
\hline Serviços públicos & RLB & & $\mathbf{\square}$ & RLB, OLS & & $\mathbf{\square}$ \\
\hline Apoio de instituições & RLB & $\mathbf{\square}$ & & RLB, OLS & $\mathbf{\square}$ & \\
\hline Ambiente competitivo & RLB & $\mathbf{\square}$ & & RLB, OLS & & $\mathbf{\square}$ \\
\hline
\end{tabular}

1) RLB: Regressão Logística Binária; 2) Regressão Logística Multinomial; 3) Ordinary Least Squares

Pela Tabela 118 verifica-se que do conjunto de seis indicadores, cinco demonstraram-se significantes na explicação dos desempenho das PMEs (Rejeitou-se $\mathrm{H}_{0}$ ). Não foi possível rejeitar a hipótese nula do indicador "apoio de instituições" (INST).

\subsubsection{Teste da Hipótese $\mathrm{H}_{0,5}$ - Motivação e Percepção do Risco}

Schaefer (2012) destaca que o sucesso de uma empresa pode estar alicerçado no motivo que embasou a decisão de empreender. Allen (2012) classifica os negócios como empreendedorismo de subsistência (cuja finalidade é o sustento do proprietário e/ou da família) e o empreendedorismo empresarial (as empresas possuem objetivos permeados pelo crescimento, inovação e tomada de riscos). Esta dimensão buscou testar se a motivação para empreender e a percepção do risco são determinantes da sobrevivência ou desempenho da empresa. Foram utilizados os seguintes indicadores:

a) OP_NEC - Decisão de empreender: Oportunidade versus Necessidade;

b) MOT_EMP - Motivador principal da decisão de empreender;

c) RISCO - Percepção do grau de risco implícito nas PMEs.

Na Tabela 119 observa-se que 54\% das empresas não sobreviventes pautaram sua decisão de empreender na "necessidade", enquanto das empresas sobreviventes, $63 \%$ informaram que a decisão foi baseada na "oportunidade".

A percepção do risco ficou prejudicada na análise em função do efeito ex post facto nas empresas não sobreviventes, ou seja, o fato de não terem sobrevivido pode induzi-las a adotar uma postura frente ao risco que não teriam (ou não possuíam) enquanto estavam em 
atividade. Conforme já observado na descrição deste indicador, o percepção de risco muito alto por parte das não sobreviventes foi de $37,8 \%$, enquanto das sobreviventes esse índice foi de $20 \%$.

Tabela 119 - Frequência cruzada: Decisão de Empreender e Status da empresa

\begin{tabular}{lccc}
\hline \multicolumn{1}{c}{ Status } & \multicolumn{2}{c}{ Decisão de Empreender } & \multirow{2}{*}{ Total } \\
& Oportunidade & Necessidade & \\
\hline Não sobreviventes & $34(46 \%)$ & $40(54 \%)$ & 74 \\
Sobreviventes & $206(63 \%)$ & $122(37 \%)$ & 328 \\
TOTAL & $\mathbf{2 4 0}$ & $\mathbf{1 6 2}$ & $\mathbf{4 0 2}$ \\
\hline
\end{tabular}

Alternativamente foi utilizado somente as empresas sobreviventes para testar se existe relação entre nível de risco e desempenho, mas não foi encontrado evidências da existência dessa relação.

Não foram encontradas evidências significativas de que a "motivação e percepção de risco" sejam determinantes do desempenho das PMEs, não rejeitando-se a hipótese nula desta dimensão.

\subsubsection{Teste da Hipótese $\mathbf{H}_{0,6}$ - Características Organizacionais}

Para testar esta dimensão foram utilizados sete indicadores:

a) ESP_GEN - Especialidade ou generalidade do negócio;

b) AF_IND - Negócios afiliados ou independentes ;

c) QUAL_E - Grau de qualificação dos empregados;

d) TREIN_E - Nível de treinamento recebido pelos empregados;

e) SOCIOS - Número de sócios do quadro social

f) REL_SOC - Relacionamento entre os sócios

g) INOV - Grau de inovação exigido no negócio

h) SITE - Se a empresa possui sítio (site)

i) CONS_W - Se os produtos da empresa podem ser consultados no sítio

j) VND_W - Se a empresa faz vendas pelas internet

Devido ao baixo número de empresas afiliadas (franquias, representações etc.), ficaram 
prejudicados os testes com este indicador (AF_GEN). Da mesma forma, os indicadores SITE, CONS_W, VND_W não foram testados devido a baixa frequência destes indicadores.

Na matriz de correlações (Tabela 120) verifica-se baixa associação entre os indicadores dessa dimensão. Destaca-se a relação entre QUAL_E e INOV, demonstrando que à medida que aumenta o nível de inovação da empresa, também aumenta o nível de treinamento.

Tabela 120 - Matriz de Correlações - Características Organizacionais

\begin{tabular}{|c|c|c|c|c|c|}
\hline & & QUAL_E & TREIN_E & SOCIOS & REL_SOC \\
\hline TREIN_E & $\begin{array}{l}\rho \\
p \text {-valor } \\
\mathrm{N}\end{array}$ & $\begin{array}{r}0,170^{* *} \\
0,002 \\
344\end{array}$ & & & \\
\hline SOCIOS & $\begin{array}{l}\rho \\
p \text {-valor } \\
\mathrm{N}\end{array}$ & $\begin{array}{r}0,010 \\
0,852 \\
352\end{array}$ & $\begin{array}{r}-0,060 \\
0,276 \\
336\end{array}$ & & \\
\hline REL_SOC & $\begin{array}{l}\rho \\
p \text {-valor } \\
\mathrm{N}\end{array}$ & $\begin{array}{r}0,164^{* *} \\
0,004 \\
304\end{array}$ & $\begin{array}{r}-0,072 \\
0,225 \\
289\end{array}$ & $\begin{array}{r}0,073 \\
0,186 \\
330\end{array}$ & \\
\hline INOV & $\begin{array}{l}\rho \\
p \text {-valor } \\
\mathrm{N}\end{array}$ & $\begin{array}{r}0,117^{*} \\
0,027 \\
357\end{array}$ & $\begin{array}{r}0,307^{* *} \\
0,000 \\
343\end{array}$ & $\begin{array}{r}0,035 \\
0,498 \\
386\end{array}$ & $\begin{array}{r}0,048 \\
0,382 \\
328\end{array}$ \\
\hline
\end{tabular}

Como não foi possível constituir o construto para esta dimensão devido à baixa consistência entre os indicadores, o modelo regressor foi constituído incluindo-os individualmente, conforme demonstrado na Tabela 121.

Tabela 121: Regressão múltipla: Valores de entrada - Características Organizacionais

\begin{tabular}{lllll}
\hline \multicolumn{2}{c}{ Variáveis } & \multicolumn{1}{c}{ Tipo } & Escala & \multicolumn{1}{c}{ Método } \\
\hline \multirow{2}{*}{ Dependente } & DSP & Construto & Razão & Escala somada \\
& OP_NEC & Indicador & Dummy & $(0,1)$ \\
& QUAL_E & Indicador & Likert & Likert $(4 \mathrm{pt})$ \\
\multirow{4}{*}{ Independentes } & TREIN_E & Indicador & Likert & Likert $(4 \mathrm{pt})$ \\
& SOCIOS & Indicador & Razão & - \\
& REL_SOC & Indicador & Likert & Likert $(5 \mathrm{pt})$ \\
& INOV & Indicador & Likert & Likert $(5 \mathrm{pt})$ \\
\hline
\end{tabular}

Os indicadores OP_NEC, SOCIOS e REL_SOC não apresentaram significância e foram suprimidos. O modelo final apresentou poder de explicação de $24 \%(F=35,98 ; p<0,001)$. 
Os resultados (Tabela 122) mostram que 35,8\% da variância de desempenho é explicado pelo nível de qualificação dos empregados, seguida da participação em treinamentos (18\%) e do grau de inovação do negócio $(15,3 \%)$.

Tabela 122 - Coeficientes da regressão ${ }^{\mathrm{a}}$ : Características Organizacionais

\begin{tabular}{|c|c|c|c|c|c|c|c|}
\hline \multirow{2}{*}{ Modelo } & \multicolumn{2}{|c|}{$\begin{array}{c}\text { Coeficientes não } \\
\text { padronizados }\end{array}$} & \multirow{2}{*}{$\begin{array}{c}\begin{array}{c}\text { Coeficientes } \\
\text { padronizados }\end{array} \\
\text { Beta }\end{array}$} & \multirow[b]{2}{*}{ t } & \multirow{2}{*}{ Sig. } & \multicolumn{2}{|c|}{$\begin{array}{l}\text { Estatísticas de } \\
\text { colinearidade }\end{array}$} \\
\hline & $\beta$ & $\begin{array}{l}\text { Erro } \\
\text { padrão }\end{array}$ & & & & Tolerância & VIF \\
\hline (Constante) & $-1,307$ & 2,959 & & $-0,442$ & 0,659 & & \\
\hline TREIN_E & 1,388 & 0,394 & 0,180 & 3,528 & 0,000 & 0,876 & 1,141 \\
\hline QUAL_E & 5,509 & 0,757 & 0,358 & 7,274 & 0,000 & 0,945 & 1,059 \\
\hline INOV & 2,310 & 0,770 & 0,153 & 3,001 & 0,003 & 0,886 & 1,129 \\
\hline
\end{tabular}

a) Variável dependente: DSP

A influência da qualificação do staff no desempenho das empresas tem sido evidenciada com frequência pela literatura (FLAHVIN, 1985; BRUNO et. al., 1987; VAN GELDEREN et. al., 2006; LUSSIER e CORMAN, 1996; LUSSIER, 1996). Lussier e Pfeirfer (2001), utilizandose de uma amostra de 120 empresas na Croácia, concluíram que a qualidade do staff é determinante na sobrevivência dos pequenos negócios. Em outro estudo de Lussier (1995), envolvendo 216 pequenas empresas norte-americanas, dentre um conjunto de 15 variáveis, a qualidade do staff apresentou o segundo maior poder de discriminação, ficando apenas abaixo de "uso de serviços profissionais".

Os testes de colinearidade (VIF < 10) demonstraram que o modelo não foi afetado pela correlação entre QUAL_E e TREIN ( $\rho=0,307 ; p<0,001)$, assim como a constante não é significativa. O modelo estimado foi definido como:

$$
D S P=5,51\left(Q U A L_{-} E\right)+2,31(I N O V)+1,39\left(T R E I N_{-} E\right)
$$

O modelo logístico binário não apresentou poder discriminatório entre os grupos "não sobreviventes" e "sobreviventes", e entre "não sobreviventes" e "sobrevivência marginal" mas pode ser validado na classificação entre "não sobreviventes" e "alto desempenho".

Os testes de coeficientes de Omnibus $\left(x^{2}=55,339 ; p<0,001\right)$ e as estimativas de verossimilhança de $\log -2(110,883)$ e os pseudo- $R^{2}$ de Cox e Snell $(0,369)$ e Nagelkerke $(0,493)$ demonstram que o modelo é explicativo. A adequação dos dados também foi validada pelo teste de Hosmer e Lemeshow $\left(x^{2}=1,723 ; p=0,886\right)$. 
Tabela 123 - Coeficientes do modelo logístico - Características Organizacionais

\begin{tabular}{|c|c|c|c|c|c|c|c|c|}
\hline \multirow{2}{*}{ Modelo } & \multirow{2}{*}{$\boldsymbol{\beta}$} & \multirow{2}{*}{$\begin{array}{c}\text { Erro } \\
\text { Padrão }\end{array}$} & \multirow{2}{*}{ Wald } & \multirow{2}{*}{$g l$} & \multirow{2}{*}{ Sig. } & \multirow{2}{*}{$e^{\beta}$} & \multicolumn{2}{|c|}{ IC $95 \%$ para $e^{\beta}$} \\
\hline & & & & & & & Inferior & Superior \\
\hline QUAL_E & & & 22,614 & 2 & 0,000 & & & \\
\hline $\mathrm{QUAL}^{-} \mathrm{E}(1)$ & 1,939 & 1,098 & 3,119 & 1 & 0,077 & 6,948 & 0,808 & 59,736 \\
\hline QUAL_E(2) & 2,521 & 0,531 & 22,558 & 1 & 0,000 & 12,446 & 4,397 & 35,229 \\
\hline TREIN & & & 12,639 & 2 & 0,002 & & & \\
\hline TREIN_E(1) & $-1,580$ & 0,609 & 6,728 & 1 & 0,009 & 0,206 & 0,062 & 0,680 \\
\hline TREIN_E(2) & $-2,588$ & 0,764 & 11,478 & 1 & 0,001 & 0,075 & 0,017 & 0,336 \\
\hline Constante & 0,063 & 0,587 & 0,011 & 1 & 0,915 & 1,065 & & \\
\hline
\end{tabular}

Na Tabela 123 estão apresentados os coeficientes da classificação entre os grupos "não sobreviventes" (0) e "alto desempenho" (2). Observa-se que apenas os indicadores "qualificação" e "treinamento" dos empregados demonstraram-se discriminantes. Verifica-se que, se o quadro de empregados da empresa encontrar-se na categoria "qualificado" [QUAL_E(2)], ao invés de "pouco qualificado ou sem qualificação" (QUAL_E), as chances de passagem do grupo "não sobreviventes" para o grupo "alto desempenho" aumenta 11,5 vezes $\left(e^{\beta}=12,446 ; p<0,001\right)$.

Com relação ao treinamento, se a empresa encontrar-se na categoria "até 12 horas anuais" [TREIN_E(1)] ao invés da categoria "mais de 24 horas anuais" (TREIN_E), a probabilidade de passagem de grupo (de 0 para 2$)$ diminui em 79,4\% $\left(e^{\beta}=0,206 ; p<0,001\right)$, sendo também discriminante na categoria "de 12 a 24 horas anuais" $\left(e^{\beta}=0,075 ; p<0,001\right)$.

Tabela 124 - Classificações corretas - Características Organizacionais

\begin{tabular}{lccc}
\hline \multirow{2}{*}{ Observado } & \multicolumn{3}{c}{ Previsto } \\
\cline { 2 - 4 } & $\begin{array}{c}\text { Não } \\
\text { Sobreviventes }\end{array}$ & $\begin{array}{c}\text { Alto } \\
\text { Desempenho }\end{array}$ & $\begin{array}{c}\text { Porcentagem } \\
\text { correta }\end{array}$ \\
\hline Não Sobreviventes & 46 & 12 & $79,3 \%$ \\
Alto Desempenho & 15 & 47 & $75,8 \%$ \\
Porcentagem global & & & $77,5 \%$ \\
\hline
\end{tabular}

Do conjunto de 58 empresas não sobreviventes, 46 (79,3\%) foram classificadas corretamente, enquanto o índice de acerto para o grupo de alto desempenho foi $47(75,8 \%)$ de um total de 62 (Tabela 124). Pelo teste de significância da área sob a curva ROC conclui-se que o poder discriminatório do modelo é muito bom $(c=0,850 ; p<0,001)$. 


\subsubsection{Teste da Hipótese $\mathrm{H}_{0,7}$ - Tamanho}

Os indicadores de tamanho foram:

a) INV - Capital investido na constituição do negócio

b) EMP_A - Quadro atual de empregados

c) FAT - Faturamento bruto anual da empresa

$\mathrm{Na}$ Tabela 125 verifica-se que as relações entre os indicadores são significativas, tendo sido validadas no teste de confiabilidade $(\alpha=0,774)$.

A medida de tamanho de PMEs resultou do escore fatorial de EMP_A, FAT e INV. A análise fatorial foi validada no teste $K M O(0,628)$ e pelo teste de Bartlet $\left(x^{2}=378,18 ; p<0,001\right)$. A variância total explicada pelo construto (TAM) foi de $69 \%$.

Tabela 125 - Matriz de Correlações - Tamanho

\begin{tabular}{ll|rr}
\hline & & EMP_A & \multicolumn{1}{c}{ INV } \\
\hline \multirow{4}{*}{ INV } & $\rho$ & $0,387^{* *}$ & \\
& $p$-valor & 0,000 & \\
& $\mathrm{~N}$ & 371 & \\
& $\rho$ & $0,728^{* *}$ & $0,314^{* *}$ \\
FAT & $p$-valor & 0,000 & 0,000 \\
& $\mathrm{~N}$ & 369 & 393 \\
\hline
\end{tabular}

Para testar se o tamanho influencia o desempenho foi realizada a regressão linear simples tendo o desempenho (DSP) como variável dependente e o tamanho (TAM). O modelo teve baixo poder explicativo ( $3 \%)$ porém significativo $(F=12,177 ; p=0,001)$. O tamanho explicou $18 \%$ das variâncias do desempenho.

A capacidade do TAM em escala fatorial não foi consistente na utilização do modelo logístico para discriminar sobreviventes e não sobreviventes. Optou-se por utilizar o quadro atual de empregados como medida de tamanho (TAM).

Não foi encontrado poder de discriminação conseguiu discriminar os grupos "não sobreviventes" em relação a "sobreviventes" e, "não sobreviventes" em relação a "sobrevivência marginal". No entanto, o tamanho (TAM) demonstrou-se discriminante para os grupos "não sobreviventes" e "alto desempenho". 
Os teste de razão de verossimilhança $\left(G^{2}=18,549 ; p<0,001\right)$, de ajuste de Pearson $\left(x^{2}=\right.$ $16,722 ; p=0,542)$ e Deviance $\left(x^{2}=17,859 ; p=0,465\right)$ validam a significância e a adequação dos dados ao modelo. Os pseudo- $R^{2}$ de Cox e Snell $(0,125)$, Nagelkerke $(0,167)$ e McFadeden $(0,097)$ demonstram limitações, e os resultados devem ser considerados com parcimônia, dado o fraco poder de discriminação (área sob a curva ROC: $c=0,649 ; p=0,003$ ).

Em síntese, o modelo demonstrou que a cada funcionário adicional as chances da empresa passar do grupo "não sobrevivente" para o grupo "alto desempenho" aumentam em $12,2 \%\left(e^{\beta}\right.$ $=1,122 ; p=0,001)$.

Tabela 126 - Classificações corretas - Desempenho

\begin{tabular}{lccc}
\hline \multicolumn{1}{c}{ Observado } & \multicolumn{3}{c}{ Previsto } \\
\cline { 2 - 4 } & $\begin{array}{c}\text { Não } \\
\text { Sobreviventes }\end{array}$ & $\begin{array}{c}\text { Alto } \\
\text { Desempenho }\end{array}$ & $\begin{array}{c}\text { Porcentagem } \\
\text { correta }\end{array}$ \\
\hline Não Sobreviventes & 66 & 8 & $89,2 \%$ \\
Alto Desempenho & 41 & 24 & $36,9 \%$ \\
Porcentagem global & & & $64,7 \%$ \\
\hline
\end{tabular}

Na Tabela 126 observa-se que das 74 empresas não sobreviventes, o tamanho (TAM) conseguiu discriminar corretamente 66 (89,2\%). Entretanto, no caso das empresas de "alto desempenho" o índice de acerto foi de 36,9\% (24 em 65). Observa-se que, em geral, as empresas não sobreviventes possuem menos funcionários do que as de alto desempenho, mas que, por sua vez, existem empresas de alto desempenho que possuem poucos funcionários.

Diante das evidências obtidas rejeita-se a hipótese nula para a dimensão "tamanho" $\left(\mathrm{H}_{0,7}\right)$

\subsubsection{Teste da Hipótese $\mathbf{H}_{0,9}$ - Demografia pessoal}

Nesta dimensão foi testado se os indicadores pessoais do empreendedor influenciam o desempenho. Foram testados: a) ID - Idade; b) CIVIL - Estado Civil, e; c) GEN - Gênero

Nos testes de qui-quadrado, correlação de Pearson (ID x ESCORE), regressão logística e regressão linear com variáveis dummy não se encontrou evidência da influência desses indicadores no desempenho das PMEs. 


\subsection{Modelo Geral}

\subsubsection{Regressão Linear Multivariada}

Após a realização dos testes no contexto das dimensões de cada uma das hipóteses, procurouse checar o modelo conjunto com os indicadores e construtos. As variáveis foram testadas até a obtenção do conjunto que definiu o modelo estimado final. As variáveis selecionadas foram:

a) ID_E - Idade da empresa

b) FIN_CP - Utilização de fontes de financiamento de curto prazo

c) INOV - Grau de inovação exigido no negócio

d) SUP_GOV - Suporte Governamental

e) QUAL_E - Nível de qualificação do quadro de empregados

f) PLAN_AB - Grau de planejamento realizado antes da abertura

g) CAP_SOC - Capital Social

Tabela 127 - Resumo do modelo

\begin{tabular}{cccccc}
\hline Modelo & $\mathbf{R}$ & R quadrado & $\begin{array}{c}\text { R quadrado } \\
\text { ajustado }\end{array}$ & $\begin{array}{c}\text { Erro padrão } \\
\text { da estimativa }\end{array}$ & $\begin{array}{c}\text { Durbin- } \\
\text { Watson }\end{array}$ \\
\hline 1 & $0,662^{\mathrm{a}}$ & 0,439 & 0,420 & 9,21183 & 0,721 \\
\hline
\end{tabular}

a) Preditores: (Constante), ID_E, FIN_CP, INOV, SUP_GOV, QUAL_E, PLAN_AB, CAP_SOC

b) Variável dependente: DSP

O modelo geral conseguiu explicar 42\% do desempenho das PMEs da amostra (Tabela 127).

Tabela 128 - ANOVA - Modelo Geral

\begin{tabular}{lcrrrr}
\hline \multicolumn{1}{c}{ Modelo } & $\begin{array}{c}\text { Soma dos } \\
\text { Quadrados }\end{array}$ & gl & $\begin{array}{c}\text { Quadrado } \\
\text { Médio }\end{array}$ & F & Sig. \\
\hline Regressão & 14200,301 & 7 & 2028,614 & 23,906 & 0,000 \\
Resíduos & 18159,583 & 214 & 84,858 & & \\
TOTAL & 32359,884 & 221 & & & \\
\hline
\end{tabular}

No modelo final (Tabela 128) ficaram retidos sete indicadores/construtos com significância estatística. Nota-se que o modelo não conseguiu reter nenhum indicador referente às dimensões de "Capital Humano", "Demografia Pessoal" do empreendedor e "Tamanho". Por consequência não se rejeita a hipótese nula para estas dimensões. 
Tabela 129: Modelo Geral: coeficientes da regressão linear múltipla

\begin{tabular}{|c|c|c|c|c|c|}
\hline \multirow{2}{*}{ Modelo } & \multicolumn{2}{|c|}{$\begin{array}{c}\text { Coeficientes não } \\
\text { padronizados }\end{array}$} & \multirow{2}{*}{$\begin{array}{c}\begin{array}{c}\text { Coeficientes } \\
\text { padronizados }\end{array} \\
\text { Beta }\end{array}$} & \multirow{2}{*}{ t } & \multirow{2}{*}{ Sig. } \\
\hline & $\boldsymbol{\beta}$ & $\begin{array}{c}\text { Erro } \\
\text { padrão }\end{array}$ & & & \\
\hline (Constante) & 3,467 & 3,966 & & 0,874 & 0,383 \\
\hline PLAN_AB & $-1,481$ & 0,730 & $-0,127$ & $-2,0300$ & 0,034 \\
\hline SUP_GOV & $-2,635$ & 0,661 & $-0,222$ & $-3,989$ & 0,000 \\
\hline FIN_CP & 1,571 & 0,684 & 0,133 & 2,296 & 0,023 \\
\hline CAP_SOC & $-1,476$ & 0,768 & $-0,122$ & $-1,923$ & 0,046 \\
\hline INOV & 2,754 & 0,908 & 0,164 & 3,033 & 0,003 \\
\hline QUAL_E & 5,293 & 1,020 & 0,315 & 5,191 & 0,000 \\
\hline ID_E & $-1,013$ & 0,560 & $-0,100$ & $-1,811$ & 0,042 \\
\hline
\end{tabular}

Dentre o conjunto de variáveis estatisticamente significativas, concluiu-se que a qualidade do staff apresentou o poder explicativo mais elevado, de modo que QUAL_E explica 31,5\% das variâncias de desempenho (DSP). Ainda nesta dimensão "Características Organizacionais" observou-se que o aumento do grau de inovação implica em ganho de desempenho (o indicador INOV foi testado com escala inversa à apresentada no questionário).

Na dimensão do "Capital Social" observou-se que à medida que melhora o grau de avaliação do construto CAP_SOC (que inclui os indicadores REL_BANK, REC_CRED, VOL_CRED, DIF_CRED e IMP_CRED), melhora o desempenho da empresa e CAP_SOC explica 22\% dessa variação.

Com relação às "Características Gerencias", demonstraram-se significativos os construtos PLAN_AB (que inclui PESQ_MERC, PESQ_FORN, PESQ_AMB, PESQ_LOC e AN_VEF) e FIN_CP (que inclui ANT_REC e JURO). O construto PLAN_AB trata especificamente no nível de planejamento realizado antes da abertura do negócio. Observou-se que à medida que se intensifica essa atividade melhora o desempenho da empresa. Com relação às fontes e o custo de financiamento de curto prazo (FIN_CP), constatou-se que se diminui a utilização de antecipação de recebíveis e pagamento de juros elevados, melhora o desempenho da empresa.

O construto SUP_GOV (que inclui CRED_LA e SERV_PUB) também apresentou o sinal esperado, demonstrando que a deterioração deste fator impacta negativamente o desempenho da empresa. O modelo regressor estimado, incluindo todos os indicadores, foi:

$$
\begin{aligned}
D S P= & -1,48\left(\mathrm{PLAN} \_\mathrm{AB}\right)-2,64\left(\mathrm{SUP} \_\mathrm{GOV}\right)+1,57\left(\mathrm{FIN} \_\mathrm{CP}\right) \\
& -1,48\left(\mathrm{CAP}{ }_{-} \mathrm{SOC}\right)+2,75(\mathrm{INOV})+5,29\left(\mathrm{QUAL} \_\mathrm{E}\right)-1,01\left(\mathrm{ID} \_\mathrm{E}\right)
\end{aligned}
$$




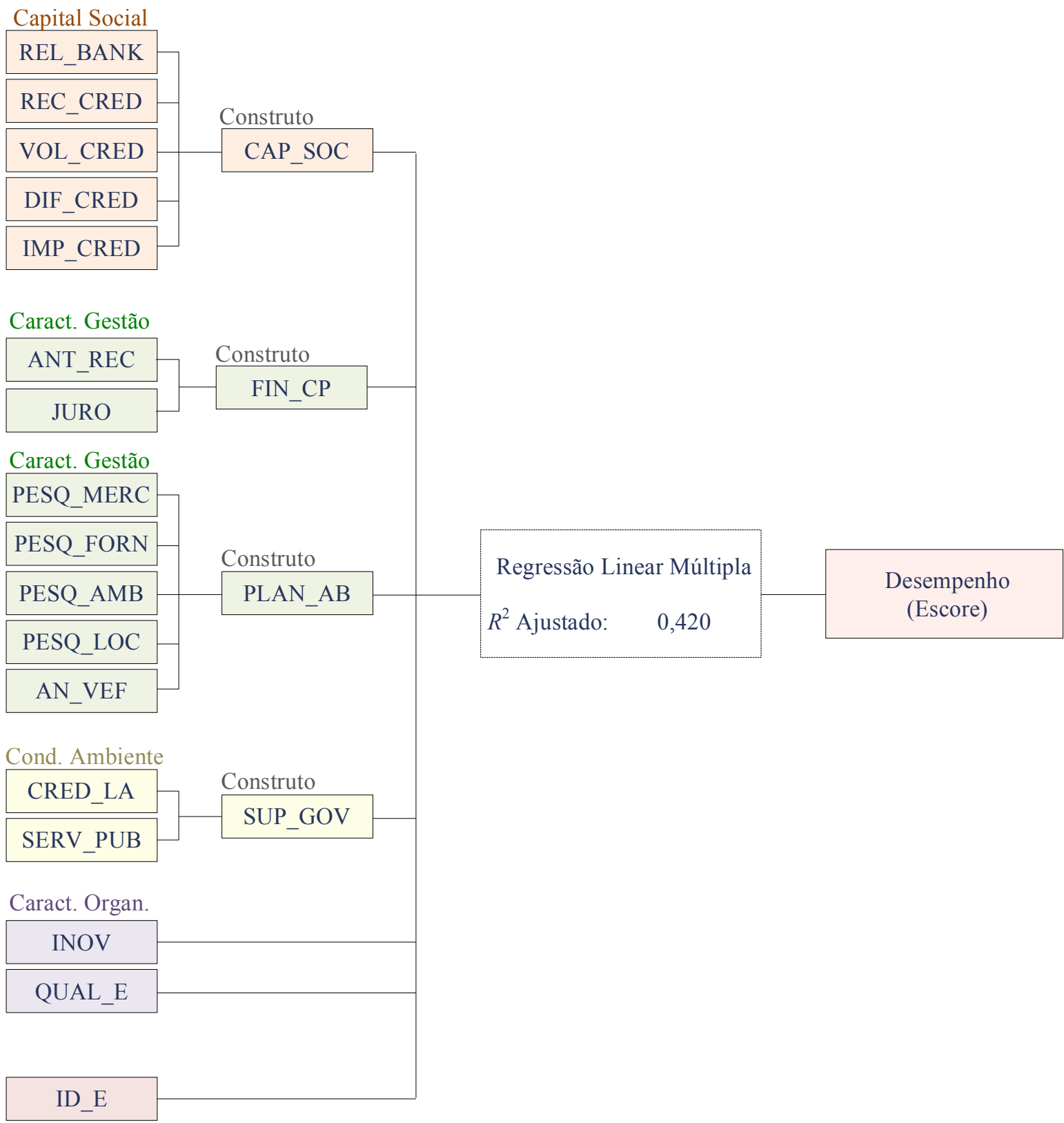

Figura 12 - Variáveis influentes e poder explicativo - regressão linear

Na Figura 12 é apresentado o resumo das conclusões dos testes de hipótese obtidos por meio da regressão linear, onde se verifica que as dimensões (1) capital social, (2) características gerenciais, (3) condições do ambiente e (4) características organizacionais apresentaram pelo menos um indicador estatisticamente significativo, para as quais rejeitam-se as hipóteses nulas concluindo que existem evidências de que estas dimensões (fatores) afetam o desempenho de PMEs. 


\subsubsection{Sobrevivência versus não sobrevivência - modelo logístico geral}

A regressão logística binária testou a capacidade de cada uma das dimensões, incluindo seus construtos e indicadores, em discriminar as empresas sobreviventes das não sobreviventes. As variáveis de entrada incluem o conjunto das variáveis definidas nos testes parciais, apresentados no item 4.2 deste estudo.

Para teste do modelo a variável dependente foi codificada como 0 (insucesso) se a empresa não sobreviveu e como 1 (sucesso) se a empresa sobreviveu. Na Tabela 130 estão apresentadas as frequências das variáveis qualitativas e a codificação dos parâmetros em função do número de categorias.

Tabela 130 - Frequência e codificação das variáveis qualitativas

\begin{tabular}{|c|c|c|c|c|}
\hline \multirow[t]{2}{*}{ Variável } & \multirow[t]{2}{*}{ Categoria } & \multirow[t]{2}{*}{$\mathbf{F}_{\mathbf{i}}$} & \multicolumn{2}{|c|}{$\begin{array}{l}\text { Codificação de } \\
\text { parâmetro }\end{array}$} \\
\hline & & & (1) & (2) \\
\hline \multirow{3}{*}{ INAD } & 1 [ Sempre ou quase sempre] & 26 & 1 & 0 \\
\hline & 2 [Muitas vezes ou algumas vezes] & 104 & 0 & 1 \\
\hline & 3 [Raramente ou nunca] & 77 & 0 & 0 \\
\hline \multirow{3}{*}{ EXP_R } & 1 [Nenhuma ou menos de 1 ano] & 138 & 1 & 0 \\
\hline & $2[$ De 1 a 5 anos] & 40 & 0 & 1 \\
\hline & 3 [Mais de 5 anos] & 29 & 0 & 0 \\
\hline \multirow{3}{*}{ EXP_OC } & 1 [Nada ou menos de 1 ano] & 44 & 1 & 0 \\
\hline & 2 [De 1 a 10 anos] & 71 & 0 & 1 \\
\hline & 3 [Mais de 10 anos] & 92 & 0 & 0 \\
\hline \multirow{3}{*}{ SAZON } & 1 [Muito ou bastante sazonal] & 59 & 1 & 0 \\
\hline & 2 [Razoavelmente sazonal] & 84 & 0 & 1 \\
\hline & 3 [Pouco ou nada sazonal] & 64 & 0 & 0 \\
\hline \multirow{3}{*}{ QUAL_E } & 1 [Muito qualificado] & 4 & 1 & 0 \\
\hline & 2 [Qualificado] & 103 & 0 & 1 \\
\hline & 3 [Pouco ou sem qualificação] & 100 & 0 & 0 \\
\hline \multirow{2}{*}{ SERV_ESP } & $2[$ Frequente $]$ & 45 & 1 & - \\
\hline & 3 [Pouco ou raramente frequente] & 162 & 0 & - \\
\hline \multirow{3}{*}{ COMP } & 1 [Altamente Competitivo] & 88 & 1 & 0 \\
\hline & 2 [Competitivo] & 80 & 0 & 1 \\
\hline & 3 [Competição baixa & 39 & 0 & 0 \\
\hline
\end{tabular}

As variáveis HIST_FAM, COMP, INAD, FIN_CP e TREIN_E, após o teste inicial, foram excluídas por não terem apresentado significância discriminatória.

O teste de coeficientes de Omnibus $\left(x^{2}=143,7 ; p<0,001\right)$ demonstrou que o modelo possui pelo menos uma variável capaz de discriminar os grupos da variável dependente, enquanto que o teste de Hosmer e Lemeshow $\left(x^{2}=3,317 ; g l=8 ; p=0,913\right)$ assegurou o ajustamento 
dos dados ao modelo.

As estimativas de verossimilhança de log $-2(80,47)$, e os pseudo- $R^{2}$ de Cox e Snell $(0,501)$ e Nagelkerke $(0,757)$ conferem ao modelo bom poder de discriminação.

Tabela 131 - Classificações corretas - Modelo Geral

\begin{tabular}{lccc}
\hline \multirow{2}{*}{ Observado } & \multicolumn{3}{c}{ Previsto } \\
\cline { 2 - 4 } & $\begin{array}{c}\text { Não } \\
\text { Sobreviventes }\end{array}$ & Sobreviventes & $\begin{array}{c}\text { Porcentagem } \\
\text { correta }\end{array}$ \\
\hline Não Sobreviventes & 40 & 8 & $83,3 \%$ \\
Sobreviventes & 5 & 167 & $97,1 \%$ \\
Porcentagem global & & & $94,1 \%$ \\
\hline
\end{tabular}

$\mathrm{Na}$ Tabela 131 observa-se que 94,1\% dos casos foram classificados corretamente. Do conjunto de 48 empresas não sobreviventes, 40 (83,3\%) foram classificadas corretamente, enquanto do grupo das empresas sobreviventes o índice de acerto foi de 97,1\%.

Tabela 132 - Coeficientes do modelo logístico geral

\begin{tabular}{lcrrrrrrr}
\hline \multicolumn{1}{c}{ Modelo } & $\boldsymbol{\beta}$ & \multicolumn{1}{c}{$\begin{array}{c}\text { Erro } \\
\text { Padrão }\end{array}$} & Wald & $\boldsymbol{g} \boldsymbol{l}$ & Sig. & $\boldsymbol{e}^{\boldsymbol{\beta}}$ & $\begin{array}{c}\text { IC 95\% } \\
\text { Inferior }\end{array}$ & $\begin{array}{l}\text { para } \boldsymbol{e}^{\boldsymbol{\beta}} \\
\text { Superior }\end{array}$ \\
\hline EXP_OC & & & 13,901 & 2 & 0,001 & & & \\
EXP_OC(1) & 3,095 & 1,040 & 1,890 & 1 & 0,169 & 2,091 & 2,875 & 169,712 \\
EXP_OC(2) & $-0,849$ & 0,618 & 8,852 & 1 & 0,003 & 0,428 & 0,127 & 1,436 \\
EXP_R & & & 8,402 & 2 & 0,015 & & & \\
EXP_R(1) & $-2,399$ & 1,154 & 4,322 & 1 & 0,038 & 0,091 & 0,009 & 0,872 \\
EXP_R(2) & 0,189 & 1,312 &, 021 & 1 & 0,885 & 1,208 & 0,092 & 15,815 \\
CAP_SOC & $-0,826$ & 0,291 & 8,033 & 1 & 0,005 & 0,438 & 0,247 & 0,775 \\
PLAN_AB & $-0,779$ & 0,343 & 5,150 & 1 & 0,023 & 0,459 & 0,234 & 0,899 \\
SAZON & & & 10,331 & 2 & 0,006 & & & \\
SAZON(1) & $-2,278$ & 0,785 & 8,426 & 1 & 0,004 & 0,102 & 0,022 & 0,477 \\
SAZON(2) & $-0,105$ & 0,704 &, 022 & 1 & 0,881 & 0,900 & 0,227 & 3,575 \\
SUP_GOV & $-1,461$ & 0,451 & 10,511 & 1 & 0,001 & 0,232 & 0,096 & 0,561 \\
QUAL_E & & & 7,763 & 2 & 0,021 & & & \\
QUAL_E(2) & 1,870 & 0,671 & 7,763 & 1 & 0,005 & 6,490 & 1,741 & 24,188 \\
TAM & 0,213 & 0,072 & 8,670 & 1 & 0,003 & 1,237 & 1,074 & 1,425 \\
Constante & 3,120 & 1,312 & 5,655 & 1 & 0,017 & 22,651 & & \\
\hline
\end{tabular}

Na Tabela 132 observa-se que o modelo discriminador de sobrevivência e não sobrevivência foi formado pelas variáveis: experiência ocupacional (EXP_OC); experiência no ramo (EXP_R); capital social (CAP_SOC); nível de planejamento antes da abertura do negócio (PLAN_AB); sazonalidade (SAZON); suporte governamental (SUP_GOV); qualificação dos empregados (QUAL_E); tamanho da empresa - número de funcionários (TAM).

Com relação à experiência ocupacional conclui-se que as chances de sobrevivência da 
empresa diminuem em $57,2 \%\left(e^{\beta}=0,428 ; p=0,003\right)$ se o empreendedor pertence à categoria "1 a 10 anos" [EXP_OC(2)] ao invés da categoria "mais de 10 anos" (EXP_OC). Entendimento equivalente segue para experiência no ramo, onde as chances da sobrevivência diminuem em $91 \%\left(e^{\beta}=0,091 ; p=0,038\right)$ se a empresa pertencer à categoria "nada ou menos de 1 ano" [EXP_R(1)] em comparação com a categoria "mais de 5 anos" (EXP_R).

Com relação ao capital social conclui-se que as chances de sobrevivência diminuem 56,2\% $\left(e^{\beta}=0,438 ; p=0,005\right)$ a cada unidade de deterioração na avaliação do construto CAP_SOC. Observa-se que o construto PLAN_AB apresentou peso semelhante, onde se constatou que a cada unidade de deterioração no nível de planejamento realizado antes da abertura, as chances de sobrevivência são diminuídas em $54,1 \%\left(e^{\beta}=0,459 ; p=0,023\right)$.

$\mathrm{Na}$ dimensão das condições do ambiente observou-se que as chances de uma empresa ser classificada como sobrevivente diminui $90 \%\left(e^{\beta}=0,102 ; p=0,004\right)$ se ela encontrar-se na categoria "muito ou bastante sazonal" [SAZON(1)] em comparação com a categoria "pouco ou nada sazonal” (SAZON). Ainda constatou-se, nesta dimensão, que as chances de sobrevivência diminuem $76,8 \%\left(e^{\beta}=0,232 ; p=0,001\right)$ a cada unidade de deterioração na avaliação do suporte governamental (SUP_GOV).

Com relação às características organizacionais concluiu-se que a probabilidade de sobrevivência aumenta 5,49 vezes $\left(e^{\beta}=6,490 ; p=0,005\right)$ se o quadro de funcionários for "qualificado" [QUAL_E(2)] em comparação com o quadro "pouco ou sem qualificação" (QUAL_E). O tamanho (tomado como o número de empregados) mostrou-se discriminante onde, a cada empregado adicional, as chances de sobrevivência aumentam $23,7 \%\left(e^{\beta}=1,237\right.$; $p=0,003)$.

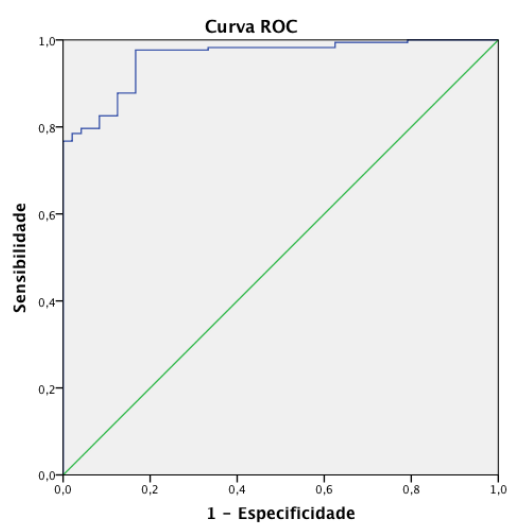

Gráfico 8 - Área sob a curva ROC - modelo logístico geral 
No Gráfico 8 verifica-se que o poder de discriminatório do modelo pode ser classificado como excelente $(c=0,960 ; p<0,001)$.

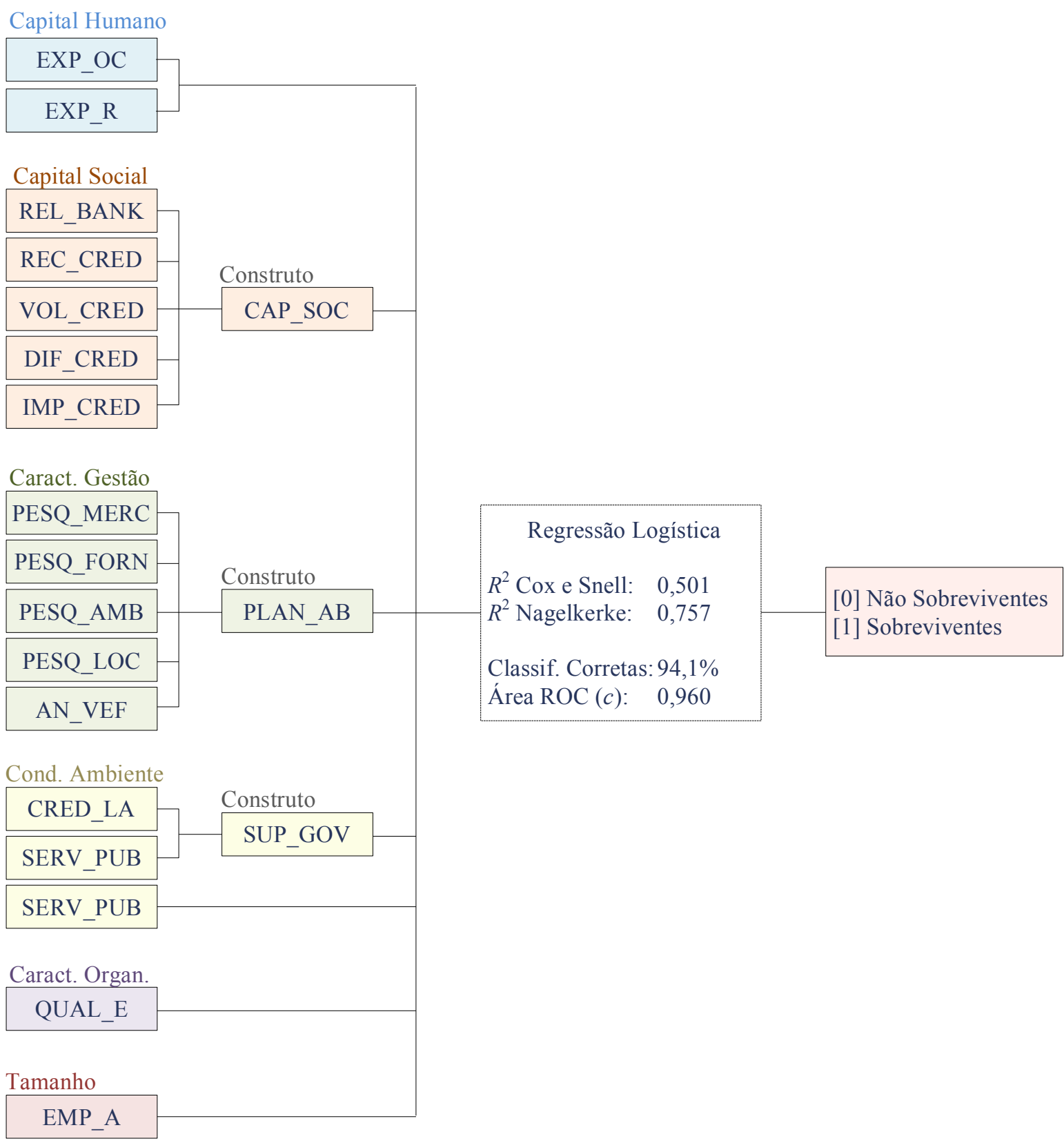

Figura 13 - Variáveis influentes e poder discriminatório - modelo logístico geral

O modelo logístico estimado é dado por:

$$
\begin{aligned}
\operatorname{Logit}(\pi)= & 3,12+3,1\left[\mathrm{EXP} \_\mathrm{OC}(1)\right]-0,85\left[\mathrm{EXP} \_\mathrm{OC}(2)\right]-2,4[\mathrm{EXP} \mathrm{R}(1)] \\
& -0,83\left(\mathrm{CAP} \_\mathrm{SOC}\right)-0,78\left(\mathrm{PLAN} \_\mathrm{AB}\right)-2,28[\mathrm{SAZON}(1)] \\
& -1,46\left(\mathrm{SUP} \_\mathrm{GOV}\right)+1,87\left[\mathrm{QUAL} \_\mathrm{E}(2)\right]+0,213(\mathrm{TAM})
\end{aligned}
$$

Na Figura 13 estão apresentados os indicadores (construtos) influentes na discriminação entre 
as empresas "não sobreviventes" e "sobreviventes". Constatou-se que as dimensões (1) capital humano, (2) capital social, (3) características de gestão, (4) condições do ambiente, (5) características organizacionais e (6) tamanho apresentaram pelo menos um indicador discriminante da sobrevivência das empresas, paras as quais rejeitam-se as hipóteses nulas concluindo que há evidências da influência desses fatores no desempenho das empresas.

\subsubsection{Regressão Logística Multinomial}

Nesse modelo de teste a variável dependente foi formada por três grupos: a) não sobreviventes; b) sobrevivência marginal, e; c) alto desempenho.

Tabela 134 - Informações do ajuste do modelo

\begin{tabular}{lcccccccc}
\hline \multirow{2}{*}{ Modelo } & \multicolumn{2}{c}{ Critérios de ajuste de modelo } & & \multicolumn{3}{c}{ Teste de razão de verossimilhança } \\
\cline { 2 - 4 } & AIC & BIC & $\mathbf{- 2 L L}$ & & $\boldsymbol{G}^{2}$ & $\boldsymbol{g} \boldsymbol{l}$ & Sig. \\
\hline Constante & 262,484 & 268,059 & 258,484 & & & & \\
Final & 162,485 & 234,960 & 110,485 & & 147,999 & 24 & 0,000 \\
\hline
\end{tabular}

O modelo final (Tabela 134) apresentou ajuste melhor que o modelo nulo (constante), observando-se menores coeficientes para AIC, BIC e -2LL e estatisticamente significativos $\left(G^{2}(24)=147,999 ; p<0,001\right)$. O teste $G$ equivale ao teste $F$ da regressão múltipla. Os dados mostraram-se adequados ao modelo nos testes de qui-quadrado de Pearson $\left(x^{2}=130,7 ; p=\right.$ $0,237)$ e de Deviance $\left(x^{2}=110,7 ; p=0,722\right)$. Os pseudo- $R^{2}$ de Cox e Snell $(0,709)$, Nagelkerke $(0,802)$ e McFadden $(0,573)$ conferem bom poder de discriminação ao modelo.

Na Tabela 135 constatou-se que o planejamento antes da abertura do negócio (PLAN_AB) apresentou o mais elevado poder de discriminação do conjunto de variáveis, tanto em relação com o grupo de sobrevivência marginal $\left(X_{\text {Wald }}^{2}=8,783 ; p=0,003\right)$, como em relação ao grupo "alto desempenho" $\left(X_{\text {Wald }}^{2}=14,603 ; p<0,001\right)$. Tem-se que a cada unidade de deterioração em PLAN_AB, as chances de passagem do grupo "não sobrevivente" para o grupo "sobrevivência marginal" diminuem em 76,5\% $\left(e^{\beta}=0,235 ; p=0,003\right)$, e as chances de passagem para o grupo "alto desempenho" diminuem em $96,5 \%\left(e^{\beta}=0,035 ; p<0,001\right)$. Ainda analisando a dimensão das características de gestão, verificou-se que as fontes de financiamento de curto prazo (FIN_CP) apresentaram capacidade discriminatória apenas no grupo $2\left(X_{W a l d}^{2}=7,888 ; p=0,005\right)$, onde a cada nível de diminuição no uso de antecipação de recebíveis e pagamento de custos financeiros elevados, as chances da empresa passar do 
grupo "não sobrevivente" para o grupo "alto desempenho" aumenta 7,4 vezes $\left(e^{\beta}=8,422 ; p=\right.$ $0,005)$.

Tabela 135 - Coeficientes do modelo

\begin{tabular}{|c|c|c|c|c|c|c|c|c|c|}
\hline \multirow{2}{*}{\multicolumn{2}{|c|}{ Grupo/Modelo }} & \multirow[b]{2}{*}{$\beta$} & \multirow[b]{2}{*}{$\begin{array}{c}\text { Erro } \\
\text { padrão }\end{array}$} & \multirow[b]{2}{*}{ Wald } & \multirow[b]{2}{*}{$g l$} & \multirow[b]{2}{*}{ Sig. } & \multirow[b]{2}{*}{$e^{\mathbf{B}}$} & \multicolumn{2}{|c|}{ IC $95 \%$ para $e^{B}$} \\
\hline & & & & & & & & $\begin{array}{c}\text { Limite } \\
\text { inferior }\end{array}$ & $\begin{array}{l}\text { Limite } \\
\text { superior }\end{array}$ \\
\hline \multirow{13}{*}{ 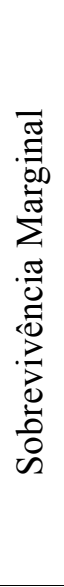 } & Constante & 0,186 & 1,676 & 0,012 & 1 & 0,912 & & & \\
\hline & PLAN_AB & $-1,449$ & 0,489 & 8,783 & 1 & 0,003 & 0,235 & 0,090 & 0,612 \\
\hline & SUP_ḠOV & $-0,489$ & 0,460 & 1,130 & 1 & 0,288 & 0,613 & 0,249 & 1,511 \\
\hline & EMP_A & 0,147 & 0,080 & 3,346 & 1 & 0,067 & 1,158 & 0,990 & 1,355 \\
\hline & FIN_C̄ & $-0,288$ & 0,411 & 0,491 & 1 & 0,484 & 0,750 & 0,335 & 1,679 \\
\hline & EXP_oC (1) & 2,289 & 1,381 & 2,746 & 1 & 0,098 & 9,861 & 0,658 & 147,758 \\
\hline & EXP_OC (2) & $-1,646$ & 0,824 & 3,988 & 1 & 0,046 & 0,193 & 0,038 & 0,970 \\
\hline & $\mathrm{EXP}_{-}^{-} \mathrm{R}(1)$ & $-0,446$ & 1,240 & 0,129 & 1 & 0,719 & 0,640 & 0,056 & 7,277 \\
\hline & EXP_R (2) & 1,332 & 1,467 & 0,824 & 1 & 0,364 & 3,787 & 0,214 & 67,131 \\
\hline & EMP_C (1) & 2,302 & 1,071 & 4,615 & 1 & 0,032 & 9,990 & 0,224 & 81,564 \\
\hline & EMP_C (2) & 1,479 & 1,134 & 1,701 & 1 & 0,192 & 4,391 & 0,475 & 40,571 \\
\hline & TREIN E (1) & $-1,673$ & 1,103 & 2,300 & 1 & 0,129 & 0,188 & 0,022 & 1,631 \\
\hline & TREIN_E (2) & $-4,071$ & 1,670 & 5,944 & 1 & 0,015 & 0,017 & 0,001 & 0,450 \\
\hline \multirow{13}{*}{ 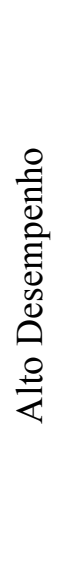 } & Constante & 0,713 & 2,072 & 0,118 & 1 & 0,731 & & & \\
\hline & PLAN AB & $-3,363$ & 0,880 & 14,603 & 1 & 0,000 & 0,035 & 0,006 & 0,194 \\
\hline & SUP_ḠGV & $-1,887$ & 0,746 & 6,399 & 1 & 0,011 & 0,151 & 0,035 & 0,654 \\
\hline & EMP_A & 0,336 & 0,114 & 8,600 & 1 & 0,003 & 1,399 & 1,118 & 1,750 \\
\hline & FIN_CP & 2,131 & 0,759 & 7,888 & 1 & 0,005 & 8,422 & 1,904 & 37,262 \\
\hline & EXP_oC (1) & 7,704 & 2,262 & . & 1 & 0,001 & - & & \\
\hline & EXP_OC (2) & 0,184 & 1,224 & 0,023 & 1 & 0,881 & 1,202 & 0,109 & 13,240 \\
\hline & EXP_R (1) & $-4,676$ & 1,901 & 6,052 & 1 & 0,014 & 0,009 & 0,000 & 0,387 \\
\hline & EXP_R (2) & $-2,705$ & 2,146 & 1,588 & 1 & 0,208 & 0,067 & 0,001 & 4,491 \\
\hline & EMP_C (1) & 2,780 & 1,621 & 2,942 & 1 & 0,086 & 16,120 & 0,673 & 386,300 \\
\hline & EMP_C (2) & 5,648 & 2,091 & 7,292 & 1 & 0,007 & 3,614 & 4,704 & 100,385 \\
\hline & TREIN_E (1) & $-2,920$ & 1,336 & 4,778 & 1 & 0,029 & 0,054 & 0,004 & 0,739 \\
\hline & TREIN_E (2) & $-3,994$ & 1,801 & 4,919 & 1 & 0,027 & 0,018 & 0,001 & 0,629 \\
\hline
\end{tabular}

Obs.: Grupo de referência: [0] não sobreviventes

Com relação ao suporte governamental, também se observou que não houve capacidade discriminante para os grupos 0 e $1\left(X_{\text {Wald }}^{2}=1,130 ; p=0,288\right)$, entretanto foi significante entre os grupos 0 e $2\left(X_{\text {Wald }}^{2}=6,399 ; p=0,011\right)$. Nesse caso, a cada unidade de piora na avaliação de SUP_GOV, as chances de passagem entre os grupos (0 para 2) diminuem em $85 \%\left(e^{\mathrm{B}}=0,151 ; p=0,011\right)$.

Sob a ótica do capital humano verificaram-se dois indicadores discriminantes: a) Experiência Ocupacional (EXP_OC), e; b) Experiência no Ramo (EXP_R). Conclui-se que as chances de mudança de grupo (de 0 para 1) são diminuídas em $80,7 \%\left(e^{\beta}=0,193 ; p=0,046\right)$ se o empreendedor ter trabalhado como empregado "de 1 a 10 anos" antes de abrir a empresa em 
comparação com aquele que trabalhou mais de 10 anos. No caso da experiência no ramo (EXP_R) verifica-se que não houve poder discriminatório entre os grupos 0 e 1. Com relação aos grupos 0 e 2 verificou-se que se empreendedor pertencer à categoria "nada ou menos de 1 ano" [EXP_R(1)] em comparação com a categoria "mais de 2 anos" (OCUP_R), a probabilidade de passagem (de 0 para 2) é diminuída em 98,6\% $\left(e^{\beta}=0,014 ; p=0,009\right)$. Ainda, se pertencer à categoria "de 1 a 2 anos" [EXP_R(2)] em comparação com "mais de 2 anos", as chances são diminuídas em $80 \%\left(e^{\beta}=0,208 ; p=0,067\right)$. Ressalte-se, nesse caso, que há ligeira perda de significância estatística.

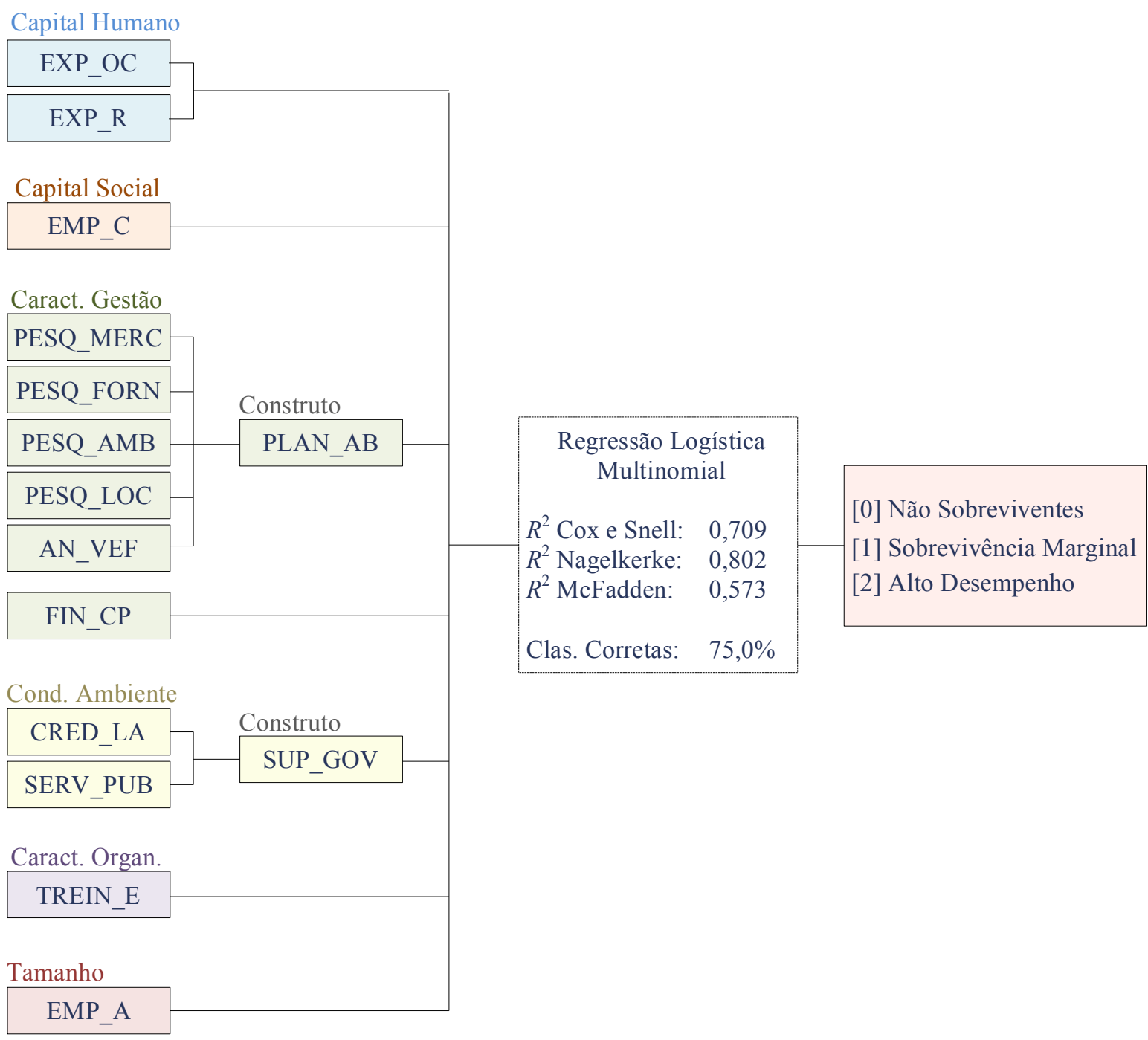

Figura 14 - Variáveis influentes - modelo multinomial

No contexto do capital social, o indicador "empréstimos na constituição do negócio" (EMP_C) apresentou capacidade discriminatória no âmbito dos dois grupos e com elevado 
grau de sensibilidade. Se o empreendedor pertencer à categoria "não utilizei empréstimos" [EMP_C(1)] ao invés da categoria "mais de 40\%" (EMP_C), suas chances de ser classificado no grupo "sobrevivência marginal" em comparação com "não sobrevivente" aumentam 9 vezes $\left(e^{\beta}=9,990 ; p=0,032\right)$, enquanto suas chances de ser classificado no grupo "alto desempenho" aumentam 2,6 vezes $\left(e^{\beta}=3,614 ; p=0,007\right)$.

No que se refere à características organizacionais, conclui-se que a quantia de treinamento recebida pelos empregados (TREIN_E) mostrou-se discriminante tanto no grupo “sobrevivência marginal" para TREI_E(2) $\left(e^{\beta}=0,208 ; p=0,067\right)$, como no grupo "alto desempenho" para TREIN_E(1) $\left(e^{\beta}=0,054 ; p=0,029\right)$ e TREIN_E(2) $\left(e^{\beta}=0,018 ; p=\right.$ 0,027).

Com relação ao tamanho (EMP_A), verificou-se poder de discriminação em relação aos dois grupos. Cada empregado adicional aumenta em 15,8\% $\left(e^{\beta}=1,158 ; p=0,067\right)$ as chances de a empresa ser classificada no grupo "sobrevivência marginal" em relação ao grupo "não sobrevivente", enquanto que essas chances são aumentadas $40 \%$ para a classificação no grupo "alto desempenho" $\left(e^{\beta}=1,399 ; p=0,003\right)$. Nota-se que a quantidade de empregados é mais discriminante do grupo "alto desempenho" que "sobrevivência marginal".

Tabela 136 - Classificações corretas - modelo multinomial geral

\begin{tabular}{lcccc}
\hline \multirow{2}{*}{ Observado } & \multicolumn{4}{c}{ Previsto } \\
\cline { 2 - 5 } & $\begin{array}{c}\text { Não } \\
\text { Sobreviventes }\end{array}$ & $\begin{array}{c}\text { Sobrevivência } \\
\text { Marginal }\end{array}$ & $\begin{array}{c}\text { Alto } \\
\text { Desempenho }\end{array}$ & $\begin{array}{c}\text { Porcentagem } \\
\text { correta }\end{array}$ \\
\hline Não Sobreviventes & 46 & 6 & 0 & $88,5 \%$ \\
Sobrevivência Marginal & 9 & 19 & 6 & $55,9 \%$ \\
Alto Desempenho & 2 & 7 & 25 & $73,5 \%$ \\
Porcentagem global & $47,5 \%$ & $26,7 \%$ & $25,8 \%$ & $75,0 \%$ \\
\hline
\end{tabular}

Na Tabela 136 nota-se que o modelo classificou corretamente $75 \%$ das empresas. O melhor desempenho foi observado na classificação das empresas "não sobreviventes", sendo que, de 52 empresas, $46(88,5 \%)$ foram classificadas corretamente, enquanto outras 6 (11,5\%) foram classificadas como "sobrevivência marginal".

Na Figura 14 estão sintetizados os indicadores (construtos) significativos do modelo. Concluise pela rejeição das hipóteses nulas nas dimensões (1) capital humano, (2) capital social, (3) características gerenciais, (4) condições do ambiente, (5) características organizacionais e (6) tamanho. As probabilidades $(P)$ de classificação, em cada grupo, é dado por: 


$$
\begin{aligned}
& P(Y=0)=\frac{1}{1+e^{-1,449\left(\mathrm{PLAN} \_\mathrm{AB}\right)-1,646\left[\mathrm{EXP} \_\mathrm{OC}(2)\right]+2,3\left[\mathrm{EMP} \_\mathrm{C}(1)\right]-4,1\left[\mathrm{TREIN} \_\mathrm{E}(2)\right]}} \\
& +e^{-3,363\left(\mathrm{PLAN}_{-} \mathrm{AB}\right)-1,89\left(\mathrm{SUP}_{-} \mathrm{GOV}\right)+0,34\left(\mathrm{EMP}_{-} \mathrm{A}\right)+2,13\left(\mathrm{FIN} \_\mathrm{CP}\right)} \\
& \times e^{-4,68\left[\mathrm{EXP} \_\mathrm{R}(1)\right]}+5,65\left[\mathrm{EMP} \_\mathrm{C}(2)-2,92\left[\mathrm{TREIN} \_\mathrm{E}(1)\right]-4\left[\mathrm{TREIN} \_\mathrm{E}(2)\right]\right. \\
& P(Y=1)=\frac{e^{-1,449\left(\mathrm{PLAN} \_\mathrm{AB}\right)-1,646\left[\mathrm{EXP} \_\mathrm{OC}(2)\right]+2,3\left[\mathrm{EMP} \_\mathrm{C}(1)\right]-4,1\left[\mathrm{TREIN} \_\mathrm{E}(2)\right]}}{1+e^{-1,449\left(\mathrm{PLAN} \_\mathrm{AB}\right)-1,646\left[\mathrm{EXP} \_\mathrm{OC}(2)\right]+2,3\left[\mathrm{EMP} \_\mathrm{C}(1)\right]-4,1\left[\mathrm{TREIN} \_\mathrm{E}(2)\right]}} \\
& +e^{-3,363\left(\mathrm{PLAN} \_\mathrm{AB}\right)}-1,89\left(\mathrm{SUP} \_\mathrm{GOV}\right)+0,34\left(\mathrm{EMP} \_\mathrm{A}\right)+2,13\left(\mathrm{FIN} \_\mathrm{CP}\right) \\
& \left.\times e^{-4,68[\mathrm{EXP}}{ }_{-} \mathrm{R}(1)\right]+5,65\left[\mathrm{EMP} \_\mathrm{C}(2)-2,92\left[\mathrm{TREIN} \_\mathrm{E}(1)\right]-4\left[\mathrm{TREIN} \_\mathrm{E}(2)\right]\right. \\
& e^{-3,363\left(\mathrm{PLAN}_{-} \mathrm{AB}\right)-1,89\left(\mathrm{SUP}_{-} \mathrm{GOV}\right)+0,34\left(\mathrm{EMP}_{-} \mathrm{A}\right)+2,13\left(\mathrm{FIN} \_\mathrm{CP}\right)} \\
& P(Y=2)=\frac{\times e^{-4,68\left[\mathrm{EXP} \_\mathrm{R}(1)\right]+5,65\left[\mathrm{EMP} \_\mathrm{C}(2)-2,92\left[\mathrm{TREIN} \_\mathrm{E}(1)\right]-4\left[\mathrm{TREIN} \_\mathrm{E}(2)\right]\right.}}{1+e^{-1,449\left(\mathrm{PLAN} \_\mathrm{AB}\right)-1,646\left[\mathrm{EXP} \_\mathrm{OC}(2)\right]+2,3\left[\mathrm{EMP} \_\mathrm{C}(1)\right]-4,1\left[\mathrm{TREIN} \_\mathrm{E}(2)\right]}} \\
& +e^{-3,363\left(\mathrm{PLAN}_{-} \mathrm{AB}\right)-1,89\left(\mathrm{SUP}_{-} \mathrm{GOV}\right)}+0,34\left(\mathrm{EMP}_{-} \mathrm{A}\right)+2,13\left(\mathrm{FIN}_{-} \mathrm{CP}\right) \\
& \times e^{-4,68\left[\mathrm{EXP} \_\mathrm{R}(1)\right]}+5,65\left[\mathrm{EMP} \_\mathrm{C}(2)-2,92\left[\mathrm{TREIN} \_\mathrm{E}(1)\right]-4\left[\mathrm{TREIN} \_\mathrm{E}(2)\right]\right.
\end{aligned}
$$

Na Tabela 137 está apresentada a síntese das inferências parciais. Constata-se que as dimensões (a) capital social, (b) características gerenciais e (c) condições do ambiente incluíram o maior número de indicadores influentes, e nas três estatísticas utilizadas (regressão linear múltipla, regressão logística binária e regressão logística multinomial). Outro aspecto relevante a ser observado é que o modelo logístico multinomial reteve mais indicadores influentes que as demais estatísticas, tanto nas inferências parciais, quanto nos modelos gerais.

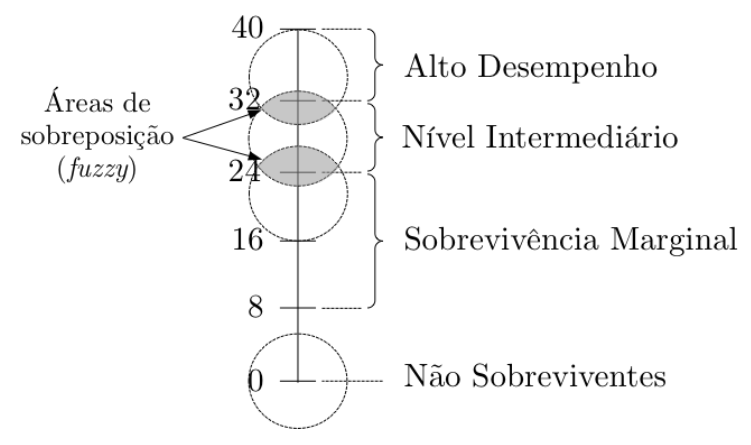

Figura 15 - Regiões fuzzy

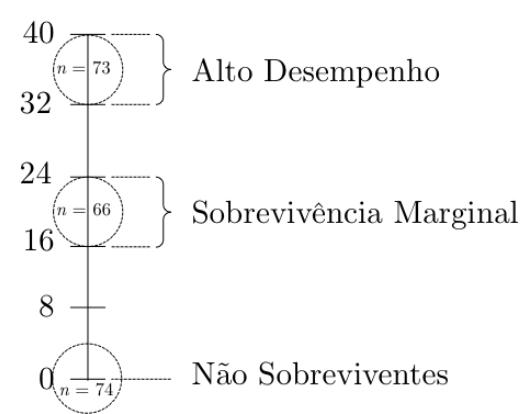

Figura 16 - Eliminação da região fuzzy

O modelo multinomial foi otimizado pela exclusão das empresas classificadas no nível intermediário, que têm seus limites inferior e superior sobrepostos aos grupos sobrevivência 
marginal (no inferior) e alto desempenho (no superior). É o que denomina-se região cinza ou fuzzy (Figura 15). Erros de classificações são comumente atribuídos à essas regiões, e.g., uma empresa que obteve 32 pontos é classificada como "nível intermediário", e outra, com 32,1 pontos, é classificada como "alto desempenho", no entanto, ambas deveriam pertencer à um mesmo grupo, possivelmente resultante da combinação da parte inferior de "alto desempenho" com a parte superior do "nível intermediário".

No modelo logístico multinomial foi excluído o grupo "nível intermediário", produzindo-se grupos sem intercorrências de regiões sobrepostas (Figura 16), o que otimizou o modelo.

Na Tabela 138 foram resumidos os resultados dos modelos gerais de acordo com cada um dos testes utilizados. Observou-se que no modelo linear "a qualidade do staff" apresentou o maior poder explicativo, enquanto nos modelos logísticos binário e multinomial, o suporte governamental e o planejamento antes da abertura, respectivamente apresentaram maior capacidade de discriminação. 


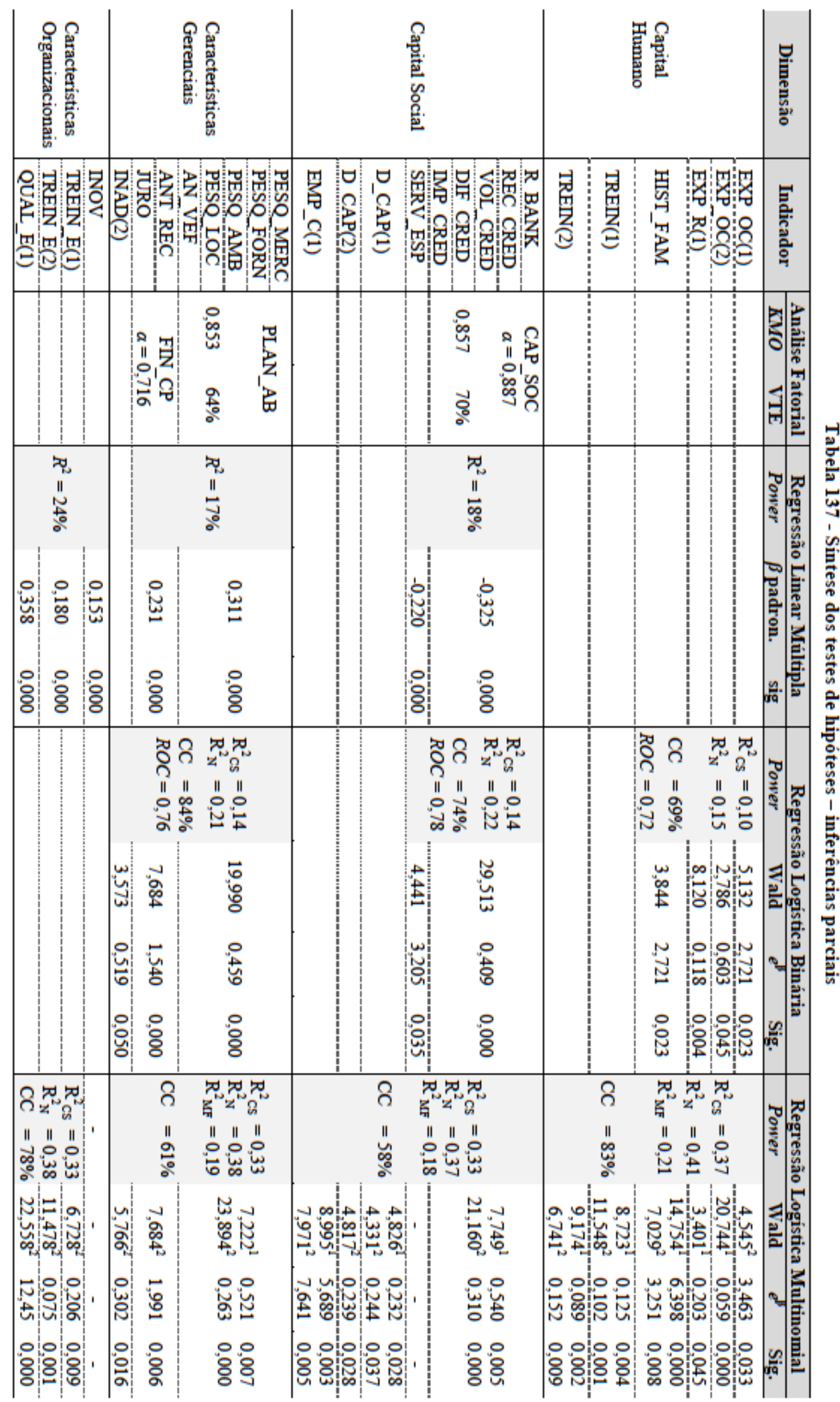



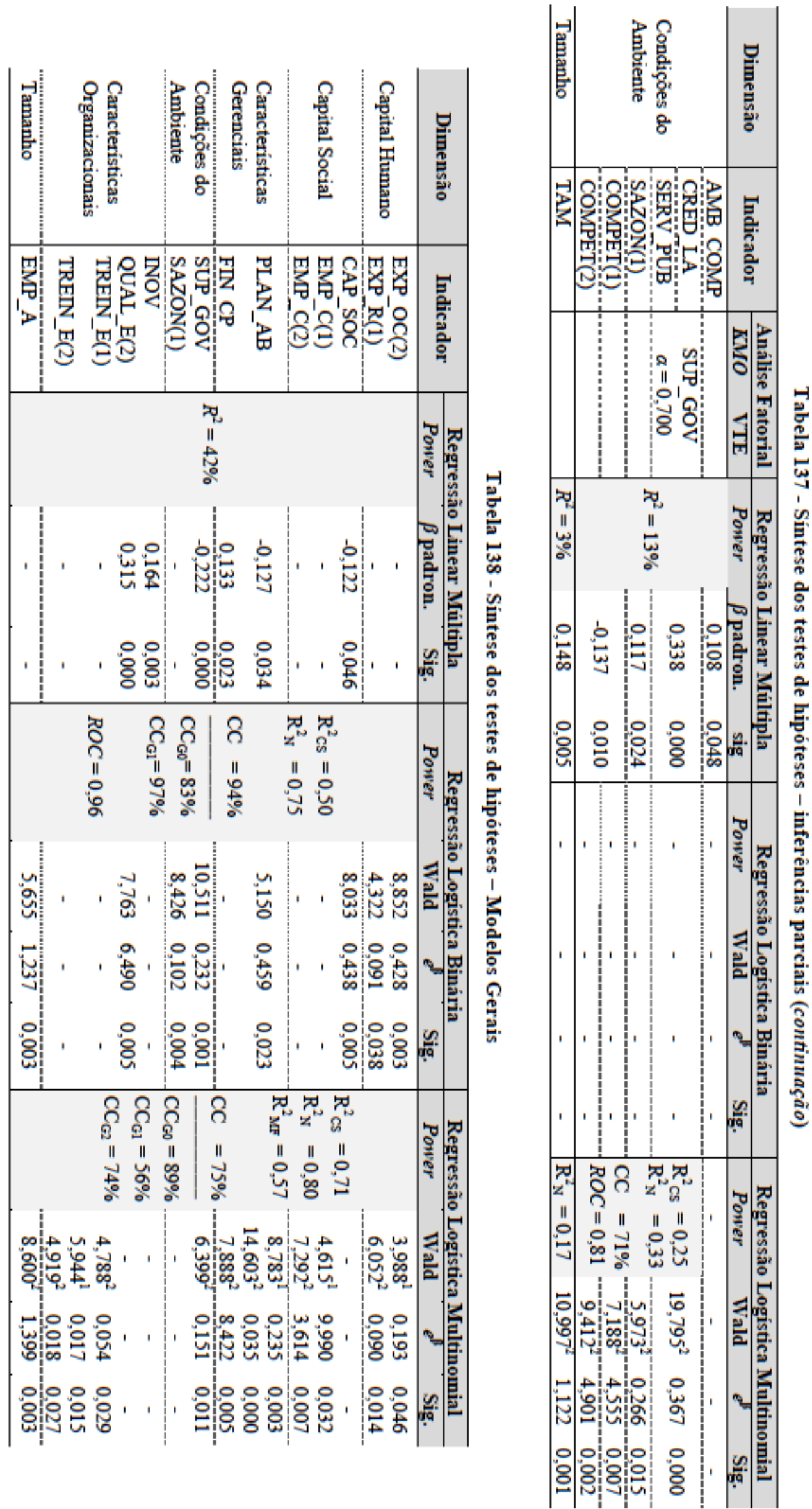


\section{Capítulo 5}

\section{CONSIDERAÇÕES FINAIS}

O objetivo desta Tese consistiu em identificar e testar os fatores determinantes do desempenho de PMEs, cuja medida foi definida mediante a utilização de indicadores subjetivos baseados nos pressupostos sugeridos por Robinson et. al. (1984), Dess e Robinson (1984), West III e Noel (2012), LeCornu et. al. (1996), Van Gelderen et. al. (2006) e Wang e Ang (2004). O desempenho foi testado sob três ângulos: 1) sobrevivência versus não sobrevivência (é a forma mais utilizada na literatura); 2) grupos de desempenho: a) não sobrevivência; b) sobrevivência marginal, e; c) alto desempenho; e, 3) Desempenho (variável contínua resultante da soma das respostas de cada um dos indicadores).

Os fatores de influência (variáveis independentes) foram segmentados em oito dimensões: 1) capital humano; 2) capital social; 3) caraterísticas gerenciais; 4) condições do ambiente; 5) motivação e percepção do risco; 6) características organizacionais; 7) características pessoais do empreendedor, e; 8) Tamanho. Cada uma destas dimensões e seu conjunto de indicadores converteram-se nas hipóteses da pesquisa, que foram testadas utilizando-se as estatísticas (1) regressão linear múltipla e (2) regressão logística. Os testes ocorreram no contexto particular de cada dimensão e simultaneamente (incluindo todas as dimensões).

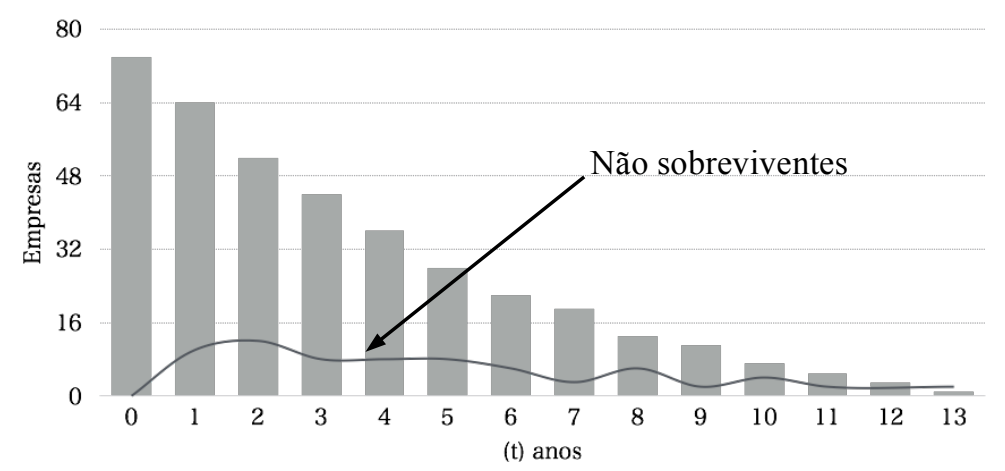

Gráfico 9 - Perfil de sobrevivência

As evidências encontradas levaram à rejeição das hipóteses nulas em sete das oito dimensões testadas. No Gráfico 9 observa-se que o pico de ocorrência da descontinuidade ocorre nos 
dois primeiros anos de atividade da empresa, sendo os primeiros seis anos o período crítico no desafio da sobrevivência.

Dos modelos gerais utilizados para testar os fatores influentes, verificou-se que o maior poder de explicação foi obtido pelo modelo logístico utilizado para discriminar "sobreviventes" e "não sobreviventes" $\left(R^{2}=75 \%\right)$ onde: suporte governamental, sazonalidade, capital social, qualificação dos empregados, planejamento antes da abertura, tamanho, experiência ocupacional e experiência no ramo - revelaram-se significantes. Infere-se que fatores relacionados com condições do ambiente, capital humano e características gerenciais do empreendedor afetam a sobrevivência e o desempenho de PMEs.

No modelo multinomial $\left(R^{2}=80 \%\right)$ revelaram-se influentes o planejamento antes da abertura (destacadamente), fontes e custos de financiamento de curto prazo, empréstimos realizados para abertura do negócio, treinamento dos empregados, tamanho, experiência ocupacional e experiência no ramo. Infere-se, por este modelo, que os atributos diretamente relacionados com o gestor incluindo o capital humano e as ferramentas utilizadas para planejar e gerenciar a empresa, associados com a qualificação dos colaborados, consistem o conjunto central de fatores impactantes da sobrevivência e desempenho de PMEs.

No modelo Ordinary Least Squares $\left(R^{2}=43 \%\right)$, o desempenho foi explicado pela qualificação dos empregados, suporte governamental, inovação, planejamento antes da abertura, capital social e fontes e custos de financiamento de curto prazo. Ratificam-se alguns aspectos já revelados e confirmados nos modelos anteriores, adicionando-se os efeitos dos aspectos financeiros sobre o desempenho de PMEs.

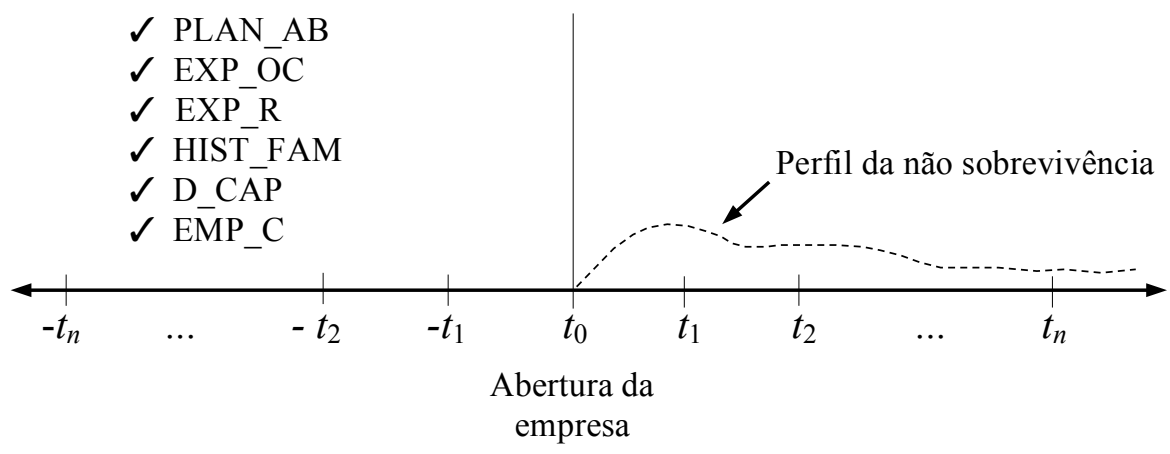

Figura 17 - Indicadores influentes: pré e pós constituição do negócio 
Em um primeiro aspecto constata-se que, do conjunto de indicadores que se demonstraram influentes, o planejamento antes da abertura, experiência ocupacional, experiência no ramo, disponibilidade de capital e empréstimos para constituição do negócio são aspectos associados com a fase anterior à abertura da empresa (Figura 17).

A significância de um conjunto elevado de fatores alocados no período pré-implantação implica a hipótese de que os meios institucionais públicos ou privados de disseminação e oferta de capacitação aos potenciais empreendedores exigem reflexões acerca de políticas públicas e planos de ações institucionais visando o preenchimento desta lacuna. Ao se constatar que aproximadamente 50\% dos empreendedores da amostra possuem ensino fundamental ou médio, possivelmente meios, ações e políticas públicas atuais não sejam suficientes ou adequadas para despertar a preocupação dos potenciais empreendedores em buscar o conjunto básico de informações, planejamento e recursos antes da abertura.

O planejamento antes da abertura (PLAN_AB) apresentou o poder de determinação (explicação) mais frequente, tanto nos modelos parciais como gerais. Anteriormente, na descrição dos indicadores desse construto (como pesquisa de clientes, mercado, ambiente competitivo, localização e viabilidade econômico-financeira) constatou-se que são aspectos que recebem pouca atenção dos empreendedores.

O maior número de indicadores significativos observados está relacionado com o aspecto financeiro: a) capital social (que inclui relacionamento e reciprocidade bancária, volume de crédito, obstrução ao crédito e impacto do crédito na expansão dos negócios); b) fontes de financiamento de curto prazo (que inclui antecipação de recebíveis e pagamento de juros elevados); c) disponibilidade de recursos para abertura do negócio, d) realização de empréstimos para constituição da empresa e, do construto "suporte governamental", ainda se extrai a disponibilidade e acesso a linhas de crédito. Constatou-se que o desempenho é significativamente afetado com a deterioração destes indicadores.

O efeito da subcapitalização sobre o desempenho da empresa é a evidência empírica de maior frequência descrita pela literatura (BARSLEY e KLEINER, 1990; BRUNO et. al., 1987; VAN GELDEREN et. al, 2006; BATES, 1995; YUSUF, 1995; HEADD, 2003). Shaefer (2012) alerta para a hipótese da subcapitalização estar associada com expectativas de receitas de vendas e lucros superestimados para o início da atividade. Nesse caso, além das demandas 
de recursos para complemento dos investimentos, novas demandas poderão surgir em decorrência das necessidades de capital de giro. Em torno de $45 \%$ desta amostra (incluindo as empresas sobreviventes e não sobreviventes) afirmaram possuir a metade ou apenas uma pequena parte dos recursos necessários para abertura da empresa. Ainda, aproximadamente $30 \%$ disseram que utilizaram empréstimos superiores a $20 \%$ para complementar os recursos demandados pelo negócio.

A falta de recursos no início ou durante atividade, associada com mecanismos pobres de registros e controles financeiros, comumente implicam fontes de financiamentos inadequadas e excessivamente caras. Constatou-se que 36\% das empresas não sobreviventes "sempre ou quase sempre" utilizam antecipação de recebíveis como fonte de caixa, enquanto $26 \%$ disseram pagarem juros elevados "sempre ou quase sempre". Tanto nas inferências parciais como nos modelos gerais obtiveram-se os sinais esperados com relação aos indicadores financeiros e de gestão.

No contexto da dimensão das Condições do Ambiente, o suporte governamental (que inclui linhas de crédito e dificuldades de acesso, e avaliação dos serviços públicos) e a sazonalidade revelaram-se significativas na explicação do desempenho. Com relação ao aspecto da sazonalidade, constatou-se que ela influencia a sobrevivência e o desempenho dos negócios. Vê-se, de forma subjacente, que esse fenômeno tem relação com as características gerenciais (planejamento e controle) e com os aspectos financeiros. A sazonalidade consiste em uma deflexão das operações e das receitas e, consequentemente, dos níveis de caixa, em um determinado período. Sendo assim, o planejamento e os controles financeiros devem estar ajustados de tal forma que incorporem esses efeitos.

$\mathrm{Na}$ dimensão das características organizacionais demonstraram-se influentes a qualificação e o treinamento dos empregados. A literatura tem registrado a presença significativa desses fatores (FLAHVIN, 1985; VAN GELDEREN et. al., 2006; BRUNO et. al., 1987; LUSSIER e CORMAN, 1996; LAUZEN, 1985), entretanto, nesse estudo, a densidade observada revelouse surpreendente. Lussier e Pfeifer (2001) salientam que as empresas que não conseguem atrair e manter empregados qualificados, têm menos chance de sucesso.

A partir das evidências encontradas nesta pesquisa, rejeita-se a hipótese nula para as dimensões: capital humano $\left(\mathrm{H}_{0,1}\right)$; capital social $\left(\mathrm{H}_{0,2}\right)$, características gerenciais $\left(\mathrm{H}_{0,3}\right)$, 
condições do ambiente $\left(\mathrm{H}_{0,4}\right)$, características organizacionais $\left(\mathrm{H}_{0,6}\right)$ e tamanho $\left(\mathrm{H}_{0,8}\right)$. Como não foram encontradas evidências, não se rejeita a hipótese nula para as dimensões: motivação e percepção de risco $\left(\mathrm{H}_{0,5}\right)$ e características pessoais do empreendedor $\left(\mathrm{H}_{0,7}\right)$.

Das constatações e conclusões desta Tese podem ser delineadas as seguintes reflexões:

1) Como há um número grande de indicadores influentes da sobrevivência de PMEs que estão associados com a fase anterior à abertura da empresa, em muitas situações, as ações e as alternativas tradicionalmente oferecidas após abertura podem apresentaremse tardias a ponto de não contribuírem para a sobrevivência do empreendimento. Reflexões são requeridas no sentido de se desenvolverem políticas de conscientização que levem os potenciais empreendedores à capacitarem-se antes de abrir a empresa;

2) Aproximadamente metade da amostra possui ensino médio ou menos. Em tempos atuais, subentende-se que é um nível de escolaridade associado à pessoas ainda bastante jovens. A observação que se pretende fazer é que há necessidade de se desenvolver mecanismos de conscientização e capacitação incluindo essa faixa etária, que requer adaptações em relação aos aspectos cognitivos e didático-pedagógicos.

\subsection{Recomendações para futuras pesquisas}

Ainda que se tenha conseguido, neste estudo, validar o construto "desempenho", a construção de um instrumento para medir o desempenho de pequenas e médias empresas é uma lacuna não preenchida. Os insights encontrados na literatura e os indicadores utilizados nesta Tese podem servir como ponto de partida ou de reflexão. Deseja-se uma dimensão com variáveis conceitualmente aderentes e internamente consistentes $(\alpha>0,9)$. A partir de medidas robustas de desempenho é possível percorrer, de forma mais efetiva, o espectro de variáveis independentes e seus efeitos sobre o desempenho de PMEs.

O modelo e seus desdobramentos e insights podem ser utilizados em outros recortes geográficos e setores. 



\section{REFERÊNCIAS}

ADAMS, B.; SYKES, V. Performance Measures and Profitability Factors of Successful African-American Entrepreneurs: An Exploratory Study. Journal of American Academy of Business. v. 2, p. 418-424, 2003.

AHMAD, Noor H.; SEET, PI-Shen. Dissecting Behaviours Associated with Business Failure: A Qualitative Study of SME Owners in Malaysia and Australia. Asian Social Science. v. 5, n. 9, p. 1-7, Sep./2009.

ALLEN, Kathleen R. Lauching New Ventures: An Entrepreneurial Approach. 6th ed. SouthWestern: Cengage Learning, 2012.

ALTMAN, Edward I.; Financial Ratios, Discriminant Analysis and the Prediction of Corporate Bankruptcy. The Journal of Finance. v. xxiii, n. 4, Sept./1968.

ANNUAL REPORT ON EU SMEs 2010/2011. Are EU SMEs recovering from de crisis? Rotherdam: Cambridge, 2011.

ASSAF NETO, Alexandre. Finanças corporativas e valor. São Paulo: Atlas, 2003

AVERY, Robert B.; BOSTIC, Raphael W. SAMOLYK, Katherine A. The role of personal wealth in small business Finance. Journal of Banking \& Finance. v. 22, p. 1019-1061, 1998.

BARNEY, J. Gaining and Sustaining Competitive Advantage. New York: AddisonWesley, 1997.

BARSLEY, G.; KLEINER, B. H. Small Business Management: Ensuring Your Client's Sucess. National Public Accountant, v. 35, p. 30-33, 1990.

BATES, Timothy. Analysis of survival rates among franchise and independent small business startups. Journal of Small Business Management, v.33, n. 2, p. 26-36. Apr./1995.

BATES, Timothy. Entrepreneur Human Capital Inputs and Small Business Longevity. The Review of Economics and Statistics, v. 72, n. 4, pp. 551-559. Nov./1990.

BEAVER, Graham; JENNINGS, Peter. Competitive advantage and entrepreneurial power The dark side of entrepreneurship. Journal of Small Business and Enterprise Development. v. 12, n. 6, p. 9-23, 2006.

BECKER, G. Human Capital. Chicago: University of Chicago Press, 1964. 
BENZING, Cynthia; MANH CHU, Hung; KARA, Orhan. Entrepreneurs in Turkey: A Factor Analysis of Motivations, Success Factors, and Problems. Journal of Small Business

Management, v. 47, n. 1, p. 58-91, 2009.

BERGER, Allen N.; UDELL, Gregory F. A more complete conceptual framework for SME finance. Journal of Banking \& Finance. v. 30, p. 2945-2966, 2006.

BERNOULLI, Daniel. Specimen Theoriae Novae Sortis (St. Petersburg, 1738). English translation: Econometrica, p. 23-36, 1954

BERKOWITZ, Jeremy; WHITE, Michelle J. Bankruptcy and Small Firms' Access to Credit. The RAND Journal of Economics. v. 35, n. 1, p. 69-84, Spring/2004.

BINKS, Martin R.; ENNEV, Christine T. Growing Firms and the Credit Constraint. Small Business Economics v. 8, p. 17-25, 1996.

BIRCH, David L. Job Creation in Amer ica. New York: Free Press, 1987.

BLANCHFLOWER, David G.; OSWALD, Andrew J. What Makes an Entrepreneur? Journal of Labor Economics, v. 16, n. 1, p. 26-60. Jan./1998.

BNDES. Circular n ${ }^{\circ} 11 / 2010$. Porte das Empresas.

BODIE, Zvi; KANE, Alex; MARCUS, Alan J. Essencials of Investments. 5th ed. New York: McGraw-Hill/Irwin, 2004.

BODIE, Zvi; MERTON, Robert C. Finance. New Jersey: Prentice Hall, 2000.

BORTOLI NETO, Adelino. Tipologia de problemas das Pequenas e Médias Empresas. São Paulo, 1980. Dissertação (Mestrado em Administração) - Programa de Pós-Graduação em Administração, Faculdade de Economia, Administração e Contabilidade. Universidade de São Paulo, 1980.

BOURDIEU, P. The forms of capital. In: RICHARDSON, J.G. (Ed.). Handbook of theory and research for the sociology of education. p. 241-258, 1986.

BREALEY, Richard A.; MYERS, Stewart C. Capital Investment and Valuation. New York: McGraw-Hill, 2003.

BREALEY, Richard A.; MYERS, Stewart C. Principles of Corporate Finance. New York: McGraw-Hill, 1996.

BREWER III, Genay H.; JACKSON III, W.; WORTHINGTO, P.R. How are small Firms 
Financed? Evidence from small business investment companies. Economic Perspectives Federal Reserve Bank of Chicago, p. 2-18, Nov.-Dec./1996.

BRIDGE, Simon; O'NEIL, Ken; CROMIE, Stan. Undestanding Enterprise, Entrepreneurship and Small Business. 2nd ed. New York: Palgrave Macmillan, 2003.

BRIGHAM, Eugene; EHRHARDT, Michel C. Financial Management - Theory and Practice. 10th ed. South-Western: Thomson Learning, 2002.

BROWN, Charles; JAMES, Hamilton; JAMES, Medoff. 1990. Employers: Large and Small. Cambridge: Harvard University Press, 1990.

BRÜDERL, Josef; PREISENDÖRFER, Peter; ZIEGLER, Rolf. Survival Chances of Newly Founded Business Organizations. American Sociological Review. v. 57, n. 2, p. 227-242, Apr./1992.

BRUNO, A.; LEIDECKER, J. e HARDER, J. Why Firms Fail. Business Horizons, p. 50-58. March-April/1987.

CAMERER, Colin; LOVALLO, Dan. Overconfidence and Excess Entry: An Experimental Approach. The American Economic Review. v. 89, n. 1, p. 306-318. Mar./1999.

CANTILLON, Richard. Essai sur la nature du commerce en général [1755]. Disponível em: <http://socserv.mcmaster.ca/econ/ugcm/3113/cantillon/> Acesso em 03 jun. 2012.

CARTER, Richard; VAN AUKEN, Howard. Small Firm Bankruptcy. Journal of Small Business Management. v. 44, n. 4, p. 493-512, 2006.

COASE, Ronald H. The Nature of the Firm. Economica, New Series, v. 4, n. 16. p. 386-405. Nov./1937.

COLEMAN, J.S. Social capital in the creation of human capital. American Journal of Sociology. v. 94, Supplement, p. 95-120, 1988.

COOPER, Ronald R.; SCHINDLER, Pamela S. Métodos de pesquisa em administração. 7 ed. Porto Alegre: Bookman, 2003.

COOPER, Arnold C.; GIMENO-GASCON, F. Javier. e WOO, Carolyn Y. A Resource-Based Prediction of New Venture Survival and Growth. Proceedings Academy of Mangement, $p$. 113-119. Summer/1991.

COOPER, Arnold C.; GIMENO-GASCON, F. Javier. e WOO, Carolyn Y. Initial Human and Financial Capital as Predictors of New Venture Performance". Journal of Business Venturing, v. 9, p. 371-395, 1994. 
COPELAND, Thomas E.; WESTON, J. Fred; SHASTRI, KULDEEP. Financial Theory and Corporate Policy. USA: Pearson Addison Wesley, 2005.

CPC. Comitê de Pronunciamentos Contábeis - Contabilidade para a Pequena e Média Empresa (CPC_PME). Brasília, dez./2009.

CRONBACH, L. Coefficient alpha and the internal structure of tests. Psychometrika, v. $1 \mathrm{n}$. 6, p. 297-37, 1951.

DAVIS, F. B. Educational measurements and their interpretation. Belmont, California (USA): Wadsworth Publishing Co., 1964.

CUNNINGHAM, J. Barton; LISCHERON, Joe. Defining Entrepreneurship. Journal of Small Business Management, v. 29, n. 1, p. 45-61. Jan./1991.

DELLOITE. As PMEs que mais crescem no Brasil. Delloite e Revista Exame - Pequenas e Médias Empresas. 2013.

DESS, Gregory G.; ROBINSON, Richard B. Measuring Organizational Performance in the Absence of Objective Measures: The Case of the Privately-Held Firm and Conglomerate Business Unit. Strategic Management Journal. v. 5, n. 3, p. 265-273. Jul./Sept.1984.

DEVELOPMENT COMMISSIONER, MSME. Final Report: Fourth all India Census of Micro, Small \& Medium Enterprises - 2006-2007: Registered Sector. New Dehli, Apr./2011.

DITTMAR, A., MAHRT-SMITH, J.; SERVAES, Henry. International corporate governance and corporate cash holdings. Forthcoming. Journal of Financial and Quantitative Analysis. 2002.

DUNNE, Timothy; ROBERTS, Mark J.; SAMUELSON, Larry. Patterns of Firm Entry and Exit U.S. Manufacturing Industries. Rand Journal of Economics. v. 19, n. 4, pp. 495-515. Winter/1988.

DUNPHY, Steven. M. The Entrepreneural Grid. Journal of Business and Entrepreneurship. v. 8, n. 2. p. 69. Oct./1996.

ENGELEN, E. How Innovative Are Dutch Immigrant Entrepreneurs? International Journal of Entrepreneural Behavior and Research. v. 8, p. 69-92, 2002.

FAIRLIE, Robert W.; ROBB, Alicia M. Gender Differences in Business Performance: Evidence from the Characteristics of Business Owners Survey. Small Business Economics, v. 33, p. 375-395, 2009. 
FAMA, Eugene F.; FRENCH, Kenneth R. The cross-section of expected stock returns. Journal of Finance. v. 47, p. 427-465, 1992.

FILARDI, Luiz F. Estudo dos fatores contribuintes para a mortalidade precoce de micro e pequenas empresas da cidade de São Paulo. São Paulo, 2006. Tese (Doutorado em Administração) - Programa de Pós-Graduação em Administração, Faculdade de Economia, Administração e Contabilidade da Universidade de São Paulo.

FLAHVIN, A. Why Small Businesses Fail. Australian Accountant. p. 17-20. Oct./1985.

FOLEY, D. An Examination of Indigenous Australian Entrepreneurs. Journal of Developmental Entrepreneurship. v. 8, p. 133-151, 2003.

FOTOPOULOS, Georgios; LOURI, Helen. Determinants of Hazard Confronting New Entry: Does Financial Structure Matter? Review of Industrial Organization, v. 17, p. 285-300, 2000 .

GARTNER, W. B. A Conceptual Framework for Describing the Phenomena of New Venture Creation. Academy of Management Review. v. 10, p. 696-706, 1985.

GASKILL, L. R.; VAN AUKEN, H. E.; MANNING, R. A. A Factor Analytic Study of the Perceived Causes of Business Causes of Small Business Failure. Journal os Small Business Management, v. 31, n. 4, p. 18-31, 1993.

GITMAN, Lawrence J. Principles of Managerial Finance. 10th ed. Addison Wesley, 2003.

Global Intrapreneurship Monitor (GEM) / Instituto Brasileiro da Qualidade e Produtividade (IBQP). Empreendedorismo no Brasil: Relatório Executivo. 2010.

GORGIEVSKI, Marjan J.; ASCALON, M. Evelina; STEPHAN, Ute. Small Business Owners' Success Criteria, a Values Approach to Personal Differences. Journal of Small Business Management, v. 49, n. 2, p. 207-232. Apr./2011.

GUNEY, Y.; OZKAN, A.; OZKAN, N. Additional international evidence on corporate cash holdings. Working paper. Department of Economics and Related Studies, University of York. 2000

HABER, Sigal; REICHEL, Arie. Identifying Performance Measures of Small Ventures -The Case of the Tourism Industry. Journal of Small Business Management. v. 43, n. 3, p. 257 286, 2005.

HAIR Jr, Joseph F.; ANDERSON, Rolph E.; TATHAM, Ronald L. BLACK, William C. Análise multivariada de dados. Porto Alegre: Bookman, 2005. 
HASWELL, Stephen; HOLMES, Scott. Estimating the Small Business Failure Rate: A Reappraisal. Journal of Small Business Management. v. 27, n. 3, p. 68-74. Jul./1989.

HEADD, Brian. Redefining Business Success: Distinguishing Between Closure and Failure Small Business Economics, v. 21, p. 51-61, 2003.

HÉBERT, R.F.; LINK, A.N. Historical perspectives on the entrepreneur. Foundations and trends in entrepreneurship, vol. 2, no 4, p. 261-408, 2006.

HEMPHILL, John K. Job Descriptions for Executives. Harvard Business Review. v. 37, n. 5, p. 55-67. Sept./1959.

HITT. M. A.; IRELAND, R. D.; CAMP, S. M.; SEXTON, D. L. Guest Editors' Introduction to the Special Strategic Entrepreneurship: Entrepreneurial Strategies for Wealth Creation. Strategic Management Journal. v. 22, p. 479-491, 2001.

HOSMER, D. W.; LEMESHOW, S. Appled Logistic Regression. 2nd. ed. John Wiley \& Sons: New York, 2000.

IBGE - Instituto Brasileiro de Geografia e Estatística. Demografia das empresas. 2013. Disponível < http://www.sidra.ibge.gov.br/bda/tabela/listabl.asp? $\mathrm{z}=\mathrm{p} \& \mathrm{o}=5 \& \mathrm{i}=\mathrm{P} \& \mathrm{c}=2718>$ Acesso em: out $/ 2013$.

INDUSTRY CANADA. Key Small Business Statistics. Public Works and Government Services Canada. Ottawa. Jul.2012.

Demografia das Empresas (2009). Set./2011.

KAHNEMAN, Daniel; TVERSKY, Amos. Prospect Theory: An Analysis of Decision Under Risk. Econometrica. p. 263-291. March./1979.

KAHNEMAN, Daniel; TVERSKY, Amos. Intuitive Prediction: Biases and Corrective Procedures. Decision Research. 1977.

KALLEBERG, A. L.; LEICHT, K. T. (1991). Gender and Organizational Performance: Determinants of Small Business Survival and Success. Academy of Management Journal. v. 34, n. 1, p. 136-161, 1991.

KAPLAN, R. S.; NORTON, D. P. The Balanced Scorecard: measures that drive performance. Harvard Business Review. v. 70, n. 1, p. 71-79, jan./feb. 1992.

KAPLAN, R.; SACCUZZO, D. Psychological testing: Principles, applications and issues. Monterey, CA: Brooks/Cole Publishing Company, 1982.

KANITZ, Stephen. Como prever falências. São Paulo: McGraw Hill, 1978. 174 p. 
KERLINGER, F. N. Metodologia da pesquisa em ciências sociais: um tratamento conceitual. São Paulo : EDUSP, 1980.

KNIGHT, F. H. Risk, Uncertainty and Profit. Chicago: University of Chicago Press, 1971 (first edition 1921).

KOS, S. R.; ANJOS R. P.; ESPEJO, M. B.; RAIFUR L. Compreensão e utilização da informação contábil pelos micro e pequenos empreendedores em seu processo de gestão. In:

Congresso USP, 2011. $11^{\circ}$ Congresso de Controladoria e Contabilidade, 2011.

KOZAN, M. Kamil; ÖKSOY, Dolun; ÖZSOY, Onur. Growth Plans of Small Businesses in Turkey: Individual and Environmental Influences. Journal of Small Business Management, v. 44, n. 1, p. 114-129, 2006.

KURATKO, Donald F. Entrepreneurship: Theory, Process and Practice. 8th ed. SouthWestern: Cengage Learning, 2009.

LAUZEN, L. Small Business Failures Are Controllables. Corporate Accounting, p. 34-38. Summer/1985.

KUHN, T.S. The structure of scientific revolutions. Chicago: University of Chicago Press, 1962.

KUPFER, David; HASENCLEVER, Lia. Economia Industrial: fundamentos teóricos e práticas no Brasil. Rio de Janeiro : Campus, 2002.

LeCORNU, Mark R. et. al. The small enterprise financial objective function. Journal of Small Business Management, v. 34, n. 3, p. 1-14. Jul./1996.

Lei Complementar $n^{0}$ 123. Estatuto nacional da micro empresa e da empresa de pequeno porte. Governo Federal, 14.12.2006.

LEBAS, Michel; EUSKE, Ken. A Conceptual and Operational Delineation of Performance. In: NEELY, Andy. Business Performance Measurement: Theory and Practice. United Kingdom: Cambridge University Press, 2002.

LEONE, N. M. As Especificidades das pequenas e Médias empresas. Revista de Administração, v. 34, n. 42. p. 91-94, abr./jun., 1999.

LIN, N. Social capital: a theory of social structure and action. Cambdrige: Cambridge University Press, 2001. 
LINTNER, John. The valuation of risk assets and the selection of risk investments in stock portfolio and capital budgets. Review of Economics and Statistics. v. 47, n. 1, p.13-37. Feb./1965.

LUSSIER, Robert N. A Nonfinancial Business Success versus Failure Prediction. Journal of Small Business Management, v. 33, n.1, p. 8-20. Jan./1995.

LUSSIER, R. N.; CORMAN, J. There are Few Differences between Successfull and Failed Small Business. Journal of Small Business Strategy, v. 6, n. 1, p. 21-33, 1995.

LUSSIER, R. N.; CORMAN, J. A Business Success versus Failure Prediction Model for Entrepreneurs with 0-10 Employees. Journal of Small Business Strategy, v. 7, n. 1, p. 21 $35,1996$.

LUSSIER R. N. A Business Success Versus Failure Prediction Model for Services Industry. Mid-Atlantic Journal of Business, v. 32, n. 2, p. 9-92, 1996.

LUSSIER, Robert N.; PFEIFER, Sanja. A Crossnational Prediction Model for Business Success. Journal of Small Business Management, v. 39, n. 3, p. 228-239, 2001.

LYRA, Ricardo Luiz Wüst Corrêa de; CORRAR, Luiz João. A Percepção dos Docentes quanto os Indicadores Contábeis: Um Estudo Exploratório utilizando a técnica Delphi. III CONGRESSO IAAER - ANPCONT 2009, Anais... São Paulo, 2009.

MARKOWITZ, Harry. Portfolio selection. Journal of finance. American Finance Association, v. 7, n. 1, p. 77-91. Mar./1952.

MAROCO, João. Análise estatística - com utilização do SPSS. 3 ed. Lisboa (Portugal): Silabo, 2007

MATA, José; PORTUGAL, Pedro. Life Duration of New Firms. The Journal of Industrial Economics, v. 42, n. 3, p. 227-245. Sept./1994.

MATARRAZO, Dante C. Análise financeira de balanços: abordagem básica e gerencial. 5 ed. São Paulo: Atlas, 1998.

MATIAS, Alberto B. Indicadores contábeis e financeiros de previsão de insolvência: a experiência da pequena e média empresa brasileira. Tese (Livre Docente). Faculdade de Economia, Administração e Contabilidade. Universidade de São Paulo. São Paulo, 1976.

MENDES, Gerônimo. Fatores condicionantes de sucesso das pequenas e médias empresas na região metropolitana de Curitiba e sua contribuição para o desenvolvimento local. Dissertação de Mestrado. (Programa de Mestrado em Organizações e Desenvolvimento). UNIFAE - Centro Universitário. Curitiba. 2006. 
MINELLO, Ítalo F. Resiliência e insucesso empresarial: um estudo exploratório sobre o comportamento resiliente e os estilos de enfrentamento do empreendedor em situações de insucesso empresarial, especificamente em casos de descontinuidade do negócio. 2010. 321f. Tese de Doutorado. (Programa de Pós-Graduação em Administração) - Faculdade de Economia, Administração e Contabilidade. Universidade de São Paulo. São Paulo. 2010.

MIZUMOTO, Fabio M. A sobrevivência de empresas nascentes no estado de São Paulo: um estudo sobre capital humano, capital social e práticas gerenciais. Revista de Administração, v.45, n.4, p. 343-355. Out./Nov./Dez./2010.

MOSSIN, Jan. Equilibrium in a capital asset market. Econometrica. Evanston, v. 34, n. 4, p. 768-783. Oct./1966.

MTE/CAGED. Ministério do Trabalho e Emprego. Dados e Estatísticas. 2012. Disponível em: <http://portal.mte.gov.br/dados_estatisticos/> Acesso: ago/2012.

MURPHY, K. R.; DAVIDSHOFER, C. O. Psychological testing: Principles and applications. Englewood Cliffs, New Jersey: Prentice Hall, 1988.

NAJBERG, Sheila; PUGA, Fernando P.; OLIVEIRA, Paulo A. S. Sobrevivência das Firmas no Brasil: Dez.1995/Dez. 1997. Revista do BNDES, v. 7, n. 13, p. 33-48. Jun./2000.

NEWBY, R.; WATSON, J.; WOODLIFF, D. Using Focus Groups in SME Research: The Case of Owner-Operator Objectives. Journal of Developmental Entrepreneurship. v. 8, p. 237-246, 2003.

NUNNALLY, J. C. Psychometric theory. New York: McGraw-Hill Inc., 1978.

OCDE/CEPAL. Perspectivas económicas de América Latina 2013: Políticas de PyMEs para el cambio structural. OCDE/CEPAL, 2012.

OPLER, T. et. al. The determinants and implications of cash holdings. Journal of Financial Economics, v.52, p. 3-46. 1999.

PAIGE, R. C.; LITTRELL, M. A. Craft Retailers' Criteria for Success and Associated Business Strategies. Journal of Small Business Management. v. 40, p. 314-331, 2002.

PENROSE, Edith. The Theory of the Growth of the Firm. New York: Oxford University Press, 1973.

PINCHOT, Gifford. Intrapreneurship: How Firms can Encourage and Keep Their Bright Innovators. International Management: Europe, v. 38, n. 1, p. 11-12. 1983. 
PINKOWITZ, L.; WILLIAMSON, R. Bank power and cash holdings: evidence from Japan. Reviewof Financial Studies. v. 14, p. 1059-1082. 2001.

PIORE, Michael J.; SABEL, Charles F. The Second Industrial Divide: Possibilities for Prosperity. New York: Basic Books, 1984.

PORTAL BRASIL. Mapa das micro e pequenas empresas. Disponível em:

http://www.brasil.gov.br/economia-e-emprego/2012/02/o-mapa-das-micro-e-pequenasempresas. Acessado: out/2013.

PORTER, Michel E. Vantagem competitiva: criando e sustentando um desempenho superior. 6 ed. Rio de Janeiro: Elsevier, 1992.

PUTNAM, Robert D. Making democracy work: civic traditions in modern Italy. Princeton: Princeton University Press, 1993.

ROBINSON, R B. Jr. PEARCE, J. A. The relationship between stage of development and small firm planning and performance. Journal of Small Business Management, v. 22, n. 2, p. 45-52. Apr./1984.

ROSS, Stephen A.; WESTERFIELD, Randolph W.; JAFFE, Jeffrey F. Corporate Finance. $3^{\text {rd }}$ Ed. United States of America: McGraw-Hill/Irwin, 1993.

SAY, Jean-Baptiste. A Treatise on Political Economy: or the Production, Distribution and Consumption of Wealth. New York: A. M. Kelley Publishers, 1971 (first ed. 1803).

SADLER-SMITH, E.; HAMPSON, Y.; CHASTON, Y.; BADGER, B. Managerial Behavior, Entrepreneurial Style, and Small Firm Performance. Journal of Small Business

Management, v. 41, n. 1, p. 47-67, 2003.

SCHAEFER, Patricia. Why Small Business Fail: Top 7 Reasons Startups Fail and How to Avoid Failure. Disponível em: < http://www.businessknowhow.com/startup/businessfailure.htm >. Acesso em: 26/05/2012.

SCHERR, Frederick C. Causality, Regression, Discriminant Analysis, and Research. Akron Business and Economic Review. v. 20, n. 1, p. 8-21. Spring/1989.

SCHUMPETER, J. The Theory of Economic Development. Cambridge: Harvard University Press, 1934 (first edition 1911).

SCHUMACKER, R. E.; LOMAX, R. G. A Beginner's Guide to Structural Equation Modeling. Lawrence Erlbaum Associates. Mahwah, New Jersey, 1996.

SEBRAE-SC. Critério de classificação de empresas: EE-ME-EPP. Disponível em: $<\mathrm{http}: / /$ www.sebrae-sc.com.br/leis/default.asp?vcdtexto=4154> Acesso: Ago/2012. 
SEBRAE-SP. 10 anos de monitoramento da mortalidade e sobrevivência das empresas. São Paulo. 2008.

SEBRAE. Aumentar participação no PIB é desafio para micro e pequenas empresas da América Latina e Caribe. Agência Sebrae de Notícias (ASN). 2010. Disponível em: http://www.agenciasebrae.com.br/noticia/10770645/economia/aumentar-participacao-no-pibe-desafio-para-micro-e-pequenas-empresas-da-america-latina-e-caribe/ Acesso: out/2013.

SEITZ, Neil; ELLISON, Mitch. Capital budgeting and long-term financing decisions. 3rd. ed. EUA: Thomson Learning, 1999.

SHARPE, William F. Capital asset prices: a theory of market equilibrium under conditions of risk. Journal of Finance. American Finance Association, v. 19, n. 3, p. 425-442, 09/1964.

SILVA, José P. Administração de crédito e previsão de insolvência. São Paulo: Atlas, 1983

SMITH, N. R.; MINER, J. B. Type of entrepreneur, type of firm, and managerial motivation: Implications for organizational life circle theory. Strategic Management Journal, v. 4, p. 325-340. 1983.

SOUSA, Almir F.; LUPORINI, Carlos; SOUZA, Milanez S. Gestão do Capital de Giro. Caderno de Pesquisas em Administração. v. 1, n. 3. São Paulo. $2^{\circ}$ sem./1996.

STOKES, David; BLACKBURN, Robert. Learning de hard way: the lessons of ownermanagers Who have closed their business. Journal of Small Business and Enterprise Development. v. 9, n. 1, p. 17-27, 2002.

SULLIVAN, T.; WARREN, E.; WESTBROOK, J. Financial Difficulties of Small Business and Reasons for Their Failure. Springfield: National Tecnical Information Service. 1998.

TAYLOR, Shelly E.; BROWN, J. D. Illusion and Well-Being: A Social Psycological Perspective on Mental Health. Psychological Bulletin. v. 103, n. 2, p. 193-210. Mar./1988.

TIMMONS, J. A. New Venture Creation: Entrepreneurship for the 21st Century. Chicago: Irwin, 1994.

TVERSKY, Amos; KAHNEMAN, Daniel. Rational Choice and the Framing of Decisions. Journal of Business. p. S251-S278. Oct./1986.

VAN DE VEN; HUDSON, A. R.; SCHROEDER, D. Designing New Business Start-Up: Entrepreneurial, Organizational and Ecological Considerations. Journal of Management. v. 10, n. 1, p. 87-107, 1984.

VAN GELDEREN, Marco; THURIK, Roy; BOSMA, Niels. Success and Risk Factors in the Pre-Startup Phase. Small Business Economics, v. 26, p. 319-335. Spring/2006. 
VAN PRAAG, C. Mirjam. Business Survival and Success of Young Small Business Owners. Small Business Economics, v. 21, n. 1, p. 1-17. Aug./2003.

VESPER, Karl H. New Venture Strategies. Englewood Cliffs, New Jersey : Prentice Hall, 1980.

VON NEUMANN, J.; MORGENSTERN, O. (1947). Theory of games and economic behavior, 2nd ed. Princeton, NJ: Princeton University Press.

WANG, Clement K.; LIAN ANG, Bee. Determinants of Venture Performance in Singapore. Journal of Small Business Management, v. 42, n. 4, p. 347-363, 2004.

WATSON, Kathryn; HOGARTH-SCOTT; Sandra, WILSON, Nicholas. Small business startups: success factors and support implications. International Journal of Entrepreneurial Behaviour \& Research, v. 4, n. 3, p. $217-238,1998$.

WATSON, John; EVERETT, Jim E. Do Small Businesses Have High Failure Rates? Journal of Small Business Management, v. 34, n. 4, p. 45-62. Oct./1996.

WEST III, G. Page; NOEL, Terry W. The Impact of Knowledge Resources on New Venture Performance. Journal of Small Business Management. v. 47, n. 1, p. 1-22, 2009.

WESTON, J. Fred; BRIGHAM, Eugene F. Fundamentos da administração financeira. São Paulo: Makron Books, 2000.

WEINSTEIN, Neil D. Unrealistic Optimism About Future Life Events. Journal of Personality and Social Psychology. v. 39, n. 5, p. 806-820. Nov./1980.

WESTHEAD, P.; COWLING, M.; HOWORTH, C. The development of family companies: Management and ownership imperatives. Family Business Review, v. 14 n. 4, p. 369-385. 2001.

WIGHT, C. Business Failures: Early Diagnostics and Remedies. Australian Accountant, p. 30-39, Sept./1985.

WIJEWARDENA, Hema; NANAYAKKARA, Gunapala; ZOYSA, Anura De. The owner/manager's mentality and the financial performance of SMEs. Journal of Small Business and Enterprise Development, v. 15, n. 1, p. 150-161, 2008.

WIJEWARDENA, Hema; TIBBITS, Garry E. Factors Contributing to the Growth of Small Manufacturing Firms: Data From Australia. Journal of Small Business Management. v. 37, n. 2, p. 88-95. Apr./1999.

WILLIAMSON, Oliver E. The economic institutions of capitalism: firms, markets, relational contracting. Free Press, 1987. 
WOOD, D. L. Why New Business Fail and How to Avoid Disaster. Corporate Cashflow, p. 26-27. Aug./1989.

WOOLDRIDGE, Jefrey M. Introdutory Econometrics: a modern approach. $2^{\text {nd }}$. Ed. United States: Thomson South-Western, 2003.

YUSUF, Attahir. Critical success factors for small business: Perceptions of South Pacific entrepreneurs. Journal of Small Business Management, v. 33, n. 2, p. 68-73. Apr./1995.

ZAR, J. Bioestatistical Analysis. 4th. ed. Prentice-Hall: Englewood Cliff, (1999). 



\section{UNIVERSIDADE DE SÃO PAULO - USP \\ Faculdade de ECONOMIA, Administração e CONTABILIDADE - FEA Pesquisa EMPRESARIAL}

Caro Empreendedor!

Este questionário tem por objetivo a construção da base de dados para a Tese de Doutorado, cujo tema são as Pequenas e Médias Empresas. Encarecidamente pedimos não mais que 10 minutos do seu já escasso tempo, pois dependemos da colaboração dos empresários para que os objetivos da pesquisa sejam alcançados.

Asseguramos os sigilo e o anonimato das informações aqui prestadas.

Desde já agradecemos a sua valiosa colaboração!

Léo Raifur

Doutorando - FEA/USP
Prof. Dr. Almir F. Sousa

Professor Orientador - FEA/USP

\section{DADOS DO EMPREENDEDOR}

1.1 Gênero
Masculino

$\bigcirc$ Feminino

1.2 Ano de Nascimento: [ ]

1.3 Estado Civil
Solteiro
Casado
$\bigcirc$ Divorciado
Outro

1.4 Escolaridade (nível completo)

$\bigcirc$ Ensino Fundamental

$\bigcirc$ Ensino Médio

$\bigcirc$ Ensino Superior

Especialização

$\bigcirc$ Mestrado / Doutorado

\section{DADOS DA EMPRESA}

2.1 Ano de fundação da empresa: [ ]

2.2 Qual é a natureza predominante na sua empresa?
Indústria
Comércio
$\bigcirc$ Serviços

2.3 O regime fiscal utilizado por sua empresa é:
SIMPLES
Lucro Presumido
$\bigcirc$ Lucro Real

2.4 Quantos empregados (formais e/ou informais) a empresa possuía quando foi fundada/adquirida?
Nenhum. Eu gerenciava tudo sozinho.
Eu e familiares diretos (esposa e/ou filhos)
○ 1 a 2 empregados
○ 3 a 5 empregados
6 a 10 empregados
Mais de 10. Quantos? [ ......... ]

2.5 Número atual de empregados: [
2.6 Para constituir ou adquirir a empresa, quanto foi gasto $(R \$)$ ? (Inclui-se a compra de equipamentos, edificações, reformas, capital de giro etc.)

Menos de $10 \mathrm{mil}$

De 10 mil até 25 mil

$\bigcirc$ De 25 mil até 120 mil

De 120 mil até 240 mil

De 240 mil até 720 mil

De 720 mil até 1,2 milhões

$\bigcirc$ De 1,2 milhões a 5 milhões

Mais de 5 milhões

2.7 Qual o faturamento bruto anual da empresa?

Menos de 360 mil

De 360 mil a 720 mil

De 720 mil a 1,2 milhões

$\bigcirc$ De 1,2 milhões a 2,4 milhões

$\bigcirc$ De 2,4 milhões a 5 milhões

De 5 milhões a 10 milhões

$\bigcirc$ De 10 milhões a 20 milhões

De 20 milhões a 50 milhões

Mais de 50 milhões 
3.1 Antes de ser empresário(a), você já tinha trabalhado como empregado?
○ Não
Menos de 1 ano
De 1 a 5 anos
De 6 a 10 anos
De 11 a 20 anos
Mais de 20 anos

3.2 Antes de ser empresário(a) você já tinha trabalhado no ramo em que abriu o negócio?
○ Não
Menos de 1 ano
$\bigcirc$ De 1 a 2 anos
$\bigcirc$ De 3 a 5 anos
De 6 a 10 anos
Mais de 10 anos

3.3 Antes de ser empresário(a) você ocupou cargo/função na qual possuía pessoas/empregados sob seu comando?
○ Não
Menos de 1 ano
$\bigcirc$ De 1 a 2 anos
$\bigcirc$ De 3 a 5 anos
De 6 a 10 anos
Mais de 10 anos

3.4 Considerando os últimos 24 meses, indique a média anual de horas em cursos técnicos, palestras, feiras, seminários etc., relacionados com o seu negócio que você participou
Menos de 12 horas por ano
$\bigcirc$ De 12 a 24 horas
De 25 a 36 horas
De 36 a 48 horas
De 48 a 60 horas
Mais de 60 horas

3.5 Seus pais são ou foram empresários?
O Sim
○ Não

3.6 Antes da empresa atual, você teve outra empresa anteriormente a essa?

$\bigcirc \operatorname{Sim}$

Não

3.7 Se sim, que fim ela teve?

O Simplesmente parei(amos) com a atividade

Saí da sociedade

A empresa foi vendida

3.8 Se sim, além da atual, de quantas empresas já foi dono ou sócio? [ ] ]

\section{CAPITAL SOCIAL}

4.1 Com relação à disponibilidade de capital para abertura da empresa, você diria que possuía:

Todos os recursos inclusive uma sobra para necessidades inesperadas na fase inicial;

A quantia suficiente para abertura da empresa;

U ma boa parte dos recursos, mas ao final faltou um pouco de dinheiro;

Aproximadamente metade dos recursos necessários

Apenas uma pequena parte dos recursos

4.2 Com relação ao total de recursos necessários para a abertura da empresa, os empréstimos representaram:

O Nada. Não utilizei empréstimos

Menos de $20 \%$

$\bigcirc$ Entre $21 \%$ e $40 \%$

$\bigcirc$ Entre $41 \%$ e $70 \%$

Mais de $70 \%$
4.3 Com relação aos fornecedores principais, aqueles que representam em torno de $70 \%$ do total de matérias-primas, mercadorias etc. são:

Menos de 3 fornecedores

De 3 a 7

De 8 a 12

$\bigcirc$ De 13 a 20

Mais de 20

4.4 Com relação aos fornecedores, você diria que:

Raramente ocorrem alterações no quadro de fornecedores

O Uma pequena parte (em torno de $25 \%$ ) é substituída, revezada

$\bigcirc$ Tenho trocado em torno da metade dos fornecedores optando por àqueles que oferecem melhores condições.

Há um rodízio grande de fornecedores, mas mantenho uma parceria firme com cerca de $25 \%$ deles

$\bigcirc$ Tenho muito poucos fornecedores contínuos (firmes). 
4.5 A relação da sua empresa com bancos é:
Excelente
Ótima
O Boa
Regular
$\bigcirc$ Ruim

4.6 Com relação ao nível de parcerias ou uso de serviços especializados como Sebrae, Universidades, Associações e Federações, Consultorias etc., você diria que é:

$\bigcirc$ Muito Frequente

Razoavelmente Frequente

$\bigcirc$ Pouco Frequente

Raramente ou nunca utilizado

4.7 Marque a intensidade equivalente para cada uma das assertivas abaixo

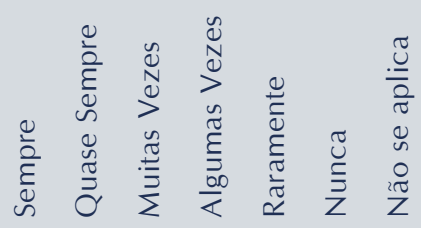

a) Quando preciso de um empréstimo bancário, o banco é atencioso comigo

$\bigcirc \bigcirc \bigcirc \bigcirc \bigcirc \bigcirc \bigcirc$

b) Quando preciso de um empréstimo bancário, o banco aprova integralmente a quantia solicitada

c) Quando preciso de um empréstimo bancário, sinto que o banco dificulta a aprovação e liberação dos recursos

d) A dificuldade e o custo do crédito têm atrapalhado a expansão do negócio

\section{Características Gerenciais}

5.1 Antes de abrir a empresa, você:



a) Pesquisou o mercado de atuação e o perfil dos potenciais clientes

$\bigcirc \bigcirc \bigcirc \bigcirc \bigcirc \bigcirc \bigcirc$

b) Identificou e estabeleceu contato com os principais fornecedores

c) Analisou os principais concorrentes, preços, atendimento, competitividade

$\bigcirc \bigcirc \bigcirc \bigcirc \bigcirc \bigcirc \bigcirc$

d) Fez estudos sobre a localização do negócio

e) Fez estudos atestando a viabilidade econômica e financeira do negócio

$\bigcirc \bigcirc \bigcirc \bigcirc \bigcirc \bigcirc \bigcirc$

$\bigcirc \bigcirc \bigcirc \bigcirc \bigcirc \bigcirc \bigcirc$

$\bigcirc \bigcirc \bigcirc \bigcirc \bigcirc \bigcirc \bigcirc$

5.2 Marque a intensidade equivalente para cada uma das assertivas abaixo



a) Conheço detalhadamente as entradas e saídas de caixa que ocorrerão no mês $\bigcirc \bigcirc \bigcirc \bigcirc \bigcirc \bigcirc \bigcirc$

b) Utilizo antecipação de recebíveis (desconto de duplicatas, cheques pré ou borderôs de cartão de crédito) para fazer caixa

c) Tenho problemas com inadimplência

d) Tenho pago juros elevados ao(s) banco(s)

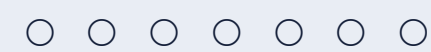

5.3 Sua empresa possui site?

$\bigcirc \mathrm{Sim}$

$\bigcirc$ Não

5.4 Se sim, os produtos/serviços podem ser consultados no site?

$\bigcirc \operatorname{Sim}$
5.5 Sua empresa faz vendas pela internet?
Sim
Não

5.6 Se sim, qual o percentual da receita total obtida das vendas pela internet?

$[$............. $] \%$ 
6.1 Como você avalia a sazonalidade na sua empresa (ocorrência de picos de vendas em um período e baixo em outro)
Muito sazonal
Bastante Sazonal
$\bigcirc$ Razoavelmente sazonal
O Pouco sazonal
O Nada sazonal

6.2 Com relação à concorrência e o grau de competição, pode-se dizer que o seu negócio situa-se em um ambiente:

$\bigcirc$ Altamente competitivo

$\bigcirc$ Competitivo

Competição média

Pouco competitivo

$\bigcirc$ Nada competitivo

6.3 No seu setor, ou em termos gerais quando se refere às pequenas e médias empresas, como você avalia o suporte governamental / institucional.



a) Linhas de crédito e acesso ao crédito

b) Qualidade dos serviços públicos

c) Apoio de instituições (Sebrae, associações, escolas etc)

d) Ambiente competitivo (lealdade dos competidores; grau de formalidade)

\section{MotivaçÃo e PeRcepÇão do RISco}

7.1 Qual das situações abaixo melhor representa sua decisão de empreender

Oportunidade

$\bigcirc$ Necessidade

7.2 Qual das opções abaixo pode ser considerado o motivador de maior destaque na sua decisão de empreender:

O Garantir a renda e a subsistência familiar

Explorar uma oportunidade em potencial

$\bigcirc$ Ganhar dinheiro

7.3 Investir em um negócio próprio significa assumir um risco que pode ser considerado:

Muito alto

O Alto

Nem alto, nem baixo

$\bigcirc$ Baixo

Muito baixo
7.4 Com relação às expectativas que você possuía antes de abrir a empresa, comparando com o desempenho após a abertura, você diria que foi:

$\bigcirc$ Muito acima das expectativas

$\bigcirc$ Um pouco acima das expectativas

$\bigcirc$ Dentro das expectativas

$\bigcirc$ Um pouco abaixo das expectativas

$\bigcirc$ Muito abaixo das expectativas

7.5 Se você pudesse voltar no tempo imediatamente anterior à seu ingresso no negócio atual, você:

○ Não abriria uma empresa.

Investiria novamente no mesmo negócio

Investiria no mesmo negócio, porém faria um planejamento mais detalhado

$\bigcirc$ Investiria em outro tipo/ramo de negócio

\section{PERCEPÇÃo DE DESEMPENHO}

8.1 Qual o lucro médio atual obtido pela empresa em relação ao faturamento bruto?

Menos de $3 \%$

De $3 \%$ a $5 \%$

De $6 \%$ a $10 \%$

De $11 \%$ a $15 \%$

De $16 \%$ a $20 \%$

De $21 \%$ a $25 \%$

Mais de $25 \%$
8.2 Com relação ao faturamento bruto, levando em conta os últimos 12 meses, você diria que:

Aumentou mais de 20\%

Aumentou até $20 \%$

O Permaneceu estável

Diminuiu até 20\%

Diminuiu mais de $20 \%$ 
8.3 Com relação ao número de empregados, levando em conta os últimos 12 meses, você diria que:

Aumentou mais de $20 \%$

Aumentou até $20 \%$

P Permaneceu estável

Diminuiu até $20 \%$

Diminuiu mais de $20 \%$

8.4 Comparativamente com outras empresas do seu setor de atuação, como você avalia o desempenho da sua empresa?

O Muito acima da média

U Um pouco acima da média

O Igual a média do setor

Um pouco abaixo da média

Muito abaixo da média
8.5 Quanto à satisfação pessoal com relação à sua empresa, você diria que está:

Muito satisfeito

Satisfeito

$\bigcirc$ Nem satisfeito, nem insatisfeito

Insatisfeito

Muito insatisfeito

8.6 Com relação à qualidade de vida pessoal e da família, você diria que o negócio impactou:

$\bigcirc$ Muito positivamente

$\bigcirc$ Positivamente

Não teve impacto

$\bigcirc$ Negativamente

$\bigcirc$ Muito Negativamente

\section{Características Organizacionals}

9.1 Com relação grau de especialidade / generalidade, seu negócio é:

$\bigcirc$ Baseado em produto/serviço especializado

$\bigcirc$ Diversificado

9.2 Com relação ao grau de afiliação, seu negócio é:

$\bigcirc$ Afiliado (franquia, representação etc.)

$\bigcirc$ Independente

9.3 O quadro de empregados da empresa pode ser definido como:
$\bigcirc$ Muito qualificado
$\bigcirc$ Qualificado
Pouco qualificado
Sem qualificação
○ Não se aplica (não possui empregados)

9.4 Por ano, em média, quantas horas de treinamento (cursos, palestras, feiras etc.) os empregados realizam?

$\bigcirc$ Até 12 horas

$\bigcirc$ De 12 a 24 horas

$\bigcirc$ De 24 a 48 horas

Mais de 48 horas

○ Não se aplica
9.5 Indique o número do sócios que fazem parte do quadro social da empresa:
$\bigcirc 1$
$\bigcirc 2$
$\bigcirc 3$
$\bigcirc$
Mais de 4

9.6 O relacionamento entre os sócios:
$\bigcirc$ Excelente
$\bigcirc$ Bom
Regular
Ruim
$\bigcirc$ Péssimo

9.7 Pode-se afirmar que existem familiares em cargos (funções) importantes da empresa?
$\bigcirc$ Sim
Não

9.8 Com relação ao grau de inovação exigido no seu negócio, você diria que é:
Muito alto
Alto
Razoável
Baixo
Muito baixo 



\section{UNIVERSIDADE DE SÃO PAULO - USP \\ Faculdade de ECONOMia, AdMinistraÇÃo e CONTABILIDADE - FEA PESQUISA EMPRESARIAL}

Caro Respondente!

Este questionário tem por objetivo a construção da base de dados para a Tese de Doutorado, cujo tema são as Pequenas e Médias Empresas. Encarecidamente pedimos não mais que 10 minutos do seu já escasso tempo, pois dependemos da colaboração dos empresários para que os objetivos da pesquisa sejam alcançados.

Asseguramos os sigilo e o anonimato das informações aqui prestadas.

Desde já agradecemos a sua valiosa colaboração!

Léo Raifur

Doutorando - FEA/USP
Prof. Dr. Almir F. Sousa

Professor Orientador - FEA/USP

\section{DADOS DO EMPREENDEDOR}

1.1 Gênero

Masculino

$\bigcirc$ Feminino

1.2 Ano de Nascimento:

]

1.3 Estado Civil

Solteiro

Casado

Divorciado

Outro
1.4 Escolaridade (nível completo)

Ensino Fundamental

Ensino Médio

$\bigcirc$ Ensino Superior

Especialização

Mestrado / Doutorado

1.5 A empresa que você possuía foi:

Vendida

Fechada

Alteração do contrato social / Transferência

\section{DADOS DA EMPRESA}

2.1 Ano de fundação da empresa: [

2.1a. Ano de descontinuação da empresa: [

2.2 Qual natureza foi predominante na empresa?
Indústria
Comércio
$\bigcirc$ Serviços

2.3 O regime fiscal utilizado pela empresa foi:
SIMPLES
Lucro Presumido
$\bigcirc$ Lucro Real

2.4 Quantos empregados (formais e/ou informais) a empresa possuía quando foi fundada/adquirida?

Nenhum. Eu gerenciava tudo sozinho.

Eu e familiares diretos (esposa e/ou filhos)

$\bigcirc 1$ a 2 empregados

○ 3 a 5 empregados

6 a 10 empregados

Mais de 10. Quantos? [ .......... ]

$2.5 \mathrm{~N}^{\circ}$ empregados quando encerrada: [ ]
2.6 Para constituir ou adquirir a empresa, quanto foi gasto $(\mathrm{R} \$)$ ? (Inclui-se a compra de equipamentos, edificações, reformas, capital de giro etc.)

Menos de $10 \mathrm{mil}$

De 10 mil até 25 mil

De 25 mil até 120 mil

De 120 mil até 240 mil

De 240 mil até 720 mil

$\bigcirc$ De 720 mil até 1,2 milhões

$\bigcirc$ De 1,2 milhões a 5 milhões

$\bigcirc$ Mais de 5 milhões

2.7 Qual era o faturamento bruto anual da empresa logo antes da descontinuação?

$\bigcirc$ Menos de 360 mil

De 360 mil a 720 mil

$\bigcirc$ De 720 mil a 1,2 milhões

$\bigcirc$ De 1,2 milhões a 2,4 milhões

$\bigcirc$ De 2,4 milhões a 5 milhões

$\bigcirc$ De 5 milhões a 10 milhões

$\bigcirc$ De 10 milhões a 20 milhões

$\bigcirc$ De 20 milhões a 50 milhões 
3.1 Antes de ser empresário(a), você já tinha trabalhado como empregado?
○ Não
Menos de 1 ano
De 1 a 5 anos
De 6 a 10 anos
De 11 a 20 anos
Mais de 20 anos

3.2 Antes de ser empresário(a) você já tinha trabalhado no ramo em que abriu o negócio?
O Não
Menos de 1 ano
$\bigcirc$ De 1 a 2 anos
De 3 a 5 anos
$\bigcirc$ De 6 a 10 anos
Mais de 10 anos

3.3 Antes de ser empresário(a) você ocupou cargo/função na qual possuía pessoas/empregados sob seu comando?
○ Não
Menos de 1 ano
$\bigcirc$ De 1 a 2 anos
$O$ De 3 a 5 anos
De 6 a 10 anos
Mais de 10 anos

3.4 Considere o último ano em que permaneceu na empresa. Indique a média anual de horas em cursos técnicos, palestras, feiras, seminários etc. relacionados com o seu negócio que você participou.

$\bigcirc$ Menos de 12 horas por ano

De 12 a 24 horas

De 25 a 36 horas

De 36 a 48 horas

De 48 a 60 horas

Mais de 60 horas

3.5 Seus pais são ou foram empresários?

$\bigcirc \mathrm{Sim}$

Não

3.6 Antes da empresa descontinuada, você teve outra empresa anteriormente a ela?

O Sim

Não

3.7 Se sim, que fim ela teve?

O Simplesmente parei(amos) com a atividade

Saí da sociedade

A empresa foi vendida

3.8 Se sim, além da empresa descontinuada, de quantas empresas já foi dono ou sócio?[

\section{CAPITAL SOCIAL}

4.1 Com relação à disponibilidade de capital para abrir a empresa, você diria que possuía:

Todos os recursos inclusive uma sobra para necessidades inesperadas na fase inicial;

A quantia suficiente para abertura da empresa;

O Uma boa parte dos recursos, mas ao final faltou um pouco de dinheiro;

O Aproximadamente metade dos recursos necessários

$\bigcirc$ Apenas uma pequena parte dos recursos

4.2 Com relação ao total de recursos necessários para a abertura da empresa, os empréstimos representaram:

O Nada. Não utilizei empréstimos

Menos de $20 \%$

Entre $21 \%$ e $40 \%$

Entre $41 \%$ e $70 \%$

Mais de $70 \%$
4.3 Com relação aos fornecedores principais, aqueles que representam em torno de $70 \%$ do total de matérias-primas, mercadorias etc. são:

Menos de 3 fornecedores

$\mathrm{De} 3$ a 7

De 8 a 12

$\bigcirc$ De 13 a 20

O Mais de 20

4.4 Com relação aos fornecedores, quando a empresa estava em atividade, você diria que:

Raramente ocorriam alterações no quadro de fornecedores

$\bigcirc$ Uma pequena parte (em torno de $25 \%$ ) era substituída, revezada

O Substituía em torno da metade dos fornecedores optando por aqueles que ofereciam melhores condições.

Havia um rodízio grande de fornecedores, mas mantenho uma parceria firme com cerca de $25 \%$ deles

Tinha poucos fornecedores contínuos (firmes). 
4.5 A relação da sua empresa, quando em atividade, com bancos era:

$\bigcirc$ Excelente

Ótima

Boa

Regular

$\bigcirc$ Ruim
4.6 Com relação ao nível de parcerias ou uso de serviços especializados como Sebrae, Universidades, Associações e Federações, Consultorias etc., você diria que foi:

$\bigcirc$ Muito Frequente

$\bigcirc$ Razoavelmente Frequente

Pouco Frequente

Raramente ou nunca utilizado

4.7 Marque a intensidade equivalente para cada uma das assertivas abaixo

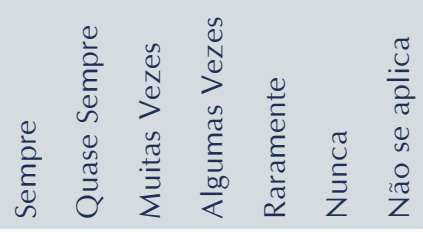

a) Quando precisei de um empréstimo bancário, o banco foi atencioso comigo

b) Quando precisei de um empréstimo bancário, o banco aprovou integralmente a quantia solicitada

c) Quando precisava de um empréstimo bancário, sentia que o banco dificultava a aprovação e liberação dos recursos

d) A dificuldade e o custo do crédito atrapalharam o negócio

\section{Características Gerenciais}

5.1 Antes de abrir a empresa, você:

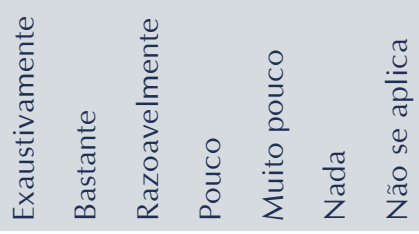

a) Pesquisou o mercado de atuação e o perfil dos potenciais clientes

$000 \bigcirc 000$

b) Identificou e estabeleceu contato com os principais fornecedores

c) Analisou os principais concorrentes, preços, atendimento, competitividade

0000000

d) Fez estudos sobre a localização do negócio

e) Fez estudos atestando a viabilidade econômica e financeira do negócio

5.2 Marque a intensidade equivalente para cada uma das assertivas abaixo, levando em conta o período de funcionamento da empresa:

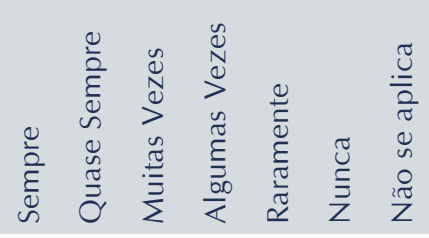

a) Conhecia detalhadamente as entradas/saídas de caixa que ocorreriam no mês

b) Utilizava antecipação de recebíveis (desconto de duplicatas, cheques pré ou borderôs de cartão de crédito) para fazer caixa

c) Tinha problemas com inadimplência

d) Pagava juros elevados ao(s) banco(s)

$\circ \bigcirc \bigcirc \bigcirc \bigcirc \bigcirc \bigcirc$

\subsection{Sua empresa possuía site?}
O $\operatorname{sim}$
○ Não

5.4 Se sim, os produtos/serviços podiam ser consultados no site?

O Sim

Não
5.5 Sua empresa fazia vendas pela internet?

\section{O Sim \\ ○ Não}

5.6 Se sim, qual o percentual da receita total era obtida das vendas pela internet?

$[$............. $] \%$ 
6.1 Como você avalia a sazonalidade na empresa (ocorrência de picos de vendas em um período e baixo em outro)

Muito sazonal

Bastante Sazonal

Razoavelmente sazonal

Pouco sazonal

O Nada sazonal
6.2 Com relação à concorrência e o grau de competição, pode-se dizer que o seu negócio situava-se em um ambiente:

Altamente competitivo

Competitivo

Competição média

O Pouco competitivo

$\bigcirc$ Nada competitivo

6.3 No seu setor, ou em termos gerais quando se refere às pequenas e médias empresas, como você avalia o suporte governamental / institucional.

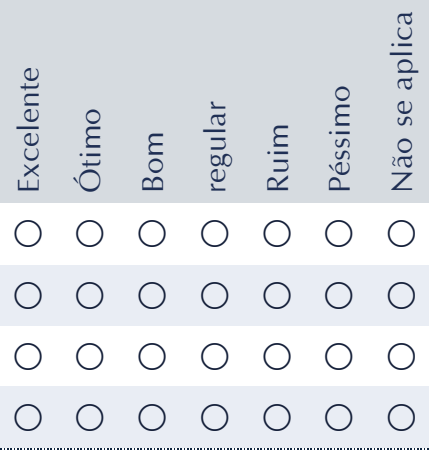

a) Linhas de crédito e acesso ao crédito

b) Qualidade dos serviços públicos

c) Apoio de instituições (Sebrae, associações, escolas etc)

d) Ambiente competitivo (lealdade dos competidores; grau de formalidade)

\section{MOTIVAÇÃO E PERCEPÇÃO DO RISCO}

7.1 Qual das situações abaixo melhor representou sua decisão de empreender

Oportunidade

Necessidade

7.2 Qual das opções abaixo pode ser considerado o motivador de maior destaque na sua decisão de empreender:

Garantir a renda e a subsistência familiar

Explorar uma oportunidade em potencial

$\bigcirc$ Ganhar dinheiro

7.3 Investir em um negócio próprio significa assumir um risco que pode ser considerado:

Muito alto

O Alto

Nem alto, nem baixo

Baixo

Muito baixo
7.4 Com relação às expectativas que você possuía antes de abrir a empresa, comparando com o desempenho após a abertura, você diria que foi:

$\bigcirc$ Muito acima das expectativas

$\bigcirc$ Um pouco acima das expectativas

$\bigcirc$ Dentro das expectativas

$\bigcirc$ Um pouco abaixo das expectativas

$\bigcirc$ Muito abaixo das expectativas

7.5 Se você pudesse voltar no tempo imediatamente anterior à seu ingresso na atividade empresarial, você:

Não abriria uma empresa.

O Investiria novamente no mesmo negócio

Investiria no mesmo negócio, porém faria um planejamento mais detalhado

O Investiria em outro tipo/ramo de negócio 
9.1 Com relação grau de especialidade / generalidade, seu negócio era:

Baseado em produto/serviço especializado

Diversificado

9.2 Com relação ao grau de afiliação, seu negócio era:

Afiliado (franquia, representação etc.)

$\bigcirc$ Independente

9.3 O quadro de empregados da empresa podia ser definido como:

$\bigcirc$ Muito qualificado

Qualificado

$\bigcirc$ Pouco qualificado

Sem qualificação

Não se aplica (não possui empregados)

9.4 Por ano, em média, quantas horas de treinamento (cursos, palestras, feiras etc.) os empregados realizavam?

$\bigcirc$ Até 12 horas

De 12 a 24 horas

De 24 a 48 horas

O Mais de 48 horas

$\bigcirc$ Não se aplica
9.5 Indique o número do sócios que faziam parte do quadro social da empresa:
$\bigcirc 1$
$\bigcirc 2$
$\bigcirc 3$
$\bigcirc 4$
Mais de 4

9.6 O relacionamento entre os sócios era:
$\bigcirc$ Excelente
Bom
Regular
Ruim
Péssimo

9.7 Pode-se afirmar que existiam familiares em cargos (funções) importantes da empresa?
O Sim
Não

9.8 Com relação ao grau de inovação exigido no seu negócio, você diria que era:
Muito alto
O Alto
O Razoável
Baixo
Muito baixo 